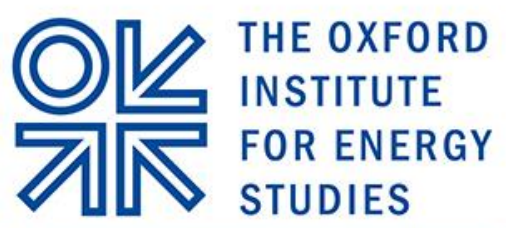

A RECOGNIZED INDEPENDENT CENTRE OF THE UNIVERSITY OF OXFORD

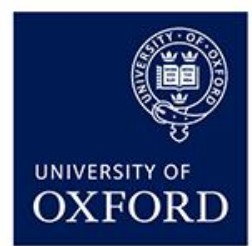

June 2014

\section{The Outlook for Natural Gas Demand in Europe}

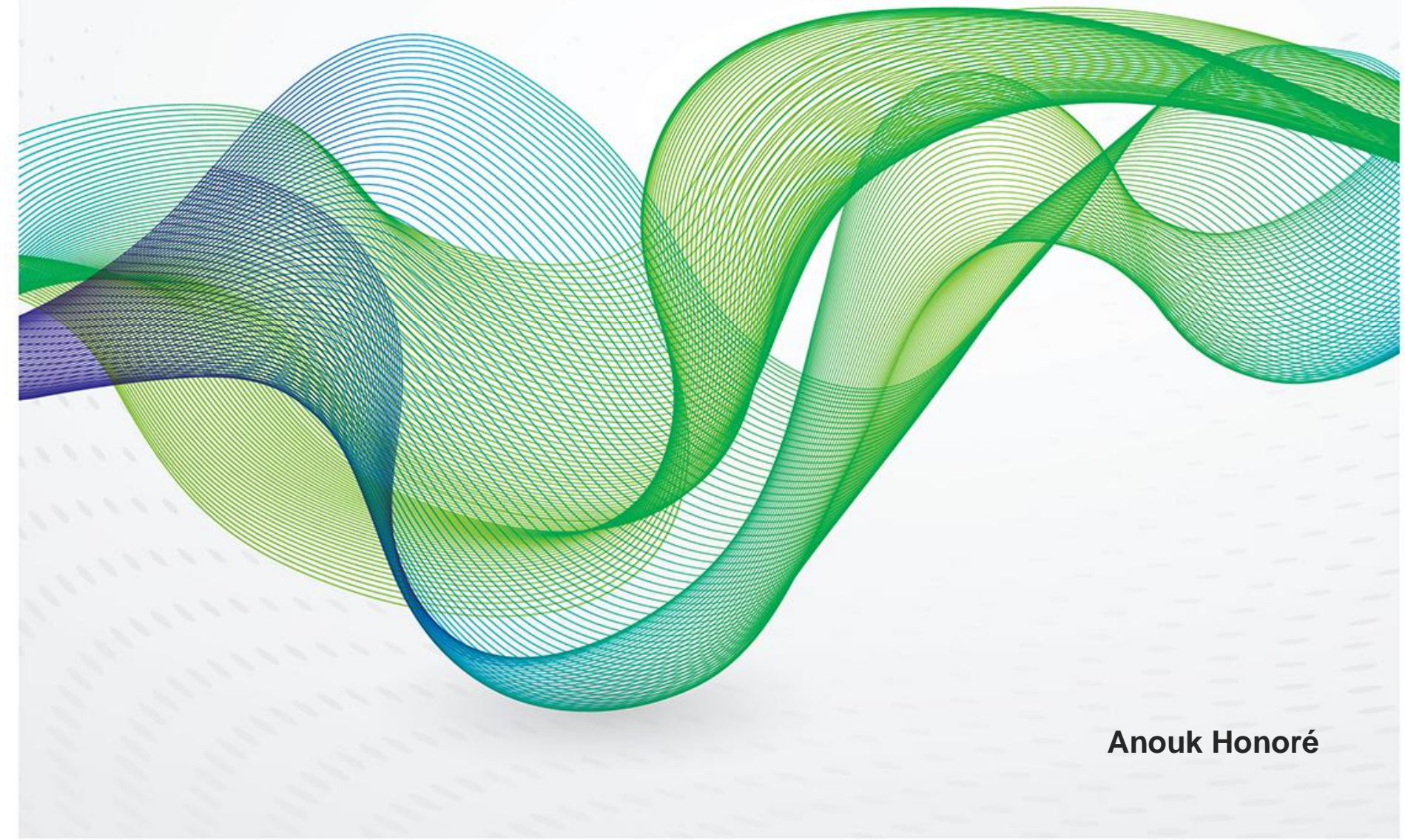


The contents of this paper are the author's sole responsibility. They do not necessarily represent the views of the Oxford Institute for Energy Studies or any of its members.

Copyright $@ 2014$

Oxford Institute for Energy Studies

(Registered Charity, No. 286084)

This publication may be reproduced in part for educational or non-profit purposes without special permission from the copyright holder, provided acknowledgment of the source is made. No use of this publication may be made for resale or for any other commercial purpose whatsoever without prior permission in writing from the Oxford Institute for Energy Studies.

ISBN 978-1-78467-003-0 


\section{Acknowledgements}

My grateful thanks go to my colleagues at the Oxford Institute for Energy Studies (OIES) for their help and advice, and in particular Howard Rogers, Jonathan Stern and John Elkins for their careful reading, very helpful comments and editorial corrections of the draft.

A big thank-you to the sponsors of the Natural Gas Research Programme (OIES) ${ }^{1}$ for their support and useful remarks, in particular Joshua Prentice from the Swedish Energy Agency for reading the whole draft and giving me valuable comments. I would also like to thank our colleagues from Gasunie and National Grid for their constructive remarks on the draft.

It is a particularly difficult time to work on natural gas demand scenarios in Europe, and I am very grateful to everyone who accepted to share their opinions and knowledge with me.

Last but not least, many thanks to Kate Teasdale and Hannah Shipton who made all the arrangements for the production of this paper.

The contents of this paper do not necessarily represent the views of the OIES, our sponsors or of the people I have thanked in these acknowledgments.

All the opinions expressed and any remaining errors are my sole responsibility.

Anouk Honoré

Oxford, June 2014 

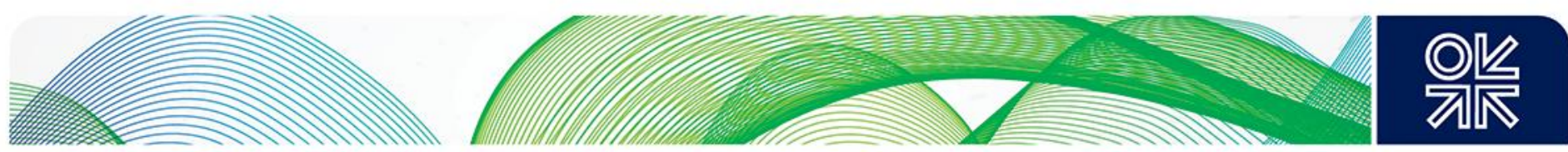

\section{Preface}

The discovery and development of European indigenous conventional natural gas came later than in North America, and in the 1960s and 1970s, it soon became evident that imports would be required to meet demand across the European geography. Northern European markets, closest to the onshore Dutch discoveries and those offshore the UK, Norway and Denmark were the first to develop at scale, displacing coal and oil products in the space heating and industrial sectors. These supplies were supplemented by import flows of pipeline gas from the Former Soviet Union and North Africa, and LNG supplies from a growing network of suppliers, allowing south and central European national markets to develop and grow.

The widespread adoption of the highly efficient combined cycle gas turbine from the 1990s onwards provided an additional spur for European gas demand in the power sector, again taking market share from coal and oil products. In the early 2000s prospects for a continued healthy future growth of European gas demand seemed assured and industry participants took every opportunity to urge Russia in particular to ensure a brisk pace of upstream investment to meet the anticipated rapid growth in European demand for gas.

Even before the financial crisis of 2008 and subsequent financial recession, European demand growth had slowed, however a product of both a maturing market, low population growth, higher gas prices (in large part due to the oil price linkage in much of its contracted imports) and the migration of manufacturing industry to other world regions.

Assessing the long term prospects for European gas demand against this backdrop would be challenge enough. The additional dimensions of EU renewables and decarbonisation policy, the Large Combustion Plant Directive, the Industrial Emissions Directive, the German Energiewende and other country-specific policies and diverse national power generation mix 'starting points' take the challenge into 'formidable' territory, especially in the current uncertain post-economic crisis landscape.

I am immensely grateful to Anouk Honoré for taking on this challenge and creating this paper which addresses all the major 'known unknowns' as far as this is possible. Her determination to apply a consistent analytical approach at a time of data flux and uncertainty is admirable and in keeping with the spirit of the OIES Gas Programme in producing quality research on gas markets of critical importance in terms of their place in the developing global gas system. In particular, readers will find in the appendix all the key assumptions set out in detail at a national level which, when aggregated, form the basis for Anouk's demand outlook scenario.

Howard Rogers

Oxford, June 2014 


\section{Table of contents}

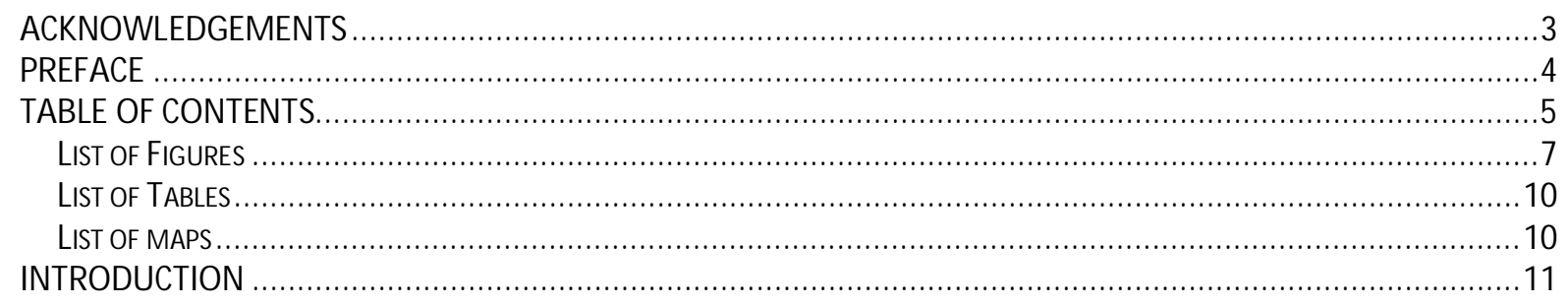

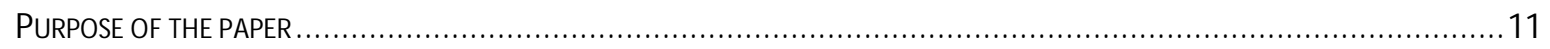

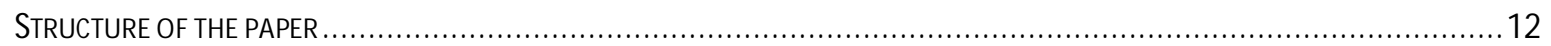

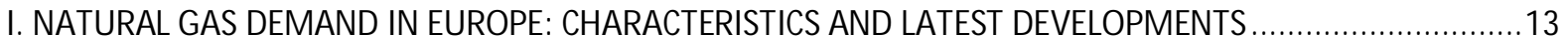

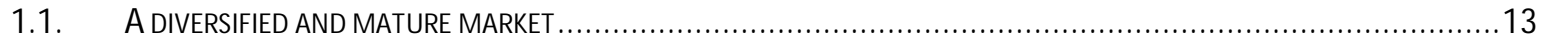

1.1.1. The role of natural gas in total primary energy supply ............................................. 13

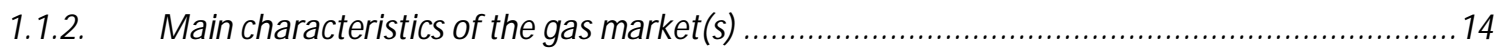

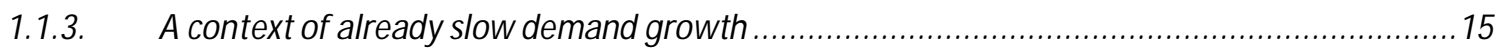

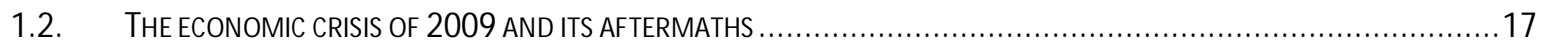

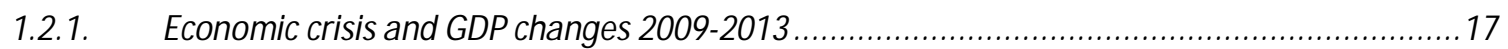

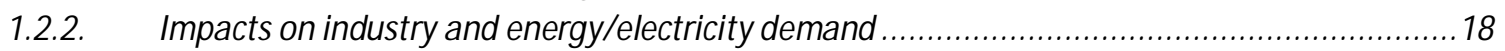

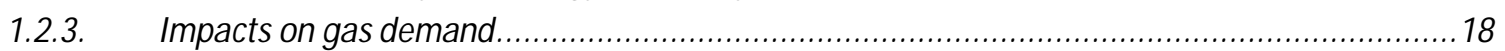

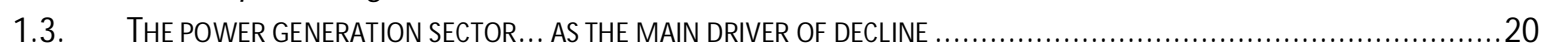

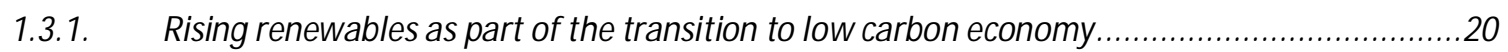

1.3.2. Rising competition from coal due to effects of US shale gas and low $\mathrm{CO}_{2}$ prices....................22

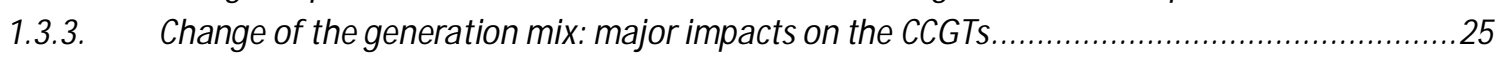

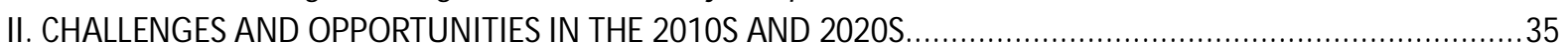

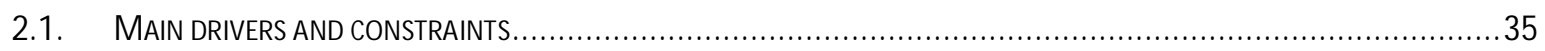

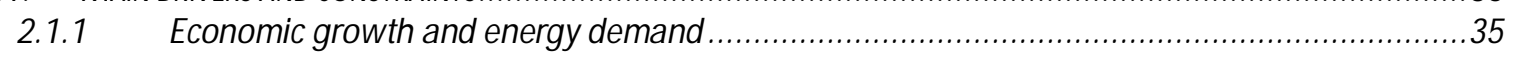

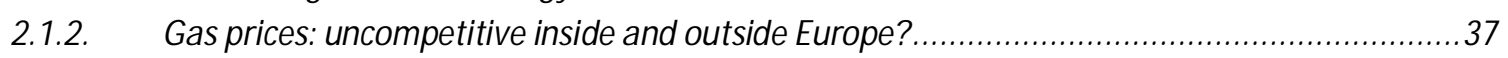

2.1.3. The role of energy policies: focus on the renewable and the $\mathrm{CO}_{2}$ targets...........................38

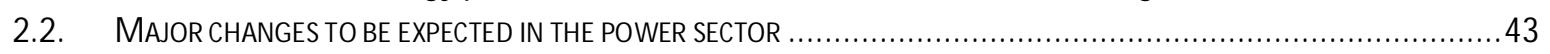

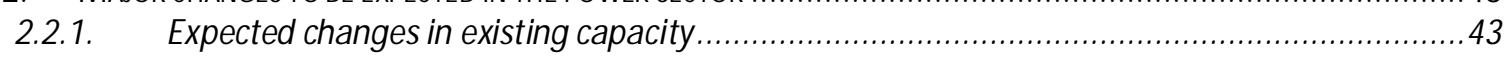

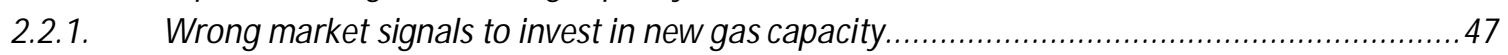

2.2.3. Is there a future for gas-fired power plants in Europe? ..............................................50

2.3. KEY ISSUES IN THE OTHER SECTORS: INDUSTRY, RESIDENTIALAND COM M ERCIAL, AND TRANSPORT ........................55

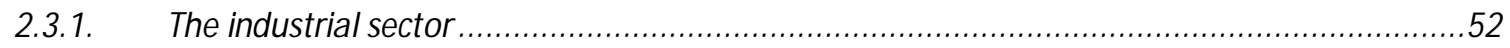

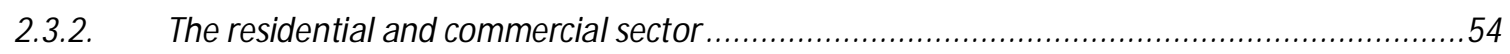

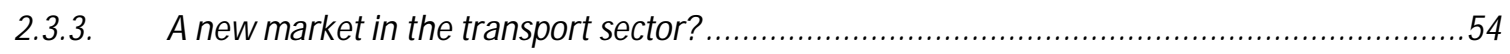

III. OUTLOOK FOR GAS DEMAND IN EUROPE UP TO 2030 ....................................................................57

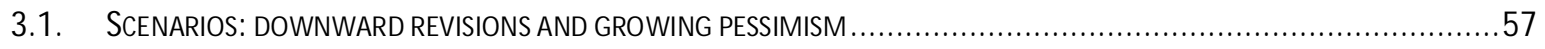

3.1.1 A gloomy vision of the interaction between gas and renewables ....................................5.

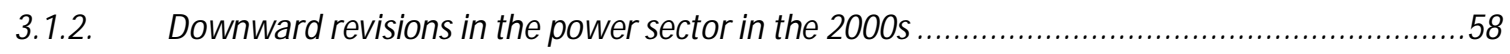

3.1.3. Renewables may not mean the end of gas for power demand after all .............................6 60

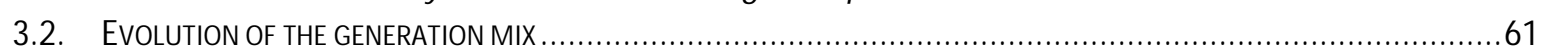

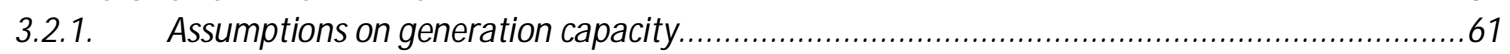

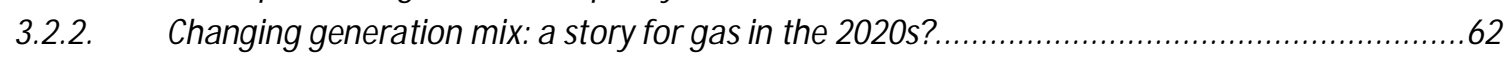

3.2.3. Focus on three key markets with high renewables integration .......................................6. 62

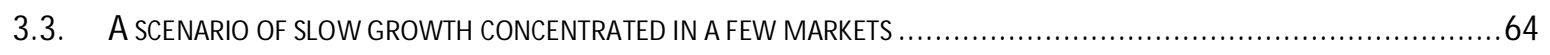


3.3.1. Slow recovery expected in the 2020s.

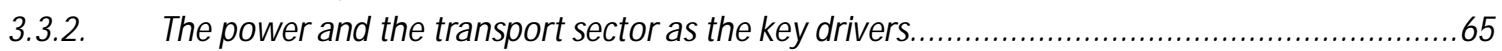

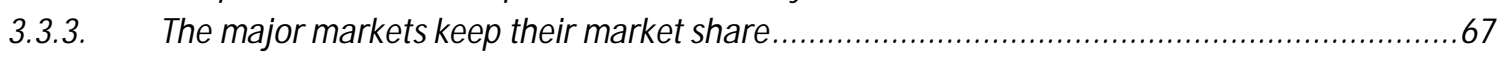

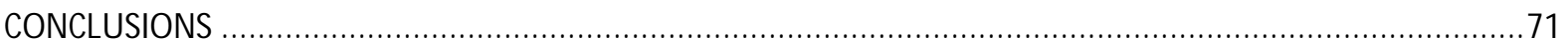

APPENDIX 1: NATURAL GAS DEMAND IN EUROPE

APPENDIX 2: GENERAL ASSUM PTIONS AND NATIONAL M ARKETS' SPECIFICS..........................................74

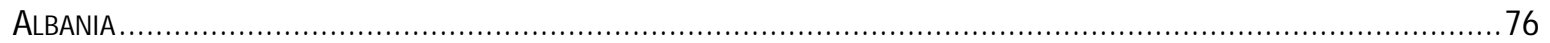

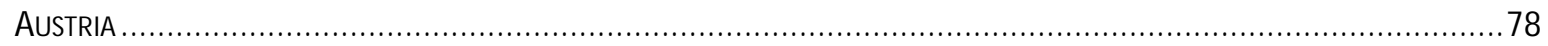

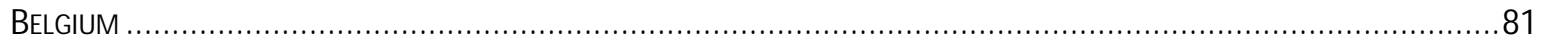

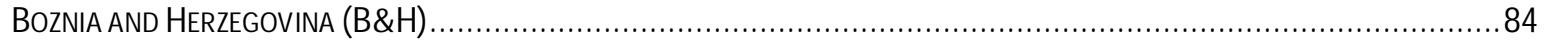

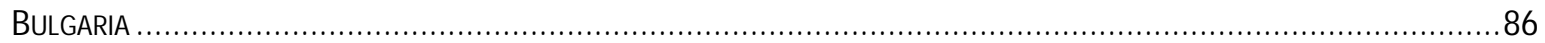

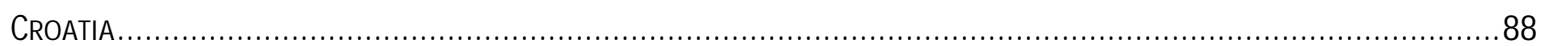

CYPRUS

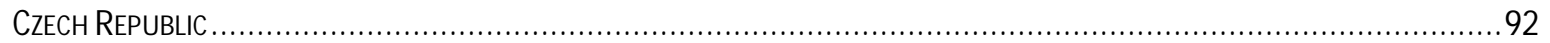

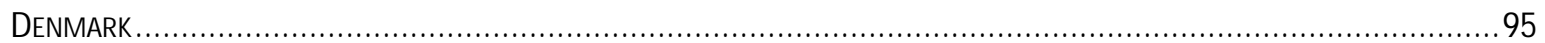

ESTONIA …

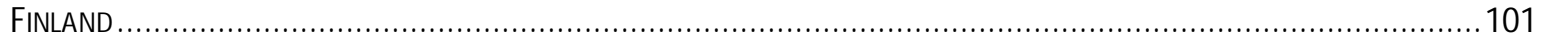

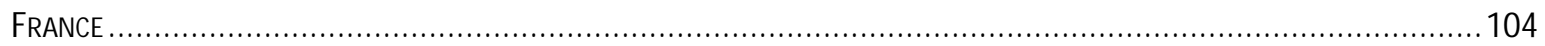

GERM ANY

GREECE

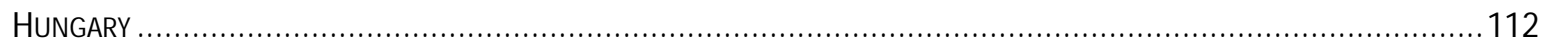

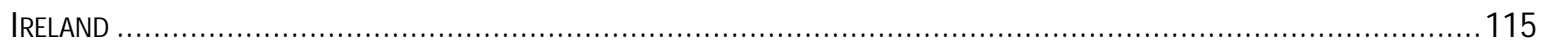

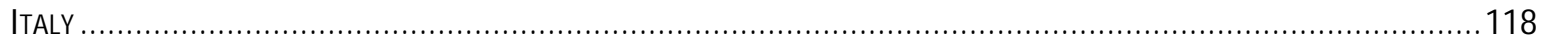

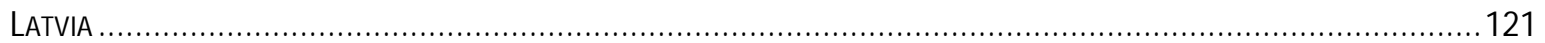

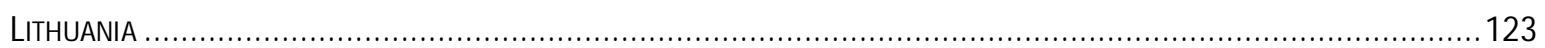

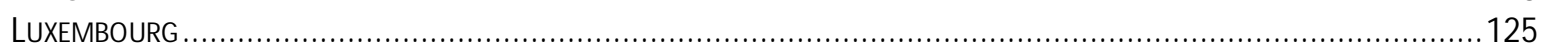

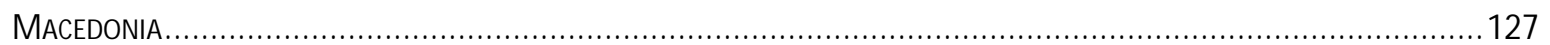

M ALTA

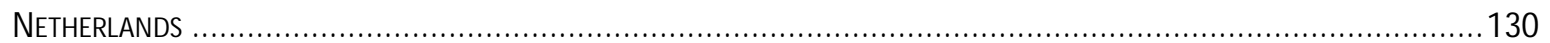

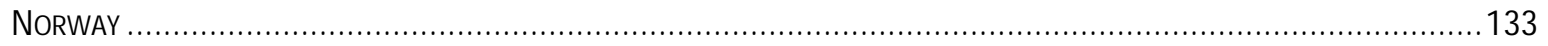

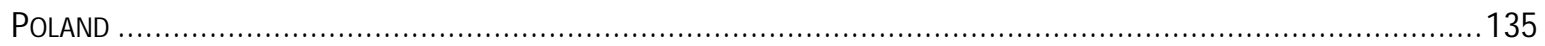

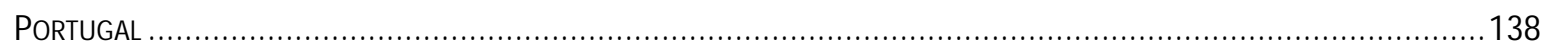

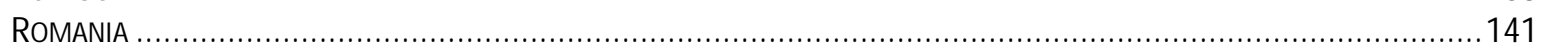

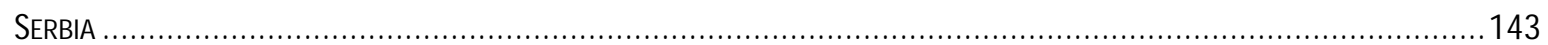

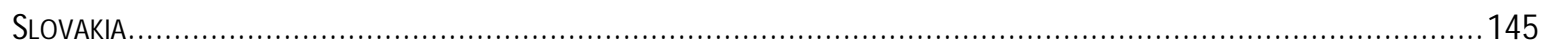

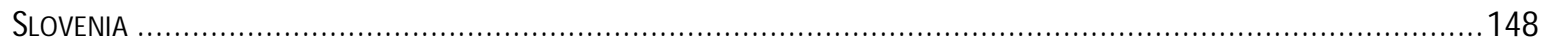

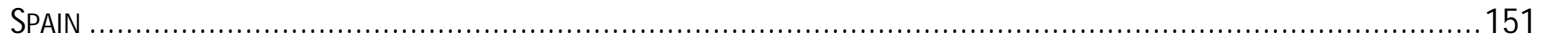

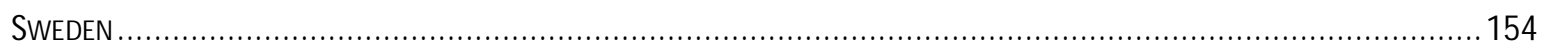

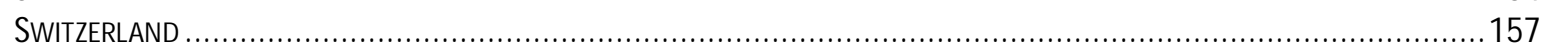

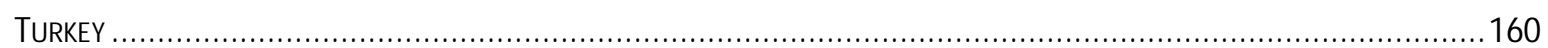

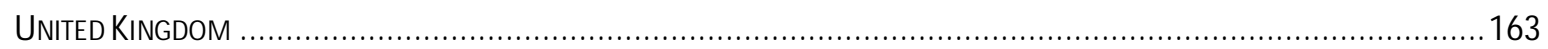

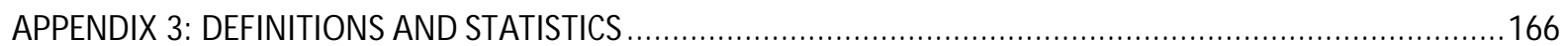

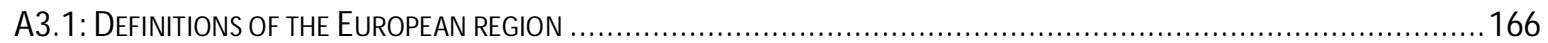

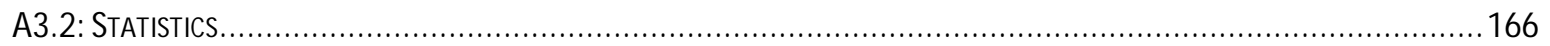

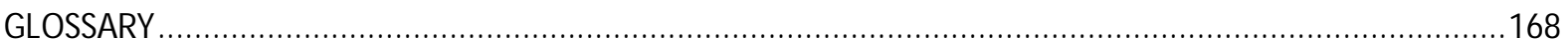

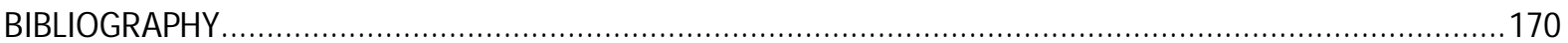




\section{List of Figures}

Figure 1: Share of natural gas in TPES of selected European markets in 2012, in \% .......................................14

Figure 2: Gas demand by sector in OECD Europe, 1971-2011 (M M cm) ...................................................16

Figure 3: GDP growth rate in OECD Europe, seasonally adjusted, 2008-2013 (\% change over the previous

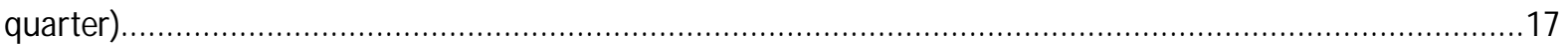

Figure 4: Industrial production (excluding construction) in the European Union, 2004-13 (index 2010=100) ...18

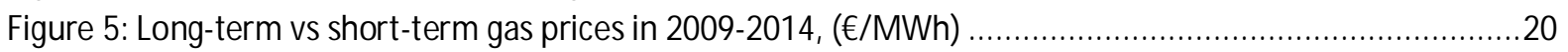

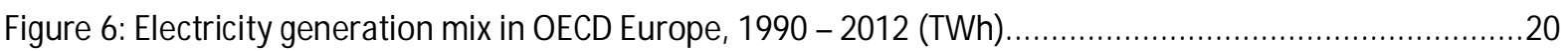

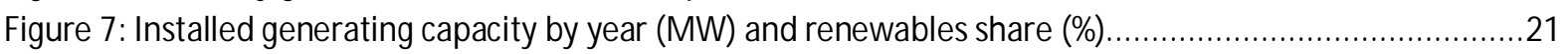

Figure 8: Installed power capacity in the EU in 2000 and in 2013 (GW) .....................................................21

Figure 9: Day ahead base spark spread and dark/clean dark spreads (month ahead) (€/M Wh) ......................22

Figure 10: Clean spark spread in April 2014 (50\% efficient) and generation costs in the UK (month ahead)

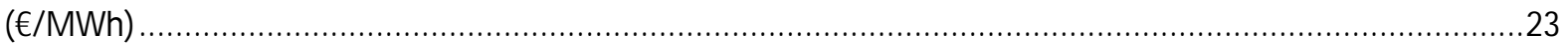

Figure 11: Comparisons of monthly electricity baseload prices in regional electricity markets ( $€ / \mathrm{M} \mathrm{Wh}) \ldots \ldots \ldots .24$

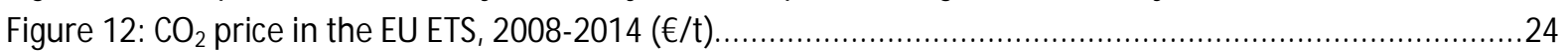

Figure 13: Electricity generation mix in OECD Europe by fuels, 2008-2012 (TWh) .....................................26

Figure 14: Electricity generation mix in selected countries by fuels, 2008 and 2012 (TWh) ............................27

Figure 15: Electricity generation mix in selected countries by fuels, 2008 and 2012 (\%) ...............................27

Figure 16: Spain: power generation by fuel and renewables share, 2000 and 2012 (TWh) ...........................28

Figure 17: Average power generation costs from gas and coal in Spain, 2010-2013, €/M Wh .......................28

Figure 18: Spain: Natural gas used in CCGTs vs maximum potential use of gas in CCGTs, 2003-2012 (GWh/d). 29

Figure 19: Spain: natural gas used in the power sector ( $\mathrm{Bcm}$, left axis) and annual load factors of gas-fired

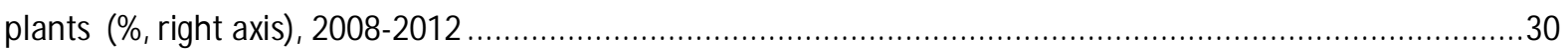

Figure 20: Spain: close relationship between the daily volatility of wind generation and CCGTs generation .....30

Figure 21: Italy: power generation by fuel and renewables share, 2000 to 2012 (TWh)................................31

Figure 22: Annual utilisation by renewable energy in Italy, 2007-2011 (hours) .............................................32

Figure 23: Germany: power generation by fuel and renewables share, 2000 to 2012 (TWh) .........................33

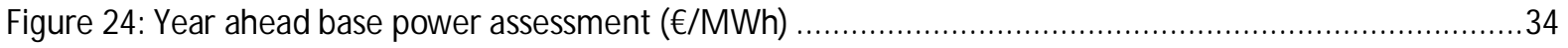

Figure 25: GDP growth in Europe and selected countries, in constant prices, 2000-2018 (forecast from 2013).36

Figure 26: Energy intensity of the economy: gross inland consumption of energy divided by GDP ( $\mathrm{kg}$ of oil

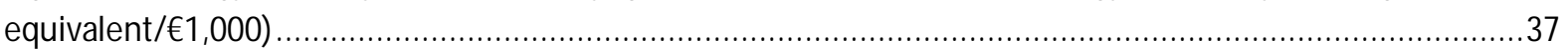

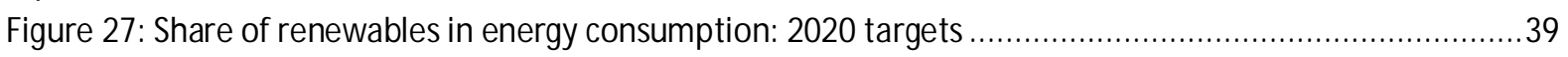

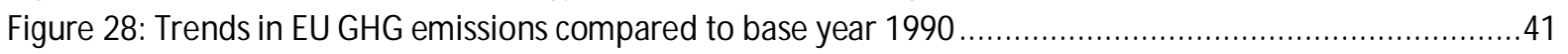

Figure 29: Age of existing and projected fossil fuel power plants in the EU, 2011 (GW) ..............................46

Figure 30: Non-renewable power plant projects in early 2014 (GW) ........................................................... 47

Figure 31: Capacity of gas fired-power plant projects under construction in early 2014 (GW) ........................47

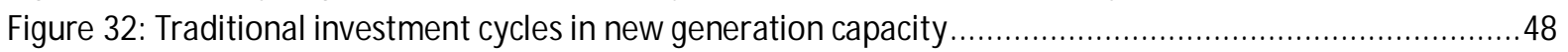

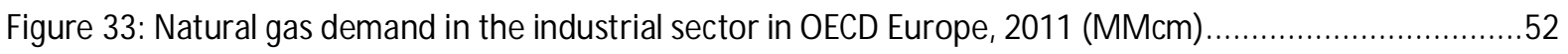

Figure 34: Production indices for total industry excluding construction seasonally adjusted (base year 2005)..53

Figure 35: Absolute change in emissions by sector in EU-27, 1990 -2011 (M M t CO ${ }_{2}$-eq) ..............................55

Figure 36: Italian total gas demand vs consumption in the transport sector, 2000-2011 (Bcm) ......................56

Figure 37: Scenarios for gross inland gas consumption in the EC Energy Roadmap 2050 (M M toe) .................57

Figure 38: Gas role in electricity generation in the transition, Energy Roadmap 2050 (TWh) .........................58

Figure 39: IEA WEO scenarios, reference scenarios and new policies scenarios, WEO 2002 to WEO 2011,

M M toe. 
Figure 40: IEA WEO scenarios, reference scenarios and new policies scenarios, focus on the WEO 2008 to WEO

2013, M M toe

Figure 41: IEA WEO 2012: possible additional power generation from gas even in a high renewable scenario,

2010-2035, TWh... 60

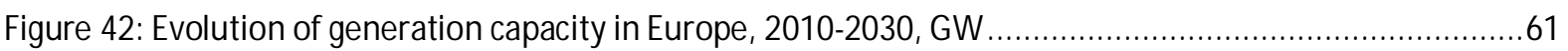

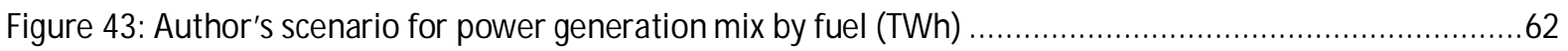

Figure 44: Author's assumptions for the power generation mix in Spain, Italy and Germany up to 2030 (TWh)63

Figure 45: Author's scenario for gas demand in Europe with 35 countries, up to $2030(\mathrm{Bcm})$.......................64

Figure 46: Author's scenario: share by sectors in 2010 and in 2030 in Europe with 35 countries,(\%)..............65

Figure 47: Author's scenario for natural gas demand in the transport sector in Europe with 35 countries, 2010-

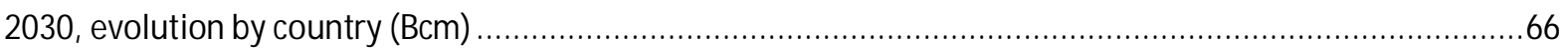

Figure 48: Author's scenario for natural gas demand in the power sector in Europe with 35 countries, 2010-

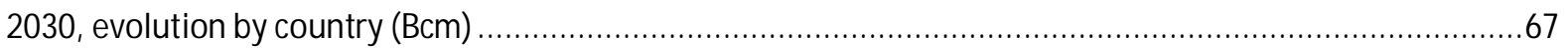

Figure 49: Author's scenario for natural gas demand in 2010- 2030, by country $(\mathrm{Bcm})$...............................67

Figure 50: Author's scenario: share per country for natural gas demand in 2010- 2030 (\%) ..........................68

Figure 51: Author's scenario, natural gas demand changes by sector in selected countries, 2010 to 2030 (Bcm)

Figure 52: Gas production by country vs demand in OECD Europe, 1971 -2012 (MM cm)

Figure 53: GDP annual growth in Albania (\%), in constant prices, 2000-2018 (forecast from 2008) ..................76

Figure 54: GDP annual growth in Austria (\%), in constant prices, 2000-2018 (forecast from 2012) ..................78

Figure 55: Scenario for power generation mix in Austria, up to 2030, in GWh..........................................79

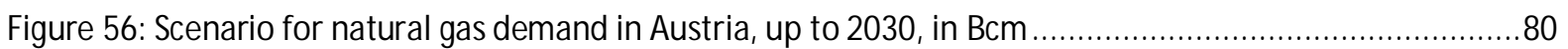

Figure 57: GDP annual growth in Belgium (\%), in constant prices, 2000-2018 (forecast from 2012)...............81

Figure 58: Scenario for power generation mix in Belgium, up to 2030, in GWh .............................................83

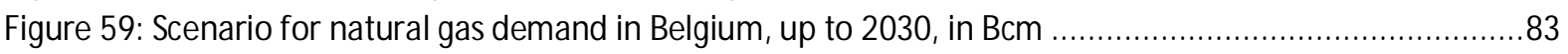

Figure 60: GDP annual growth in B\&H (\%), in constant prices, 2000-2018 (forecast from 2012) .....................84

Figure 61: GDP annual growth in Bulgaria (\%), in constant prices, 2000-2018 (forecast from 2012) ...............86

Figure 62: GDP annual growth in Croatia (\%), in constant prices, 2000-2018 (forecast from 2012) ..................88

Figure 63: GDP annual growth in Cyprus (\%), in constant prices, 2000-2018 (forecast from 2012) .................90

Figure 64: GDP annual growth in Czech Republic (\%), in constant prices, 2000-2018 (forecast from 2012) .......92

Figure 65: Scenario for power generation mix in Czech Republic, up to 2030, in GWh ..................................93

Figure 66: Scenario for natural gas demand in Czech Republic, up to 2030, in $\mathrm{Bcm}$.......................................94

Figure 67: GDP annual growth in Denmark (\%), in constant prices, 2000-2018 (forecast from 2012)............... 95

Figure 68: Scenario for power generation mix in Denmark, up to 2030, in GWh ...........................................96

Figure 69: Scenario for natural gas demand in Denmark, up to 2030, in Bcm ...............................................97

Figure 70: GDP annual growth in Estonia (\%), in constant prices, 2000-2018 (forecast from 2012).................98

Figure 71: Scenario for power generation mix in Estonia, up to 2030, in GWh ..............................................99

Figure 72: Scenario for natural gas demand in Estonia, up to 2030, in Bcm...............................................100

Figure 73: GDP annual growth in Finland (\%), in constant prices, 2000-2018 (forecast from 2012)................101

Figure 74: Scenario for power generation mix in Finland, up to 2030, in GWh .......................................... 102

Figure 75: Scenario for natural gas demand in Finland, up to 2030, in Bcm............................................... 103

Figure 76: GDP annual growth in France (\%), in constant prices, 2000-2018 (forecast from 2012)................. 104

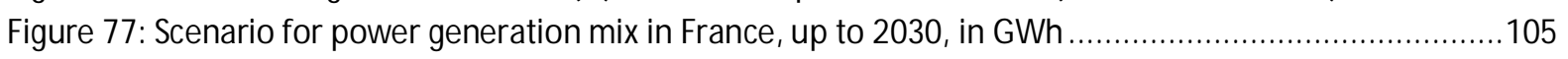

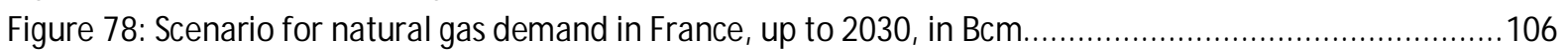

Figure 79: GDP annual growth in Germany (\%), in constant prices, 2000-2018 (forecast from 2012).............107

Figure 80: Scenario for power generation mix in Germany, up to 2030, in GWh ..........................................109 
Figure 81: Scenario for natural gas demand in Germany, up to 2030, in Bcm ........................................109

Figure 82: GDP annual growth in Greece (\%), in constant prices, 2000-2018 (forecast from 2013) ................110

Figure 83: Scenario for power generation mix in Greece, up to 2030, in GWh.........................................111

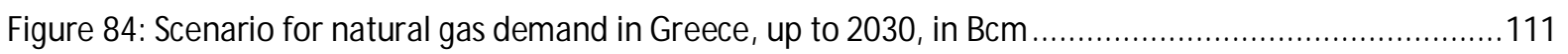

Figure 85: GDP annual growth in Hungary (\%), in constant prices, 2000-2018 (forecast from 2012) ..............112

Figure 86: Scenario for power generation mix in Hungary, up to 2030, in GWh......................................113

Figure 87: Scenario for natural gas demand in Hungary, up to 2030, in $\mathrm{Bcm}$..............................................114

Figure 88: GDP annual growth in Ireland (\%), in constant prices, 2000-2018 (forecast from 2012) ...............115

Figure 89: Scenario for power generation mix in Ireland, up to 2030, in GWh...........................................116

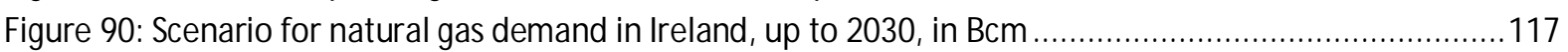

Figure 91: GDP annual growth in Italy (\%), in constant prices, 2000-2018 (forecast from 2012) .....................118

Figure 92: Scenario for power generation mix in Italy, up to 2030, in GWh .............................................119

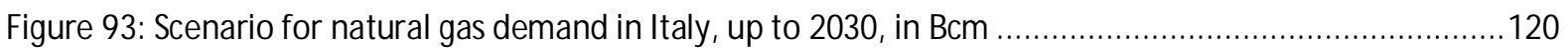

Figure 94: GDP annual growth in Latvia (\%), in constant prices, 2000-2018 (forecast from 2012).................121

Figure 95: GDP annual growth in Lithuania (\%), in constant prices, 2000-2018 (forecast from 2012).............123

Figure 96: GDP annual growth in Luxembourg (\%), in constant prices, 2000-2018 (forecast from 2012)........125

Figure 97: Scenario for power generation mix in Luxembourg, up to 2030, in TWh......................................126

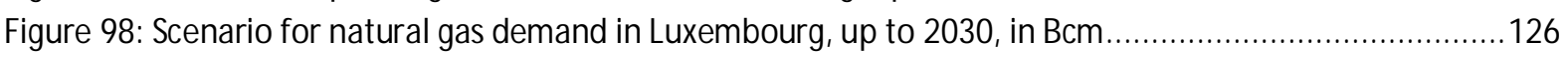

Figure 99: GDP annual growth in Macedonia (\%), in constant prices, 2000-2018 (forecast from 2012)..........127

Figure 100: GDP annual growth in Malta (\%), in constant prices, 2000-2018 (forecast from 2012) .................128

Figure 101: GDP annual growth in Netherlands (\%), in constant prices, 2000-2018 (forecast from 2012) .......130

Figure 102: Scenario for power generation mix in the Netherlands, up to 2030, in GWh..............................131

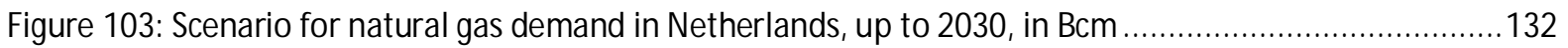

Figure 104: GDP annual growth in Norway (\%), in constant prices, 2000-2018 (forecast from 2012) ..............133

Figure 105: Scenario for power generation mix in Norway, up to 2030, in GWh........................................134

Figure 106: Scenario for natural gas demand Norway, up to 2030, in Bcm ..............................................134

Figure 107: GDP annual growth in Poland (\%), in constant prices, 2000-2018 (forecast from 2012) ...............135

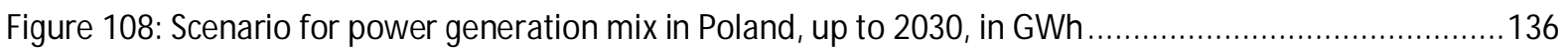

Figure 109: Scenario for natural gas demand in Poland, up to 2030, in Bcm ..........................................137

Figure 110: GDP annual growth in Portugal (\%), in constant prices, 2000-2018 (forecast from 2012) ............138

Figure 111: Scenario for power generation mix in Portugal, up to 2030, in GWh.........................................139

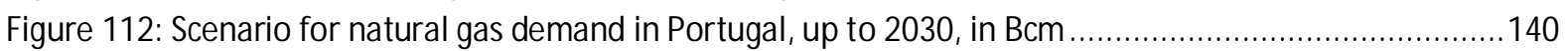

Figure 113: GDP annual growth in Romania (\%), in constant prices, 2000-2018 (forecast from 2012) ............141

Figure 114: GDP annual growth in Serbia (\%), in constant prices, 2000-2018 (forecast from 2011) ...............143

Figure 115: GDP annual growth in Slovakia (\%), in constant prices, 2000-2018 (forecast from 2012).............145

Figure 116: Scenario for power generation mix in Slovakia, up to 2030, in GWh ........................................146

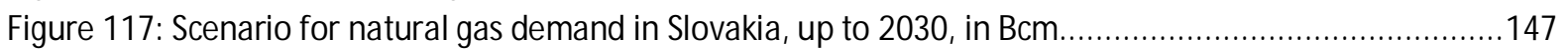

Figure 118: GDP annual growth in Slovenia (\%), in constant prices, 2000-2018 (forecast from 2012) ............ 148

Figure 119: Scenario for power generation mix in Slovenia, up to 2030, in GWh........................................ 149

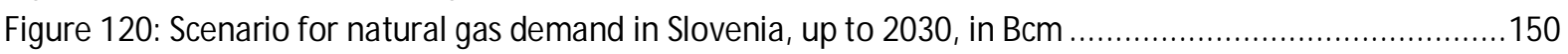

Figure 121: GDP annual growth in Spain (\%), in constant prices, 2000-2018 (forecast from 2012).................151

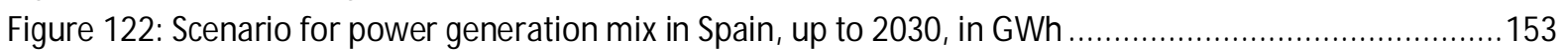

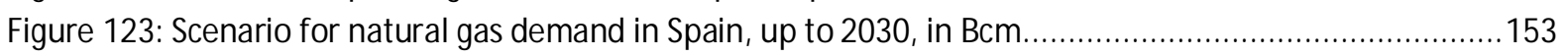

Figure 124: GDP annual growth in Sweden (\%), in constant prices, 2000-2018 (forecast from 2012).............154

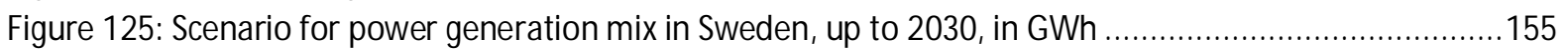

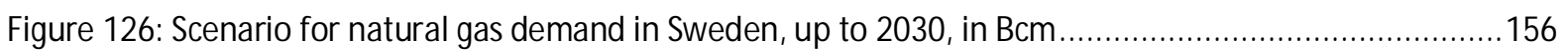


Figure 127: GDP annual growth in Switzerland (\%), in constant prices, 2000-2018 (forecast from 2012) .......157

Figure 128: Scenario for power generation mix in Switzerland, up to 2030, in GWh.................................... 158

Figure 129: Scenario for natural gas demand in Switzerland, up to 2030, in $\mathrm{Bcm}$.........................................159

Figure 130: GDP annual growth in Turkey (\%), in constant prices, 2000-2018 (forecast from 2012)................160

Figure 131: Scenario for power generation mix in Turkey, up to 2030, in GWh ..........................................161

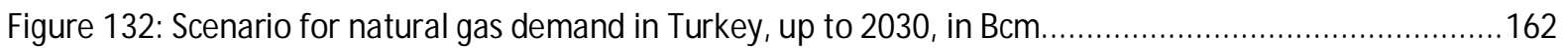

Figure 133: GDP annual growth in the UK (\%), in constant prices, 2000-2018 (forecast from 2012)..............163

Figure 134: Scenario for power generation mix in the UK, up to 2030, in GWh .....................................165

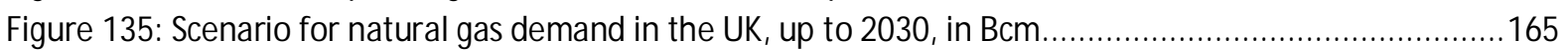

\section{List of Tables}

Table 1: Natural gas consumption in Europe in 2012-2013 and share by country ( $\mathrm{Bcm}$ and \%).....................15

Table 2: Gas demand in OECD Europe and in selected countries, 2008-2013 ..........................................19

Table 3: Natural gas consumption (observed) in 35 European countries in 2008 and 2012/2013, Bcm ............73

\section{List of maps}

Map 1: Capacity mechanisms across Europe. 


\section{Introduction}

\section{Purpose of the paper}

Europe still remembers the years of rapid gas demand growth, largely driven by the expansion of gas in the power sector in the 1990s and early 2000s. Optimism was the predominant mood in the gas industry: gas power plants were the favoured investments options in a newly liberalised market with ambitions on curbing carbon dioxide $\left(\mathrm{CO}_{2}\right)$ emissions, and demand scenarios showed straight growth lines in the 2010s and 2020s. Even so, scenarios taking into account a more optimistic development of environmental policies, with fast growing renewables and the maturity of the older gas markets, were already starting to question the linear trajectories of gas demand growth, but without too much attention from the gas industry. ${ }^{2}$

The energy world and of course the gas industry are not isolated from what happens in the rest of the economy, and the impacts of the economic crisis of 2009 came as a shock for many gas players. Gas demand in Europe ${ }^{3}$ lost about 40 Billion cubic metres $(\mathrm{Bcm})$ in one year alone or about $6 \%$ of total gas consumption. More importantly, the following years reminded everyone that natural gas does not have a captive market. In 2013, gas demand in Europe was estimated to still be about $10 \%$ below the level of 2008 and showed no strong signs of recovery. ${ }^{4}$ Worse, the power sector, once the undisputed key driver for additional demand, was now under threat as gas consumption has been squeezed by a combination of low energy demand due to ongoing economic problems, cheap imported coal and growing non-market-based ${ }^{5}$ renewables in many European countries.

All these factors, both at the regional and national levels, have created a level of confusion as to the future of gas in Europe that is unprecedented, and even raises the possibility of a peak demand for gas having occurred in 2008. Gas demand data for the period 2008-2013 do not give any clear indication on which trends can be expected or anticipated, worse, they even provide opposite signals from one year to another. Is this a short/medium term problem or should we consider low gas demand -or even a declining trend- as the new norm? What are the driving factors/constraints in this new world? If growth can be envisaged, where will this additional gas demand growth come from? The industrial and the residential and commercial sectors are mature in most markets, and the power sector is the focal point of most of the uncertainties. While the economic situation and the competitiveness of gas prices are part of a cycle, the development of renewables needs to be seen as a long term change of the energy mix that has and will continue to have an important impact on the economics of gas-fired plants.

Despite progress towards the creation of a regional market for gas and electricity, the most interesting story may not be at the European level, but at the national level. Economic factors - recession or fuel prices; policies and regulations; and natural factors - temperatures - will not have the same impacts on gas demand in the various countries around Europe. The regional market as a whole entity hides

\footnotetext{
2 See Honoré (2010), chapter 3 for more information.

${ }^{3}$ In this text, Europe includes 35 countries, unless otherwise stated. See Appendix 3 for a list of the 35 countries and a discussion on statistics.

${ }^{4}$ Author's estimates as data for gas consumption in 2013 for all 35 countries was not available at the time of writing (early 2014).

${ }^{5}$ The investment is driven and funded by EU and government policy.
} 

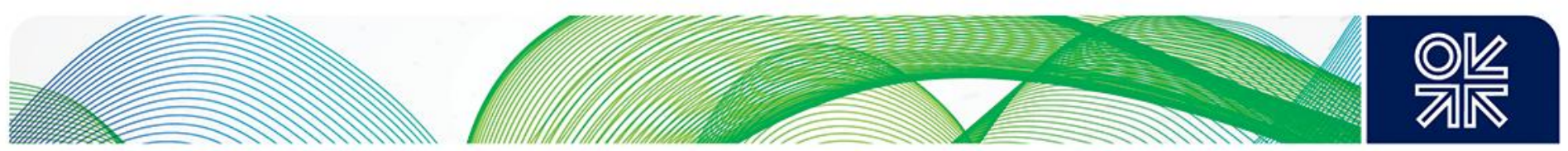

important differences and potentially different paths of recovery. It is essential to understand the specific characteristics of individual markets in order to infer future trends. Research and scenarios which attempt to describe and project trends in 'European' gas markets miss these essential complexities.

This was the starting point of this research, which was carried out with the objective to propose an overview of the gas demand fundamentals to 2020 and 2030 horizons in a comprehensive way with some highlights of individual market trends. Energy and gas markets are evolving rapidly, and the writing of this paper was substantially completed by early 2014 with information and statistical data available at the time. The trends and scenarios will need to be updated as policies/prices/generation mix evolve in the future, but the main conclusion of this research is that the outlook for the gas industry includes the potential for modest future growth from 2013 levels, although it is unlikely to see a return to 1990s - 2000s gas demand growth rates. The methodology used was a bottom-up approach by looking at each sector, in each of the markets considered and building up a picture from there. In order to do so, the research was split into three chapters, which are detailed below.

\section{Structure of the paper}

Following this introduction, the first chapter focuses on the major changes that have happened in the natural gas industry in Europe in 2008-2013, with a focus on the dramatic evolution that happened in the power sector. The second chapter analyses the key factors that will shape gas demand in the 2010 s and 2020s, and highlights the main development to be expected in the major sectors of consumption: power, industry, residential and commercial and also transport. The third chapter reflects on these trends and builds up scenarios to highlight the challenges and opportunities up to 2030. The final section draws together some conclusions. The appendices offer additional information which is not covered in the main text such as a quick overview of the energy situation and our scenario for gas demand in each national market, the methodology, definitions and statistical problems encountered. 


\section{Natural gas demand in Europe: characteristics and latest developments}

Natural gas consumption in Europe had been a story of success since its early developments in the 1960 s. $^{6}$ Expectations of growing gas demand were largely undisputed... at least until the 2000s and the development of low carbon policies. Slow changes started to occur in the energy mix but without too much attention thanks to energy demand growth, which left enough room for gas even in a growing competitive environment. The major shock happened with the financial and economic crisis in 2008-2009. By 2013, gas demand in Europe had not recovered to its pre-crisis levels. Worse, it seems that gas has been losing its market share, especially in the power sector, without much hope of (any) recovery this side of the 2020s at least. This first chapter looks back at the latest developments by first introducing the characteristics of a diversified European gas market(s); second, by looking back at the period 2008-2013 with the impacts of the financial crisis and the arrival of cheap coal from the USA on gas demand; and finally, by focusing on the major changes that happened in the power sector, the key driver of gas demand decline in the early 2010s. The objective of this chapter is to set the scene for the subsequent chapter, which will look forward at the main challenges and opportunities up to 2030.

\subsection{A diversified and mature market}

\subsubsection{The role of natural gas in total primary energy supply}

The market share of natural gas has increased rapidly from less than $10 \%$ of the total primary energy supply (TPES) in the early 1970 s to about $24 \%$ in 2012 , replacing the use of oil and, to a lesser extent, coal. ${ }^{7}$ However, this global picture hides important differences as gas penetration varies among countries with a gas usage share well over $30 \%$ of total energy demand in the Netherlands, Italy, Hungary and the UK, but $15 \%$ or less of the TPES in France and Poland as seen in Figure 1. The differences can be explained by national endowment of natural resources and historical developments of gas and electricity markets. ${ }^{8}$

\footnotetext{
${ }^{6}$ See Honoré (2010), Chapter 1, section 1 for additional information.

7 IEA (2013a), p.IV.34 and IEA (2013b), individual countries: Albania, Bosnia and Herzegovina, Bulgaria, Croatia, Latvia, Lithuania, Former Yugoslav Republic of Macedonia, Romania and Serbia.

${ }^{8}$ See Honoré (2010), Chapter 1 , section 1 for additional information.
} 
Figure 1: Share of natural gas in TPES of selected European markets in 2012, in \%

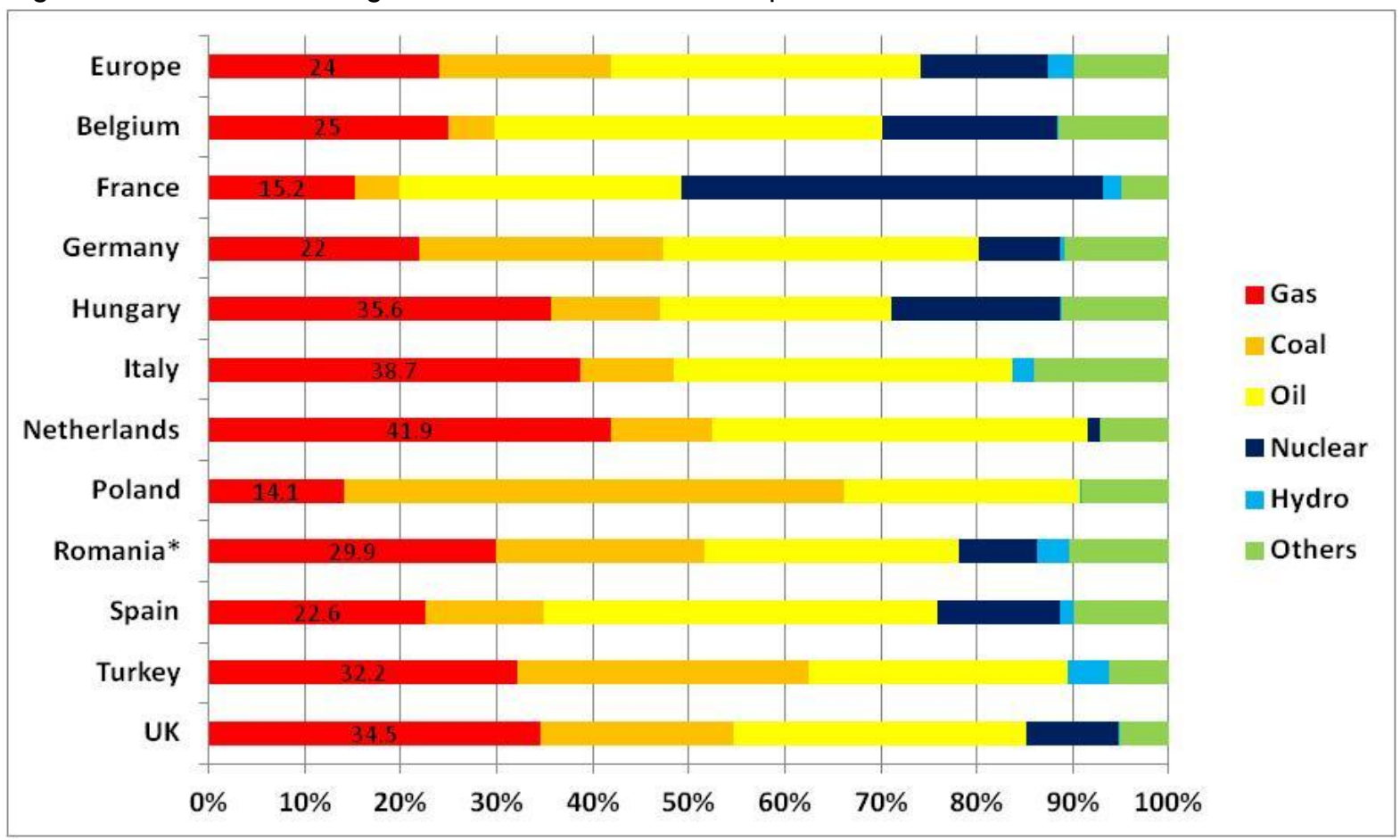

* Romania: the data is for 2011

Source: IEA (2013a), Part IV, Country data and IEA (2013c), p.II.237

\subsubsection{Main characteristics of the gas market(s)}

In 2012, 35 countries in Europe consumed $539 \mathrm{Bcm}$ of natural gas, representing about $15.6 \%$ of the world consumption and formed the second largest regional market behind the United States (720 $\mathrm{Bcm}$ ) and ahead of Russia (470 Bcm).

In 2013, European gas demand was down at $528 \mathrm{Bcm}$ according to first estimates. However, this regional data hides important features as shown in Table 1. Germany, the UK, Italy and the Netherlands alone accounted for more than half of gas consumption. Eleven countries represented $87 \%$ of the total demand, but among these major markets, only seven countries consumed more than (or close to) $30 \mathrm{Bcm}$ of gas: Germany, the UK, Italy, Netherlands, Turkey, France and Spain, while the remaining four 'big' markets consumed between 20 and $10 \mathrm{Bcm}$ : Belgium, Poland, Romania and Hungary. The 24 other markets, representing $13 \%$ of the total gas consumed, lagged far behind. ${ }^{9}$

\footnotetext{
${ }^{9}$ This study focuses on the major markets, but additional information on the other countries can be found in the Appendix 2.
} 
Table 1: Natural gas consumption in Europe in 2012-2013 and share by country ( $\mathrm{Bcm}$ and \%)

\begin{tabular}{|l|r|r|r|r|}
\hline & $\begin{array}{c}\text { Consumption } \\
\text { in 2012, in } \\
\text { bcm }\end{array}$ & $\begin{array}{c}\text { Consumption } \\
\text { in 2013*, in } \\
\text { bcm }\end{array}$ & $\begin{array}{c}\text { Share of total } \\
\text { European } \\
\text { consumption } \\
\text { in 2013, in \% }\end{array}$ & $\begin{array}{c}\text { Cumulated } \\
\text { share of total } \\
\text { European } \\
\text { consumption } \\
\text { in 2013, in \% }\end{array}$ \\
\hline Germany & 87.2 & 88.8 & 16.8 & 16.8 \\
\hline United Kingdom & 78.1 & 77.3 & 14.6 & 31.4 \\
\hline Italy & 74.9 & 70.0 & 13.3 & 44.7 \\
\hline Netherlands & 46.0 & 46.5 & 8.8 & 53.5 \\
\hline Turkey & 45.2 & 45.6 & 8.6 & 62.1 \\
\hline France & 44.1 & 43.3 & 8.2 & 70.3 \\
\hline Spain & 32.5 & 29.9 & 5.7 & 76.0 \\
\hline Poland & 18.1 & 18.2 & 3.4 & 79.4 \\
\hline Belgium & 17.9 & 17.7 & 3.4 & 82.8 \\
\hline Romania & 13.6 & 12.5 & 2.4 & 85.2 \\
\hline Hungary & 10.2 & 9.3 & 1.8 & 86.9 \\
\hline Others & 71.0 & 69.1 & 13.1 & 100.0 \\
\hline
\end{tabular}

* 2013 data are estimates

Source: IEA (2013a), pp.II.8 and 9

Natural gas demand is mainly concentrated in North-West Europe and Italy, where gas markets developed 50 years ago, plus Turkey and Spain where gas was a relatively recent addition to the fuel balance. ${ }^{10}$ This explains why these two countries had the fastest demand growth rates on the Continent in the 2000s. In some countries in Central and Eastern Europe, natural gas industries developed principally from Soviet supplies and residential and industrial consumers - rather than power generation - were the main end-users. ${ }^{11}$

\subsubsection{A context of already slow demand growth}

In 2011, gas used in the residential and commercial sector of OECD Europe represented $35.1 \%$ of total demand, the power sector followed closely with $34.2 \%$. The industry sector was third with $20.3 \%$. The other sectors accounted for the remaining $10.4 \% .{ }^{12}$ This break down reflects the important transformation that has happened since the early 1990s with the rapid growth of the power sector thanks to large investment in new gas-fired power plants, ${ }^{13}$ as seen in Figure 2. The liberalisation process led to investments in new Combined-Cycle Gas Turbines (CCGTs), ${ }^{14}$ the cheapest and least risky option for profit-driven private companies in a competitive context. For both economic and environmental reasons, natural gas became the fuel of choice for power generation in most European markets, a sharp contrast to the early development of gas demand.

\footnotetext{
IEA (annual data b).

IEA (annual data b).

IEA (2013a).

Europe rebalanced its energy mix by adding about $120 \mathrm{GW}$ of gas plants between 2000 and 2012 (net addition).

CCGT: Combined Cycle Gas Turbine. These are plants using a combination of thermodynamic power sources to reduce costs and improve efficiency, which can reach close to $60 \%$ for new plants (on baseload).
} 
Figure 2: Gas demand by sector in OECD Europe, 1971-2011 (MMcm)

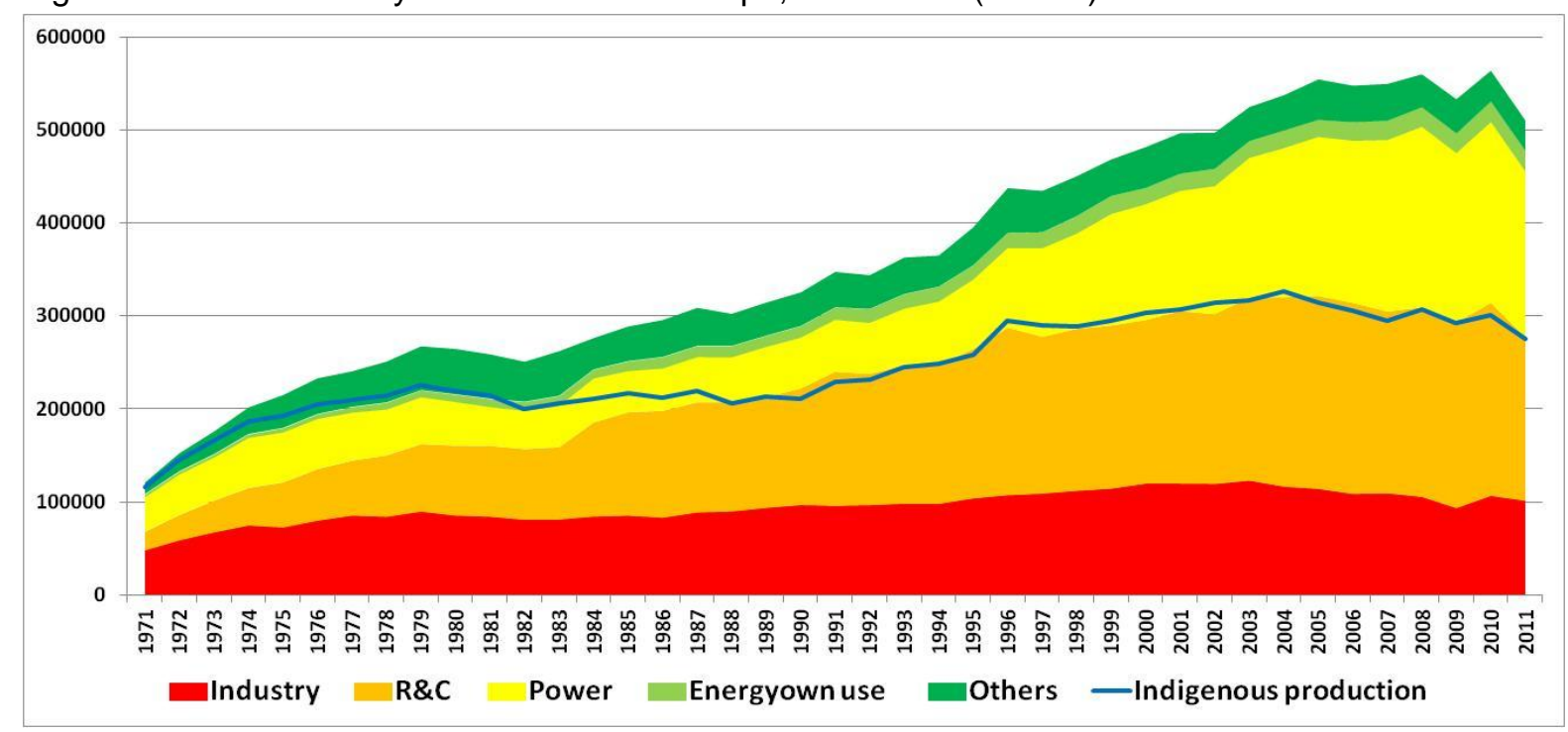

Source: IEA (annual data_a)

However, this general statement hides important features in time and geography. Gas demand grew at an annual average rate of $2.4 \%$ from 1990 to 2008 -before the impacts of the economic crisis started to be felt, but slowed to an annual average growth rate of $1.9 \%$ from 2000 to 2008 .

- This slowdown was probably due to market maturity especially in North-West Europe and Italy, where the gas market started to develop in the early 1960s. This factor combined with higher gas prices between 2003 and 2008 and progressive relocation of energy intensive industries away from Europe led to stagnation of gas consumption in the non-power sectors, while gas for power generation became the most important growth sector for natural gas consumption in Western markets.

- In Central and East Europe, gas industries were developed principally from Soviet supplies; and residential and industrial consumers - rather than power generation - were the main end-users in most countries. This trend continued in the 1990s after the Soviet Union's collapse into independent states. But post-Soviet gas prices time were too high to compete with local supplies of coal.

- In South-east Europe, Bulgaria and Romania saw their gas demand halve between 1990 and 2008.

- On the contrary, the younger Southern Europe markets around the Mediterranean Sea were the fastest growing markets in Europe, with growth of more than $5 \% / y e a r$ throughout the period despite a slight decline from the early 2000 s due to higher gas prices.

- In the North, the Baltic countries showed a decline in consumption after the end of the USSR; Slovenia and Sweden's growth has been flat; while Denmark and Finland presented sustained growth until the mid-2000s. ${ }^{15}$

At the regional level, gas demand peaked in 2005, and then remained fairly flat until 2008 when the effects of the economic recession started to be felt. The fundamentals, which had been historically driving gas demand up, had already changed by 2008 , including in the power sector, which had been

\footnotetext{
${ }^{15}$ The data on Norway cannot be interpreted. The data on demand represent the difference between indigenous production (and imports if any) and exports and stock changes. The data show strange patterns for a producing country, Norway, which uses most of its gas for own-energy use and more recently for power generation.
} 

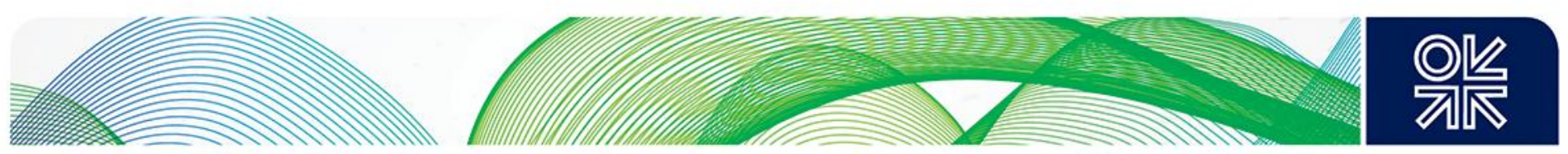

the source of expected additional gas demand in the 2010s and 2020s. The residential and commercial sector was also already reaching saturation, as was the industrial sector which was even showing signs of decline in the 2000s. As a result, gas demand growth was already slowing down and the industry was considered a mature market in most countries. The 2008/9 economic crisis happened in a context of already moderating gas demand growth in Europe due to mature markets, high gas prices and growing competition in the energy mix.

\subsection{The economic crisis of 2009 and its aftermaths}

This section provides an overview of the major changes that took place in 2008-2013 in Europe: the downturn of economic activity, and lower production output in industry and electricity generation, two sectors where gas demand has been particularly hard hit.

\subsubsection{Economic crisis and GDP changes 2009-2013}

The financial crisis began in mid-2007 and triggered the global economic crisis that transformed into a severe recession in the second half of $2008 .^{16}$ The globalisation of the economic contraction and the pace of the downturn were unprecedented post-World War II. ${ }^{17}$ OECD Europe entered recession by the third quarter of 2008 and emerged from it in the third quarter of $2009 .^{18}$ However, the region went back into recession in the third quarter of 2011, and only emerged from it in the first quarter of 2013 [Figure 3]. This was thanks to a rebound in Turkey and in the UK, complemented by a recovery in the two biggest economies in the Euro area, Germany and France by the second quarter, and an easing of recession in the third and fourth largest economies in Italy and Spain. ${ }^{19}$

Figure 3: GDP growth rate in OECD Europe, seasonally adjusted, 2008-2013 (\% change over the previous quarter)

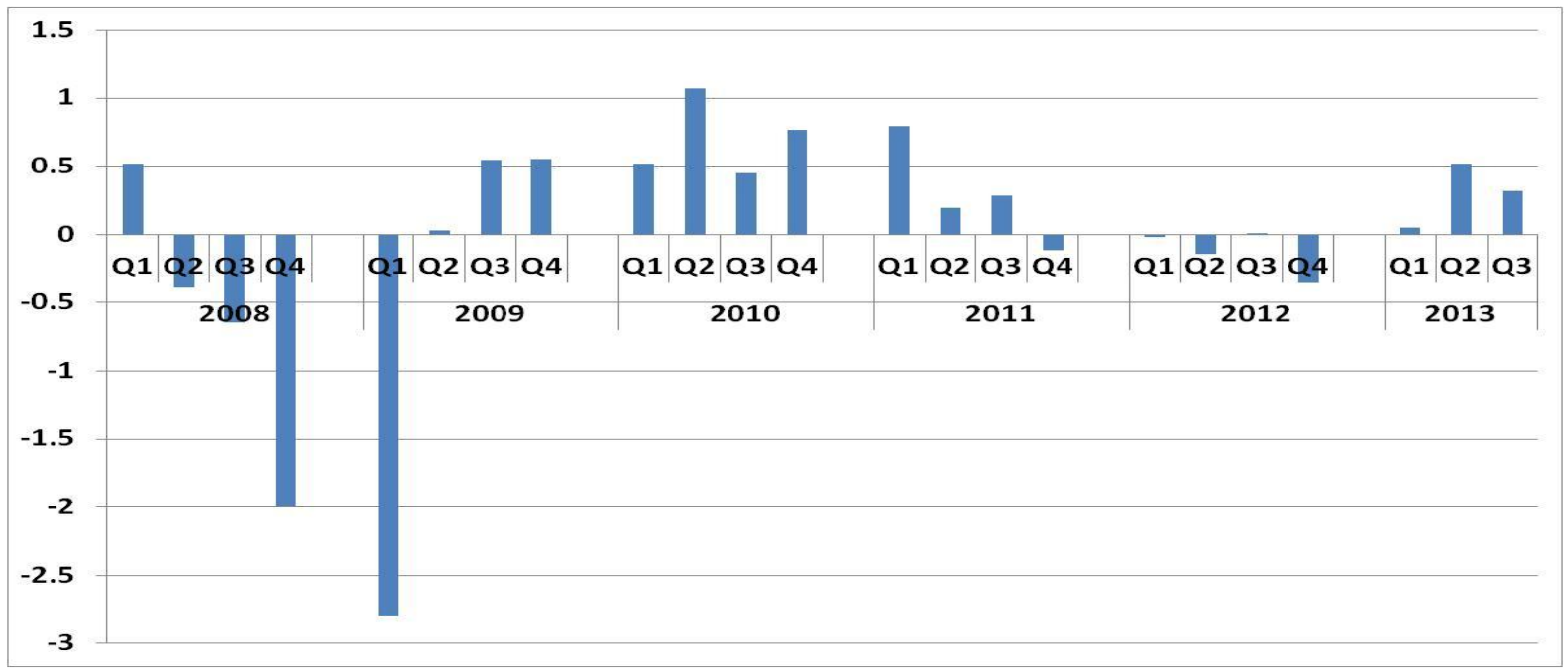

Source: OECD database retrieved in January 2014

\footnotetext{
${ }^{16}$ For more information on the economic crisis of the late 2000s, see IMF (2009a)

${ }^{17}$ IMF (2009b) and OECD (2010)

${ }^{18}$ Eurostat (Monthly), tables on growth rates of GDP in volume (based on seasonally adjusted data)

${ }^{19}$ See Appendix 2 for national details
} 

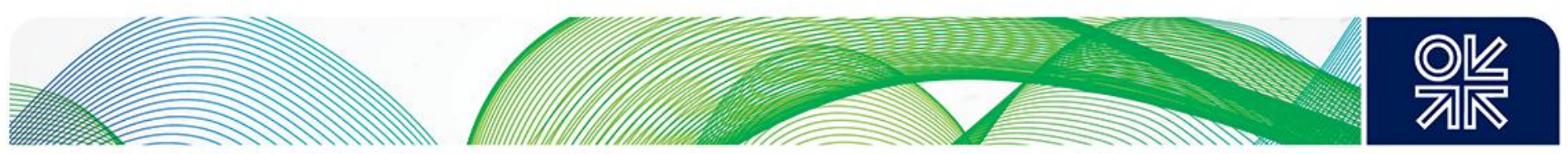

\subsubsection{Impacts on industry and energy/electricity demand}

As a result of the crisis, many factories closed or reduced output and indices for industry production show abrupt decline in 2009. Even major economies such as Germany, Italy, Spain and the UK saw a decline of between $10 \%$ and $20 \% .{ }^{20}$ By early 2014 , despite some recovery in 2009-2010, industrial production was not back at its pre-crisis levels as seen in Figure 4. As an important sector of gas consumption, the evolution of industrial production provides an insight on how industrial gas demand has been affected by the economic recession over the period 2008-2013. ${ }^{21}$

Figure 4: Industrial production (excluding construction) in the European Union, 2004-13 (index

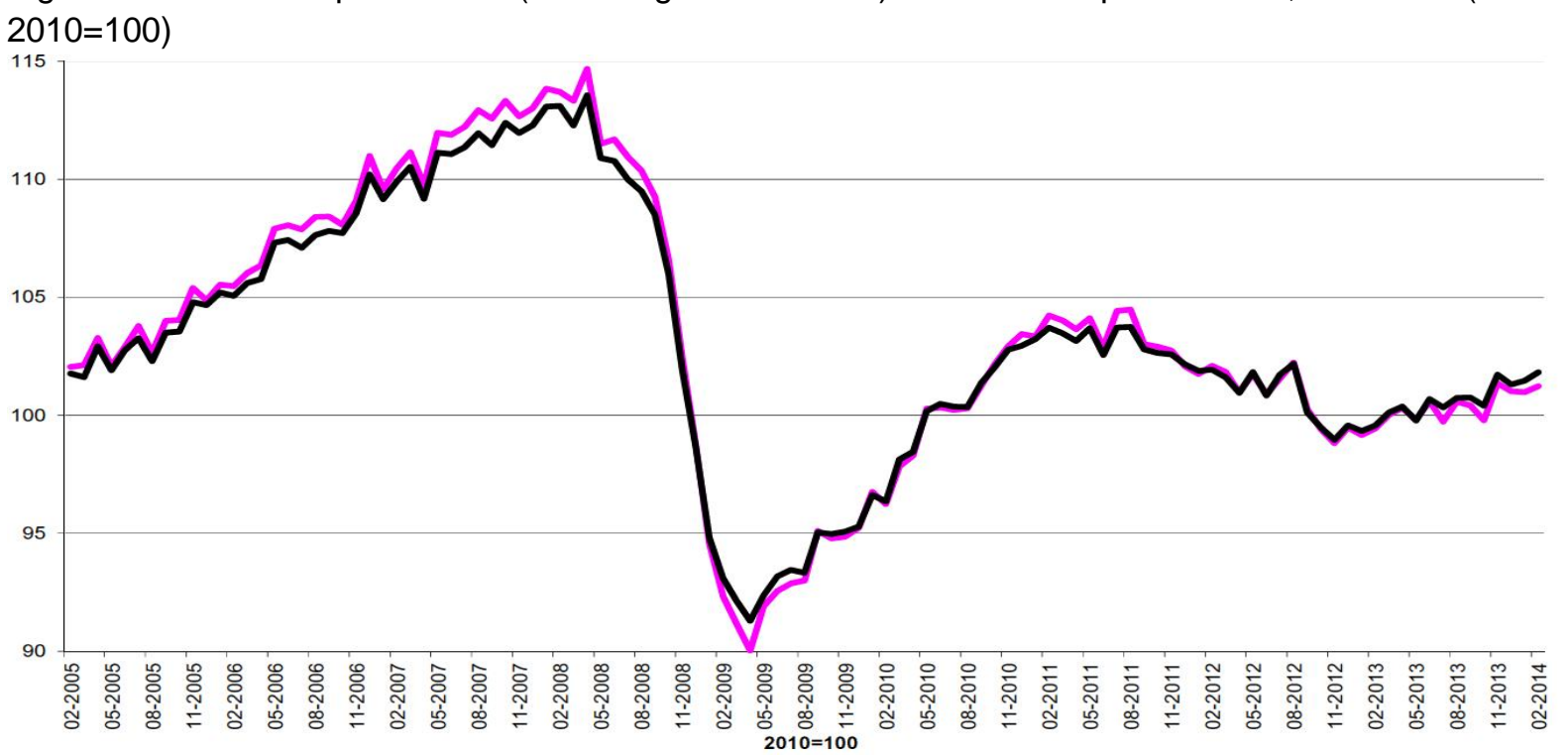

Euro area, seasonally adjusted series

EU28, seasonally adjusted series

Source: Eurostat (2014), p.1

\subsubsection{Impacts on gas demand}

The energy sector, like all other economic sectors, was affected by the economic downturn. TPES dropped by $5.34 \%$ in OECD Europe while gas demand declined by $5.67 \%$ in 2009 (and by as much as $6.6 \%$ in the 35 countries). Primary energy demand was still $4.5 \%$ lower in 2012 compared to 2008 due to the combined effect of continuing economic difficulties, high energy prices and improvements in efficiency measures. The share of natural gas declined from $25.2 \%$ to $24 \%$ of the TPES during the same period. This decline was compensated to a large extent by renewables and partly by coal. ${ }^{22}$ As a result, gas consumption was hit even harder than primary energy demand.

Gas demand levels in 2012 were still 8.1\% below 2008 levels in Europe and about 10\% below in 2013 according to first estimates, but the situation in the seven major markets was worse with gas demand

\footnotetext{
${ }^{20}$ Eurostat (Monthly), tables on growth rates of GDP in volume (based on seasonally adjusted data)

${ }^{21}$ Data on gas demand by sector is only available with a time gap of about two years for most countries. As a result, changes in industrial production give early indications of gas usage in this sector (both the existing plant capacity and the relative prices in the period 2008-2013 did not encourage switching from fuel oil to gas).

22 IEA (2009a) and IEA (2013a), OECD Europe, p. IV.34
} 
still $5-26 \%$ below 2008 levels apart from Turkey, as seen in Table 2. The most affected markets were the UK and Spain, with demand down by more than $20 \%$. Italy was also lagging behind by double digits at close to $18 \%$.

Table 2: Gas demand in OECD Europe and in selected countries, 2008-2013

\begin{tabular}{|l|r|r|r|r|r|r|r|r|}
\hline & Europe & France & Germany & Italy & NL & Spain & Turkey & UK \\
\hline 2009 vs 08 & -6.7 & -3.3 & -7.0 & -8.1 & 0.9 & -10.6 & -4.2 & -8.4 \\
\hline 2010 vs 09 & 8.6 & 10.3 & 9.7 & 6.5 & 12.0 & -0.6 & 8.6 & 9.0 \\
\hline 2011 vs 10 & -7.6 & -13.0 & -8.8 & -6.2 & -12.7 & -7.1 & 17.2 & -16.7 \\
\hline 2012 vs 11 & -1.9 & 3.2 & 1.4 & -3.9 & -4.0 & -2.3 & 1.3 & -5.3 \\
\hline $2013^{*}$ vs 12 & -2.6 & -1.9 & 1.8 & -6.5 & 1.2 & -8.0 & 0.9 & -0.9 \\
\hline & & & & & & & & \\
\hline 2010 vs 08 & 1.4 & 6.6 & 2.0 & -2.1 & 13.0 & -11.1 & 4.0 & -0.2 \\
\hline 2011 vs 08 & -6.4 & -7.2 & -6.9 & -8.2 & -1.3 & -17.5 & 21.9 & -16.8 \\
\hline 2012 vs 08 & -8.1 & -4.2 & -5.6 & -11.7 & -5.2 & -19.4 & 23.5 & -21.2 \\
\hline $2013^{*}$ vs 08 & -10.5 & -6.0 & -3.9 & -17.5 & -4.1 & -25.8 & 24.5 & -21.9 \\
\hline
\end{tabular}

* 2013: estimates

Source: IEA (2013a), various countries, Tables 3A

Maybe more worryingly, the early 2010s have given no clear signs of recovery. In 2009, the plunging of natural gas demand in the face of economic contraction was due especially to the industrial sector $(-11.6 \%$ in OECD Europe) and to a lesser extent, the power sector $(-5.7 \%)$. This followed a decline in power demand and relatively high NBP and oil $\square$ linked gas prices (which explain the drop in the use of gas-fired plants in 2009 because CCGTs are often run at the margin). However, a different generation mix and pricing structure made the share of gas actually increase in the generation mix of the UK and the Netherlands thanks to the availability of cheaper gas on the spot markets. In 2010, demand for gas recovered to 2008 levels and even more with growth in the three major sectors helped by the cold weather which kept domestic and commercial heating demand relatively strong (+10.7\%). We estimate that demand in the winter $2009 / 10$ was about $9.5 \mathrm{Bcm}$ higher than it would have been in an average winter, but there were already some signs of economic recovery which translated into higher gas demand. Some switching to gas in the power sector also helped the rebound of gas consumption. However, by 2011, the encouraging signs of recovery in 2010 had ceased and natural gas demand experienced a sharp drop of almost $60 \mathrm{Bcm}$ (almost 50\% more than in 2009) as a consequence of the warm weather, renewed economic difficulties at the end of the year, expansion in the use of renewable sources and a shift to coal in thermoelectric production due to a cost advantage. While detailed consumption by sector was not available for all the countries at the time of writing for 2012 and 2013, initial estimates showed a continuation of these trends. Despite a very cold February 2012 and March 2013, winters were fairly mild, limiting the need for gas in the heating sector. Gas demand in the industrial sector remained low as a consequence of the economic difficulties, low rates of industrial growth, high gas prices [Figure 5] and an already high gas penetration in the industrial sector. There was an even worse situation in the power sector, which is examined in detail in the subsequent section. 
Figure 5: Long-term vs short-term gas prices in 2009-2014, (€/MWh)

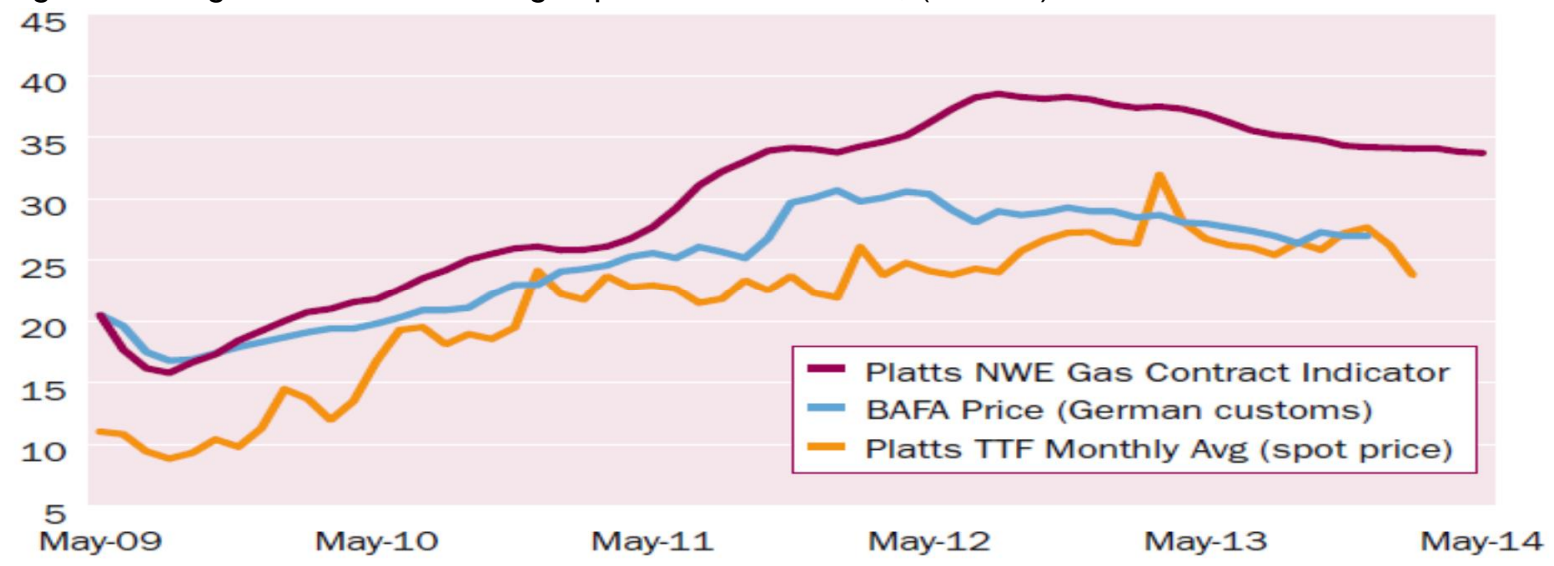

Source: Platts (February 2014)

\subsection{The power generation sector... as the main driver of decline}

The economic situation, high energy prices, efficiency policies and the energy savings adopted by consumers as a result of economic hardship had a limited impact on the need for power: electricity generation was only about $0.5 \%$ below its 2008 level in 2012. Most important though was the reduction of the electricity produced from gas during that period from 869 TWh in 2008 to $665 \mathrm{TWh}$ in 2012, a loss of about $23.5 \%$ as seen in Figure 6.

Figure 6: Electricity generation mix in OECD Europe, 1990 - 2012 (TWh)

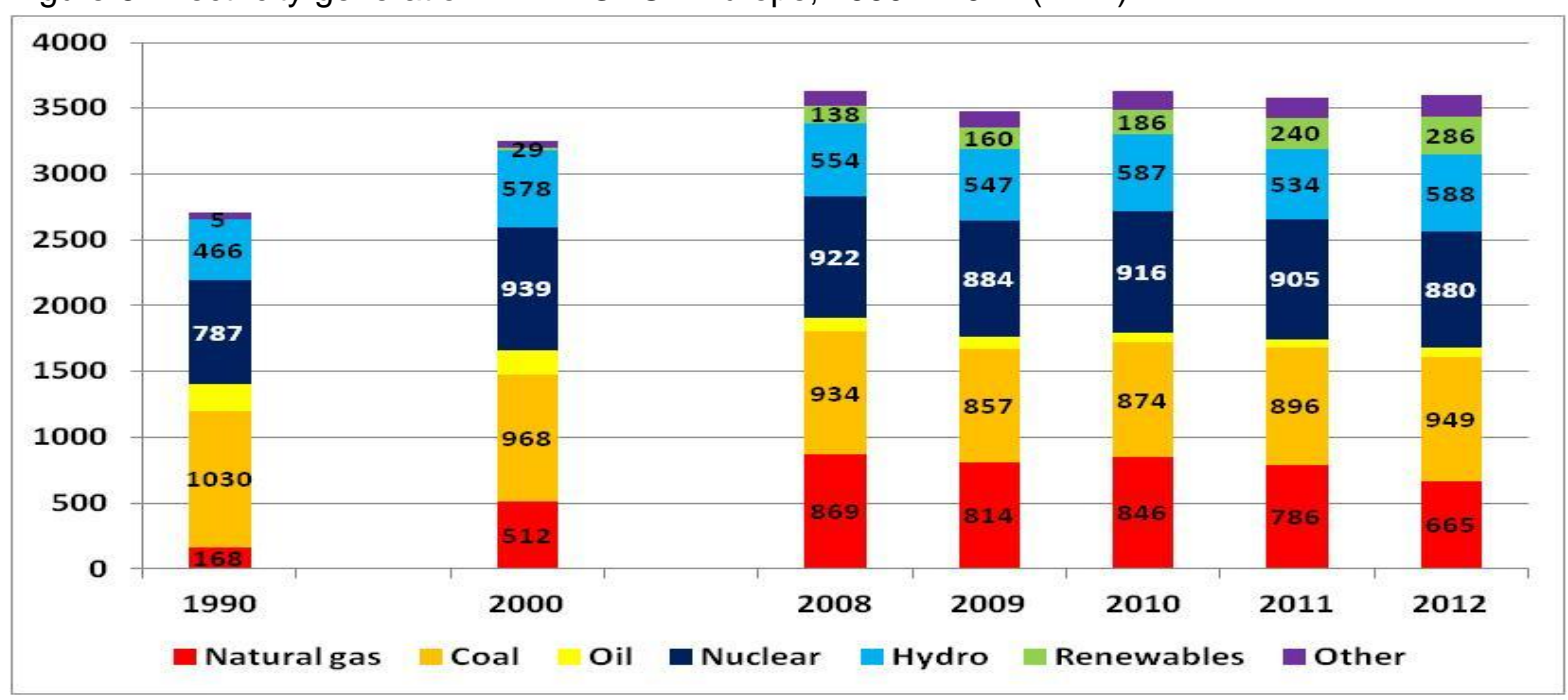

Source: IEA (annual data_c)

\subsubsection{Rising renewables as part of the transition to low carbon economy}

The power generation sector is in transition in Europe. Because of environmental policies and the policy driven transformation to a low carbon economy, the regional markets have committed significant investment in renewable energy. The rapid growth of renewable generating capacity since 2000 was unprecedented thanks to high buy-back tariffs for electricity, as renewable energy was 
viewed as one of the best ways of reducing $\mathrm{CO}_{2}$ emissions. Gas turbines and renewables (especially wind and photovoltaic) dominated the investment made in power generation across Europe in the 2000s. According to EWEA statistics, between 2000 and 2013, there was a net capacity growth for wind $(+105 \mathrm{GW})$, gas $(+103 \mathrm{GW})$ and solar $(+80 \mathrm{GW})$, but a net decline of nuclear $(-13 \mathrm{GW})$, coal $(-19$ $\mathrm{GW})$ and fuel oil (-24 GW) as seen in Figure 7 and Figure $8 .{ }^{23}$

Figure 7: Installed generating capacity by year (MW) and renewables share (\%)

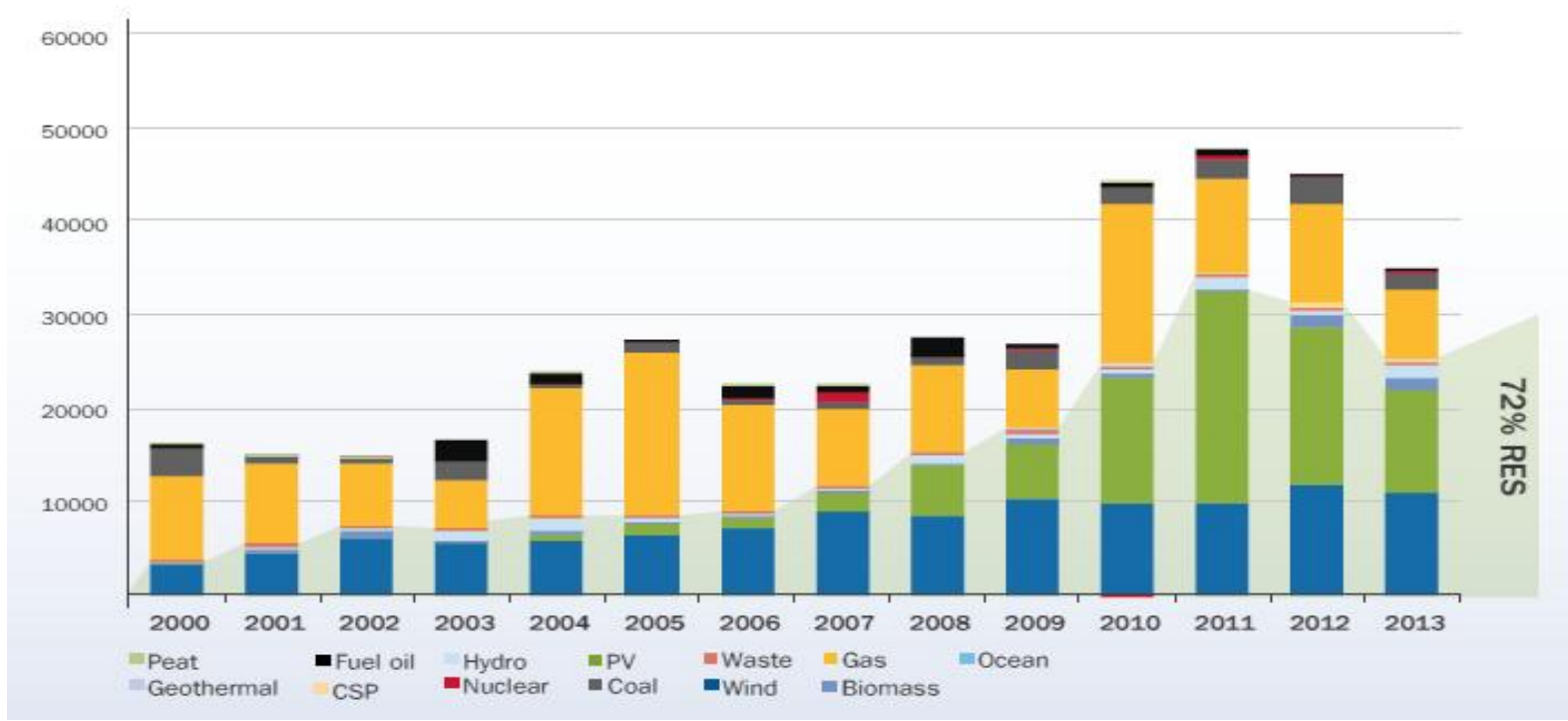

Source: EWEA (2014), p.7

Figure 8: Installed power capacity in the EU in 2000 and in 2013 (GW)
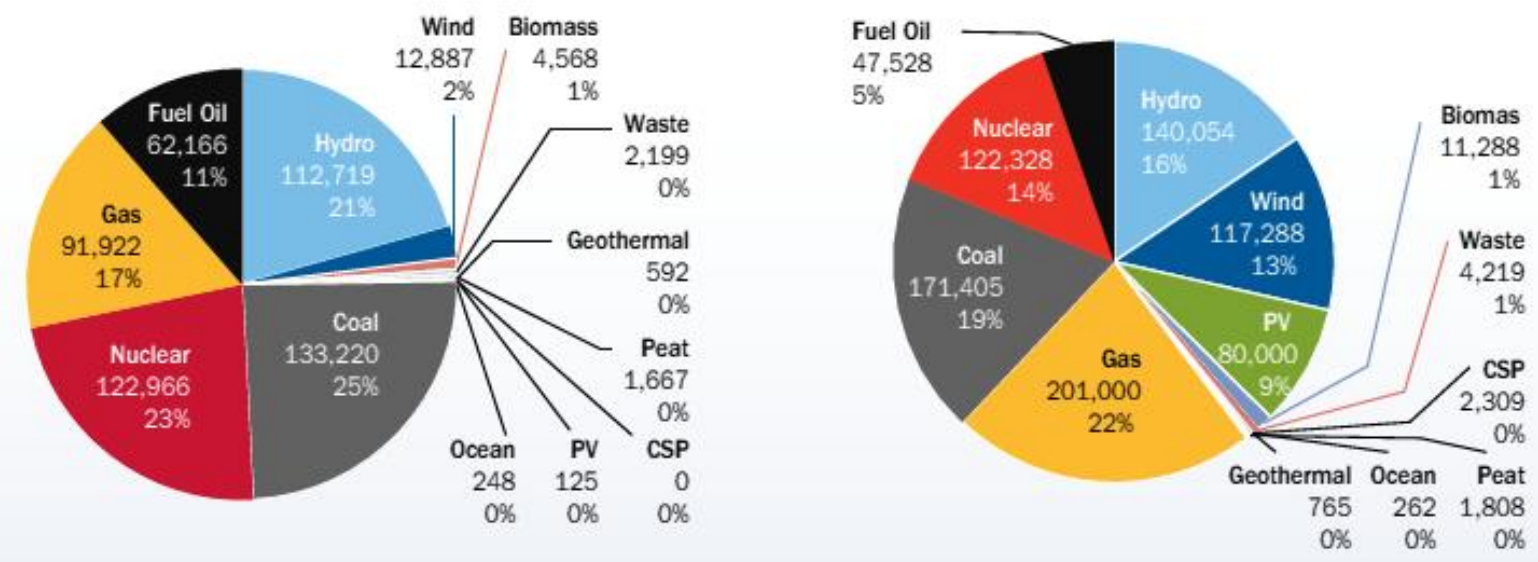

Source: EWEA (2014), p.8

The development of renewable energy in the 2000s had a limited impact on gas as long as electricity demand was rising. But from 2009, the combination of lower power demand and rising renewables made gas compete against coal for a shrinking share of total electricity generation as fossil fuels plants are usually dispatched after nuclear, hydro and renewable which are 'must $\square$ run' capacity with

\footnotetext{
${ }^{23}$ EWEA (2014), p.8.
} 
low marginal costs. Losing the competition with coal for baseload generation has put further pressure on the use of gas in the power sector.

\subsubsection{Rising competition from coal due to effects of US shale gas and low $\mathrm{CO}_{2}$ prices}

Shale gas developments in the USA created an additional consumption of gas, especially in the power generation sector, and at the expense of coal which was then (re-)exported towards other markets, including Europe. This combined with relatively high gas prices which, after a relief in the second half of 2008 to 2009 , started to increase again in 2010, and changed the economics of gas versus coal in the power sector.

Coal prices plummeted in 2008, and despite a relative recovery in 2011, the rise of coal prices hasn't matched the rise in gas prices. Since mid-2011, the competitiveness of gas prices versus coal prices has changed dramatically. The average spark spread (gas plant profit margin ${ }^{24}$ ) dropped below zero in many countries in the first half of 2012 and again in 2013. This is especially remarkable when compared to the clean dark spread (coal plant profit margin) which has remained positive during the same period, as seen in Figure 9. By 2013, coal prices were still at competitive levels against gas prices in Europe, putting gas-fired plants at a disadvantage in the merit order.

Figure 9: Day ahead base spark spread and dark/clean dark spreads (month ahead) (€/MWh)
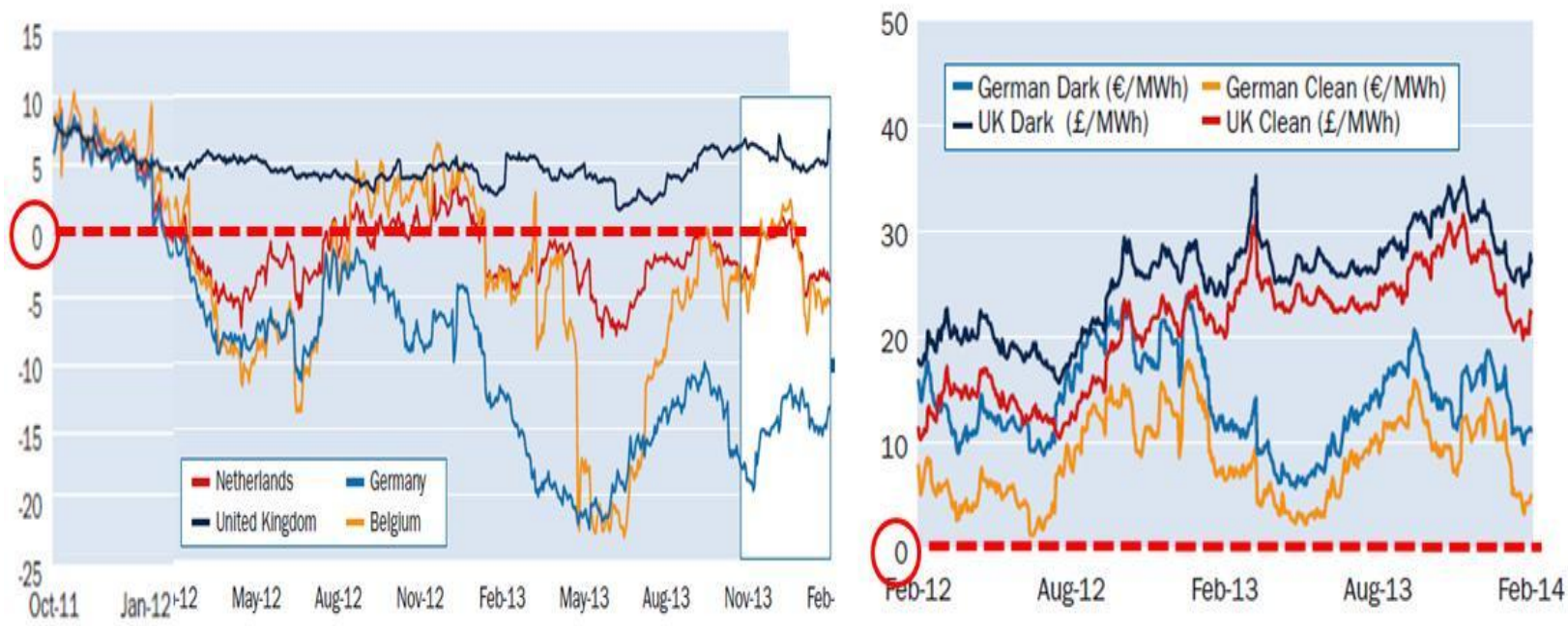

Source: Platts (March 2014a), p.10

Even in countries with low but positive spark spread such as the UK or in Italy due to gas plants being at the margin, the cost of producing electricity from gas compared to producing it from coal does not leave much support for gas-fired plants, as seen below in Figure 10.

\footnotetext{
${ }^{24}$ Spark spreads measure the financial margin between the price of electricity and the cost of buying gas to generate the power. Clean spark spreads also take into account the cost of carbon. It is a measure of profit margins for gas-fired plants.
} 

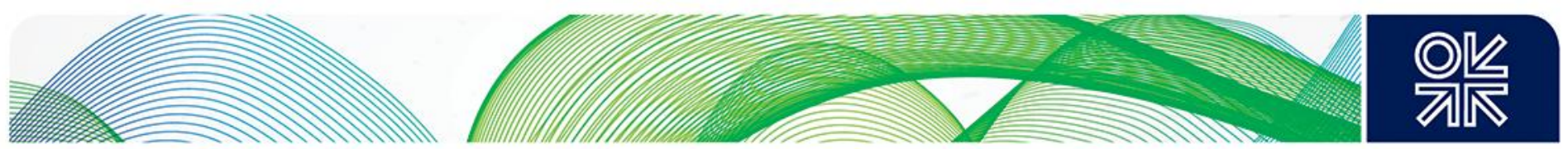

Figure 10: Clean spark spread in April 2014 (50\% efficient) and generation costs in the UK (month ahead) (€/MWh)

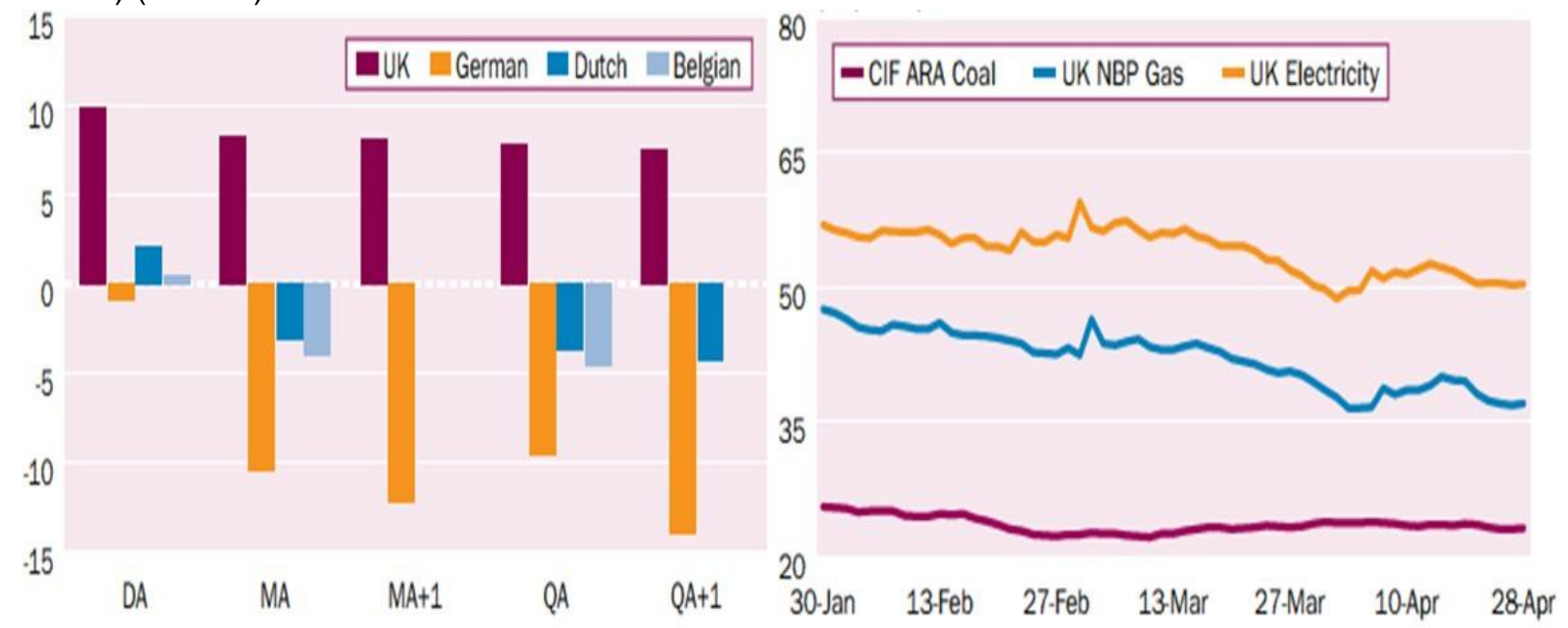

Source: Platts (April 2014a), p.5

It is no wonder that companies with a diversified portfolio have preferred coal to gas plants in order to minimize spark spread losses and maximize dark spread gains. For instance, Enel said that in the first nine months of 2012, nearly half of its electricity generation in Italy came from its coal-fired plants, producing over three times as much electricity as its CCGTs even though its CCGTs and coal installed capacities are fairly similar (6,746 MW coal and 5,916 MW CCGTs). ${ }^{25}$ Enel also indicated that its clean spark spread at end-September 2012 was about €3-4/MWh (still a better figure than in most Western European countries), and that it expected a spark spread close to zero 'in the near future'.

Gas plants with oil-linked supply contracts have been even less profitable than plants in countries with access to spot gas, which led to contract renegotiations in 2011-2012. The lower price for gas has resulted in a downward pressure on wholesale electricity prices by the end of 2012 compared to 2011 [Figure 11]. Unfortunately, this engendered even lower clean spark spreads despite the fall of gas fuel costs. ${ }^{26}$

\footnotetext{
${ }^{25}$ Platts (November 2012), p.4-5.

${ }^{26}$ In the fourth quarter of 2012 , the average baseload power price was down by $16 \%$ compared to the same period in 2011 . In addition to lower gas prices, power generation costs also fell due to the lower share of gas-fired generation (53\% in 2011 vs $45 \%$ in 2012), while the share of renewable energy increased from $22 \%$ to $29 \%$ in the same period, Source: European Commission (2012), p.16.

The end of the green certificates is also expected to bring another discount on electricity prices by 2015 . Source: ICIS Heren (December 2012).
} 
Figure 11: Comparisons of monthly electricity baseload prices in regional electricity markets (€/MWh)

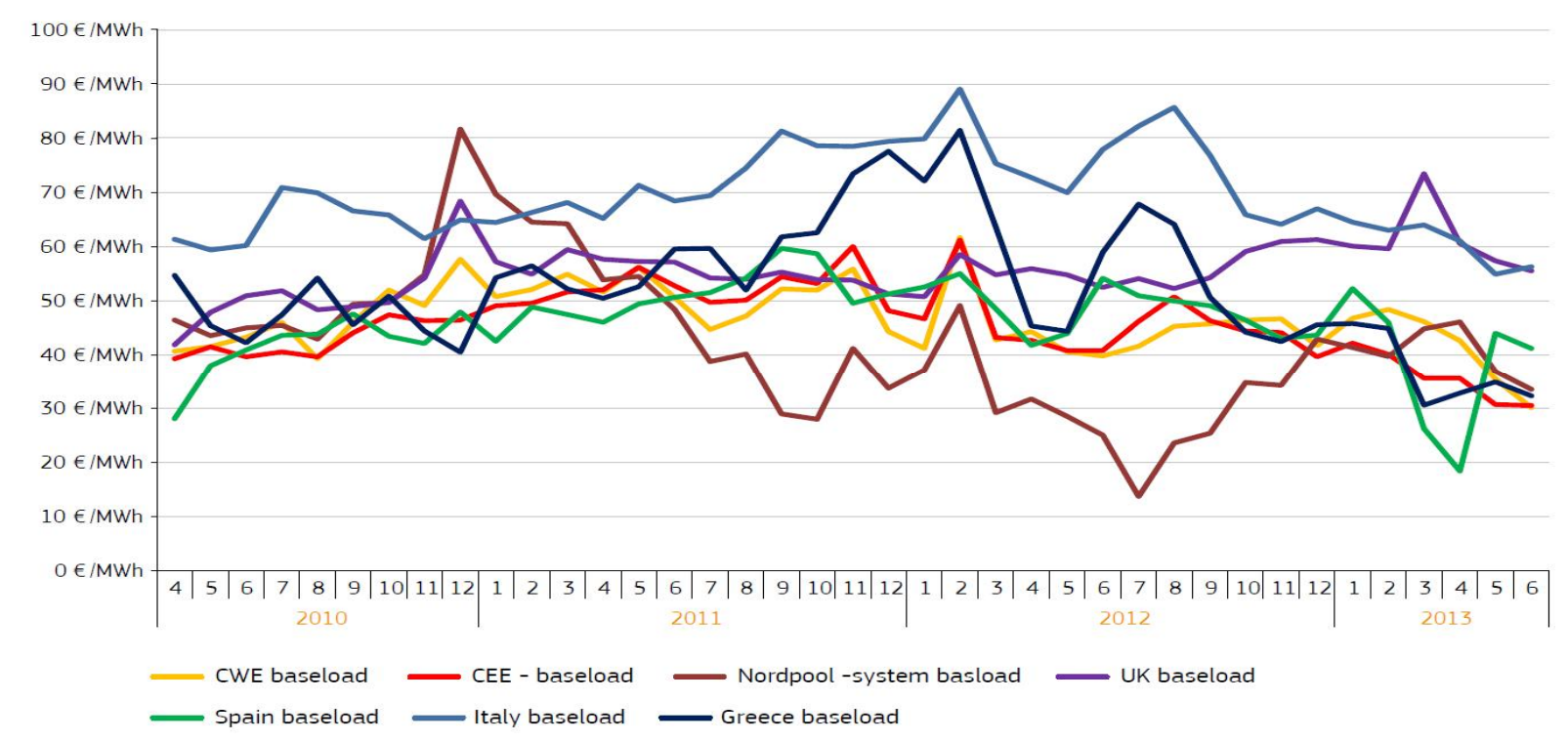

Sources: Platts, European power exchanges in European Commission (2013), p.10

The competition between high gas prices and low coal prices was exacerbated by the fall of the $\mathrm{CO}_{2}$ price in the European Union Emissions Trading System (EU ETS) which further strengthened the attractiveness of high-emitting coal over gas (coal plants emit twice as much $\mathrm{CO}_{2}$ as gas plants and should normally be penalised by $\mathrm{CO}_{2}$ prices). Approximately all allowances (97\%) were distributed free of charge during the second trading period according to the historical emissions of the installation. As the economic crisis depressed the need for emissions more than anticipated, installations sold off their excess allowances on the spot market to gain funds. Free allocation, drop in both industrial production and electricity demand were the leading causes for the accumulation of the surplus. As a consequence of this surplus, $\mathrm{CO}_{2}$ prices fell sharply from about $€ 28 / t$ before the crisis, to just about €20/t in early 2011, down to less than €5/t for most of 2013 as seen in Figure 12 .

Figure 12: $\mathrm{CO}_{2}$ price in the EU ETS, 2008-2014 (€/t)

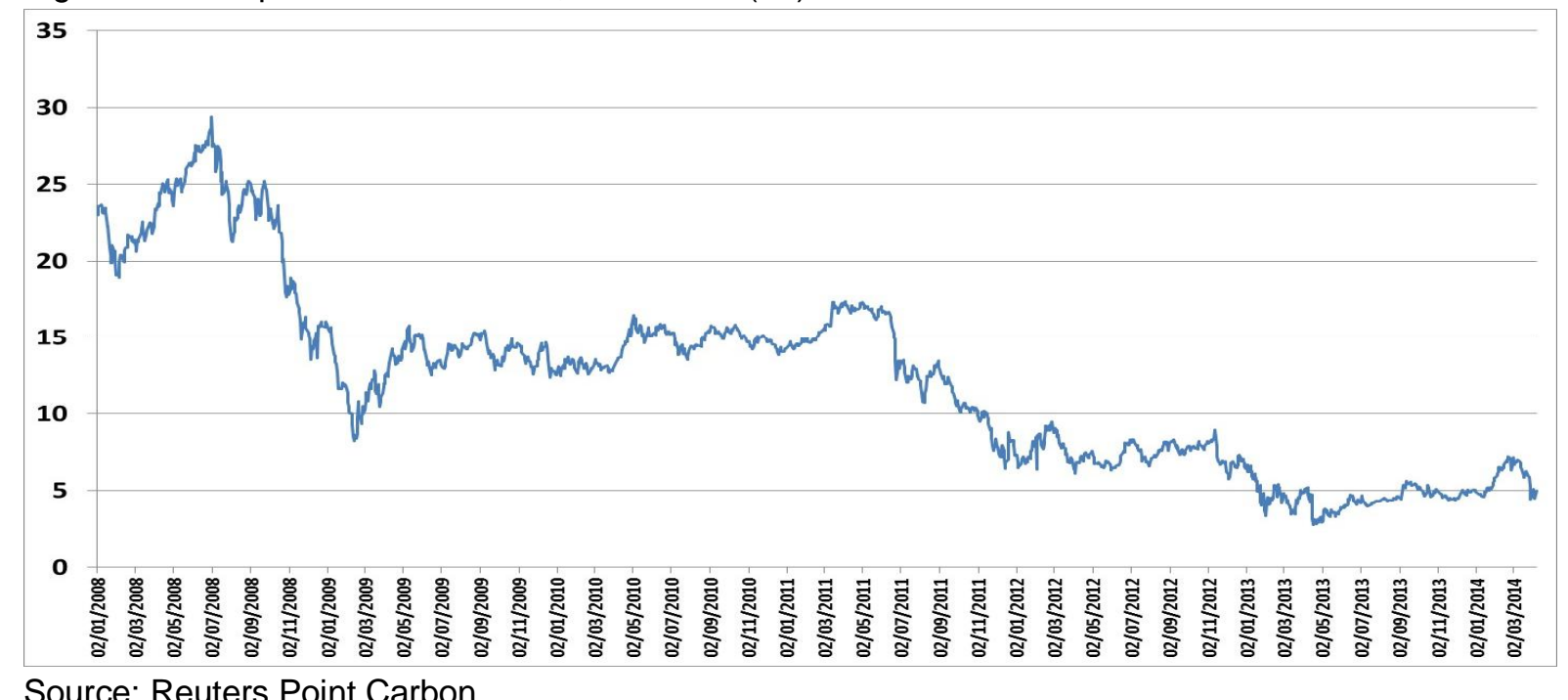



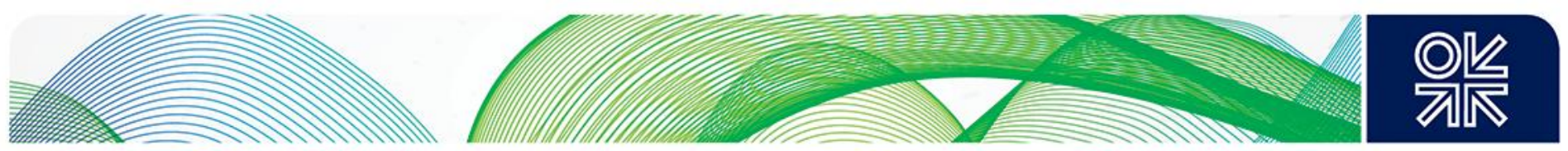

At such low levels, $\mathrm{CO}_{2}$ prices have no impact on a switch from coal to gas to produce electricity (even if the switch prices may differ from one country to another depending on the combination of energy mix, supply contracts and structure of the market). Low carbon prices help coal power plants, the most emissions-intensive technology, to gain market share in the energy mix. Wind and solar energies benefit from financial support mechanisms. Gas-fired power plants, which produce less emissions than coal, are squeezed out of the market. Moreover, because the free allocation of certificates was based on historical emissions, coal-fired plants often had a larger surplus of allowances to sell compared to gas plants. In other words, installations with a higher level of emissions were made financially better off from the surplus than less polluting plants, contradicting the main purpose of the EU ETS which is to support the transition to a low-carbon economy.

\subsubsection{Change of the generation mix: major impacts on the CCGTs}

As a consequence of these factors, the generation mix in Europe changed dramatically over the period 2008-2012/13. Because renewables, hydro and nuclear have low short $\square$ term marginal cost, the level of electricity they generated was less affected by changes in fuel prices than plants using combustible fuels. As seen in Figure 13, electricity from nuclear has remained fairly high since 2009, despite the aftermath of the Fukushima disaster and the initial questions about the future of nuclear in the world and in Europe as seen in particular with the German decision to instantly shut down $8 \mathrm{GW}$ of nuclear capacity. ${ }^{27}$ Hydro availability changed across the years, leaving potential room for additional power from gas in 2009 and 2011, but with no clear impact.

With high gas prices in most Continental European countries, gas $\square$ fired power was at a disadvantage in the merit order, especially for companies with no access to cheap spot gas supplies. As of 2014, gas-fired power plants have fallen to structural minimums in order to balance the market and ensure grid security in most markets, with only the UK and Italy where gas plants still run on base-load. The sharp reduction in the market share of electricity from gas $(-23.5 \%)$ was compensated by renewables with an increase of $+26.3 \%$ (or $+107 \%$, from a much lower base, if hydro energy is excluded), and partly by coal which increased steadily after a sharp drop in 2009 to levels just above $2008(+1.6 \%)$. Coal's share in total generation increased slightly from $25.7 \%$ to $26.4 \%$, renewables' share shot up to $24.3 \%$ (from $19 \%$ ) while gas' share fell to $18.5 \%$ from $24 \% .{ }^{28}$ Despite a strong political will to decarbonise the economy, and since the publication of the 20-20-20 targets, coal generation was very high in 2012. Early data for 2013 show that renewables, including hydro, dominated the generation mix in the European Union, just above coal and nuclear while gas registered another annual decline. ${ }^{29}$

See chapter II, section 2.2.

For more information on the German market, see Dickel (2014).

${ }^{28}$ IEA (2009b), OECD Europe, p.III.47 and IEA (2013e), OECD Europe, p.III.47.

${ }^{29}$ Le Monde (May 2014) 
Figure 13: Electricity generation mix in OECD Europe by fuels, 2008-2012 (TWh)

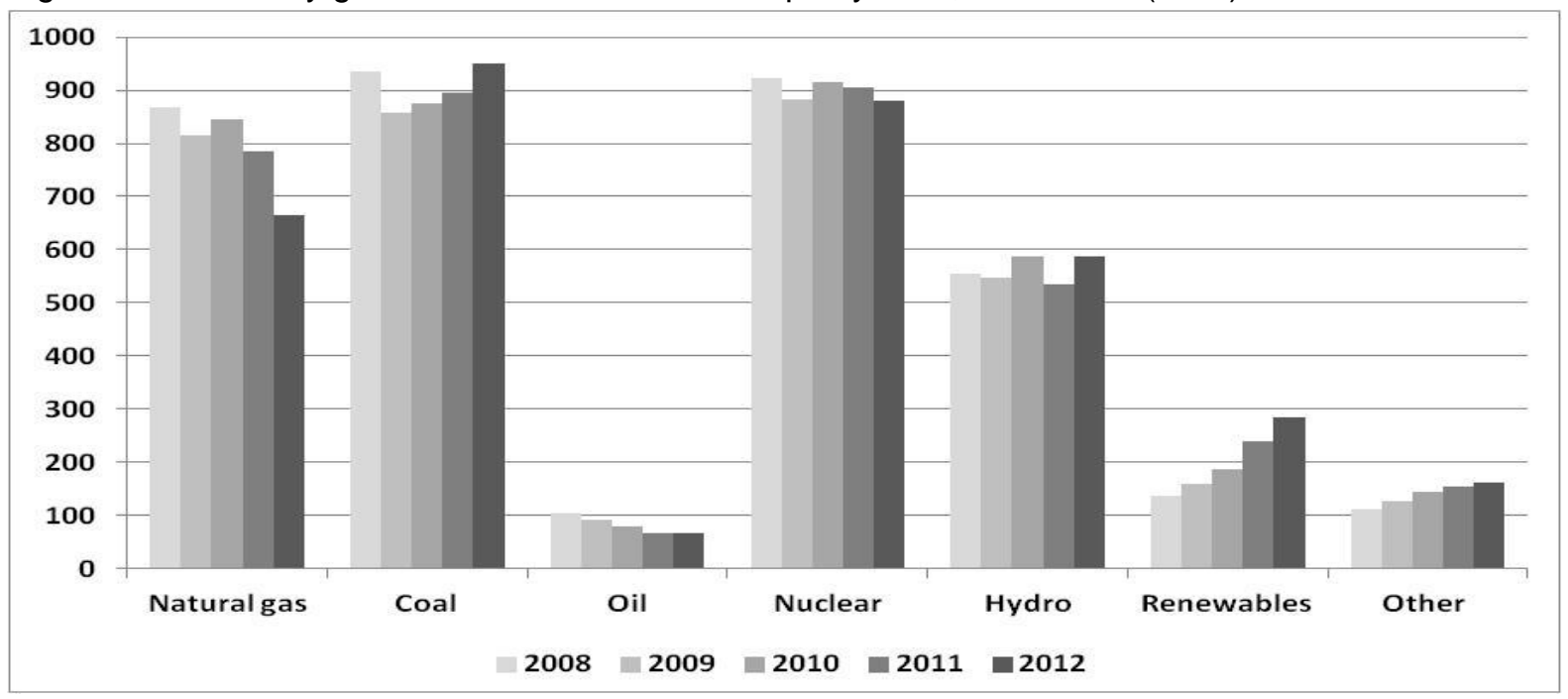

Source: IEA (annual data_c)

Gas fired plants had been planned to be used for 4,000-5,000 hours annually (45-57\% load factor) when Final Investment Decision (FID) were taken, mostly before 2008. But with lasting economic difficulties, non-market-based renewable policies and both low coal and carbon prices, gas-fired plants have been squeezed in the merit order. As a result, gas-fired plant has been operating mostly in peak periods for most of 2012 and probably 2013. In 2012, average load factors of European CCGTs were probably about $30-35 \%$ (while coal plants ran at $55-60 \%$ load factors). ${ }^{30}$ The decreasing number of periods of cost recovery logically engendered poor returns from investment in gas-fired power. The declining value of gas-fired power stations was the main reason for about $€ 8$ billion of impairment charges being made in 2012 by the main generating utilities. ${ }^{31}$ In response, existing power stations are increasingly being mothballed or ramped down for at least part of their capacity because it is no longer economic to keep them on with low electricity and carbon emissions prices. At the regional level, it is likely that more than $30 \mathrm{GW}$ of gas-fired capacity has been mothballed by early $2014,{ }^{32}$ and up to $40 \mathrm{GW}$ could be shut down or mothballed by $2015 .^{33}$ This situation is not only affecting small new players, but even major utilities cannot keep their gas plants running. For instance, at the end of 2013, GDF Suez had mothballed around $10 \mathrm{GW}$ of generation capacity and placed between 5 to $7 \mathrm{GW}$ of additional capacities under review. ${ }^{34}$ Another (of many) example(s) is E.ON, which mothballed its 2-year old 430 MW CCGT at Malzenice (Slovakia) because only about half of the existing capacity ran for peak load for most of 2013, while it had been planned to be used for 4,000-5,000 hours annually when construction was approved in $2008 .{ }^{35}$

The same general trends - low demand, gas competing against growing renewables and coal at the margin- could be observed in the major gas markets, although with some disparities due to differences in the electricity generation mix: lower electricity production in 2012 compared to 2008 except in Turkey. Interestingly, the role of gas in the two largest electricity markets, Germany and France, is relatively limited [Figure 14].

\footnotetext{
${ }^{30}$ Author's estimates

${ }^{31}$ Platts (May 2013a)

${ }^{32}$ Author's estimates based on a cursory examination of the press, as of early 2014.

${ }^{33}$ Le Figaro (January 2014)

${ }^{34}$ The Wall Street Journal (January 2014)

${ }^{35}$ Platts (July 2013), p.4
} 

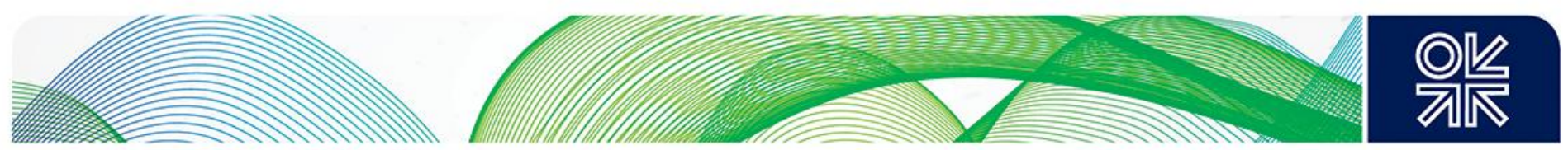

Figure 14: Electricity generation mix in selected countries by fuels, 2008 and 2012 (TWh)

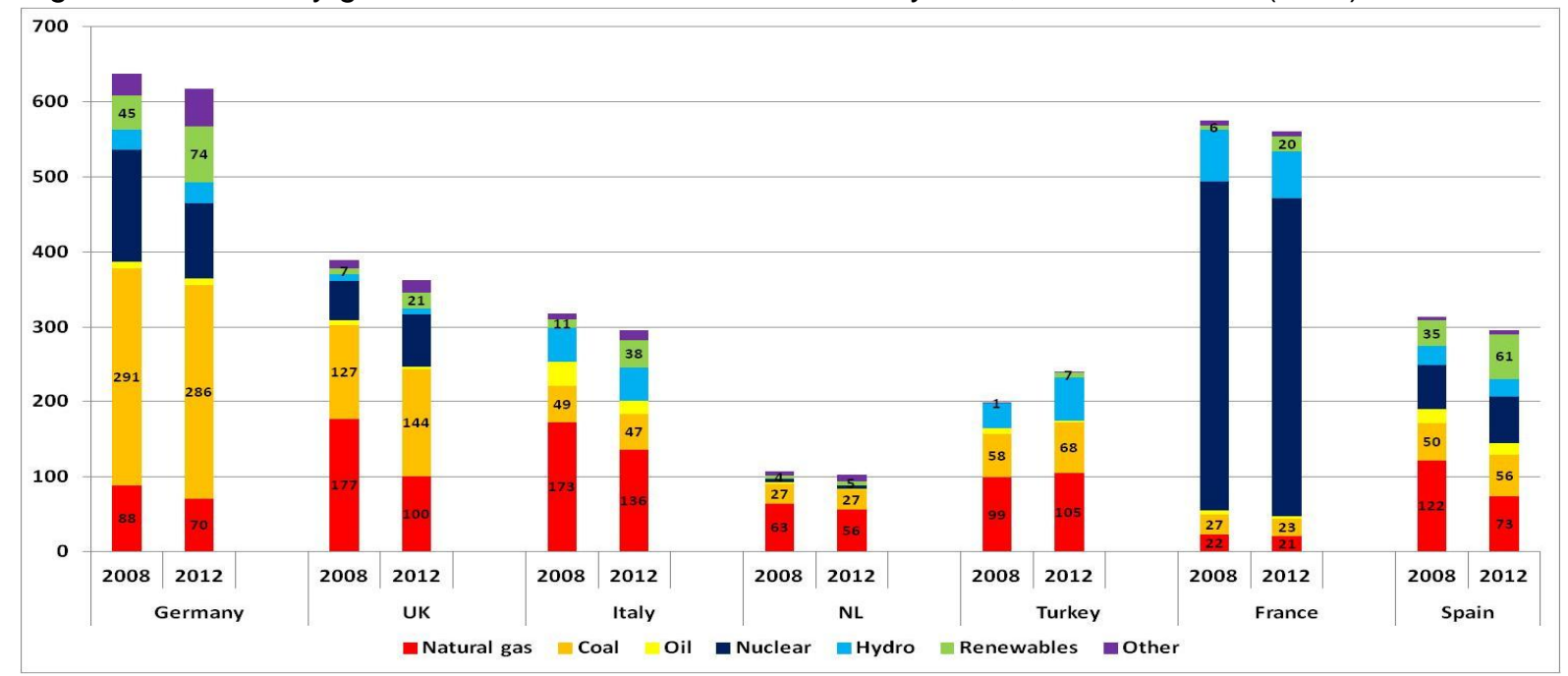

Source: IEA (annual data_c), individual countries, Table 3

In all these markets, gas lost market share, apart from France, where it remained flat and very low. The share of coal increased slightly or remained fairly flat thanks to the competitiveness of its prices apart from the UK were there was a drastic shift between coal and gas. Consequently, it appears that the increase in renewable energy, whether wind and solar as in Spain, Italy or Germany or hydro as in Turkey has primarily affected the use of gas over the period considered [Figure 15].

Figure 15: Electricity generation mix in selected countries by fuels, 2008 and 2012 (\%)

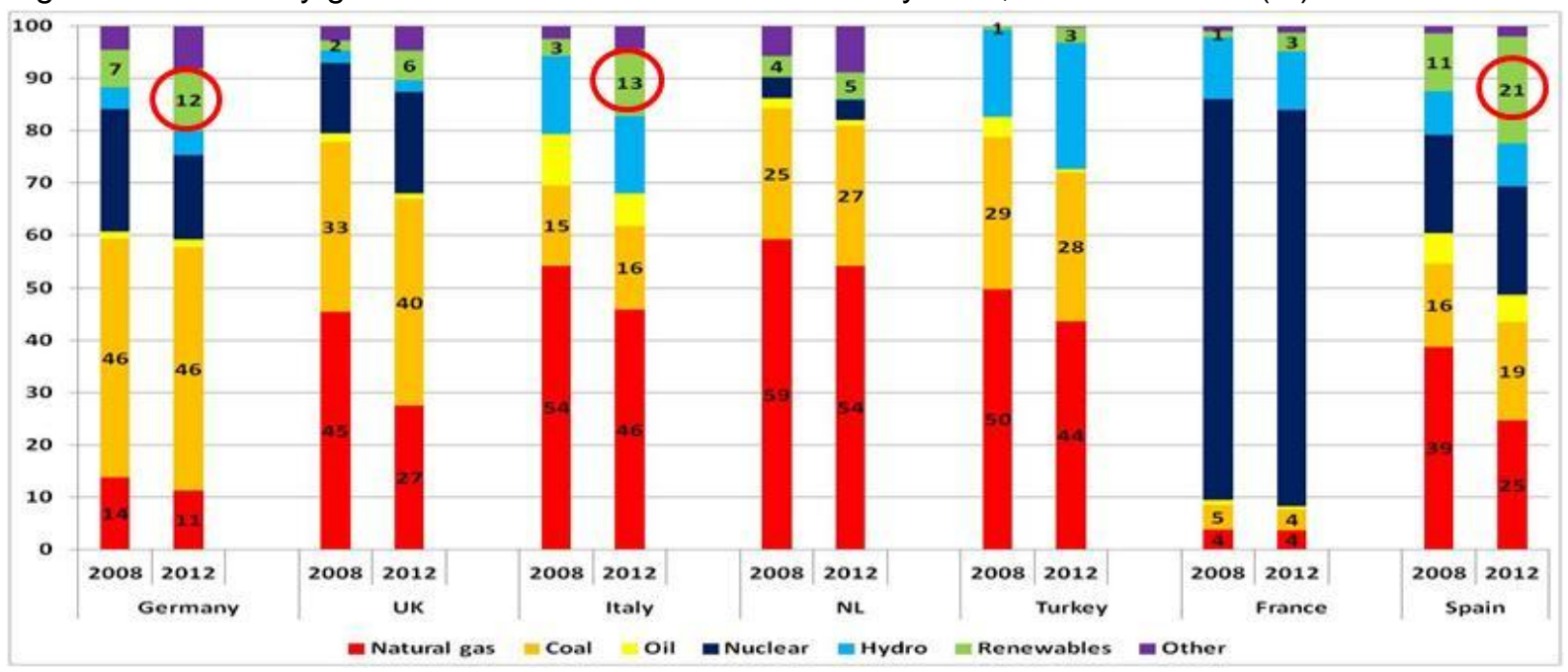

Source: Author's calculation from IEA (annual data_c), individual countries, Table 3

The following paragraphs look at Spain, Italy and Germany, the three major gas markets with the largest share of renewables in 2012, and considers the impacts on the CCGTs and gas for power generation. 

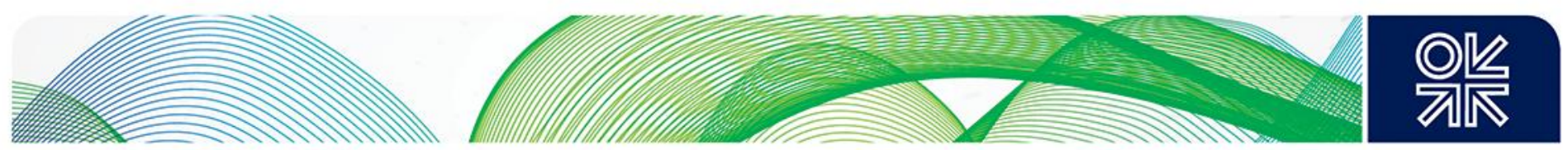

\section{Spain}

In Spain, renewables produced about 35\% of the electricity in 2010 (including hydro) [Figure 16]. This presents an interesting case study because it is the level of penetration needed in the power sector to reach the European $20 / 20 / 20$ target of $20 \%$ of renewable in energy consumption.

Figure 16: Spain: power generation by fuel and renewables share, 2000 and 2012 (TWh)

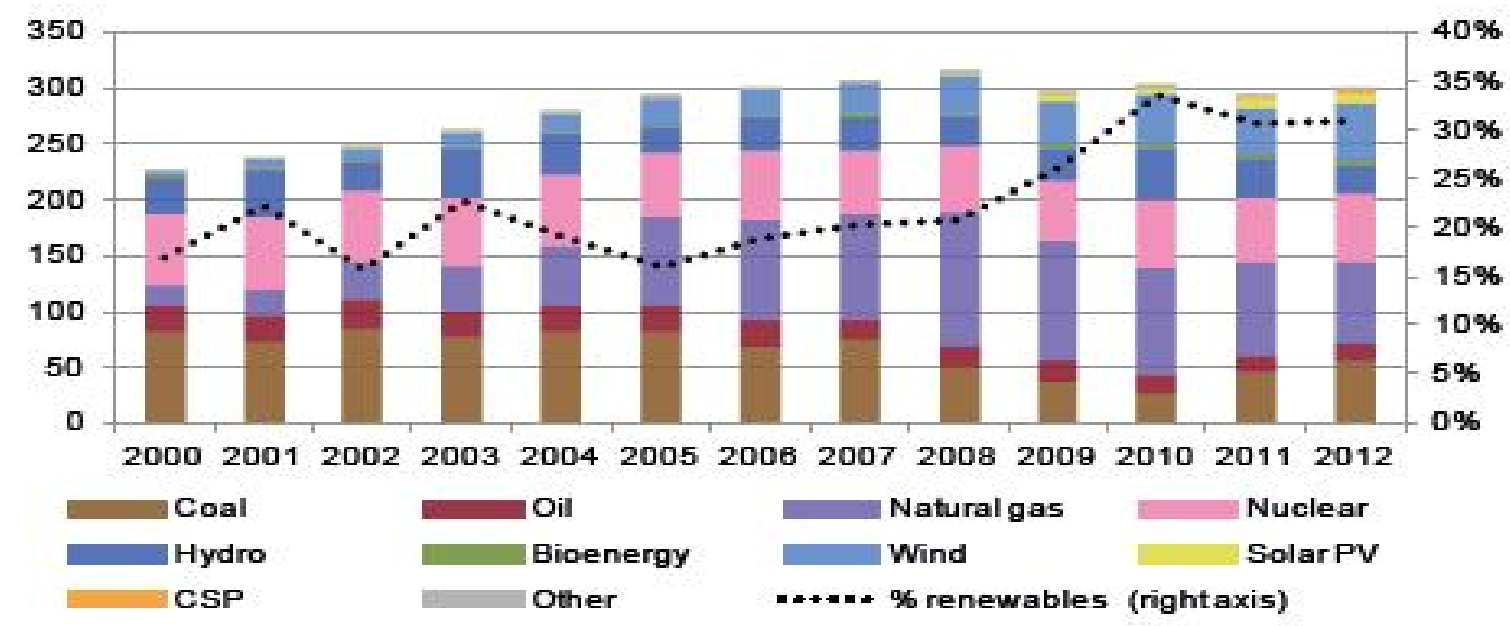

Source: IEA (2013d), p.96

Massive investments were made in gas $\square$ fired capacity in the 2000s. However, gas is still dispatched after hydro, wind, solar and nuclear which represent around $50 \%$ of total generation. In addition, because gas is imported under long $\square$ term contracts, mostly under oil $\square$ indexed formulae, gas has been losing market share to coal as the cost of generating power from gas became uncompetitive compared to the cost of generating power from coal in $2012-2013$ as seen in Figure $17 .^{36}$

Figure 17: Average power generation costs from gas and coal in Spain, 2010-2013, €/MWh

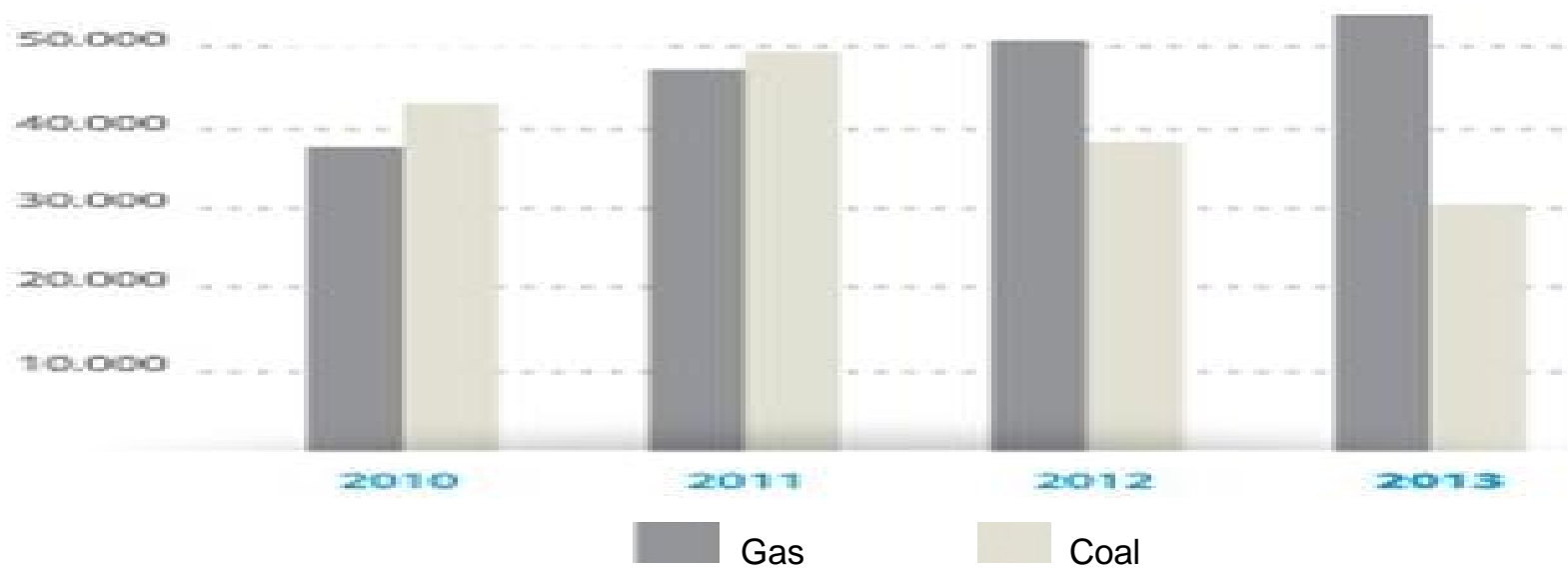

Source: Enagás (2014), p.39

While the renewables share in electricity generation increased from $24 \%$ in 2008 to $32 \%$ in 2012 , coal's share rose from $16 \%$ to $20 \%$, leaving gas with a share in the power mix shrinking from $32 \%$ to

${ }^{36}$ See Honoré (2010) for more information. 

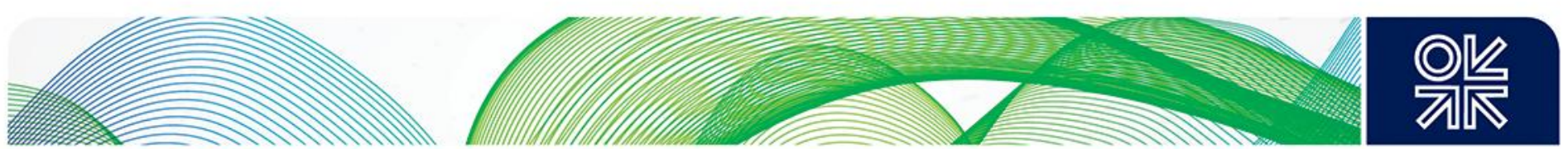

14\%. Figure 18 shows the maximum level of gas that can be used in the existing CCGTs (green line), whose capacity continued to increase up to 2010, and compares it to the actual level of gas consumed in the plants, with an ever widening gap from 2008.

Figure 18: Spain: Natural gas used in CCGTs vs maximum potential use of gas in CCGTs, 2003$2012(\mathrm{GWh} / \mathrm{d})$

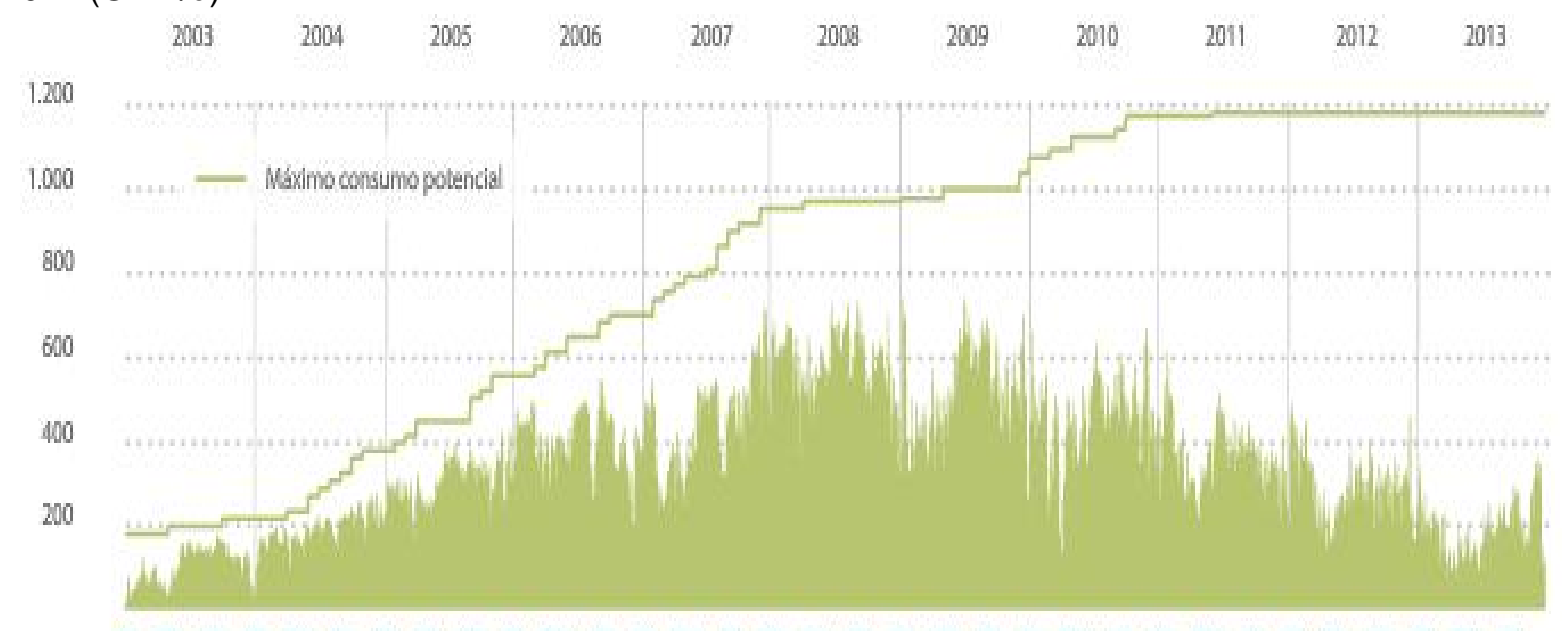

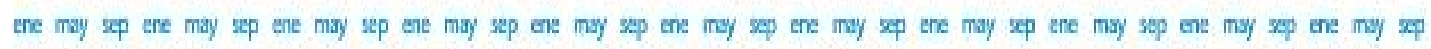

Source: Enagás (2014), p.41

Gas consumed in the power sector has been steadily decreasing since 2008. The plants, which were expected to run on $55-60 \%$ annual load factors when built had declined to below $20 \%$ in 2012 and even $13 \%$ in 2013 [Figure 19], and on days of high wind availability, it has gone under $5 \%$ in early 2013 as the relatively new fleet of gas plants provide the flexible capacity needed to balance the system with the intermittency of renewables [Figure 20]. This move from baseload generation to peak/mid merit use of CCGTs leads to wide daily but also annual gas demand variations. The overcapacity in the Spanish system permits this change in CCGTs usage ${ }^{37}$ but this may be more complicated to replicate in countries with older plants or less flexibility in their transmission systems.

${ }^{37}$ See Honoré (2011) for more information. 
Figure 19: Spain: natural gas used in the power sector (Bcm, left axis) and annual load factors of gasfired plants (\%, right axis), 2008-2012

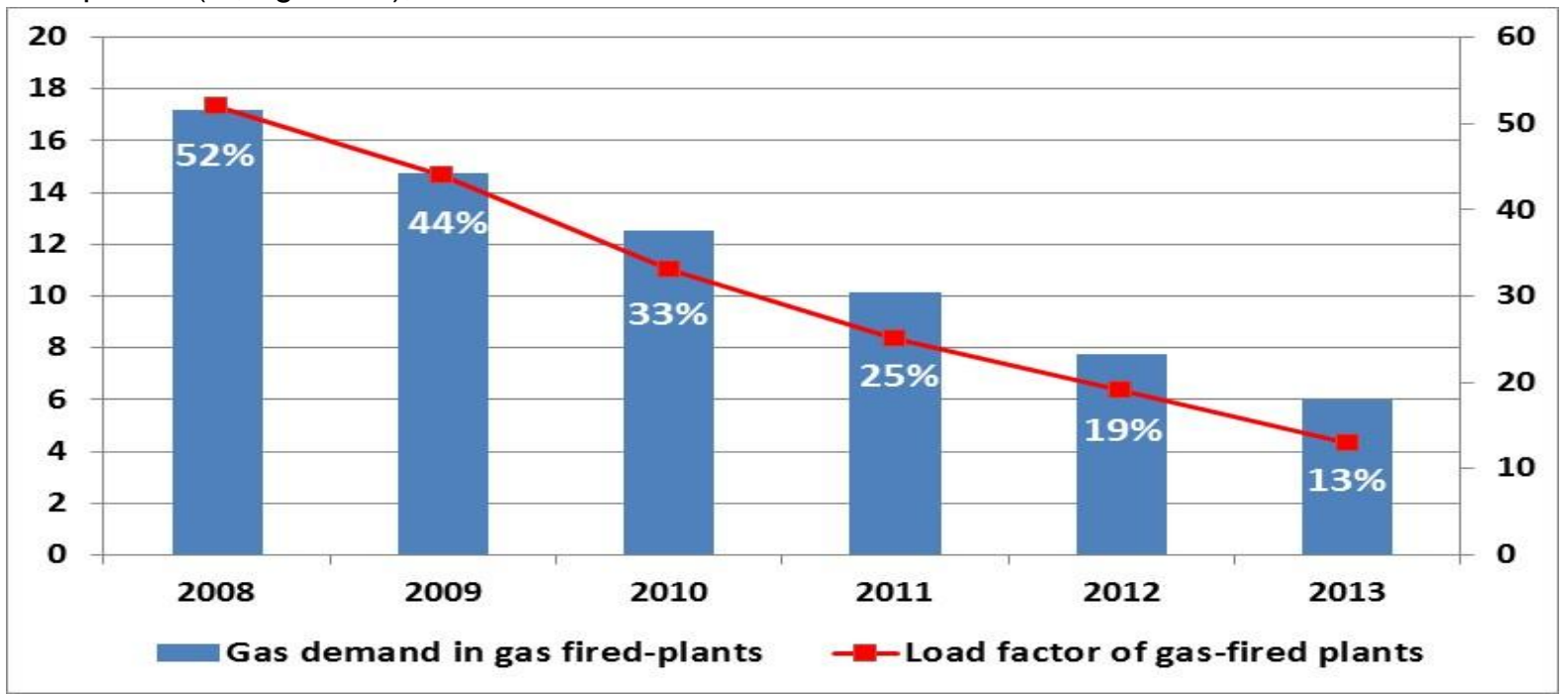

Source: Enagás (2014), p.41

Figure 20: Spain: close relationship between the daily volatility of wind generation and CCGTs generation

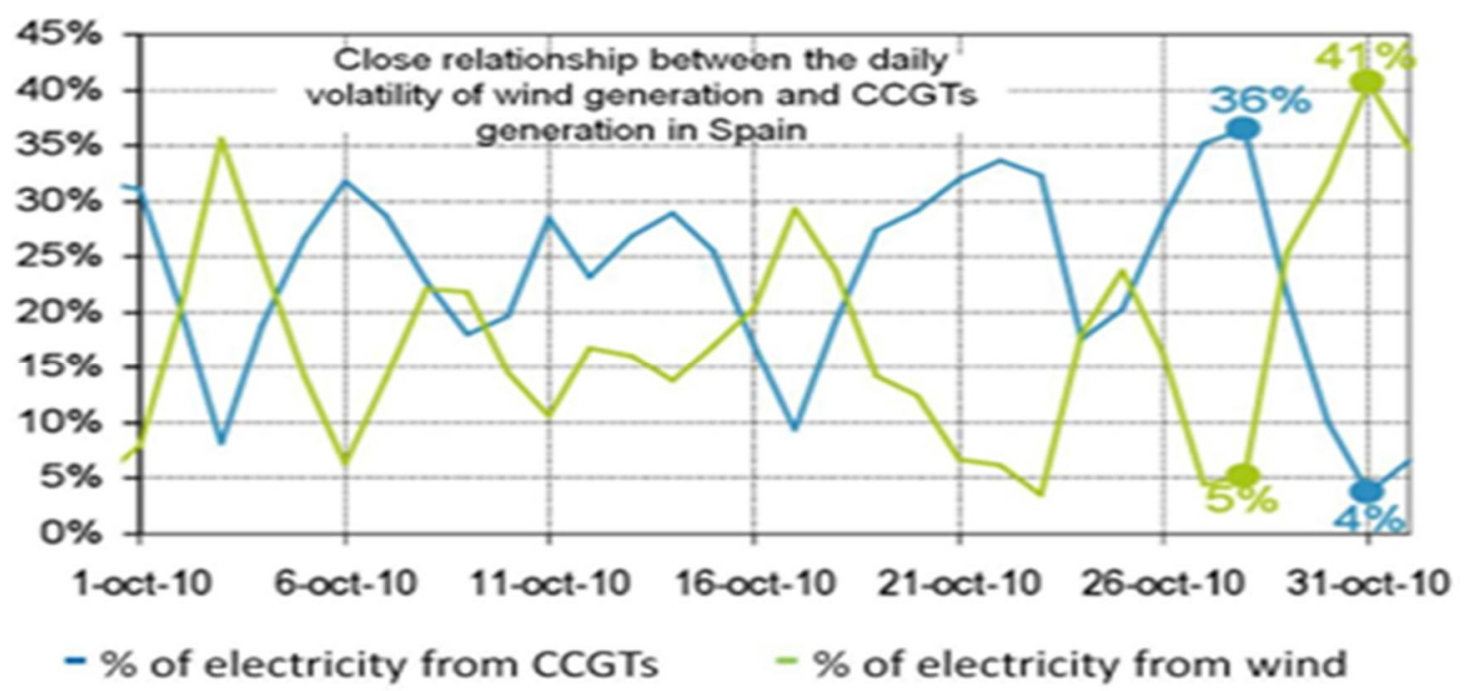

Source: Enagás (2011), p.26 


\section{Italy}

In Italy, the 2000s have been marked by diversification to reduce the heavy dependence on imports of natural gas, and lower emissions. In 2012, about $30 \%$ of electricity came from renewables including a large portion of hydro (already more than the 2020 target of 26\%) [Figure 21].

Figure 21: Italy: power generation by fuel and renewables share, 2000 to 2012 (TWh)

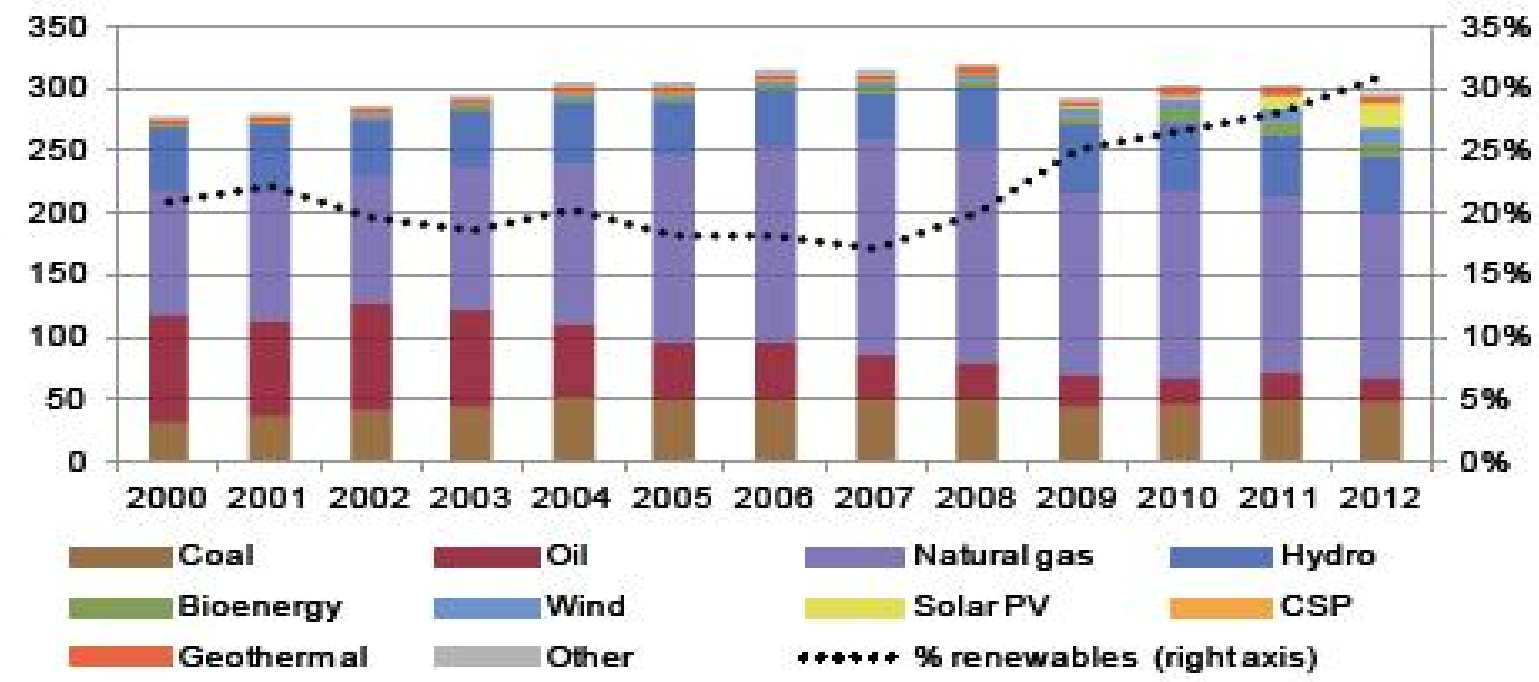

Source: IEA (2013d), p.91

Wind generation capacity reached $8 \mathrm{GW}$ at the end of 2012 (only onshore, there is no offshore capacity), roughly half of the country's wind energy potential while solar PV shot up to $16.2 \mathrm{GW}$ of installed capacity (well on course for the $23 \mathrm{GW}$ target for 2016). The total capacity attained $118 \mathrm{GW}$ but the net available capacity (for at least $50 \%$ of the time) was only $95 \mathrm{GW}$, creating some particular challenges for the generation mix. ${ }^{38}$ More renewables and a continuation of low electricity demand means a lower annual average load factor of thermal generation, especially for gas plants even if the impact was less than in Spain due to low coal capacity and no nuclear in the mix. Gas plant load factors went from about $62 \%$ in 2000 and $47 \%$ in 2008 (due to overcapacity), down to $34 \%$ in $2012 .^{39}$

Maybe even more interesting is the change in the use of gas plants to back up intermittency, because apart from geothermal and even biomass, the utilisation rates of renewable energies are modest. Solar presents the largest challenge with less than 1,500 hours/y (17\%), followed by wind with less than 2,000 hours/y $(22.8 \%)$ as seen in Figure 22. The reduced operating hours and increasing number of plant start-ups and shut-downs in order to balance renewable energy supply is something new for the Italian gas-fired power fleet. Power generators with gas-fired capacity have started to adapt to the new role of gas in power generation: more peaking, more starts and at times shut-downs. 
Figure 22: Annual utilisation by renewable energy in Italy, 2007-2011 (hours)

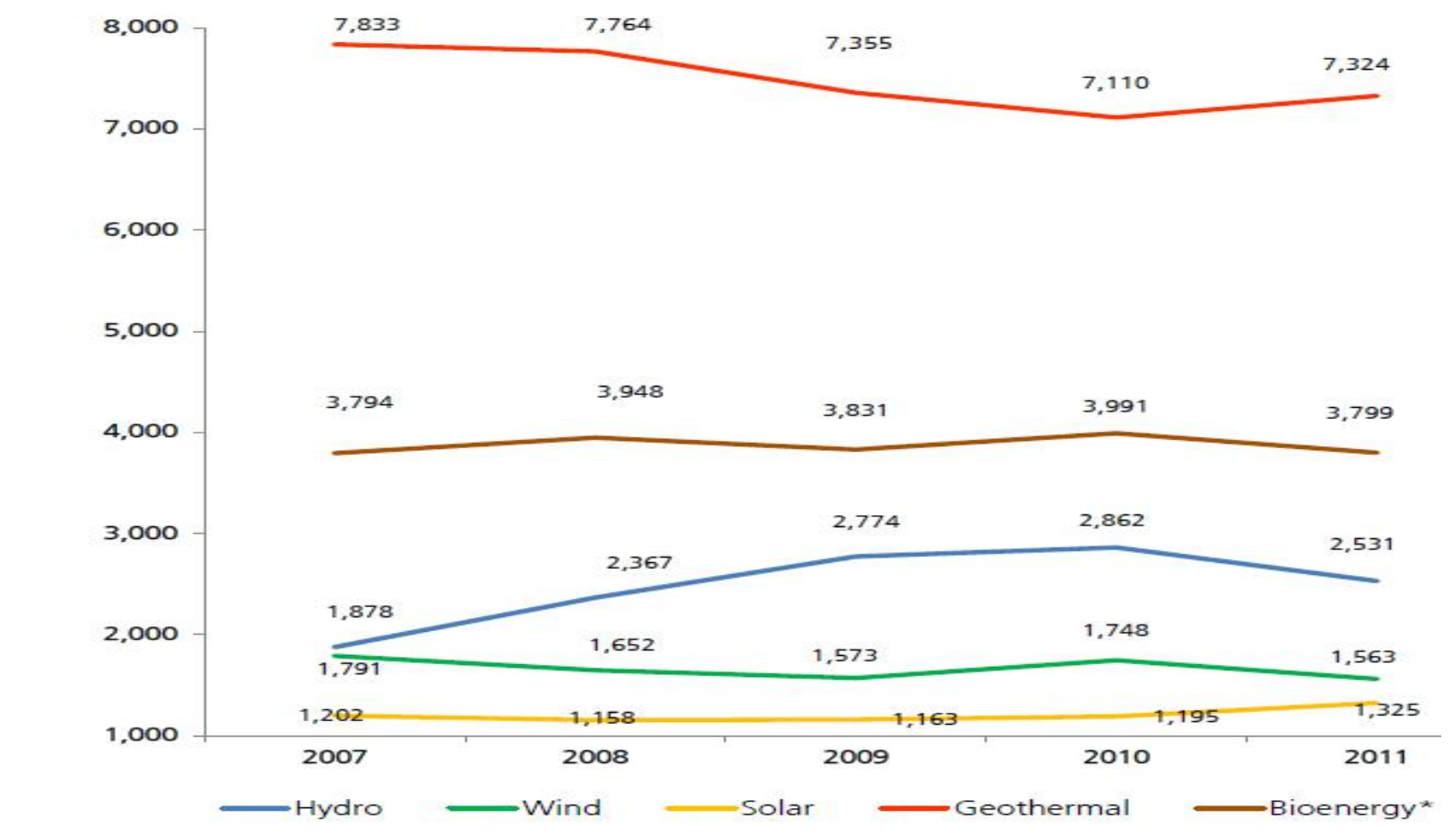

* Hybrid plants are excluded.

Source: GSE (2012), p.10

In order to maintain the security of the power system Terna, the Italian Transport System Operator (TSO), may need to curtail generation by wind power plants on some occasions. ${ }^{40}$ In 2010, Italy had the one of the highest levels of wind curtailments due to significant network congestion in some areas (especially in the centre and south), but curtailed wind energy declined in 2011 thanks to network expansions made in the most critical areas. ${ }^{41}$ The improvement of the national grid will help to integrate renewable energy into the system, but there will still be a need to back up the power generation from the increasing level of intermittent renewable capacity. The generation system also needs some back up in the form of reserve capacity, such as gas plants (and eventually oil-fired plants). ${ }^{42}$

\footnotetext{
${ }^{40}$ The dispatching procedures for non-schedulable renewable-energy generating units are defined in the regulator AEEG's Decision ARG/elt 5/10, see AEEG's website: http://www. autorita.energia.it/it/inglese/enlex/10.htm

${ }^{41}$ ACER/CEER (2012), p.89

${ }^{42}$ The Italian TSO Terna is looking for energy storage solutions to support renewable integration and has announced plans to develop 130 MW of batteries to store electricity by 2014. Source: Reuters (July 2011)

The private sector is also looking for additional solutions to manage renewable intermittency and fluctuations, such as the pilot project to develop a high power Li-ion battery Source: Bloomberg (April 2013)
} 


\section{Germany}

The third major gas market with a high share of renewables from wind and solar, Germany, presents a very different picture. First of all, contrary to Spain and Italy, gas plays no major role in the electricity mix, and never has, while coal dominates the mix [Figure 23].

Figure 23: Germany: power generation by fuel and renewables share, 2000 to 2012 (TWh)

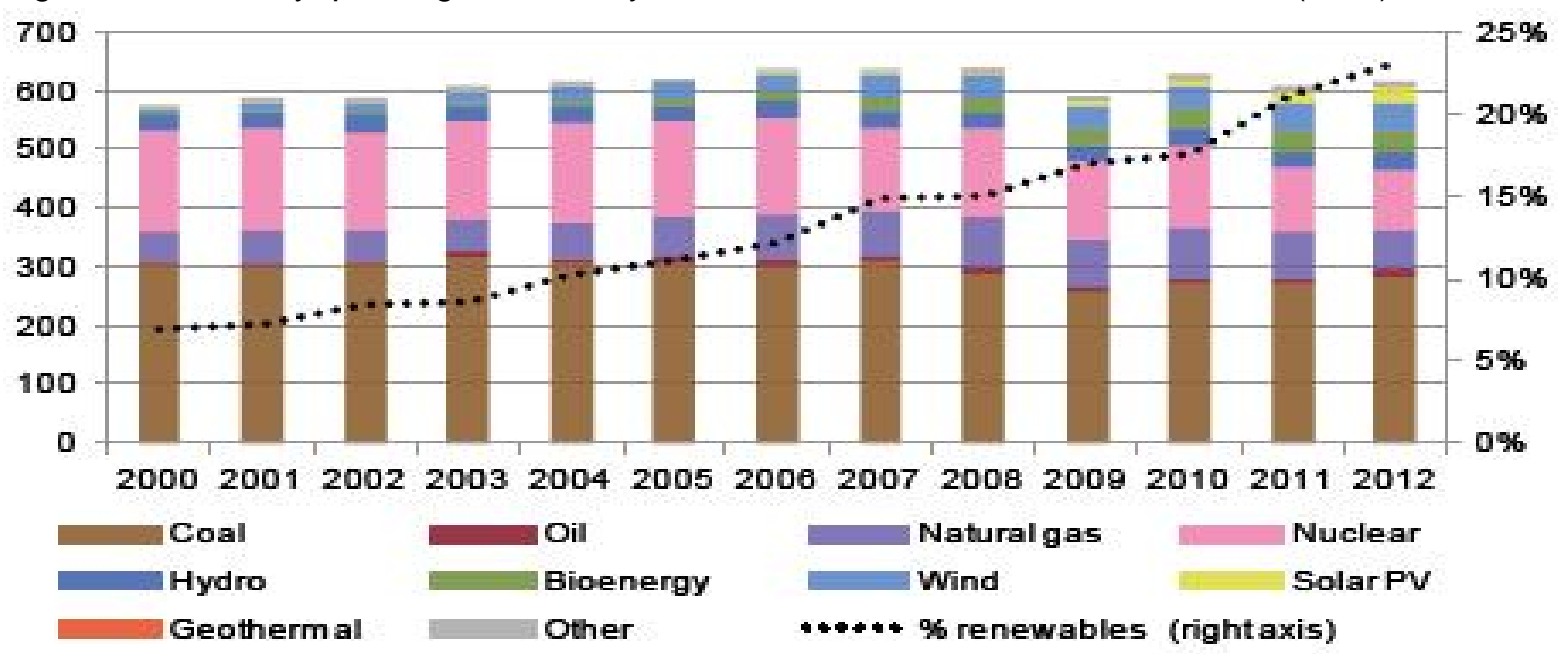

Source: IEA (2013d), p.82

Germany's energy policy, the Energiewende decided in 2011, plans the politically supervised shift from nuclear and fossil fuels to renewables, with targets of $40 \%$ of electricity from renewables by $2030^{43}$ and $50 \%$ by 2030 . The country is well on its path with a rapid increase in renewable capacity since the mid-2000s. By 2013, the country had already more than $30 \mathrm{GW}$ of wind and also more than $30 \mathrm{GW}$ of solar. Contrary to Spain and Italy, the intermittency of the renewables is mostly managed through flexible lignite plants (2/3) while gas plants (and a little hydro) provided the rest of the backup (1/3). Gas-fired plants are usually more flexible than coal-fired plants but, while adapting their fleet to account for growing fluctuations in renewable output, German operators have adapted most existing coal-plants to operate flexibly.

In addition, the increase in renewables has created an overcapacity at the national level and consequently lowered electricity prices [Figure 24]. At baseload prices below $40 € / \mathrm{MWh}$, all fossil fuel generation is in financial trouble, but the situation is most difficult for gas plants which have to face negative spark spread, and a spread between spark and clean dark spread of about $25 € / \mathrm{MWh}$ in 2013. The disappearing spread between mid-day electricity prices and night prices due to solar generation means that the niche market for gas-fired plants is not providing the same revenues: in 2007 , mid-day prices were about $150 \%$ higher than night prices and only about $25 \%$ higher in $2013 .{ }^{44}$ As a result, about 30 plants, both gas and coal, representing about $7 \mathrm{GW}$ have applied for closure for commercial reasons to the regulator as of early 2014 .

\footnotetext{
${ }^{43}$ New target decided late 2013, up from 35\%.

${ }^{44}$ Platts data in 'Power in Europe' journals
} 

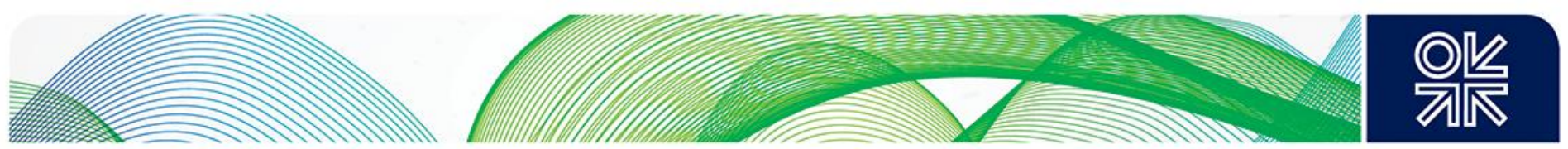

Figure 24: Year ahead base power assessment (€/MWh)

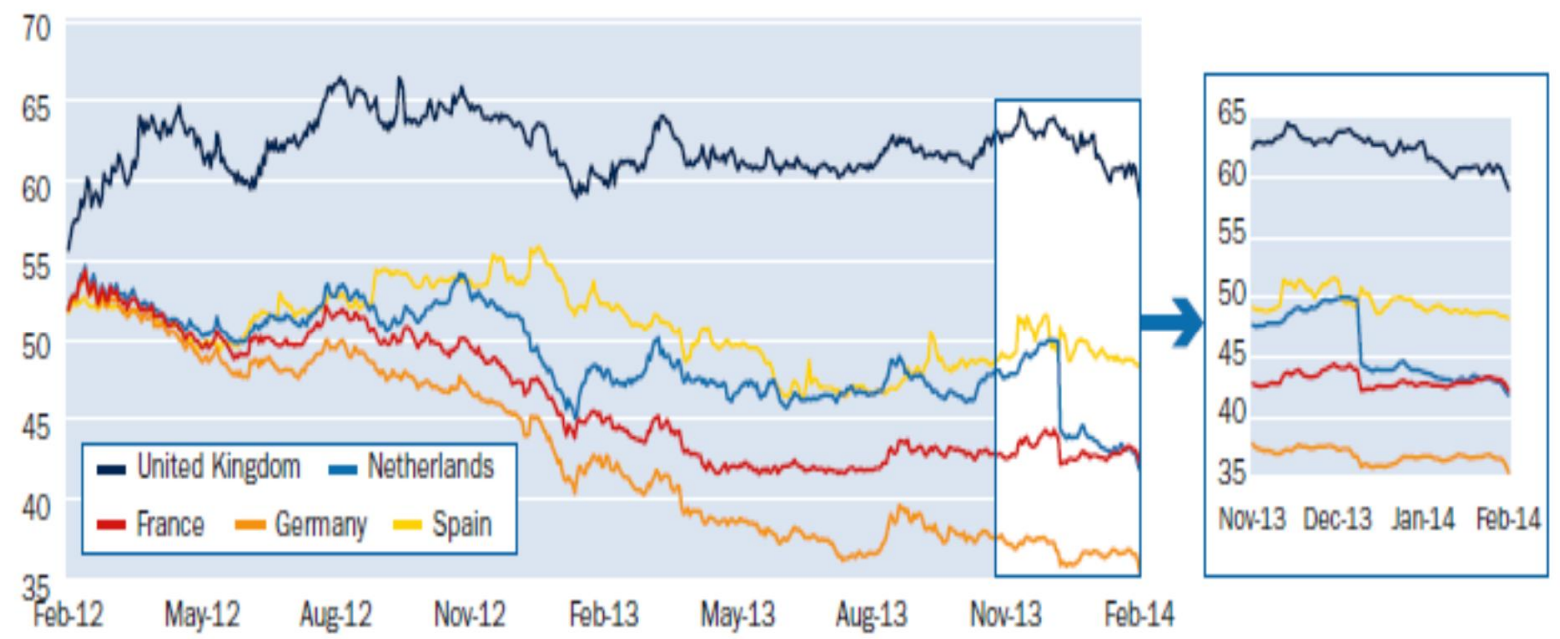

Source: Platts (March 2014a), p.9

The practicality of balancing the system is also proving to be difficult as Germany is struggling to come to grips with network bottlenecks, especially in the south, where no more closures are allowed. Thousands of kilometres of power grids are required to ensure that green energy reaches consumers, but public opposition to new power lines may complicate the balancing of the system. Already, the policies decided for the national market have repercussions in the neighbouring countries in times of low/high availability of renewables in Germany, a new feature which did not exist just a few years back and will need to be addressed in the future if renewables continue to increase in most countries.

The fundamentals, which had been historically driving gas demand up, have changed, including in the power sector which was previously expected to provide the most significant potential for additional gas demand in the 2010s and 2020s. As a result, the 2008/9 economic crisis happened in a context of already moderate gas demand growth in Europe due to mature markets, high gas prices and as a result growing competition in the energy mix. More worryingly, gas consumption was showing no sign of recovery, begging the question if the levels seen in the early 2010s were the new norm for the 2010s and beyond? 


\section{Challenges and opportunities in the 2010S and 2020S}

There are numerous factors that influence gas consumption, and these differ from one country to another depending on the national characteristics such as indigenous resources, supply contracts, transportation capacity (and access to it), power generation mix, policies, taxes and financial support mechanisms. This second chapter does not pretend to give a complete panorama, but focuses on the main drivers - and constraints - and their impact on gas demand in the $2010 \mathrm{~s}$ and $2020 \mathrm{~s} .{ }^{45}$ The challenges, but also the opportunities, for the European gas industry up to 2030 are considered in the following subsections, which are then followed by an analysis of the power sector, over which hangs the major question mark, and finally a look at the other key sectors of gas consumption: industry, residential and commercial and transport.

\subsection{Main drivers and constraints}

Economic growth and gas price competitiveness remain key elements in the evolution of gas consumption. However, the future role of gas in Europe will increasingly be a consequence of what kind of energy policies and environmental measures are put in place both at the regional and national levels - and also their affordability, which might limit their ultimate scale. The following subsections succinctly examine the assumptions we have made in our scenario on economic growth, gas prices and energy policies. ${ }^{46}$

\subsubsection{Economic growth and energy demand}

After gross domestic product (GDP) shrank by some $5.2 \%$ in 2009, signs of improvement appeared in the early 2010s, but recovery remains uncertain in Europe. The OECD Economic Outlook of December 2013 suggests that the European Union has finally emerged from an 18-month recession in the second quarter of 2013 , but the recovery is likely to be fragile. The European Commission notes signs of improvement in its European Economic Forecast of February 2014. ${ }^{47}$ GDP growth is progressively driven by domestic consumption and investment rather than by the external sector. The Commission sees the first positive consequences of the reforms adopted in several Member States (MS), and expects the economic recovery will continue spreading across countries and gain strength provided that efforts are continued.

Economic activity should remain below growth rates experienced there in the early 2000s, with even some of the key economies such as Spain, Germany, Italy and France expected to be below the regional average until at least 2018, if not later, as seen in Figure 25.

\footnotetext{
${ }^{45}$ See Honoré (2010) for a longer discussion on the major factors that influence gas consumption.

${ }^{46}$ Additional details can be found in Appendix 2.

${ }^{47}$ European Commission (2014).
} 
Figure 25: GDP growth in Europe and selected countries, in constant prices, 2000-2018 (forecast from 2013)

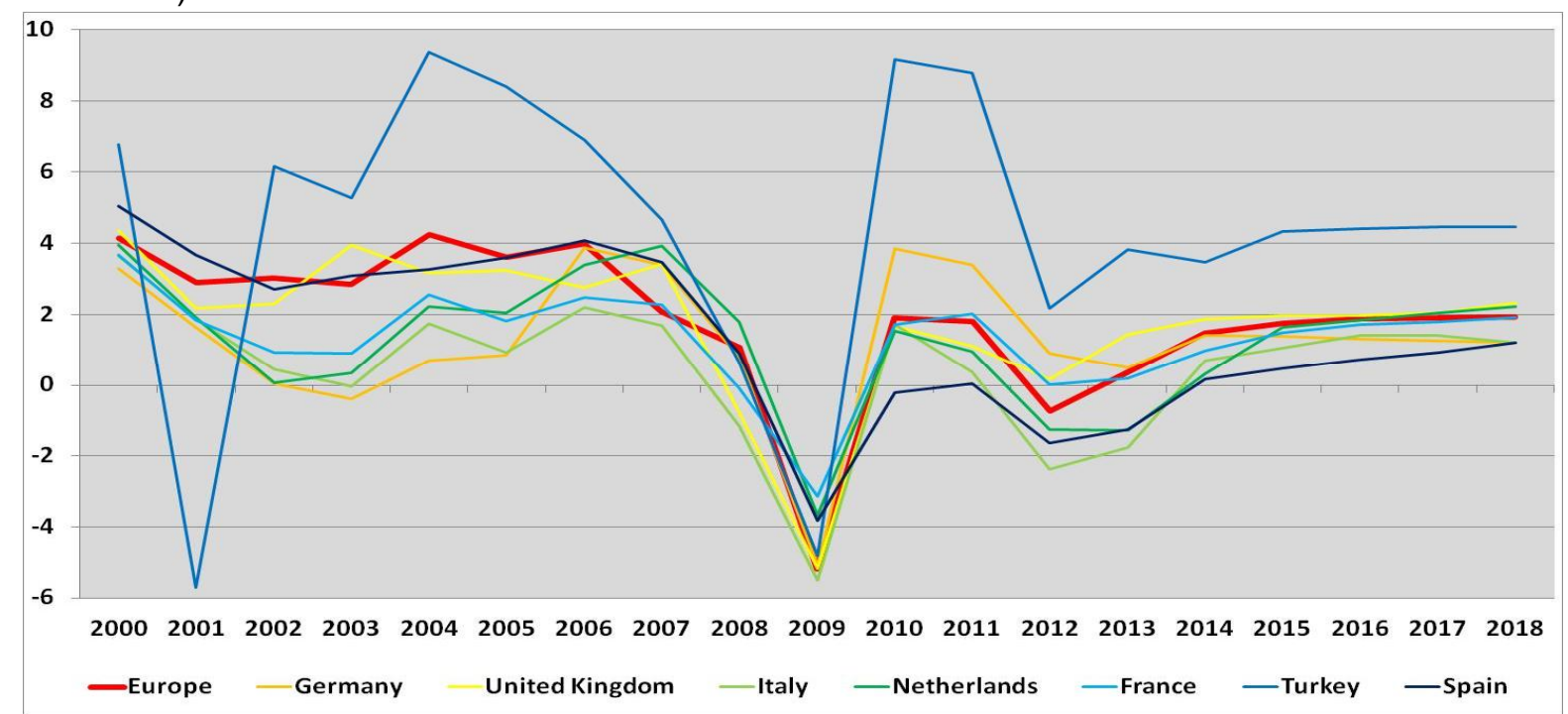

Source: IMF (2013), database

An improvement in the economic situation would certainly raise the mood of the energy sector, but one should still be cautious as post-recession recovery scenarios have been revised before in the early 2010s. In addition, an eventual return to pre-crisis economic activity may not necessarily translate into energy and/or power demand growth. It is to be expected that energy consumption will continue its decoupling from economic growth as a result of energy saving measures and efficiency improvements.

Economic growth can be offset by increasing energy efficiency measures in the industrial sector. The efficiency target was not addressed in the 20-20-20 package directly but through the 2011 Energy Efficiency Plan $^{48}$ and the 2012 Energy Efficiency Directive ${ }^{49}$ which establishes a common framework of measures for the promotion of energy efficiency within the EU in order to achieve a $20 \%$ reduction by 2020. Most of the Directive's provisions will have to be implemented by the MS by June 2014. A central element is to achieve 1.5\%/year of energy savings which, according to the submissions to the EC, are likely to be missed as most MS use the maximum exemptions allowed under the Directive. Preliminary assessment by the EC indicates that energy consumption may be only $16 \%$ lower by 2020. Additional measures will be put in place in 2014-2020, but the impact is yet unsure. It is also uncertain if a mandatory target will be decided for the 2030 horizon.

The energy efficiency and consumption reduction measures will reinforce the existing trend of improving energy intensity as seen in Figure 26, apart from Turkey, which is not committed to the efficiency target as it is not an EU Member. However, the specific scale - and timing- of the impact on gas demand is still unclear and it will vary across Europe. ${ }^{50}$

\footnotetext{
${ }^{48}$ http://ec.europa.eu/energy/efficiency/action plan/action plan en.htm

49 http://ec.europa.eu/energy/efficiency/eed/eed en.htm

50 Our assumptions on power and gas demand growth in each of the 35 markets can be found in Appendix 2 .
} 
Figure 26: Energy intensity of the economy: gross inland consumption of energy divided by GDP (kg of oil equivalent/€1,000)

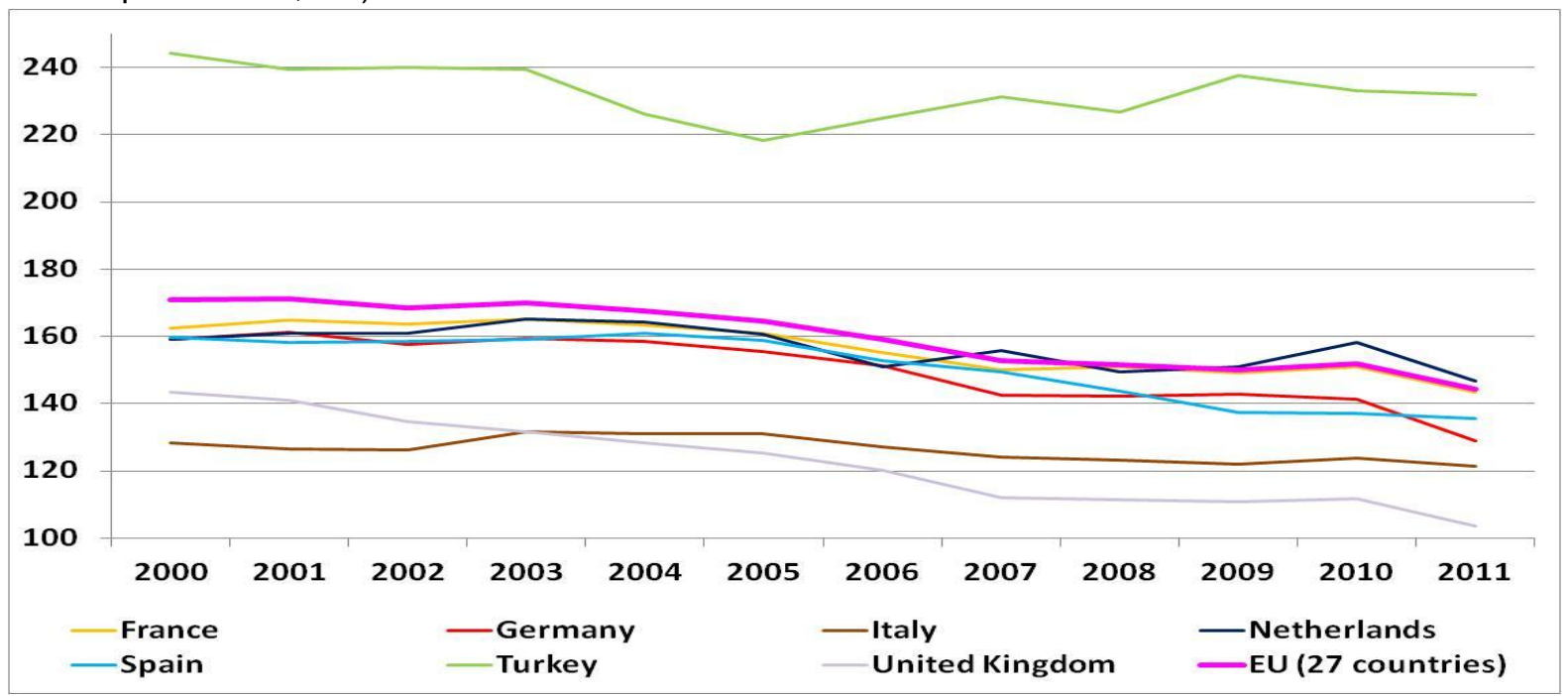

Source: Eurostat database

\subsubsection{Gas prices: uncompetitive inside and outside Europe?}

Uncompetitive gas prices may act as an even more powerful deterrent to gas demand growth:

- First, vis-à-vis other markets such as the USA and the Middle East where gas prices are lower and where companies could relocate their businesses - even if this phenomenon should have a relatively limited impact on the total level of gas consumption in Europe.

- Second, vis-à-vis other fuels because gas will have to compete with other energy sources in all market segments as it does not have a captive market, especially in the power sector, where gas can be pushed out of the mix as already seen in the early 2010s.

The general consensus is that unless gas prices drop significantly, customers will turn from gas to renewables, coal, efficiency or other lower cost options and gas-fired power generation in Europe will have a gloomy future. In the first half of 2014, the spot gas price fell by a quarter due to oversupply in Europe. As a result, the gap between coal and gas costs narrowed and some switching back to gas happened in the UK, a market part of the EU ETS with a national carbon tax since April $2013 .^{51}$ Gas, coal and $\mathrm{CO}_{2}$ prices will vary up to 2030 , but despite an encouraging evolution toward flexible gas supply and hub pricing development, hub gas prices may not be low enough to compete with clean dark spreads without lower gas prices and/or higher coal prices and/or much higher $\mathrm{CO}_{2}$ prices up to $2020{ }^{52}$ After that date, the evolution is more uncertain but we do not anticipate a major change in competitiveness. It could also be argued that as the 2010 s evolve, some coal plants will be retired due to environmental directives and renewables will be only added due to state support. Until the arrival of commercial carbon capture and storage (CCS) technology, there will be only (very) limited additions to the coal fleet and, as a result, declining gas/coal competition post 2020. It is almost as if

\footnotetext{
${ }^{51} \mathrm{http}: / /$ www.gridwatch.templar.co.uk/

52 The US was already exporting less coal to Europe by 2014, but exports from Colombia and Russia -the two main suppliers to Europe- were expected to increase in 2014-2015. South Africa, Australia and Indonesia were also expanding output, however, coal demand in Asia-Pacific is a big uncertainty and will play a major role in European coal prices. See European Commission (2010), Cornot-Gandolphe (2012) and IEA (2013f), chapter 4 for additional information about the coal market.
} 

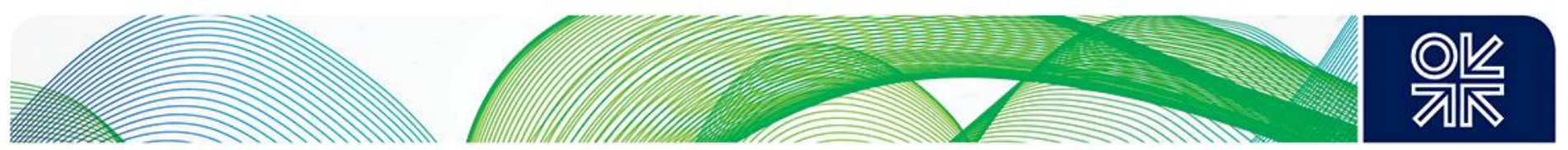

the level of gas prices will become less relevant to ensure the place of the CCGTs in the mix, which may become more a factor of energy policies and existing generation mix.

It is unlikely that coal prices will rise enough or gas prices fall enough to erode the spread for long period of times, so the main factor will be the price of $\mathrm{CO}_{2}$. It is difficult to give a level of $\mathrm{CO}_{2}$ price needed to induce a switch to gas-fired plants at the European level as the price incentive to switch from coal to gas is different from one country to another and depends on a variety of factors including the generation mix, the efficiencies of the existing plants, the supply contracts, the structure of the market or even dispatching rules. To give a simple example, at a gas price of $35 € / \mathrm{MWh}$ and a coal price of $22 € / M W h$ as seen in May 2014, it would take about $28 € / t$ of $\mathrm{CO}_{2}$ to encourage a switch from coal to gas with highly efficient plants (58\% CCGT and $45 \%$ new coal plant), but probably only about $11 € / t$ with slightly less efficient plants (55\% CCGT and 38\% coal plant). At a gas price of $50 € / \mathrm{MWh}$ and a coal price of $24 € / M W h$ as seen in 2013 , a $\mathrm{CO}_{2}$ price of about $81 € / t$ would be needed to switch from coal to gas with highly efficient plants, and about $53 € / t$ with slightly less efficient plants. ${ }^{53}$

Without a major growth of energy demand expected in our timeframe, for gas demand to grow would essentially require it to gain market share from other fuels, which we do not foresee in our timeframe even if short periods of competitiveness can be expected. However, despite the importance of gas prices, the (future) role of the gas industry is increasingly complicated by energy policies and environmental targets, which distort the market, both at the European and national levels, a seen in the following section.

\subsubsection{The role of energy policies: focus on the renewable and the $\mathrm{CO}_{2}$ targets}

It is a complicated and questionable task to try to sum up the policies of 35 different countries in one section, but it is fair to say that natural gas is not getting much attention in energy policy, or better said, the focus is almost always entirely placed on other technologies or objectives that will, on a short term or long term basis, have an impact on the use of gas. This creates a high degree of uncertainty in the gas industry as gas players try to judge how legislation is likely to unfold in order to understand its potential impacts on gas: what priorities, what measures, and how stable will the decision be, or will it change in $1,2,5$ or 10 years' time?

The European Union has made the mitigation of climate change one of its key priorities. The Kyoto protocol, the 20-20-20 targets ${ }^{54}$, the 2030 framework and the 2050 roadmap all propose a set of measures to transform the region into a low carbon economy via three main measures: increasing renewables, a $\mathrm{CO}_{2}$ cap and price and better efficiency -as previously mentioned. Despite the ambitious policies and targets proposed at the regional level, the measures decided by the European Union mainly set a common structure, as energy remains an important economic and strategic challenge for national governments. Energy policies are still very much a matter of national interest decided to match national objectives and needs albeit inside the general framework of the decarbonisation of the economy decided at the European Union level. The regional market of 35 countries that we considered in this study is in fact the result of a combination of European rules and national rules of 28 Member countries and of seven additional countries not bound by EU policies.

\footnotetext{
${ }^{53}$ Author's estimates

54 The targets, known as the "20-20-20" targets, were: a 20\% reduction in EU GHG emissions from 1990 levels, raising the share of EU energy consumption produced from renewable resources to $20 \%$, and a $20 \%$ improvement in the EU's energy efficiency.
} 

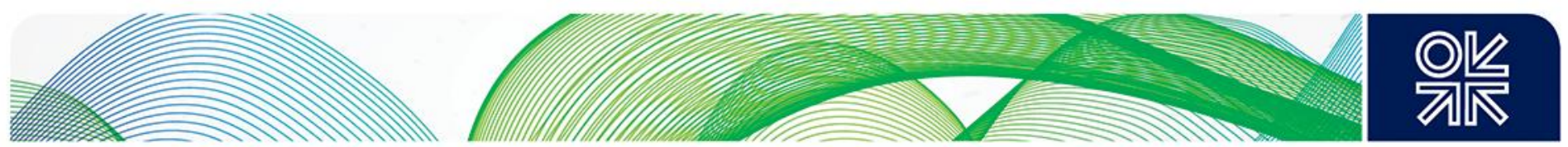

While this melting pot of policies, rules and measures was looked into carefully to design the scenarios detailed in Chapter 3 , we will only address the two most important ones in this section: renewables and emissions. ${ }^{55}$

\section{Renewables}

Renewables are at the centre stage of the European energy policy framework. Renewable energy is a strategic goal in itself and EU policymakers appear committed to specific renewable targets. In 2007, the European Union committed itself to raise the share of its energy from renewable sources to $20 \%$ by 2020. This has been a binding target since June 2009 ('Climate and Energy Package'), with a specific target for each member Country [Figure 27]. As already mentioned, to achieve this target means renewables would have a share of about $35 \%$ in the electricity sector. In 2011 , the Energy Roadmap $2050^{56}$ reinforced this policy by identifying the contribution both natural gas and renewables make as critical energy sources to 2050 in each of the seven scenarios. In all decarbonisation scenarios, renewables are the key element, with a substantial share of at least $55 \%$ in gross final energy consumption in 2050.

Figure 27: Share of renewables in energy consumption: 2020 targets

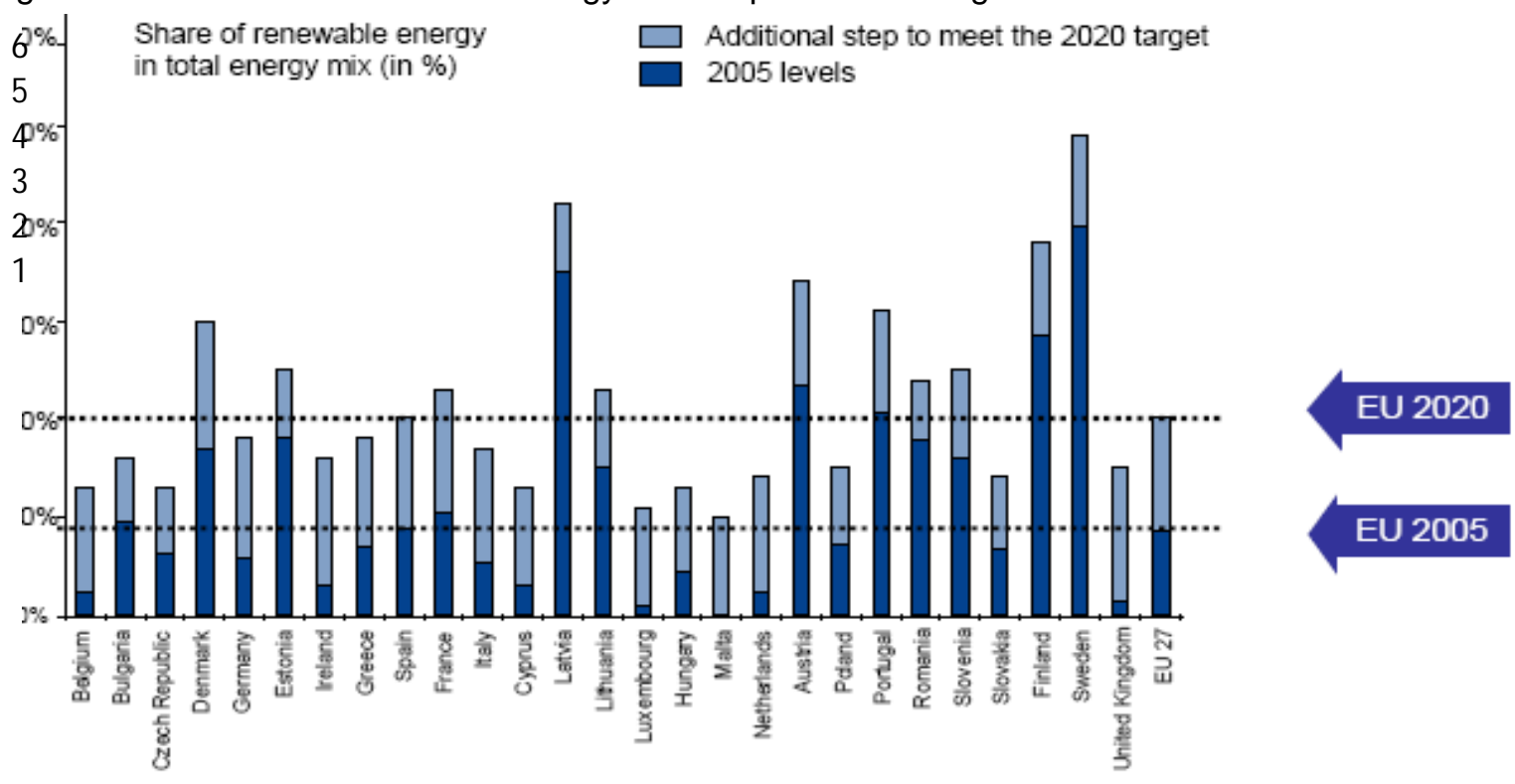

At the national level, MS have already implemented several support schemes for renewable generation in order to reach the EU 2020 targets and some (higher) national targets. ${ }^{57}$ This has resulted in the rapid increase seen in Figure 7 page 21. However, this policy has come at a cost to energy consumers and several -not to say all- countries are revising their support schemes downwards or plan to do so. For example, the Spanish government froze the support schemes for renewables and even proposed retroactive measures in July 2013 and Romania cut its support scheme for new wind, solar and small hydro renewable energy projects from January 2014 to curb

\footnotetext{
${ }^{55}$ Additional information is provided on a country basis in Appendix 2

${ }^{56}$ European Commission, Energy Roadmap 2050

57 See Appendix 2 for some examples
} 

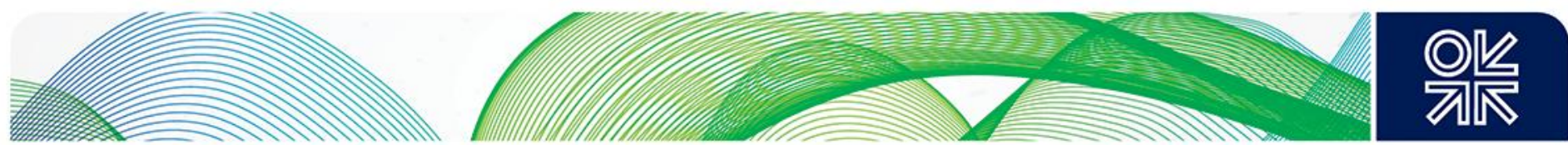

price increases for industry and homes. ${ }^{58}$ The rise of renewables outside the contestable market has undoubtedly affected thermal generation and gas plants in particular for the reasons already explained, and will continue to have an effect. In response, a group of 12 European utilities, supplying more than half of the European power consumers, has even called for the end of subsidies for 'mature renewables,' such as onshore wind and solar powers arguing that subsidies for renewable energy turned traditional power production into a losing proposition in Europe. ${ }^{59}$

With decreasing costs of construction for renewable energy (onshore wind and solar), a revision of support scheme and a transition to a more market based support as wished by the Commission make economic sense. But exactly how sustainable the growth of renewables is without state support is uncertain. At least a slowdown in new additions is to be expected in the 2010s and beyond. Public opposition to wind turbines has also been fairly vocal in several countries, such as in France where an organisation went to court and won with the result that an already-built wind farm will have to be demolished. ${ }^{60}$

In addition to the costs of the support schemes and the impacts on national electricity prices, the fast growth of renewable energy has also started to create imbalances on neighbouring systems, for instance in times of high/low wind in the German market. In other words, a national policy has started to impact the situation outside its frontiers, which is a relatively new problem and one that flexible CCGTs could certainly help with or take advantage of.

\section{Emissions}

There are two sets of targets: first, the Kyoto Protocol targets for the period 2008-2012 ${ }^{61}$ and second, the 2020 targets. In 2007, the European Union published its energy package as a set of binding legislation designed to ensure the EU meets its targets for 2020, one of which was the reform of the EU ETS. ${ }^{62}$

The EU ETS was launched in 2005 and works on the 'cap and trade' principle. Operators of around 12,000 power plants and industrial plants in 30 countries (EU27 + Iceland, Liechtenstein and Norway) are part of the EU ETS. Airlines joined the scheme in 2012, petrochemicals, ammonia and aluminum industries in 2013. The National Allocation Plans (NAPs) set out the total quantity of greenhouse gas (GHG) emission allowances that MS grant to their companies in the first (2005-2007) and the second (2008-2012) trading periods. For the third trading period (2013-2020), the allocations are determined at EU level (no more NAPs). An additional change introduced in 2013 was the progressive move towards auctioning allowances. Auctioning, not free allocation, is now the default method for

\footnotetext{
${ }^{58}$ EurActiv.com (December 2013)

59 The Wall Street Journal (January 2014)

${ }^{60}$ See the website of 'Vent de Colère!': http://www.ventdecolere.org/

${ }^{61}$ The Kyoto protocol, an international agreement linked to the United Nations Framework Convention on Climate Change signed in 1997, made it a strategic priority to cut greenhouse gas emissions. The fifteen MS before 2004 were committed to reducing emissions to $8 \%$ below 1990 levels by the years 2008-2012. These national 'burden sharing' targets were legally binding and started the region on a path to an energy-efficient, low carbon economy. All 12 MS that joined the EU after 2004 , except Cyprus and Malta, had individual emission reduction commitments under the Protocol (Croatia, which joined the EU on 1 July 2013, had a 5\% target). For the second commitment period of the Kyoto Protocol, which started on 1 January 2013 , the EU intended to fulfil its emissions reduction commitment jointly with the $27 \mathrm{MS}$, Croatia and Iceland with targets of $-20 \%$ to $30 \%$ by 2020 compared to base years. See European Environment Agency (2013), p.10 for a table on 'Greenhouse gas emissions in $\mathrm{CO}_{2}$ equivalents (excluding LULUCF) and Kyoto Protocol targets for 2008-2012'

${ }^{62}$ The other three were 1/National targets for non-EU ETS emissions, 2/National renewable energy targets and 3/Carbon capture and storage.
} 
allocating allowances. In 2013 more than $40 \%$ of allowances were auctioned, and this share will rise progressively each year. At the same time, the number of allowances will be reduced over time so that total emissions by 2020 will be $21 \%$ lower than in 2005 .

Renewable capacity in Europe was built on the basis of state support (feed in tariffs or tradable certificate schemes ${ }^{63}$ ) rather than as a consequence of the EU ETS carbon price, but it has, on the other hand, affected the demand for allowances in the power sector. With a fixed supply but a flexible demand, a surplus is a risk. The slow decline of emissions from the beginning of the 2000s was reinforced by the effects of the economic downturn post 2009. By 2013, the EU was on track to meet its $\mathrm{CO}_{2}$ reduction target, mostly thanks to the impacts of the recession since 2009, as seen in Figure 28. The sluggish economic growth and policies on renewable energy and energy efficiency created a build-up of surplus permits that crashed the price down below $3 € / t$ in April 2013, further strengthening the attractiveness of high-emitting coal over gas. Prices recovered to around $5 € / t$ in early $2014 .{ }^{64}$ In 2013, the European Parliament and the Council voted in favour of postponing ('back-loading') the auctioning of some 900 million allowances as a short term measure until 2019-2020 to allow demand to pick up. Because this measure does not reduce the overall number of allowances to be auctioned during phase 3 , but only the distribution of auctions over the period, it is likely to have only a limited impact on the level of the $\mathrm{CO}_{2}$ price in the 2010s.

Figure 28: Trends in EU GHG emissions compared to base year 1990

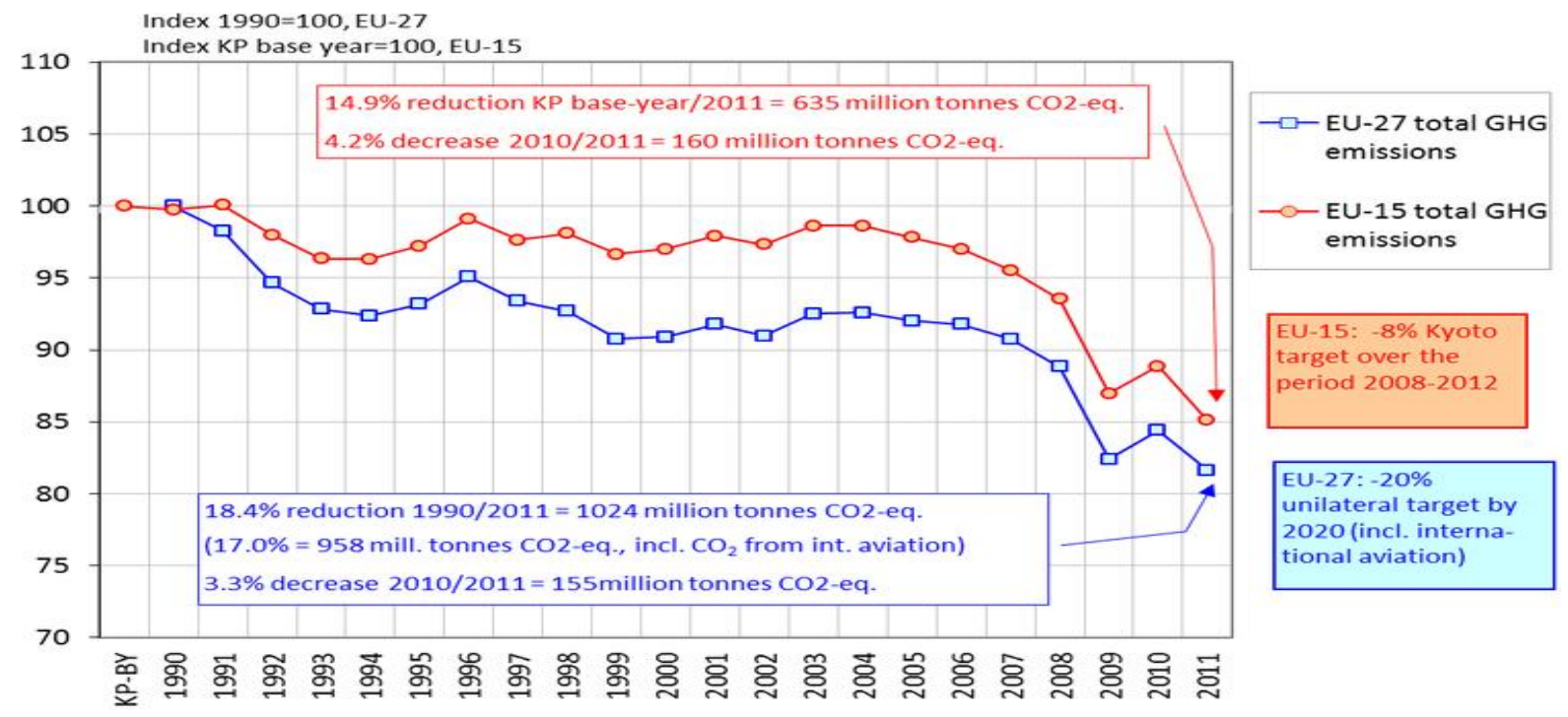

Source: http://www.eea.europa.eu/publications/european-union-greenhouse-gas-inventory-2013

The EU ETS was designed to deliver a $\mathrm{CO}_{2}$ reduction using a declining carbon cap to 2020. Technically, this means that the system does work, as the objective was to be reached irrespective of where the price goes. However, not only are the prices too low to trigger a switch from coal to gas in the 2010s, it also does not provide the right signal for investment in low carbon technologies that would still be operational in $40-50$ years.

\footnotetext{
${ }^{63} \mathrm{~A}$ number of European countries have a tradable certificate scheme in place to promote the development of renewables, such as Sweden for instance.

${ }^{64}$ Platts (January 2014), pp.6-7
} 
On January 22 2014, the European Commission presented a proposal setting out its climate and energy package to follow the 20-20-20 legislation. ${ }^{65}$ This document sets out a framework for climate change action in 2020-2030 and builds on the existing 'climate and energy package' of targets for 2020 as well as the Commission's 2050 roadmaps for energy and for a competitive low-carbon economy.

The objectives include a single overall target for GHG emissions -a 40\% reduction below the 1990 level, an EU-wide binding target for renewable energy of at least $27 \%$ of energy consumption in 2030 , renewed ambitions for energy efficiency policies, a new governance system and a set of new indicators to ensure a competitive and secure energy system. ${ }^{66}$ The proposal does not set arrangements under which the overall target is translated into binding national renewables targets. This time, driven by a more market-oriented approach, it only proposes a new governance system for the whole package based on the Commission's review of national energy plans. How exactly the more market-oriented approach and flexibility left to the MS will actually achieve this target is uncertain.

Will this new system of governance be effective? Without entering into the details of the document which remains a proposal at the time of writing ${ }^{67}$ the question is whether the region will actually be able to meet this new target. If renewable expansion does slowdown in the 2010s (and beyond?), which considering the wide revision of support schemes across Europe is more than likely, then it is very possible that natural gas power plants will find a way back into the merit order when old coal and nuclear plants are retired in the 2010s and 2020s. This could also be supported by the $\mathrm{CO}_{2}$ price in the EU ETS.

The 2030 framework seemed to learn some lessons from the 2020 framework and identified some improvements. In order to provide clearer price signals to trigger long-term reforms, the EU proposed to tighten the supply of carbon permits in times of possible surplus with a 'market stability reserve' in order to avoid another price collapse post 2020. This system would be created from 2021 to avoid excess allowances as seen in the early 2010s. Allowances would be put into the reserve in times of excess supply and returned to the market at times of shortage, hopefully maintaining a level of $\mathrm{CO}_{2}$ prices sufficient to encourage the use of gas plants versus coal plants in the 2020s. It becomes therefore possible to envisage double digit $\mathrm{CO}_{2}$ prices in the 2020 s, while the impacts of the backloading on the price in the 2010s are less uncertain. This author believes that these measures will still be insufficient to raise $\mathrm{CO}_{2}$ prices to levels that would - alone - affect a switch back to gas in the power sector for most of the time up to 2030.

Emissions from sectors outside the EU ETS would need to be cut by $30 \%$ below the 2005 level, and this effort would be shared equitably between the MS. The framework does not foresee specific subtargets on curbing emissions. This could challenge the expected development of natural gas in the transport sector, which is the fastest growing source of GHG in the EU. The region will probably fail those new emission targets without a stronger role for both natural gas and renewable methane (and electricity) used in transport. However, without strong political support, natural gas in transport,

\footnotetext{
${ }^{65}$ The proposed package will translate into law subsequent to a debate involving EU MS and the European Parliament. For more information on the package, see http://ec.europa.eu/clima/policies/2030/index en.htm

${ }^{66}$ The role of energy efficiency in the 2030 framework will be further considered in a review of the Energy Efficiency Directive due to be concluded later in 2014.

${ }^{67}$ For additional comments on the proposal, see Buchan \& Keay (2014)
} 

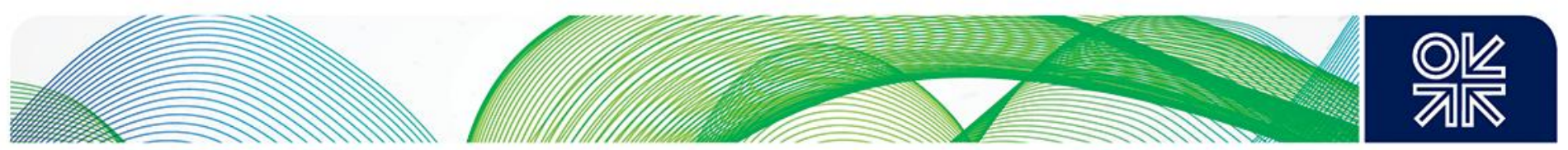

especially CNG, is unlikely to happen at scale,$^{68}$ which suggests that the expectations of the natural gas industry for this new niche market may not be realized.

Energy policies are firmly on the road to an energy transition to a low carbon economy, but sustained efforts will be needed to reach the EU goal of reducing greenhouse gas emissions by $80-95 \%$ below 1990 levels by 2050 , especially in the power sector. The following section highlights the complexities and the major changes to be expected in the generation sector up to 2030 and its impacts on natural gas demand.

\subsection{Major changes to be expected in the power sector}

The wild card remains future demand from gas-fired power plants, but they are facing major challenges mainly driven by the ambitious European and national climate and energy targets. This section focuses on the power sector and asks how the energy mix will evolve and how this may impact gas demand in this sector, which only a few years ago was seen as the incontestable key driver for additional gas consumption in Europe.

\subsubsection{Expected changes in existing capacity}

Some existing plants in 2014 will be closed in the next 16 years. It is difficult to estimate how much capacity will be retired due to commercial reasons or even old age, but we estimate that around 100 GW of baseload nuclear and coal capacity will be shut down in Europe by 2030 due to political decisions only.

\section{Nuclear plants}

There have been three major accidents in the nuclear power industry: Three Mile Island (USA, 1979), Chernobyl (Ukraine, 1986) and the latest one, Fukushima (Japan, 2011). The reactions in Europe to these past catastrophes have been varied. Sweden had a referendum in 1980 and decided to phase out nuclear power; Spain elected for a moratorium on new build in 1983; Italy also had a referendum in 1987 which led to the immediate shut down of nuclear plants; Germany decided on a phase-out policy in the early 2000s, and a ban on new build was also put in place in Switzerland. These reactions show that after some time, and even after such traumatic events, policies toward nuclear can be reversed. With the growing influence of climate change, zero carbon emission nuclear power can also be seen as a possible option as in the UK for instance. ${ }^{69}$

The German phase out of its 22 GW of nuclear power by 2022, which represented about $25 \%$ of its electricity generation in 2010, and the immediate shut down of about $8 \mathrm{GW}$ was the strongest reaction in Europe. It was a complete revision of its six-month old policy to increase the lifetimes of its nuclear plants. ${ }^{70}$ It was expected that the nuclear capacity would be replaced by renewable and gas-fired

\footnotetext{
${ }^{68}$ There may be a more important economic rationale for LNG for trucks and boats, but policy support will probably still be needed if it is to happen at scale in Europe.

${ }^{69}$ DECC website, Increasing the use of low-carbon technologies

${ }^{7}$ For more information, see Dickel (2014)
} 
plants but these expatiations were short lived. A year later, events did not turn out as expected. Closing the $8 \mathrm{GW}$ had a very limited impact on gas demand due to an overcapacity in the market thanks to the renewable boom at a time of low power demand due to the economic recession. The more efficient of the coal plants increased their production to the detriment of the CCGTs. There was no tightness in the system in 2011 despite nuclear shut down. Coal and renewables mostly replaced the $8 \mathrm{GW}$ and the country even managed to export power to neighbouring countries during the cold spell in February 2012.

Elsewhere, the reactions have been more considered. Other countries have decided to put a date on the phase out of nuclear energy. Switzerland will phase out about $40 \%$ of electricity generation in 2010 by 2034); Spain dictated a '40 years useful life', which means that the last nuclear station will close in 2028 at the latest; and Belgium opted for a phase out of nuclear by 2025, which could potentially create a serious problem because nuclear represented about $60 \%$ of its generation in 2012. By early 2014, Belgium was already in a tight situation with minimum margins and an urgent need for additional capacity. It is hard to imagine how it will manage to cope with the programmed phase out of nuclear from as soon as 2015. Additional gas plants seem to be the only baseload capacity that can be added in this timeframe, and the country has indeed placed tenders to this end.

In Italy, the Fukushima accident terminated a possible 'come back' for nuclear when $94 \%$ of the voters in a referendum decided against restarting its nuclear programme. This meant that the country remained at status quo, without any impacts on gas in the present or in the future. In Sweden, discussions about new nuclear were also cut short after the accident due to strong public opposition. However, as of 2014, it had overturned its negative views and was envisaging the possibility of new nuclear, albeit within restrictive rules. The state owned electricity provider Vattenfall had even commenced discussions with government agencies about the prospect of new nuclear capacity after 2020.

Despite the consensus that the Fukushima accident had terrible repercussions across Europe, it appears in reality that the impact was fairly small, as already seen in Figure 13, page 26. Other countries have decided to continue their nuclear programmes, such as in Finland, in the Netherlands (where the government is ready for talks on a new nuclear station), in the UK (with a high strike price of $£ 92.50 / \mathrm{MWh}$ for new nuclear capacity in its Electricity Market Reform $\left.(E M R)^{71}\right)$, in most countries of Central and Eastern Europe and finally in France, the country with the biggest nuclear capacity in Europe. After intense discussion during the presidential election of 2012 and a proposal from (future) President Hollande to lower the share of electricity generation from nuclear from about $75 \%$ in 2012 down to $50 \%$ in 2025 , it seems that only one plant will be shut down during his mandate (Fessenheim) while some of the other reactors will probably get lifetime extensions. ${ }^{72}$

Existing plants without new limitations on lifetime may also close earlier due to increasing costs. The plants that will be shut down will need to be - at least partially - replaced (how much will depend on power demand and the development of renewables). Even before the Fukushima disaster, there were no real expectations of a nuclear renaissance in Europe and only a small number of new nuclear plants were likely to come on stream in this and maybe the next decade due to the high costs of nuclear power stations and uncertain energy policies. In the absence of financial support mechanisms, it is hard to imagine many new nuclear plants, and therefore in most countries, even the ones without a moratorium, it will be replaced by other fuels. This future additional baseload 

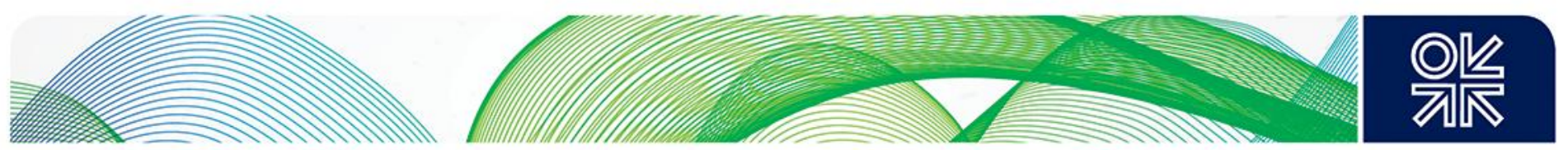

generation requirement may partially be met with some new nuclear, in the UK for instance, with some renewables in most countries, but the bulk of it will probably come from thermal plants: coal and gas. At the European level, it may not have a major impact, but at the national level, this is a different story. Germany will have to replace $12 \mathrm{GW}$, although this should not pose a major problem in the 2010s. Belgium may face more serious problems to replace its $6 \mathrm{GW}$. The closure of $7.5 \mathrm{GW}$ in Spain may provide some much needed room for the CCGTs. In the UK, the expectation of the retirement of about $11 \mathrm{GW}$ of nuclear plant by 2025 may also create some difficulties if the country does not get additional capacity rapidly.

\section{Coal plants}

Existing and new large combustion plants in Europe have to comply with environmental regulations, including the EU Large Combustion Plant Directive (LCPD) that aims to reduce acidification, ground level ozone and particulates by controlling the emissions of sulphur dioxide (SOx), oxides of nitrogen (NOx) and dust from large combustion plant. All combustion plant built after 1987 with a thermal output of $50 \mathrm{MW}$ or more must comply with the emission limits in the LCPD. ${ }^{73}$ Because of the Directive, about 55-60 GW (depending on the thermal efficiencies taken into account) ${ }^{74}$ will be shut down across Europe by the end of 2015. At the time of writing (early 2014), more than half had already shut down, leaving probably about $20 \mathrm{GW}$ or less to close. Because of low demand, there may be limited need for replacement at the regional level, but it will have different impacts at the national level. In the UK for instance, about $12 \mathrm{GW}$ of capacity is expected to close down. In other markets, the total capacity of plants that had to close was much lower with about $4 \mathrm{GW}$ in Romania and France, just below $3 \mathrm{GW}$ in Poland for instance. ${ }^{75}$ Many coal plants have envisaged conversion to biomass to help meet environmental standards, but this solution appears complicated, with a lack of financial support in the future to really trigger a large wave of conversion even if conversion has happened at some plants for at least part of their capacity.

The EU Industrial Emissions Directive (IED) entered into force on January 62011 and had to be transposed into national legislation by January 7, 2013. It brings together the Integrated Pollution Prevention and Control (IPPC) Directive and six other directives in a single directive on industrial emissions. The Directive covers large combustion plants with a total rated thermal input equal to or greater than $50 \mathrm{MW}$, irrespective of the type of fuel used, with the objective of further tightening emissions limits of SO2, NOx and particulates. ${ }^{76}$ From July 2020, all opted-in plant must comply with the IED emission limit values (ELVs). There is some flexibility for peaking plants (no more than 1500 hours/year as a rolling average over five years) with separate and higher ELVs. All coal plants which have opted into the LCPD (and which will therefore remain open from 2016 onwards) have FGD equipment already installed, so it is the need to comply with the NOx limits in the IED (from 2016 onwards) which will be the major reason for further expenditure. Coal plants will be affected and even

\footnotetext{
${ }^{73}$ Those power stations in operation before 1987 are defined as 'existing plant' and can either comply with the LCPD through installing emission abatement (Flue Gas Desulphurisation -FGD) equipment or 'opt-out' of the directive. An existing plant that chooses to 'opt-out' has been restricted in its operation since 2007 and must close by the end of 2015. For more information, see the European Commission website: Large Combustion Plant Directive

${ }^{74}$ Author's estimates

${ }^{75}$ See Appendix 2

${ }^{76}$ Coal and fuel oil plants that opt-out are allowed to run for a maximum of 17,500 hours between 2016 and 2023 without complying with the new emission limit values (ELVs), while the plants that choose to opt-in have to comply with the new ELVs, with some flexibility in early years allowed through a Transitional National Plan (TNP). The TNP defines an overall cap on emissions of SOx, NOx and particulates in each year from 2016 to June 2020 inclusive. The 2016 cap will be based on existing ELVs specified in the LCPD and will trend downwards with the cap in 2019 and the first half of 2020 being based on the ELVs specified in the IED.
} 

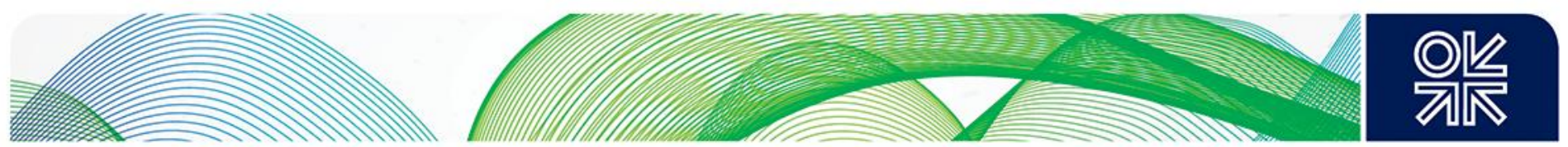

some older CCGTs will probably not comply with the IED ELV limits and will need to invest in selective catalytic reduction (SCR) or a similar NOx reducing technology, whose cost is fairly uncertain as is its ability to work in flexible mode. It was too soon to tell what the impacts will be, but based on the existing capacity, one can probably expect about 20 to $30 \mathrm{GW}$ of old plants to be shut down with some fairly important impacts in countries such as the UK, Poland or Eastern Europe that have an important fleet of old coal plants while limited impacts should be seen in others like Germany or in France. This Directive also has the potential to close old gas plants, leaving some additional room for more recent CCGTs that have been struggling to remain active post 2009.

In addition to closures triggered by these European Directives, some plants could close down due to rising costs to meet higher national emissions values such as in Germany, political agreements such as the National Agreements in the Netherlands, commercial pressure due to low wholesale electricity prices (Germany) and/or just simply for having reached the end of their working life and being replaced by new and more efficient plants (Germany, Poland) as seen in [Figure 29].

Figure 29: Age of existing and projected fossil fuel power plants in the EU, 2011 (GW)

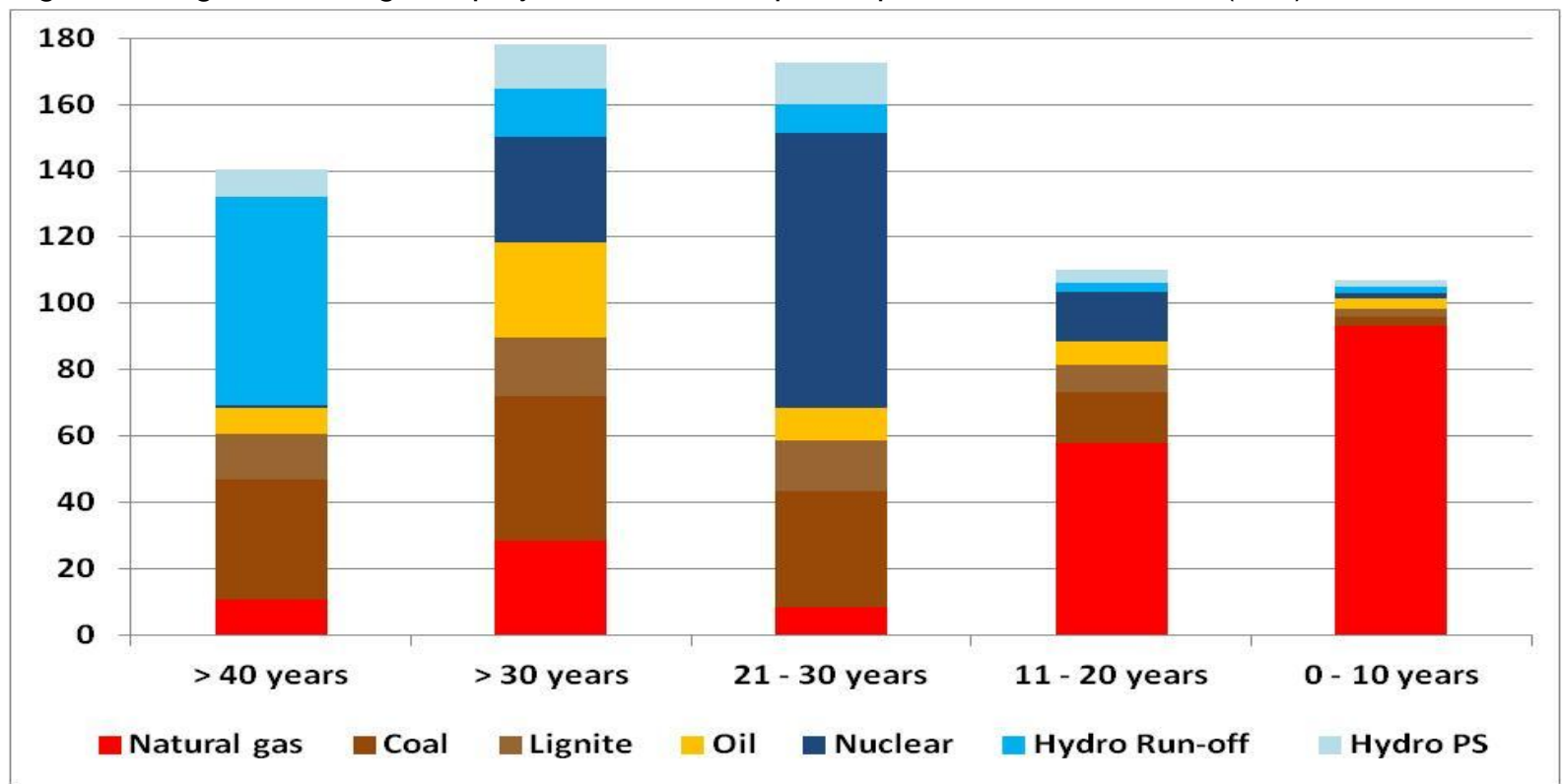

Source: Chalmers University (data for 2011), courtesy of Jan Karjstad

Even with only moderate power demand growth, this capacity will need to be replaced. Because of the difficulties in getting permits from national and regional authorities for new coal plants in Western Europe is extremely difficult, (public opposition has started to appear even in Germany in 2013), at least part of this capacity will not be replaced by the same technology. ${ }^{77}$ If these closures represent only a small share of the total generation of a country, the removed capacity should be easily covered by existing and potential additional future renewable capacity with most probably a relatively small near-term impact, if any, on gas generation. If they represent a significant proportion of the mix, then much will depend on how the gap between power demand and renewables is filled and how big the gap is. This provides a basis for additional gas usage in power generation in the 2010 s and beyond, however difficult to quantify at present.

\footnotetext{
${ }^{77}$ The commercial development of CCS on coal plants could change this view, but this is unlikely in the timeframe considered without additional political support. See Rogers (2012) for more information.
} 


\subsubsection{Wrong market signals to invest in new gas capacity}

Early 2014, about $13 \mathrm{GW}$ of gas-fired power station capacity were under construction but in only nine counties of the 35 markets considered in this study and about $15 \mathrm{GW}$ of coal plants in only six countries as shown in Figure 30.

Figure 30: Non-renewable power plant projects in early 2014 (GW)

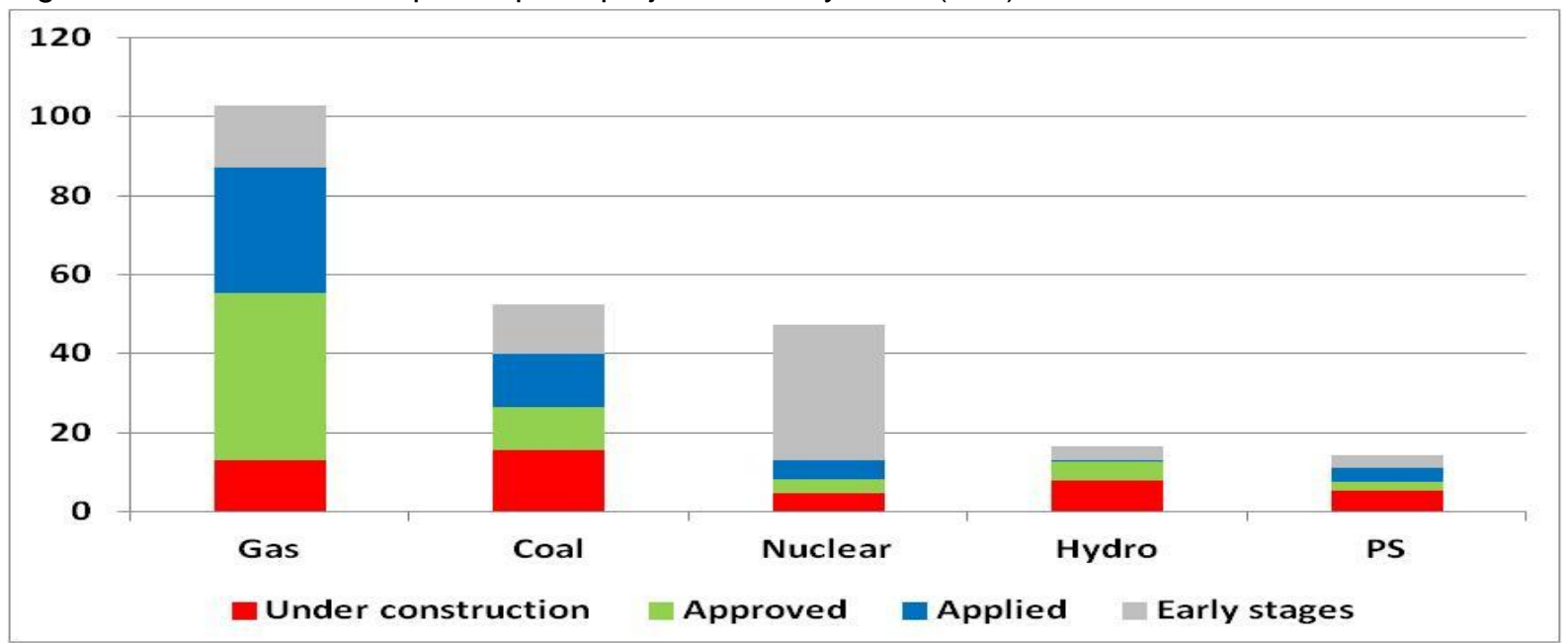

Source: Platts (power plants tracker) and Author's additions and updates

The gas capacity under construction was concentrated mostly in one country, Turkey, where more than $6 \mathrm{GW}$ were being built. This was followed by the UK, with about $2 \mathrm{GW}$. The other countries were Germany, France, Czech Republic, Greece, Poland, Ireland and Estonia [Figure 31]. The coal plants under construction were mostly in Germany (8.4 GW), Netherlands (3.5 GW) and Turkey (2 GW).

Figure 31: Capacity of gas fired-power plant projects under construction in early 2014 (GW)

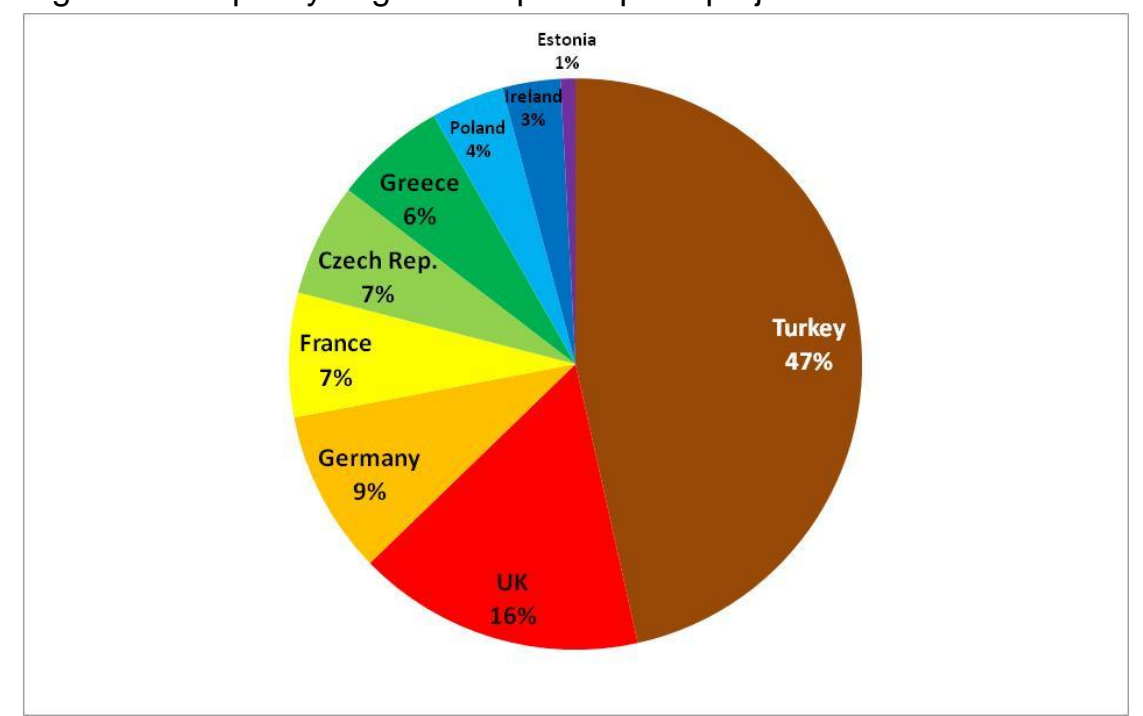

Source: Platts (power plants tracker) and Author's additions and updates 

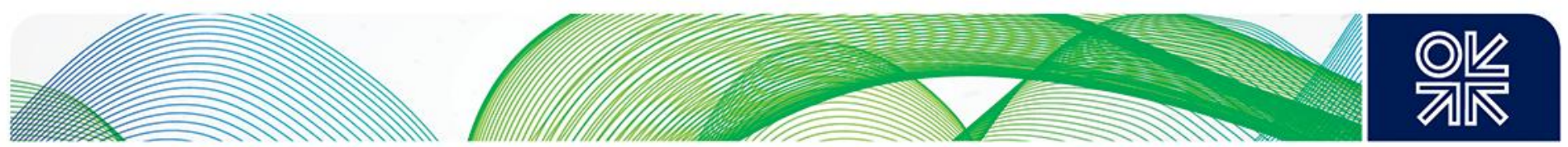

As already mentioned in Chapter 1, the rapid development of solar and wind capacity in conjunction with the economic situation post 2009 have produced an overcapacity in some markets, distorting wholesale electricity prices which have declined and became much more volatile. For instance, electricity prices in Germany are about $€ 40 / \mathrm{MWh}$, while in Spain spot electricity prices can vary from $€ 8 / \mathrm{MWh}$ on day with lots of wind to $€ 93 / \mathrm{MWh}$ on days with limited wind energy. Increasing feed-in renewables have diminished price-spreads, flattened the seasonal profile, reduced hours of production for gas plants and as a result cost recovery becomes more difficult for thermal plants. The midday opportunities for gas peaking plants have been eroded by solar PV and its flattening effect on midday prices, depriving the gas fleet of a key source of income. In Germany, peak prices at noon have even started to be lower than baseload prices. ${ }^{78}$ Even mid-merit and peak load CCGTs and Open Cycle Gas Turbines (OCGTs) struggle to recover long run marginal costs (LRMC). These new factors driving power prices are changing the traditional price signals needed to initiate a new cycle of investment [Figure 32].

Figure 32: Traditional investment cycles in new generation capacity

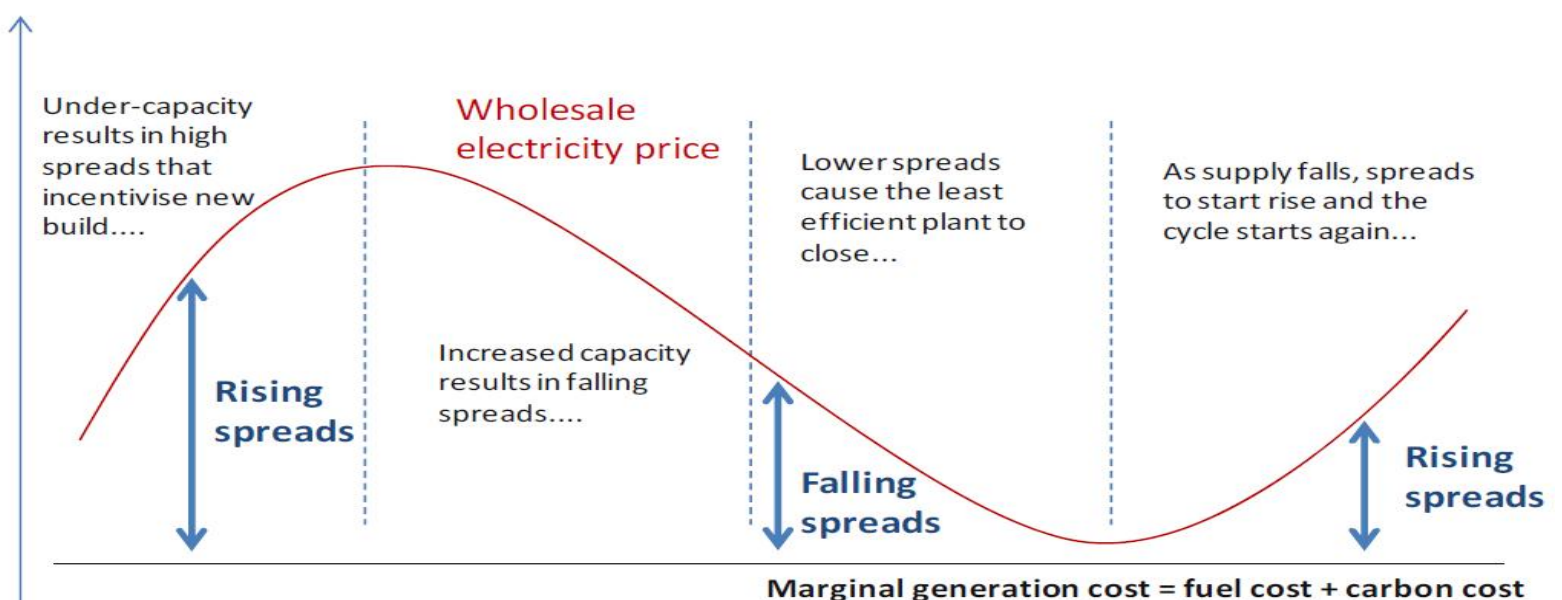

Time

Source: IEA

The projects in Figure 31 were mostly planned, approved and took FID before the credit crunch of 2008, with the notable exception of Turkey, where the economic downturn was not as severe as in the other countries and both energy and power demand kept on rising. Since 2009, few projects have started construction except in the non-contestable renewables market. The power stations nearing completion will face a new reality of stagnant power demand, low wholesale power prices (even below-cost in some countries), negative spark spreads in most countries, unfavourable competition with coal plants and a market flooded with financially-supported renewables in times of low demand. In this new context, most of the plants fully permitted (but without FID), which represent more than 20 GW of gas capacity, will not start construction. The Chief Executive Officers (CEOs) of eight major utilities - Enel, Eni, RWE, E.ON, GDF Suez, Iberdrola, Gas Natural Fenosa and Gasterra - issued a joint statement on May 21, 2013 warning that the lack of visibility on energy policies and regulatory uncertainty "will inevitably lead to an absence of energy investments with negative effects on security of supply, employment and reactivation of the European economy. The status quo is simply not an option. ${ }^{, 79}$

78 Platts (May 2012), pp.4-8
${ }^{79}$ Platts (May 2013b), pp.1-2 

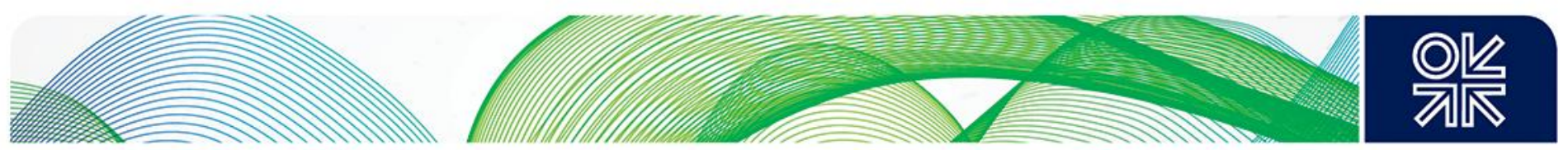

Keeping existing plants online to generate only peak load and flexible load is not as attractive an investment prospect as baseload or mid merit production. The macroeconomics conditions and fuel competitiveness are expected to remain poor in the 2010s and as a result, lead to low (if any) profit margins for gas-fired power plants. The uncertainty on policies, on future load factors, on revenues and with price forecasts for 2020 ranging from $30-80 € / \mathrm{MWh}^{80}$ mean that decisions to invest in new gas plants are more difficult than in the 1990s and 2000s when gas was the fuel of choice for any new generation across Europe. Generators are calling for capacity mechanisms both to support gas-fired plants to stay online, especially in regions where the grid is weak (Southern Italy or Southern Germany) and to decide on new investments, creating delays before making a decision.

One problem with capacity mechanisms is that there is no one-size fits-everywhere option. They can take various forms from a strategic reserve (additional reserve production), selective capacity markets (it improves the economic situation of selected technologies) or full capacity market (open to all technology options). The most important caveat is that no capacity mechanism has ever been used to cope with the short term / long term variability of renewable energy, and the solution will need to be adapted to the different characteristics of each markets, for instance, for extreme peak load coverage (France, Sweden, Finland), for a risk of losing existing flexible generation capacity (Spain, Italy) or for a weak business case for flexible generation capacity for renewable back-up (Germany). A capacity payment will help to guarantee the necessary reserve ('generation') margins in the form of an annual sum of money to be paid to the producers for every megawatt of back-up capacity they guarantee to generate. For instance in Italy, the incentive tariff would be paid by transmission system operator Terna. In mid-2012, the Italian Senate approved capacity payments to remunerate eligible gas-fired power plants based on their availability and flexibility as back-up capacity for the intermittency of renewable energy generation. ${ }^{81}$ The European Union published guidelines for capacity mechanisms in the late 2013, but the fact remains that the MS have taken the lead and a patchwork of various positions has been adopted across the region (existing capacity mechanisms, political decisions taken, political discussions ongoing and no political discussions), which adds to the already complicated climate for investment decisions [Map 1]. However, while capacity payments will help gas-fired capacity to stay on line or maybe new capacity to be built, it will only impact the capacity, not the actual generation. In other words, this may not necessarily result in a simultaneous growth of gas consumption in Europe.

${ }^{30}$ Platts (May 2012), pp.4-8

${ }^{31}$ ICIS Heren (September 2011) 
Map 1: Capacity mechanisms across Europe

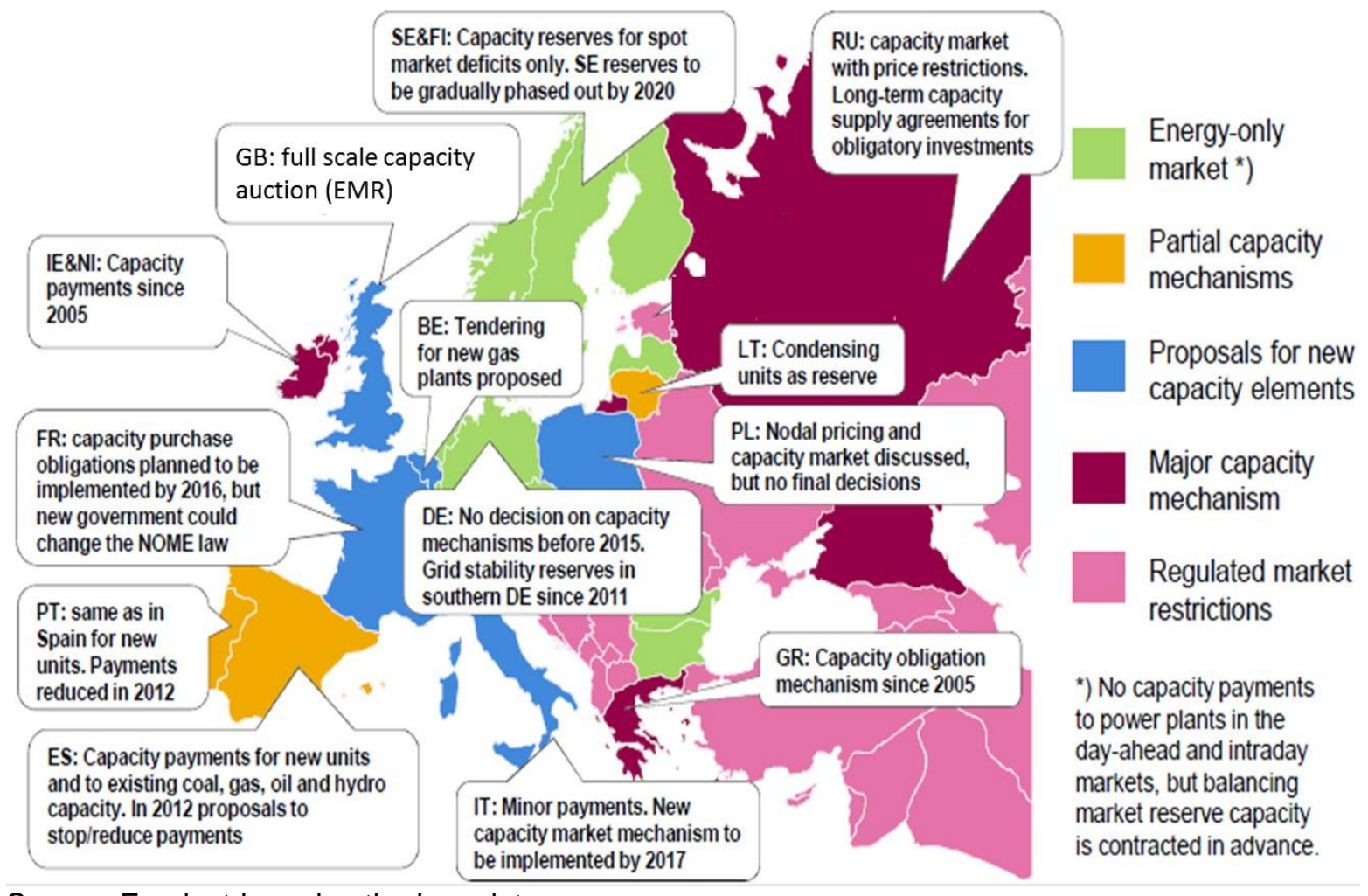

Source: Eurelectric and author's update

\subsubsection{Is there a future for gas-fired power plants in Europe?}

Rising renewables, low coal and $\mathrm{CO}_{2}$ prices and low power demand have left little room for gas-fired generation in Europe. Renewable energy from installed capacity is here to stay in the energy mix and should be seen as a long term change. It may even continue to rise, albeit at a slower pace. We expect coal prices to remain competitive due to abundant supply of relatively cheap coal, possibly lower demand in Asia and single-digit or low double digit $\mathrm{CO}_{2}$ prices in the EU ETS. Finally, even if the economic situation improved dramatically, the impacts on the actual level of power demand are uncertain thanks to improvements in energy savings and efficiency. So that's it? Is gas generation in Europe finished? Maybe not. Many baseload generation units will have to be shut down by 2030 or even before and with growing economic and political difficulties in the way of building new nuclear and coal plants across the region, there could potentially be some room for gas generation in the future... at least in some markets.

Most of the existing gas capacity in Europe is relatively young, having been built in the late 1990s and 2000s. Most of it will therefore not have to be shut down due to old age during the period considered in this study, but most likely for commercial reasons if the situation of gas for power does not improve. 
But in addition to lower gas prices (or at least a change in the competitiveness between gas and coal prices $^{82}$ ), another way to gain market share would be to adapt to the changing environment driven by the energy policies and the transition to a low carbon economy. Natural gas is a low carbon fuel compared to coal, it is less costly than most renewables or new nuclear plants. The possible flexibility of CCGTs and OCGTs also places them in a good position to provide the much needed back up capacity to the renewable intermittency, although one should not assume that it is the only option, and the gas industry should not count on its relative attractiveness alone (in terms of its flexibility) for its survival. As seen in Germany, coal plants can also be used to back up some of the intermittency. Better interconnections between national power markets will also play a major role.

Reduced operating hours and an increasing number of plant start-ups and shut-downs in order to balance renewable energy supply is something new for most of the European gas-fired power fleet. Power generators with gas-fired capacity will need to adapt to the new role of gas in power generation. For instance, Enel has already started to upgrade its CCGTs. The plants are expected to become more flexible and as a result, more competitive. The company has reduced the minimum generation of CCGTs by $20 \%$ and decreased the ramp up time of CCGTs by $50 \%$ thanks to new low NOx burners with improved flame stability. ${ }^{83}$ One of Enel's objectives is to take full advantage of future European market integration and export its flexibility to neighbouring markets as a way to diversify its commercial opportunities. Indeed, the flexible power generation potential of the Italian CCGTs could become an attractive asset to some of its neighbours, especially ones trying to integrate a large amount of intermittent generation in their energy mix. For instance, the German TSO TransnetBW contacted Terna in late 2012 about potential Italian reserve capacity in order to improve grid stability in its southern Lander. ${ }^{84}$ Further integration of its electricity grid with the rest of Europe and adaptation of certain rules will make such exports a reality in the near future and offer a future for the use of gas in the power generation sector. ${ }^{85}$

As a consequence, CCGTs will run differently from past patterns, which will change the nature of the revenues and also the risks they face. Greater value could come from the within-day and short term market, even if important changes are needed to make this work, both at national and European levels in terms of transportation, such as in access to the infrastructure, possibilities to buy/sell in other markets.

CCGTs do have a future in Europe as does gas demand from the power sector, but at lower annual levels than expected before the boom of renewables. Not only will the volatility of power prices increase but also the volatility of gas prices as the market turns toward spot supply and utilities need more flexible gas supply for dispatching power plants at short notice to back up renewable intermittency. The rise in power supply from wind and solar plants will not only benefit operators of flexible gas-fired power plants but also other providers of flexibility - such as fast-cycle storage facilities - and additional interconnections are expected to help manage the intermittency. Adaptations

\footnotetext{
${ }^{82}$ Thanks to a change in fuel prices or in $\mathrm{CO}_{2}$ prices in the EU ETS or as a consequence of national policy. For instance, the UK has introduced a Carbon Price Floor in April 2013. The carbon price floor was set to increase each year, from around $£ 16 / t$ of $\mathrm{CO}_{2}$ in 2013 , to around $£ 70 / t$ by 2030 , but as part of his 2014 budget the chancellor announced a freeze at $£ 18 / t$ from 2016 for the rest of the decade in order to lower energy prices to make British manufacturing more competitive globally.

${ }^{83}$ Hawkins (2013), slide 12 and Gas to Power journal (October 2012)

${ }^{84}$ Platts (December 2012), p.7

${ }^{85}$ Italy has 22 interconnection lines - four with France, 12 with Switzerland, one with Austria, two with Slovenia, two DC connections, one cable with Greece, one cable connecting Sardinia to the mainland through Corsica (SACOI) and one additional AC cable between Sardinia and Corsica. Interconnection developments include a line to Montenegro; a new ItalyFrance link; and the Sorgente-Rizziconi link to Sicily. Source: Scarpa (2012). An adaptation of the power spot market will be needed in order to be able to send electricity to the TSOs who need it (intra-day, balancing).
} 
all along the gas chain will be needed, as the gas industry will have to adapt to this new developments.

\subsection{Key issues in the other sectors: industry, residential and commercial, and transport}

What kind of trends can be expected in the other sectors of gas consumption? Little is usually said about the other sectors, which are considered mature with modest potential for growth... except maybe in transport, which in the early 2010 s has suddenly become regarded as a key sector for additional growth. The following sections briefly examine the anticipated trends in three main sectors: first industrial, second residential and commercial and finally, the transport sectors.

\subsubsection{The industrial sector}

Natural gas has a multitude of industrial uses, including providing the base ingredients for various products such as plastic, fertilizer, anti-freeze, and fabrics and in Europe, it is consumed primarily the chemical industry $(21 \%)$, followed by non-metallic mineral products, food processing beverages and tobacco and many others [Figure 33], and new applications are being developed frequently. In 2011, the industry sector represented about $20 \%$ of total gas demand in OECD Europe.

Figure 33: Natural gas demand in the industrial sector in OECD Europe, 2011 (MMcm)

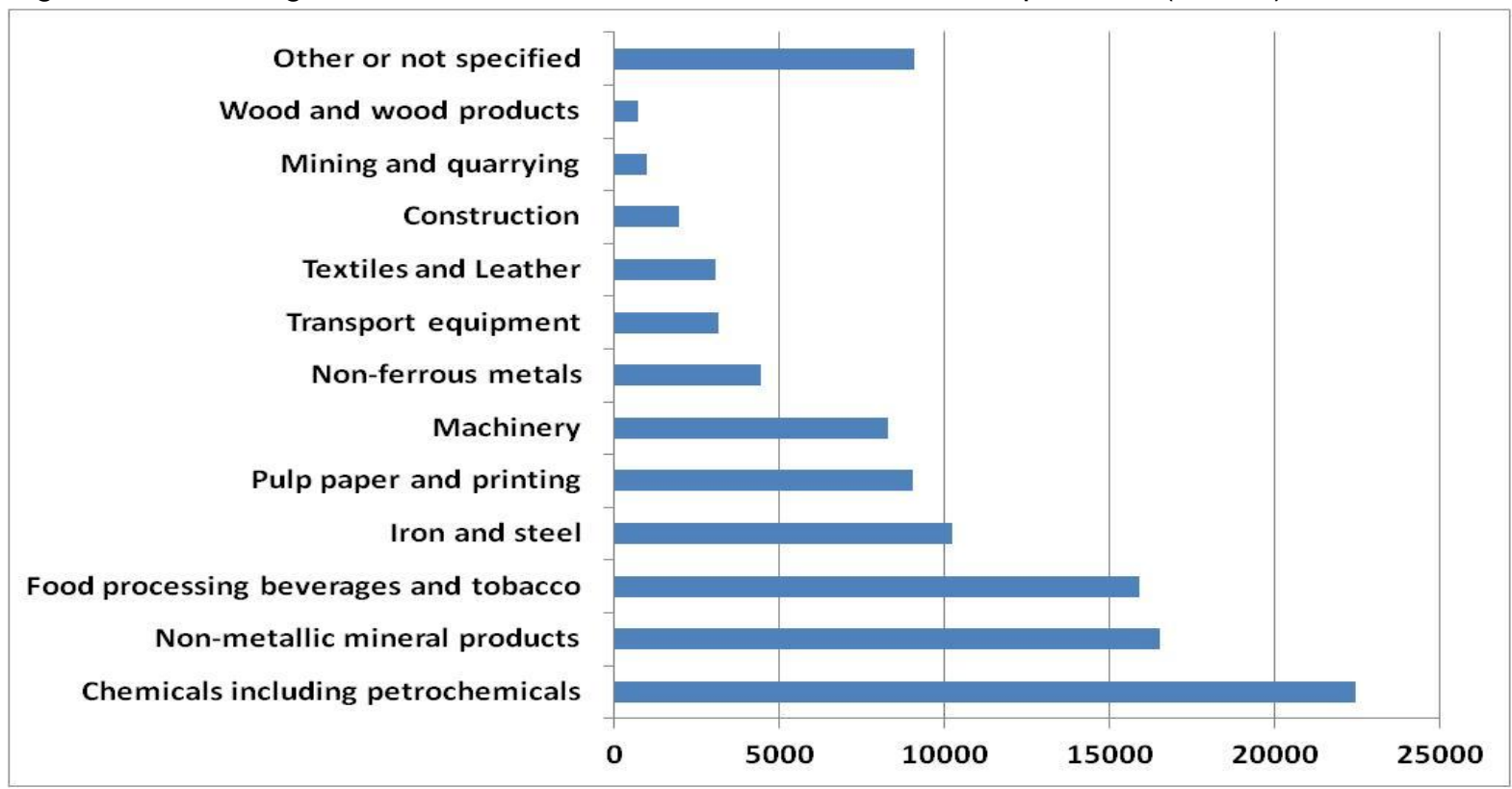

Source: IEA (2013a), p.IV.36, table 3A

The industry sector has been in (sharp) decline since the early 2000 s with an $11.5 \%$ decline in OECD Europe between 2000 and 2011. This trend was replicated in most of the major national gas markets which represented $76 \%$ of the industrial demand in 2011 with a drop of $31 \%$ in the UK, $24 \%$ in Spain, $20 \%$ in the Netherlands, $27 \%$ in France and even $44 \%$ in Italy. In Germany - the largest consumer with a $22 \%$ share alone - industrial demand stayed fairly flat with only a single digit decline $(-5 \%)$. In Turkey, on the other hand, it increased rapidly but from a very low base (388\% to reach levels 
comparable to France and higher than Spain and the Netherlands). The fall in energy intensity thanks to a shift to light industry instead of heavy industry and high gas prices especially post 2003 are the main factors for this rapid decline.

The sector suffered another significant hit with the economic crisis. Recovery is slow and industrial production is not getting back to pre-crisis levels as seen in Figure 34 (see also Figure 25 page 36 and Figure 4 page 18). Permanent gas demand destruction is likely to have happened in this sector due to factory closures. Competition from regions with lower gas prices, namely North America and the Middle East, means that it is not certain that even in the case of an economic recovery in Europe, industrial gas demand will reach previous levels, at least until the relative gas price competitiveness changes. Even if gas prices soften with the next wave of liquefied natural gas (LNG) in the second half of the 2010s, it may not be enough to change the relative competitiveness with other regions. Additional growth will also be curtailed by efficiency policies, even if some sectors such as fertilisers have already implemented energy measures and may not be able to make their production much less energy intensive. But as a result, an economic recovery may not trigger much growth in gas demand in the industry sector.

Consequently, scenarios need to take into account some demand reduction due to lower economic activity and better efficiency but also some demand destruction due to industrial relocation to other parts of the globe where gas prices are more competitive.

Figure 34: Production indices for total industry excluding construction seasonally adjusted (base year 2005)

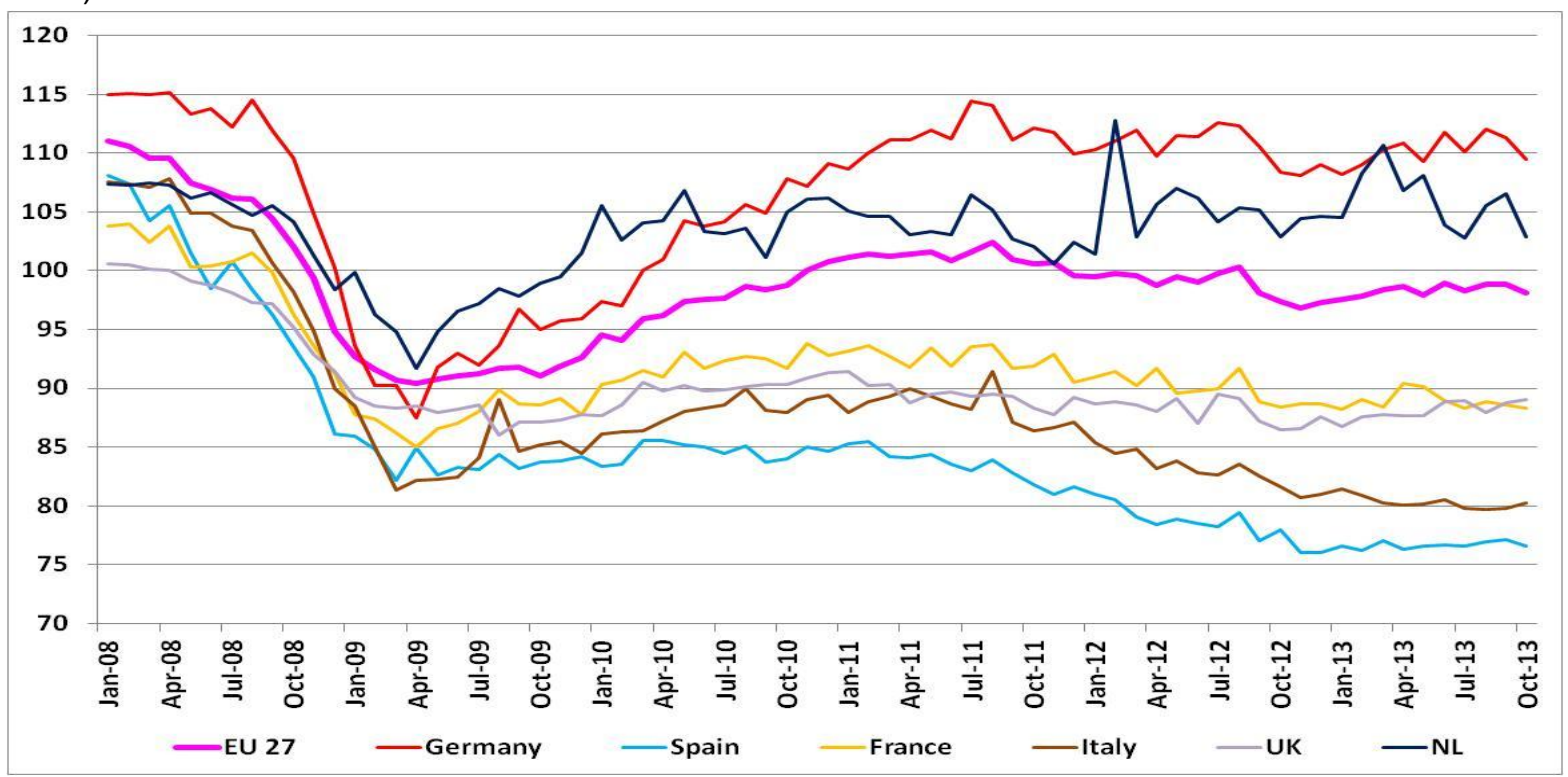

Source: Eurostat (Monthly), and for 2013: author's calculations in base year 2005

Another evolution to be expected is the development of decentralised generation by the industries, even small ones. This will not impact the statistics on gas demand for the industrial sector per se, but will change the need for centralised generation, and as a consequence, may lower the future gas needs in power. This ongoing trend is also observed in the residential and commercial sector. 


\subsubsection{The residential and commercial sector}

Small-scale generation from renewable energy sources with solar roof panels, small turbines or heat pumps in the garden for heating and cooling is also being developed in the residential and commercial sector. Self-generated and self-consumed power will have an impact on the gas consumed in this sector but it will also reduce the need for centralised generation and therefore gas for power demand.

Gas consumption growth in the residential and commercial sector is anticipated to be slow due to the near saturation of the sector in most European countries, apart maybe from Turkey because of its population growth and its rapid urbanisation and in some smaller markets.

This sector is traditionally less influenced by the economic situation in the short term. However, with uncertainties about their future income due to rising unemployment and at a time of rising energy prices, it seems that people still reacted to the cold spells seen in February 2012 and March 2013 in a more cautious way than could have been expected just a few years before. Cold temperatures did not raise gas demand by as much as they would have done in the past. This result could be explained by a change of attitude, with people starting their boilers later in the year and/or switching them off earlier at the end of the heating season in addition to lowering the thermostat, a habit that seems to have continued post 2009. Better insulation of new (and old) houses and metering systems will help to keep gas demand growth in this sector at a low rate.

Another change that is anticipated in the residential and commercial sector is the electrification of heating systems. This could have important consequences in countries with large changes in temperatures influencing the level of power demand which will peak when temperatures rise or drop to their extremes. This usually happens at times of high pressure, and therefore, when there is little or no wind. Sensitivity to a change in temperatures and additional variations in power demand will create a new need for CCGTs in order to respond rapidly to these changes. For example in France, which has electrified its heating system more than any other country in Europe (aside from Sweden), CCGTs are mostly used to cope with winter variations. These can be enormous as one degree drop in the mean temperatures creates an extra $2.3 \mathrm{GW}$ load on the system, out of about $5 \mathrm{GW}$ extra load for every one degree drop in temperature. As a matter of comparison, the temperature sensitivity of power demand in Germany, the largest European electricity market, is closer to $0.5 \mathrm{GW}$ (0.6 GW in the UK and $0.3 \mathrm{GW}$ in Italy according to the French TSO RTE ${ }^{86}$ ). The electrification of the heating system will potentially create another niche market for the CCGTs during winters, albeit with low utilisation rates throughout the year and therefore limited impacts on annual demand for gas, except maybe in exceptionally cold winters. Interestingly, higher electricity penetration also mean that the higher energy efficiency targets may not necessarily mean lower power consumption.

\subsubsection{A new market in the transport sector?}

Electricity will continue to gain a higher share of the total energy consumption, including in the transport sector. ${ }^{87}$ Together with hydrogen ${ }^{88}$ and natural gas, electricity represents the cornerstone of

\footnotetext{
${ }^{86}$ http://www.rte-france.com/en

Germany, France, the Netherlands, Spain and the UK are the leading countries with the most charging points across the EU.

${ }^{\beta 8}$ Germany, Italy and Denmark already have a significant number of hydrogen refueling stations although some of them are not publically accessible.
} 
alternative fuels in the transport sector. ${ }^{89}$ Facing rising emissions [Figure 35], the European Commission is looking at measures to ensure the development of vehicles using these fuels and the build-up of alternative fuel stations across Europe.

Figure 35: Absolute change in emissions by sector in EU-27, 1990 -2011 (MMt $\mathrm{CO}_{2}$-eq)

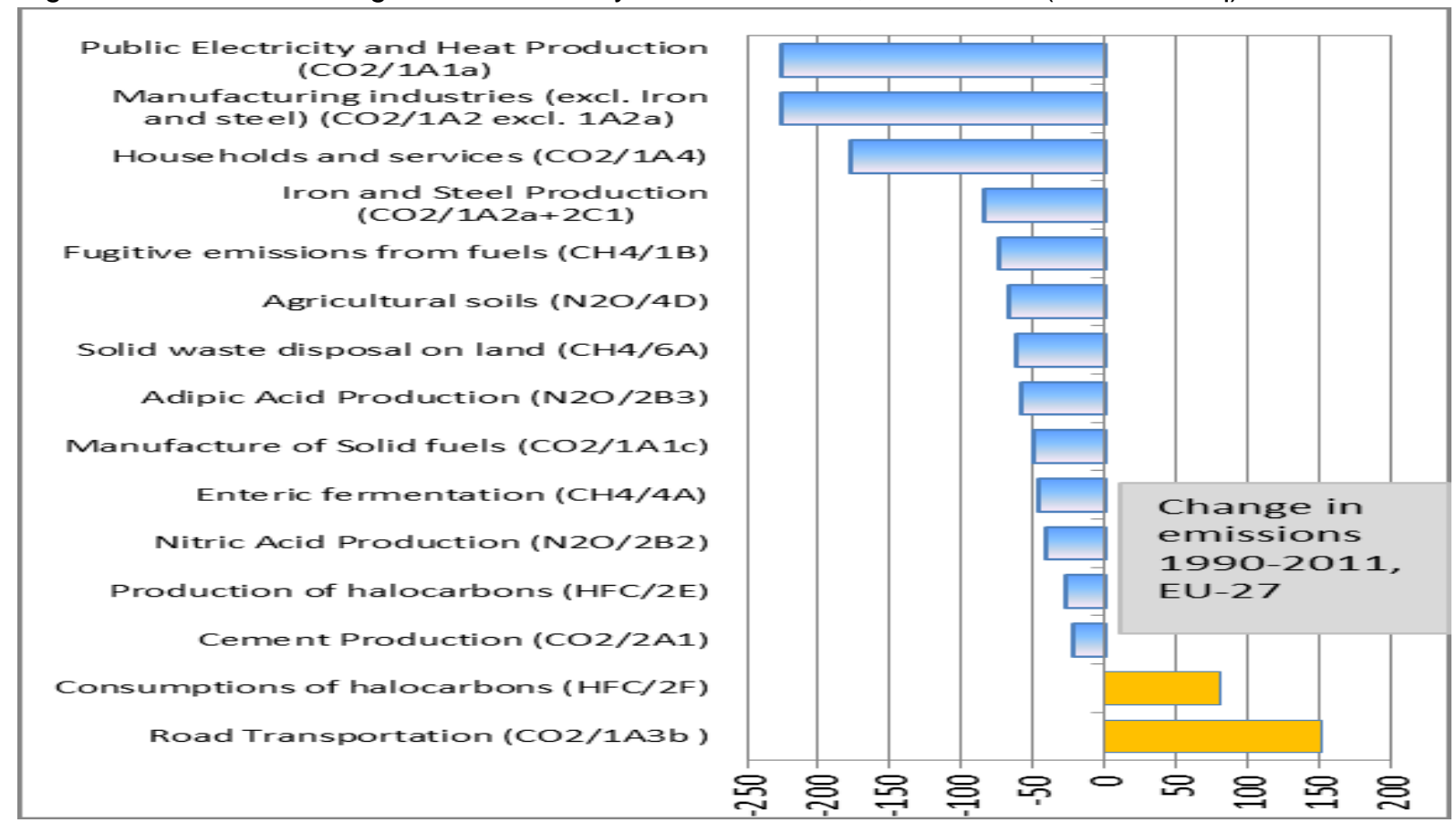

Source: http://www.eea.europa.eu/publications/european-union-greenhouse-gas-inventory-2013

In 2012, the EC confirmed new emissions standards for cars and vans from 2020, and followed in January 2013 with a clean fuel strategy. ${ }^{90}$ Although the development of compressed natural gas (CNG) vehicles ${ }^{91}$ along with LNG use for heavy goods vehicles and shipping ${ }^{92}$ are seen by some gas players as the new Eldorado for gas demand in Europe, there are several factors limiting the scope of development, at least in the 2010s: the high cost of vehicles, a low level of consumer acceptance and the lack of recharging and refuelling stations, with the notable exceptions of Germany and Italy for instance.

So is gas for transport the next key driver for additional demand in Europe? This new market does have some potential, but the demand will not be in the range of the other major sectors such as power, industry or residential and commercial, at least in the period considered in this study. In addition, as with the other sectors, natural gas does not have a captive market and policy intervention will be needed to create this market. In addition to creating some new demand for gas, it would also help curb the day/night production swing and adapt demand to supply (contrary to past patterns).

\footnotetext{
${ }^{89}$ For more information, see Le Fevre (2014)

${ }^{90}$ European Commission (January 2013)

${ }^{91} \mathrm{CNG}$ : Compressed natural gas is mainly used for cars. One million vehicles currently use this fuel representing $0.5 \%$ of the fleet - the industry aims to increase this figure ten-fold by 2020.

92 LNG is used for waterborne transport both at sea and on inland waterways. LNG infrastructure for fuelling vessels is at a very early stage, with only Sweden having a small scale LNG bunkering facility for sea going vessels, with plans in several other MS.

LNG is also used for trucks, but there are only 38 filling stations in the EU.
} 
If gas for transport is to grow in Europe or at least in some countries, it will be a policy driven evolution and as a consequence, may be concentrated in some national markets only rather than being a true European revolution. And it also may take some time. For instance, this has been a booming sector in Italy from the early 2000s, but it still represented only about 1\% of annual demand in 2012 [Figure $36 .^{93}$

Figure 36: Italian total gas demand vs consumption in the transport sector, 2000-2011 (Bcm)

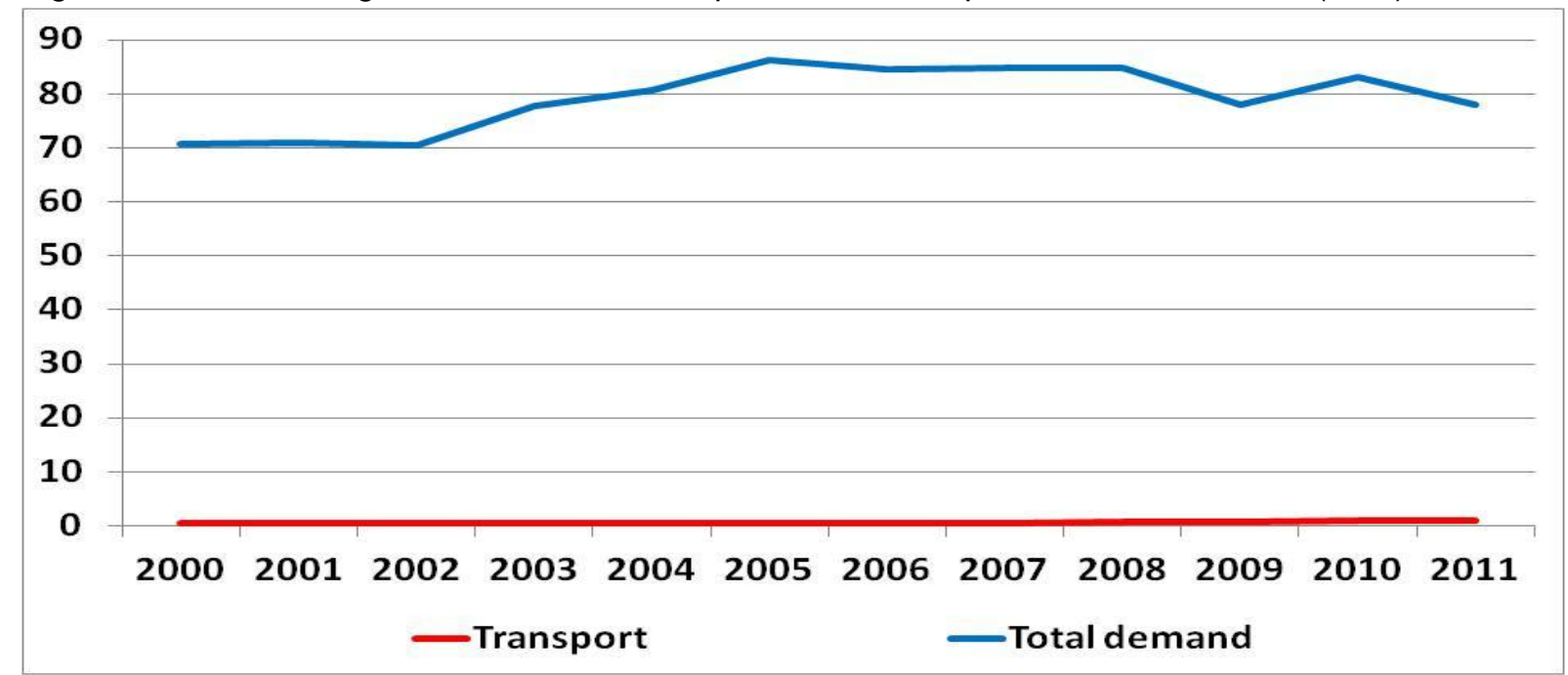

Source: IEA, Natural gas information, various editions

Whether power generation remains a potential driver for gas demand growth in Europe seems less and less certain. Additional question marks also exist in the other markets which are facing low economic recovery, uncompetitive gas prices and industry relocation, the maturity of most of the major markets and complicated policy driven changes in the energy world. Economic, political, regulatory drivers will all influence gas demand in the future, with different impacts in time, in sectors and in geography. The following chapter tries to synthesise these -sometimes- contradictory drivers and propose some scenarios for gas demand in Europe up to 2030. 


\section{Outlook for gas demand in Europe up to 2030}

The impacts of energy policies and the effects of the financial and economic crisis of 2009 were largely underestimated, but for a region that has claimed to be on the road to the energy transition to a low carbon economy, the events since 2011 seem to be at best contradictory. Electricity generation from gas is declining as gas plants are being squeezed out of the mix. The power sector, 'the former key driver for additional demand', is the possible key driver for demand decline in the 2010s and beyond, a very different picture from the pre-crisis scenarios. The following sections offer some reflections on existing scenarios and how the events in the energy world are reflected in the expectations for gas demand growth over the 2000s and early 2010s as scenarios evolved over time following the concerns/aspirations of the moment. The second and third parts propose the author's views on possible trends for the gas industry in Europe, by sectors and countries to the 2030 horizon as seen from the world in late 2013. Additional information on individual country assumptions and results can be found in Appendix 2.

\subsection{Scenarios: downward revisions and growing pessimism}

\subsubsection{A gloomy vision of the interaction between gas and renewables}

Despite the possible 'golden age for gas ${ }^{94}$ anticipated in other regions, the future seems a lot gloomier in Europe. Dark visions started to be painted in scenarios published by the European Commission in the mid-2000s which integrated impacts from environmental measures to make the European economy more climate-friendly and less energy-consuming in the 2010 s and beyond. The most recent EU scenarios can be found in the Energy Roadmap to 2050 published in 2011, a continuation of the EU's 2020 energy and climate change targets extended out further into the future, in which the role of gas remains limited in all the decarbonisation scenarios. ${ }^{95}$ Gas remains useful during the transition phase, but then gas consumption falls substantially in all scenarios aside from 'Reference low energy import prices'. The decline is greatest in decarbonisation scenarios after 2030, especially in the one with high renewables in which gas consumption falls by $43 \%$ by 2050 [Figure 37].

\footnotetext{
${ }^{94}$ See IEA (2011)

${ }^{95}$ European Commission, Energy Roadmap 2050
} 
Figure 37: Scenarios for gross inland gas consumption in the EC Energy Roadmap 2050 (MMtoe)

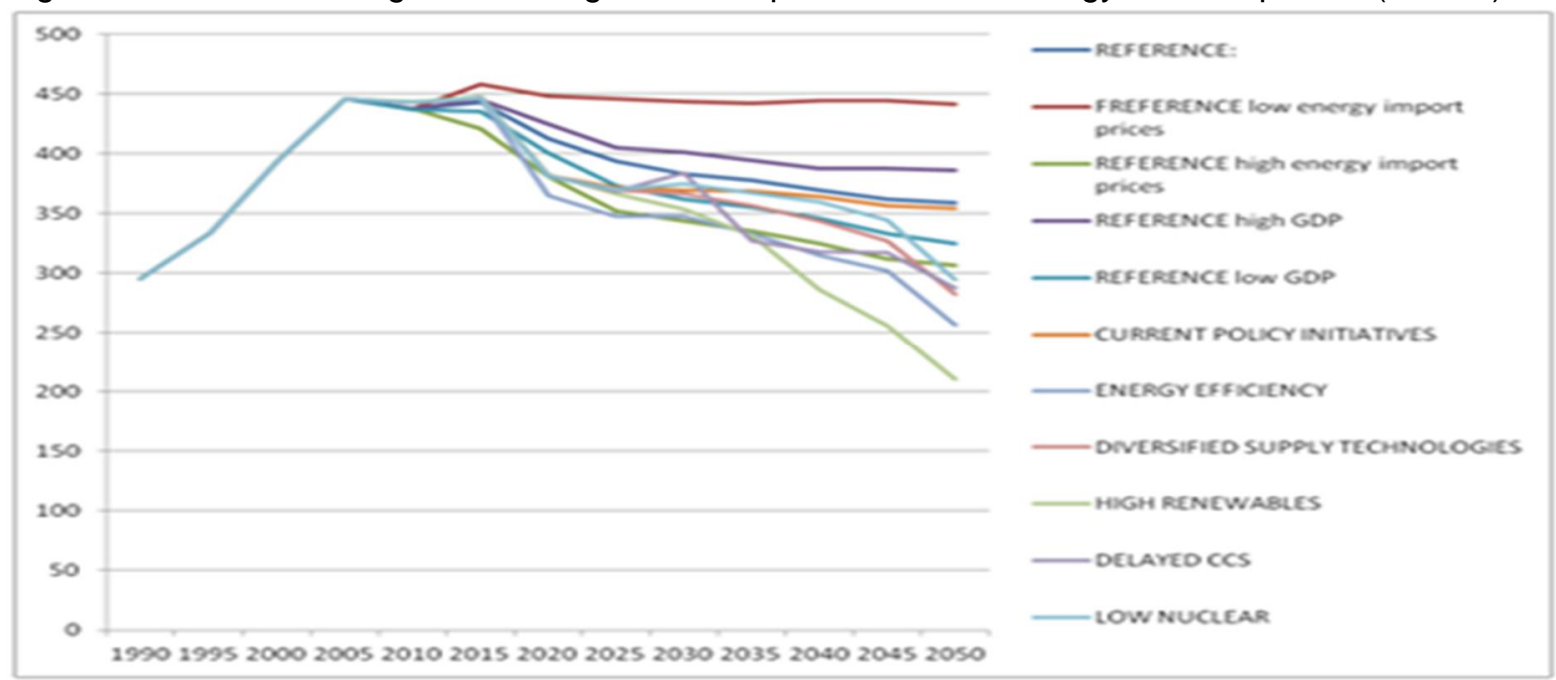

Source: European Commission, Energy Roadmap 2050, courtesy of J. Stern

The role of gas in the electricity generation sector by 2050 is ranging between two extreme scenarios. First, the high renewables scenario, in which electricity from gas is cut by half and total energy investment needs beyond 2030 are higher than in the other scenarios due to increased storage needs to cope with renewable fluctuations, extension of the grid and also back up facilities, namely gas-fired power stations. Second, a low nuclear scenario in which electricity from gas rise by $20 \%$, but as we've already discussed, this scenario seems much less likely [Figure 38]. It is therefore more important to consider the relationship between renewables and natural gas in the coming decades.

Figure 38: Gas role in electricity generation in the transition, Energy Roadmap 2050 (TWh)

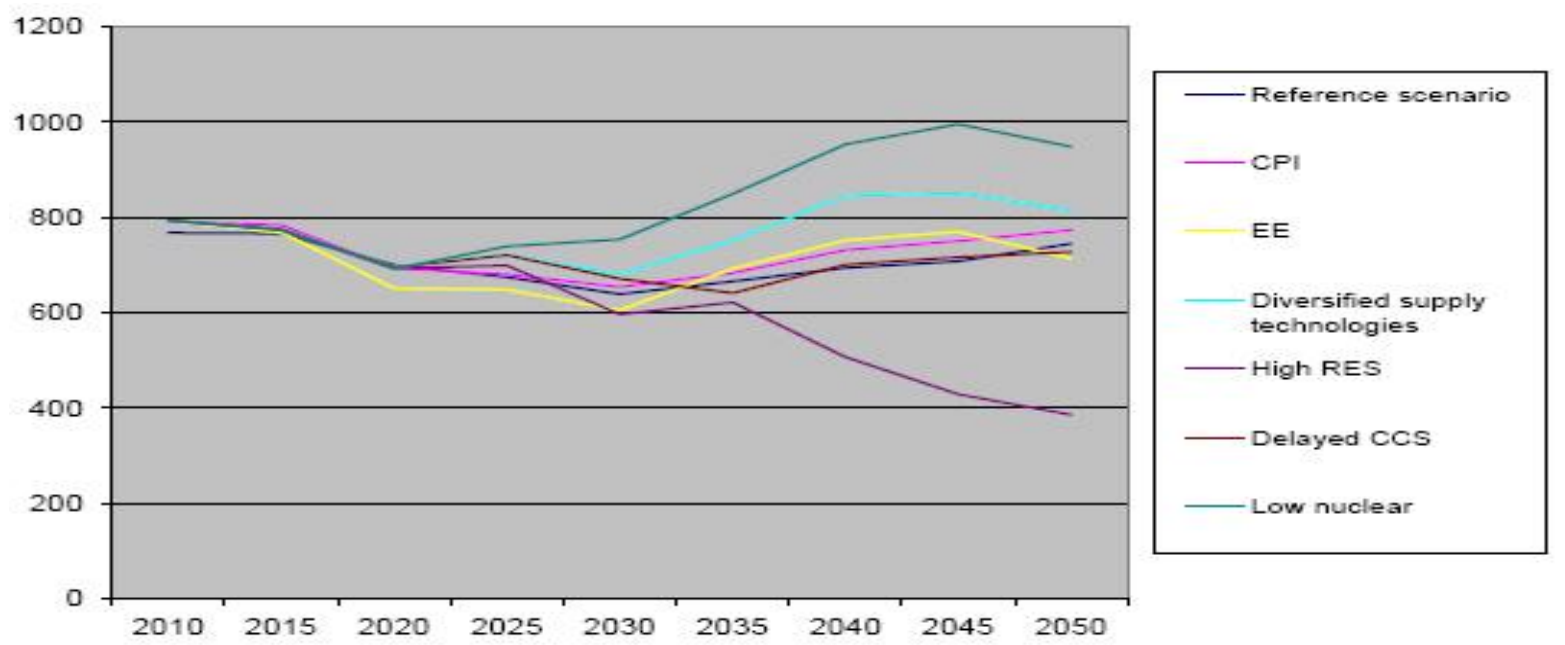

Source: European Commission, Energy Roadmap 2050

\subsubsection{Downward revisions in the power sector in the $2000 \mathrm{~s}$}

The IEA scenarios provide some insights into how the consequences for natural gas demand of environmental policies are perceived. During the early 2000s, gas consumption was expected to continue to grow in a straight line over the next two decades, mainly driven by growth in gas demand 
in the electricity sector. This scenario was called into question due partly to the rapid development of renewable energy and gas demand scenarios were revised downward all along the 2000s with the power sector taking the biggest hit in revision after revision as seen in Figure 39.

Figure 39: IEA WEO scenarios, reference scenarios and new policies scenarios, WEO 2002 to WEO 2011, MMtoe

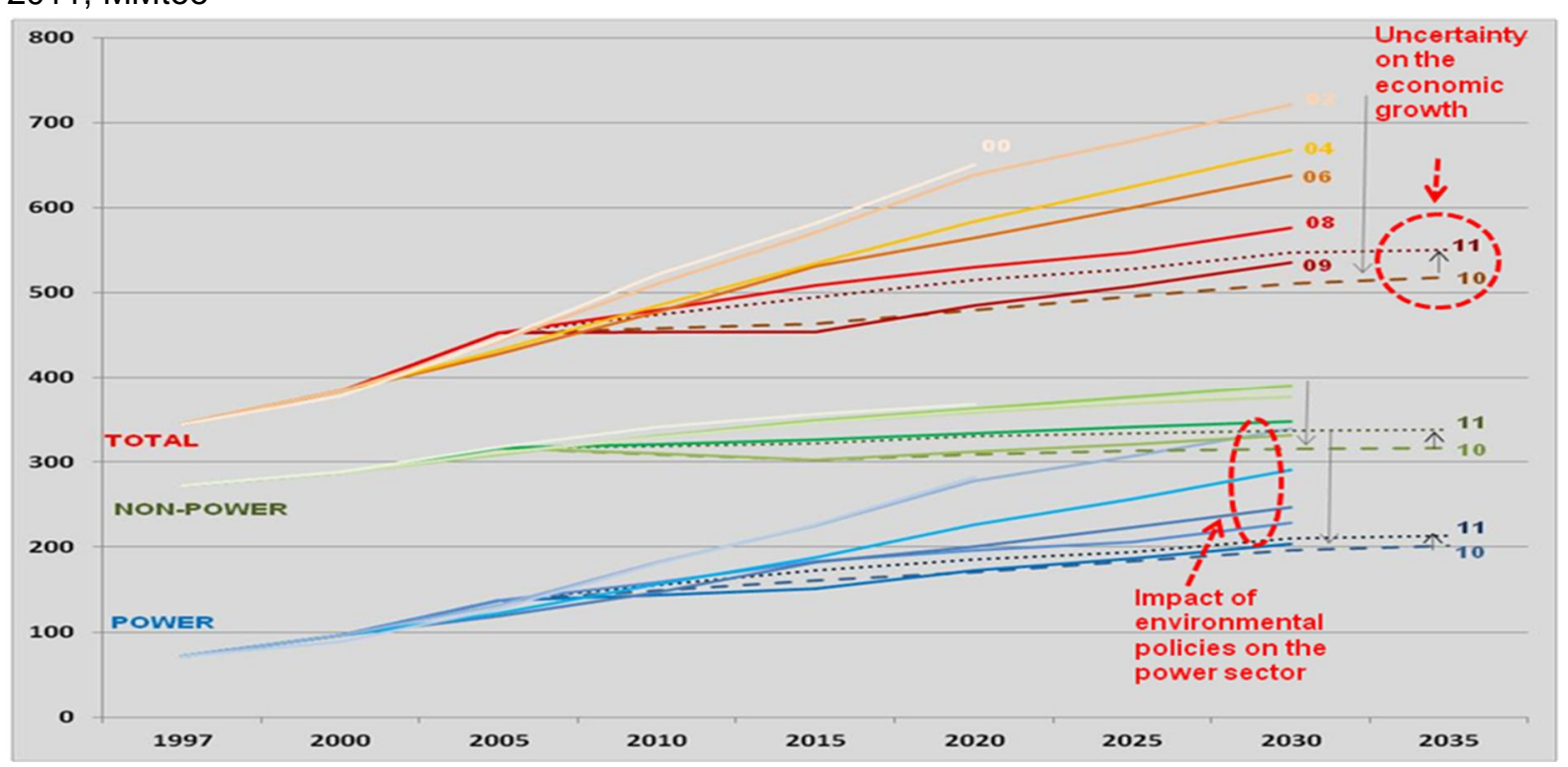

Sources: Updated from Honoré (2010), author's calculations from IEA (WEOs), Reference scenarios for WEOs 2002-2009 and new policies scenarios for WEOs 2010-2011.

Changes in the energy market that followed the economic recession that started in 2008 have added to the confusion in scenarios published in 2009-2012, with a certain return to major pessimism in the WEO 2013 in which the power sector takes a major hit once again, with gas consumption in 2030 only reaching levels previously expected in 2020 [Figure 40].

Figure 40: IEA WEO scenarios, reference scenarios and new policies scenarios, focus on the WEO 2008 to WEO 2013, MMtoe

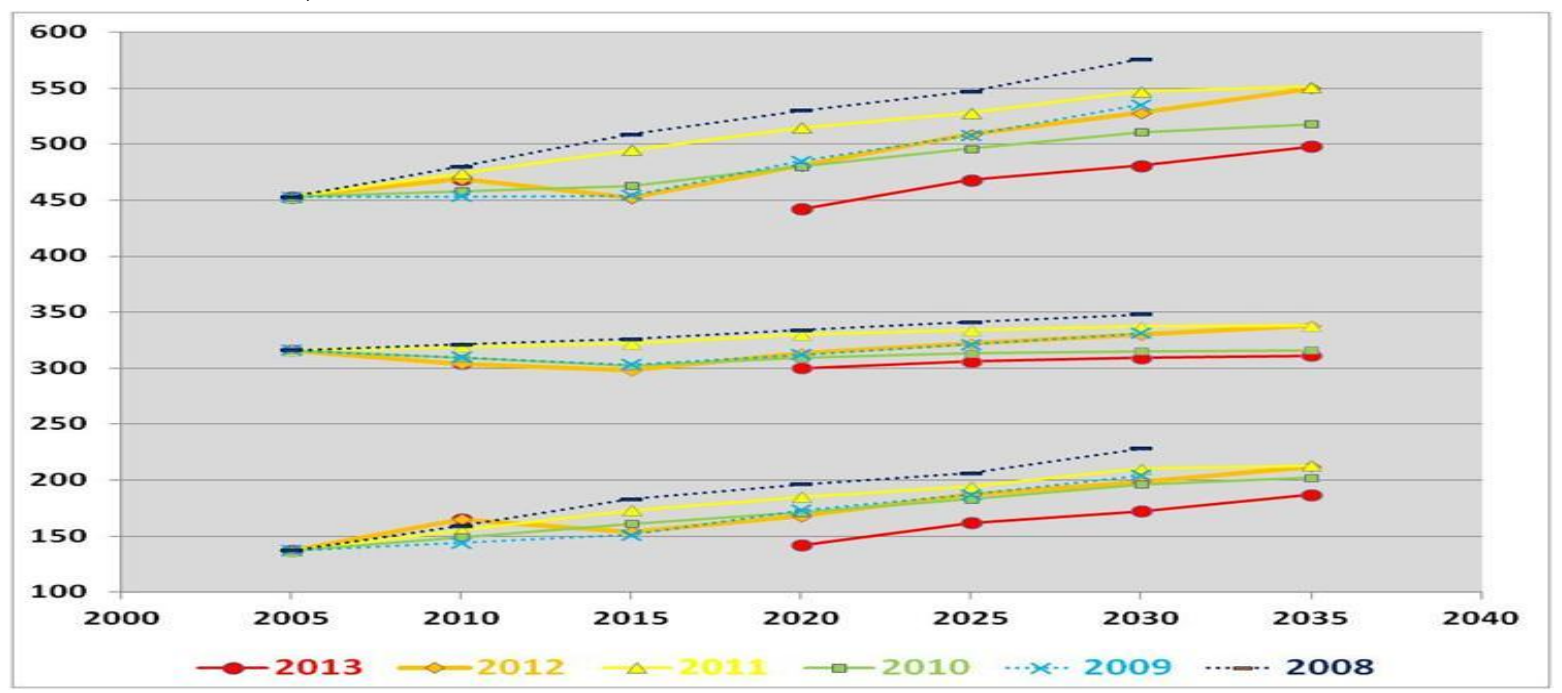

Sources: IEA (WEOs), Reference scenarios for WEOs 2002-2009 and new policies scenarios for WEOs 2010-2013 
In mid-2013, the IEA revised its forecast of European gas consumption for the mid-term down from $561 \mathrm{Bcm}$ in $2017^{96}$ to $525 \mathrm{Bcm}$ by $2018 .{ }^{97}$ Europe was the region with the largest downward revision compared to the previous year's forecast, and it was driven almost entirely by lower economic growth expectations and more conservative assumptions in the power generation sector.

\subsubsection{Renewables may not mean the end of gas for power demand after all}

One of the most interesting results was perhaps the chart below from the WEO 2012 [Figure 41] in which an increase in gas for power generation seemed possible up to 2035 despite a high level of renewables, somehow contradicting the Energy Roadmap 2050 conclusions, albeit for a different time frame. In the period 2010-2020, the main drivers are high gas prices, low carbon prices, and renewable growth while post $2020, \mathrm{CO}_{2}$ policies are expected to boost CCGTs use and CCS for gas plants gets commercially deployed post 2030. As seen in Figure 41, this also supposes the retirement of coal and nuclear capacity which, as explained earlier, will happen in several countries in Europe. As a result, the gas used in power generation was back at 2010 levels by 2020 and the annual average growth rate of total gas demand in this scenario was $0.6 \%$ in the period 2010 to 2035 . Limited growth, but growth nonetheless.

Figure 41: IEA WEO 2012: possible additional power generation from gas even in a high renewable scenario, 2010-2035, TWh

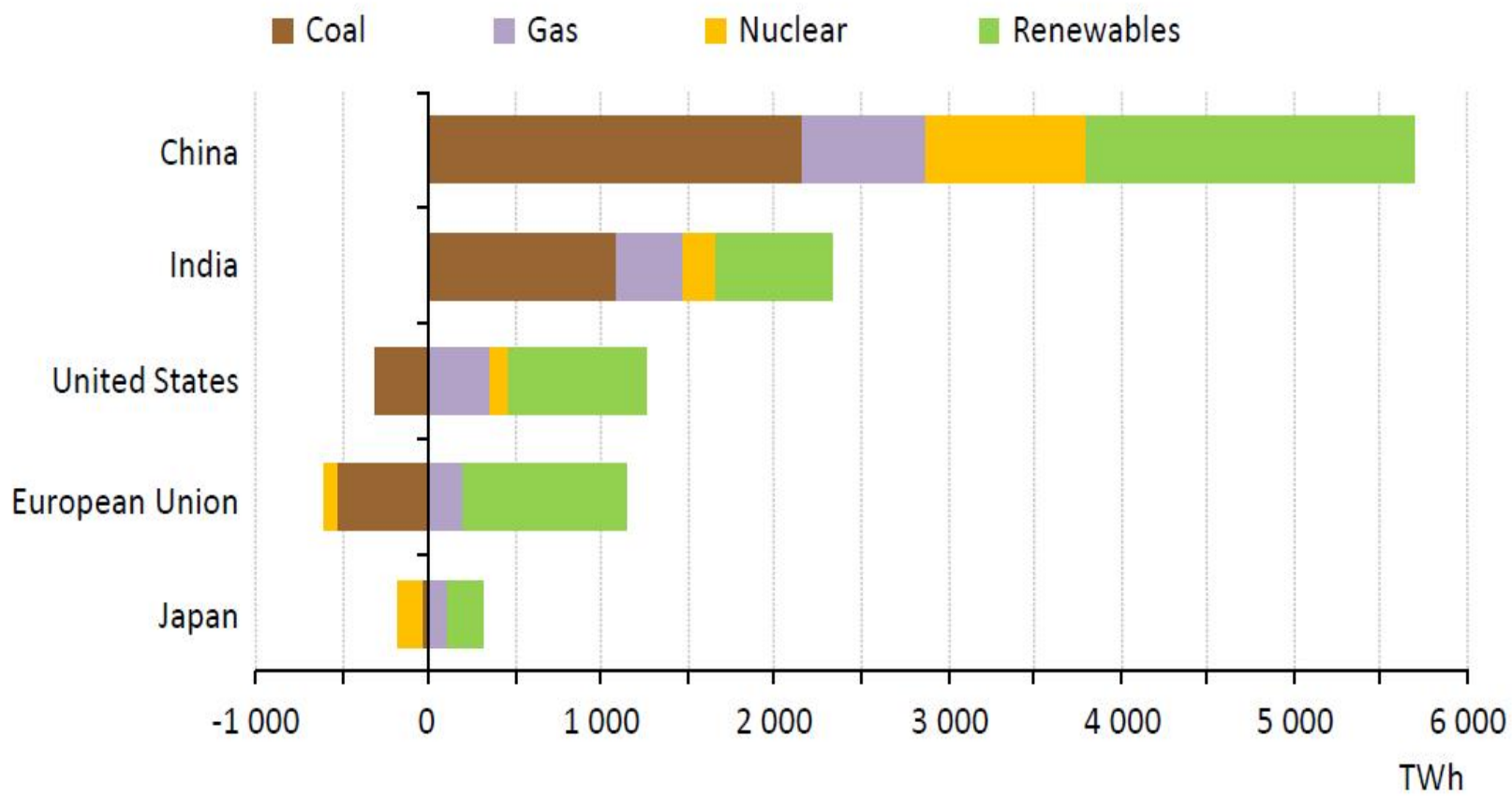

Sources: IEA (2012a), presentation to the press, slide 9 


\subsection{Evolution of the generation mix}

Sections 3.2. and 3.3 below are based on this author's assumptions.

\subsubsection{Assumptions on generation capacity}

The assumptions on the evolution of generation capacity are based on the policies as seen and anticipated in late 2013. With the continued changes in renewables support, emissions legislation and growing costs of nuclear, this is one of the least certain parameter of what the future holds for Europe. Figure 42 was built by adding the assumptions for each country. Targets and objectives have been taken into account but have not been used as constraints for the model. For instance, a national target on renewable energy was taken into account along with the policies in place and planned to reach it, but the target may or may not have been reached by the end of the timeframe. This was done for each fuel, albeit with stronger constraints posed by the LCPD or nuclear closure for instance.

Figure 42: Evolution of generation capacity in Europe, 2010-2030, GW

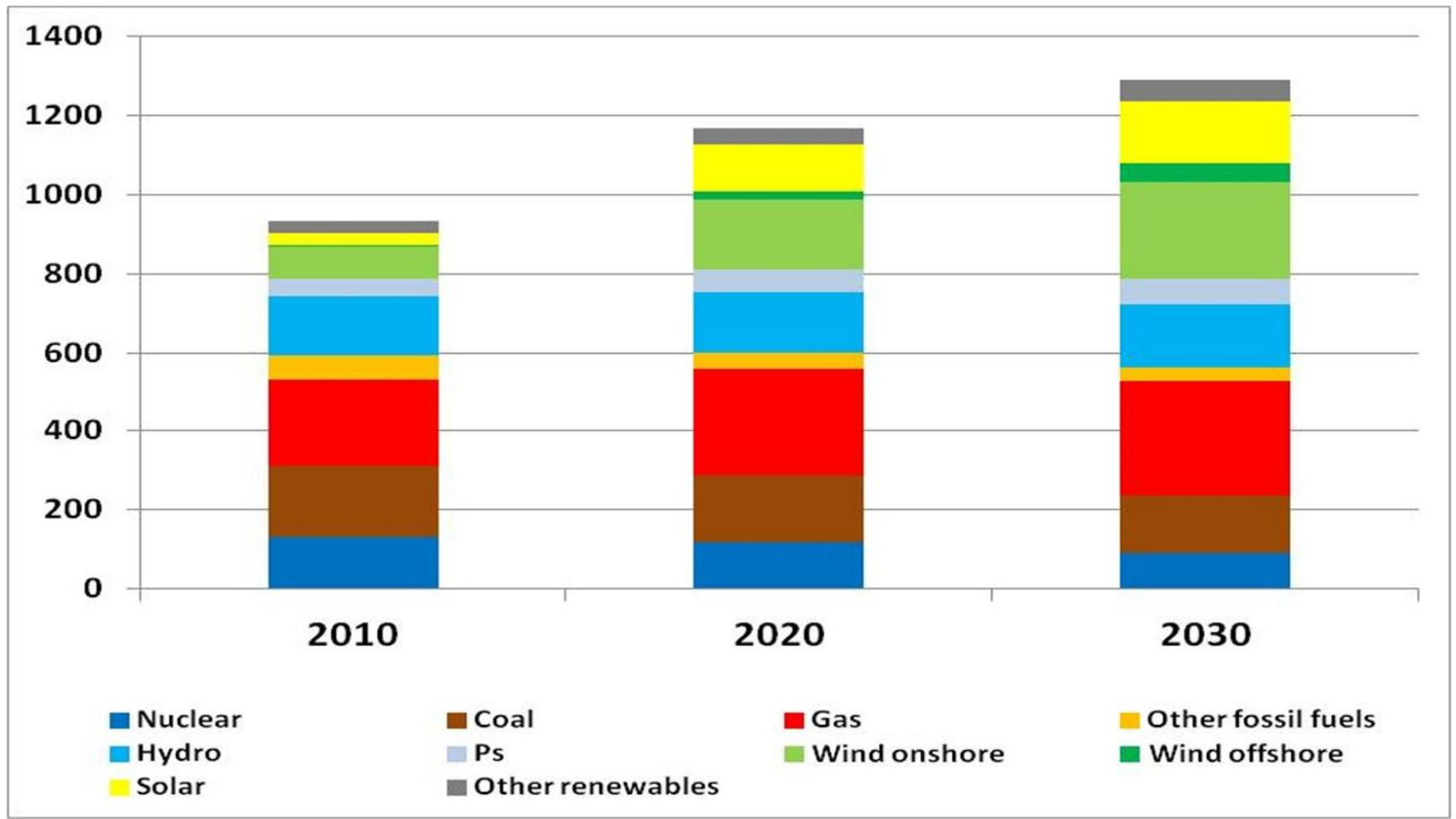

Source: Author's assumptions

The picture up to 2030 is one of declining nuclear capacity; falling coal capacity but maybe not as fast as is generally envisaged at the EU level; growing gas capacity but with uncertain impacts on the level of demand as this capacity has been used to partly back up the growth of renewables which, even if it is lower than most national ambitions, remains impressive at the regional level. The growth in renewable energy is concentrated in onshore wind and solar generation, with limited offshore capacity built partly due to costs and limited access to offshore space for most countries. 

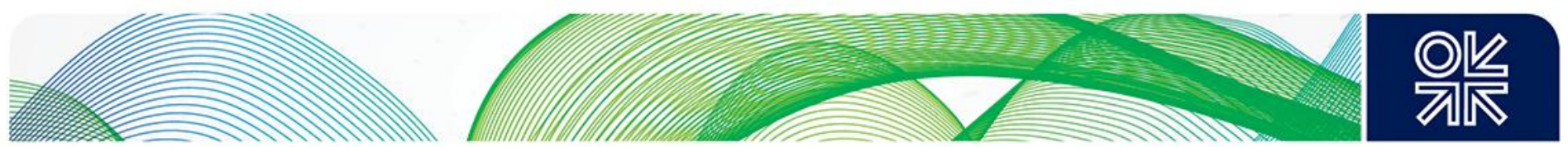

\subsubsection{Changing generation mix: a story for gas in the $2020 \mathrm{~s}$ ?}

As a result of the changes in generation capacity, the mix is also evolving to meet a very slow increasing power demand driven by the electrification of additional markets across Europe $(+0.3 \%$ /year on average between 2010 and 2030 , but $+4 \%$ / year on average in the last decade).

With a fairly baseload run for nuclear and hydro (albeit at different levels) and limited availability of renewables, the other fuels provided the flexibility into the system. As a result, coal and gas keep competing against each other during the period. The gas share drops from $23 \%$ in 2010 down to $19 \%$ in 2020 but regains its original share at $24 \%$ by 2030 thanks mostly to nuclear plants closures as seen in Figure 43. The share of coal remains fairly high in the mix all along the period from $24 \%$ in 2010 down to $17 \%$ in 2030 , surprisingly declining by not as much as one could have expected.

Figure 43: Author's scenario for power generation mix by fuel (TWh)

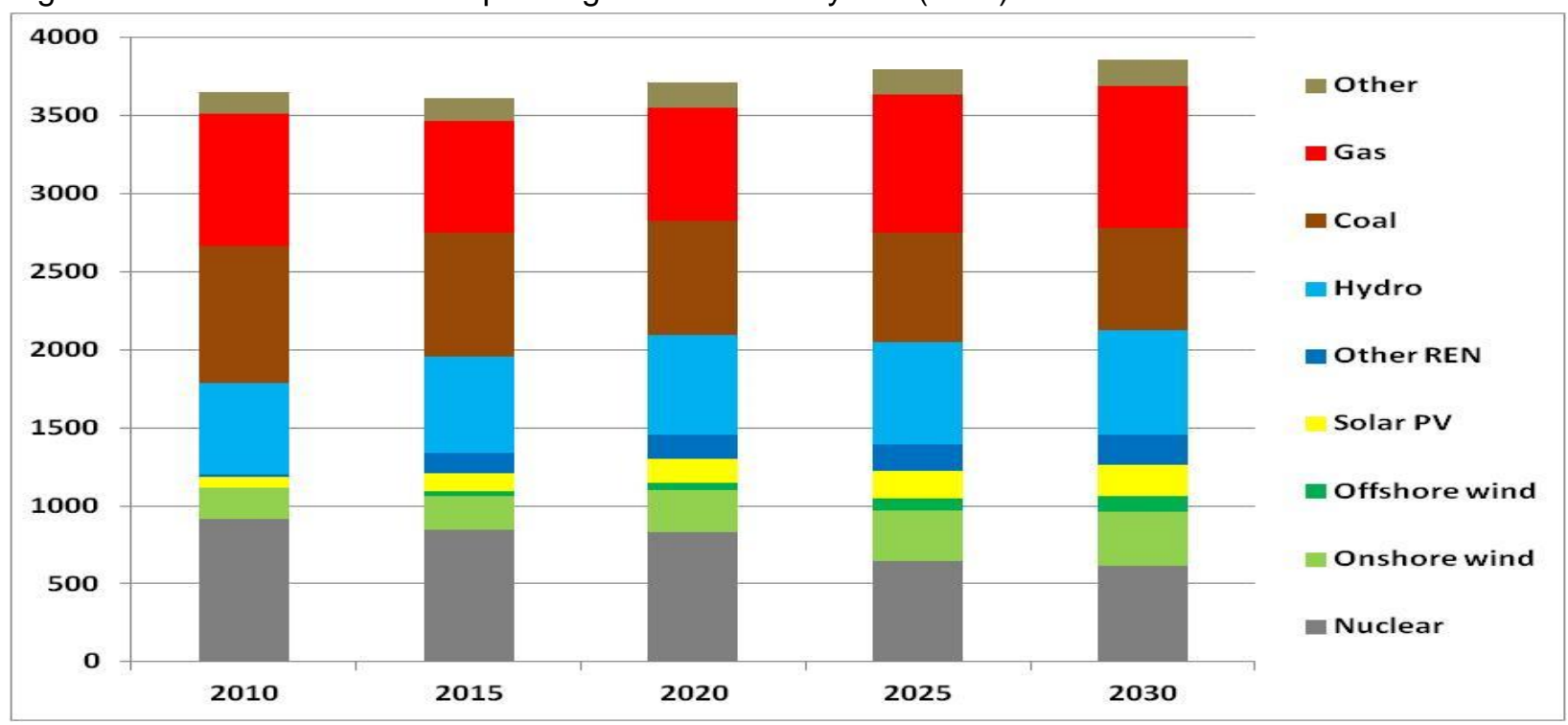

Source: 2010: IEA (2013e); scenario 2015-2030: Author's assumptions

These scenarios are based on plants capacity and utilisation assumptions in each market. Once amalgamated to form a regional picture, it turned out that the share of renewables in 2020 was $35.5 \%$, or in other words, very close to the level needed in power generation to meet the $20 \%$ renewable target for energy consumption. By 2030 , the share rises to $42.4 \%$, short of the necessary $47 \%$ of renewable in power generation to meet the $27 \%$ proposed energy consumption target. The key sector, and by far the biggest uncertainty regarding the pace of future gas demand, is the power generation sector.

\subsubsection{Focus on three key markets with high renewables integration}

Chapter 1 looked at three markets (Spain, Italy and Germany) with high growth of renewables in the 2000 s and the impacts this had already had on the gas for power sector [page 25]. The following paragraphs provide a follow-up with the evolution of the generation mix in these markets, and the first result is that there is indeed a different story to tell just by looking at these three markets [Figure 44]. 
Figure 44: Author's assumptions for the power generation mix in Spain, Italy and Germany up to 2030 (TWh)

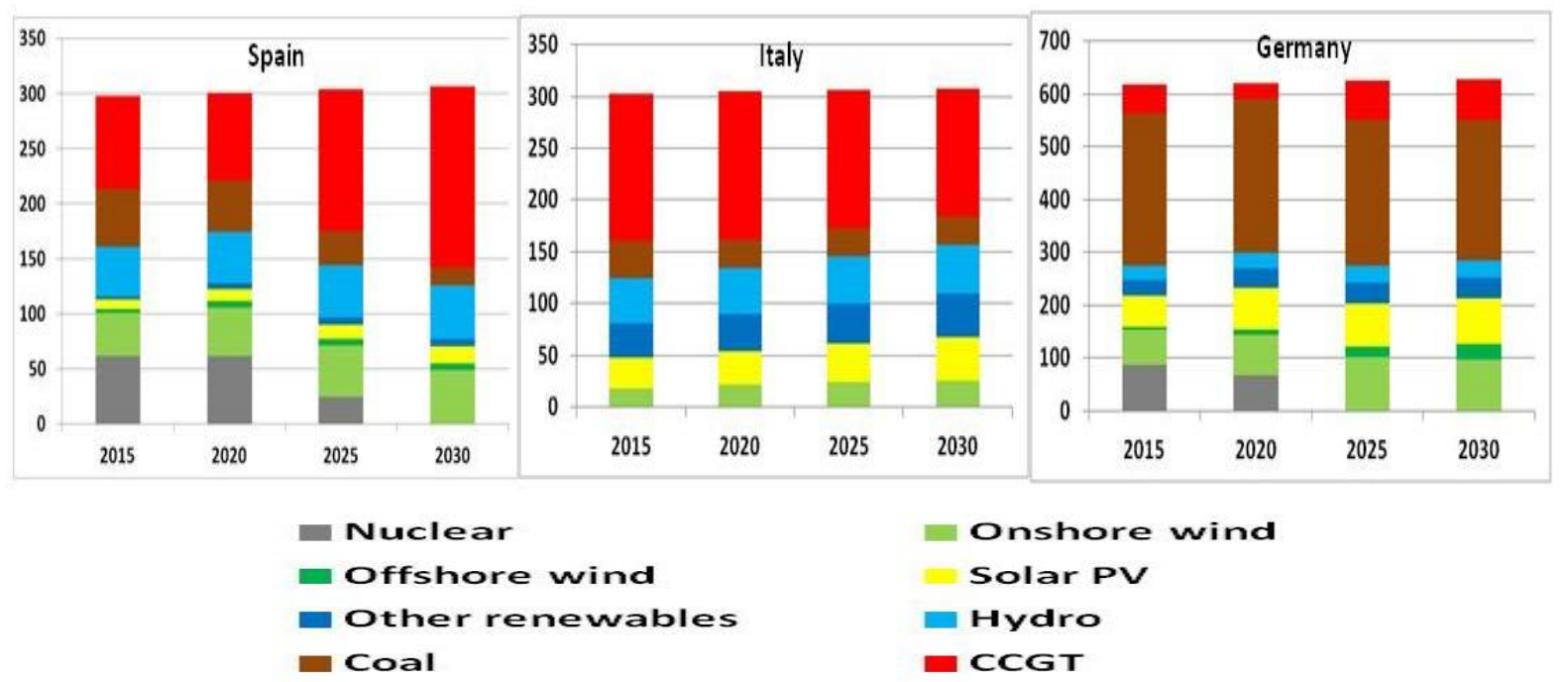

Source: 2010: IEA (2013e); scenario 2015-2030: Author's assumptions

- Spain

Gas generation is and will continue to be a key tool in balancing the system and a 'buffer' against the changing wind generation profile as wind speed fluctuates. Periods of peak demand and tight supply for gas are to be expected, but CCGTs could also provide baseload generation if/when coal and nuclear shares in the generation mix start to decline in the late 2010s and in the 2020s. Gas for power in Spain is less and less a factor of economic decision and more and more a factor of hydro and wind availability, but while the gas for power sector in Spain has been hit severely since 2009, it seems that a recovery can be envisaged in the 2020s when nuclear and coal plants are retired. The electricity produced from gas will then almost double thanks to the existence of a large existing fleet of CCGTs.

- Italy

The country has already shut down its nuclear power, therefore gas plants will not get any relief from this source. The coal fleet is also fairly limited, and the closure of old plants will not be the main driver of changes in gas for power. The evolution of renewable energy will drive the changes in the mix and as a result the need for gas. While gas remains the cornerstone of the Italian mix up to 2030, it will probably lose market share to growing renewable capacity, especially solar.

\section{- Germany}

There never has been an interesting story to tell in the gas for power sector in Germany, and it probably will not change much up to 2030. However, the rapid closure of the nuclear fleet by 2022 , the limited possibilities to get approval to build new coal plants since the early 2010s and the necessary slower pace of renewable development may leave some room for additional gas in the generation mix sometime in the 2020s, when the overcapacity is eroded by growing demand and plants retirements.

Additional details, included brief summaries of the other markets, are provided in Appendix 2. 

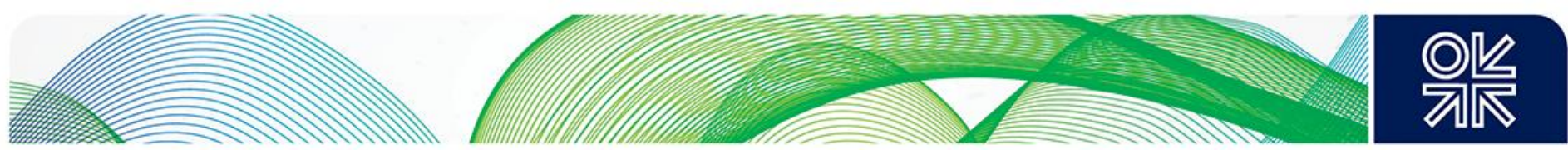

\subsection{A scenario of slow growth concentrated in a few markets}

The regional scenarios provide an interesting picture of the evolution of the gas industry, but these hide the specific characteristics and essential complexities of the national markets that will drive individual gas demand trends in the 35 countries: economic factors such as recession or fuel prices, policies and regulations and natural factors such as temperatures will not have the same impacts in all the various countries around Europe. This was the starting point for trying to recreate a bottom up scenario for gas demand in Europe to the 2030 horizon.

\subsubsection{Slow recovery expected in the $2020 \mathrm{~s}$}

The objective was not to start with a preconceived idea of what gas demand should be or which targets (renewables, emissions, and efficiency) should be achieved and therefore constrain the model. The bottom-up scenario on the contrary is based on how this author anticipates the key drivers observed in each sector of each market will evolve. While the region is on the road to the energy transition to a low carbon economy, only the consequences of existing or future policies or measures that can be reasonably expected are considered. Other assumptions involve primarily economic growth, market structure, the competitiveness of the European industry, the competitiveness of gas versus coal in the power sector, available generation capacity and the evolving mix. It is not easy to know which one(s) will be the most important and it has been a different story in each of the various markets. This method created annual scenarios for each sector in each market, which are presented in the appendices. This patchwork was then combined to create a regional scenario to the 2030 horizon [Figure 45].

Figure 45: Author's scenario for gas demand in Europe with 35 countries, up to 2030 (Bcm)

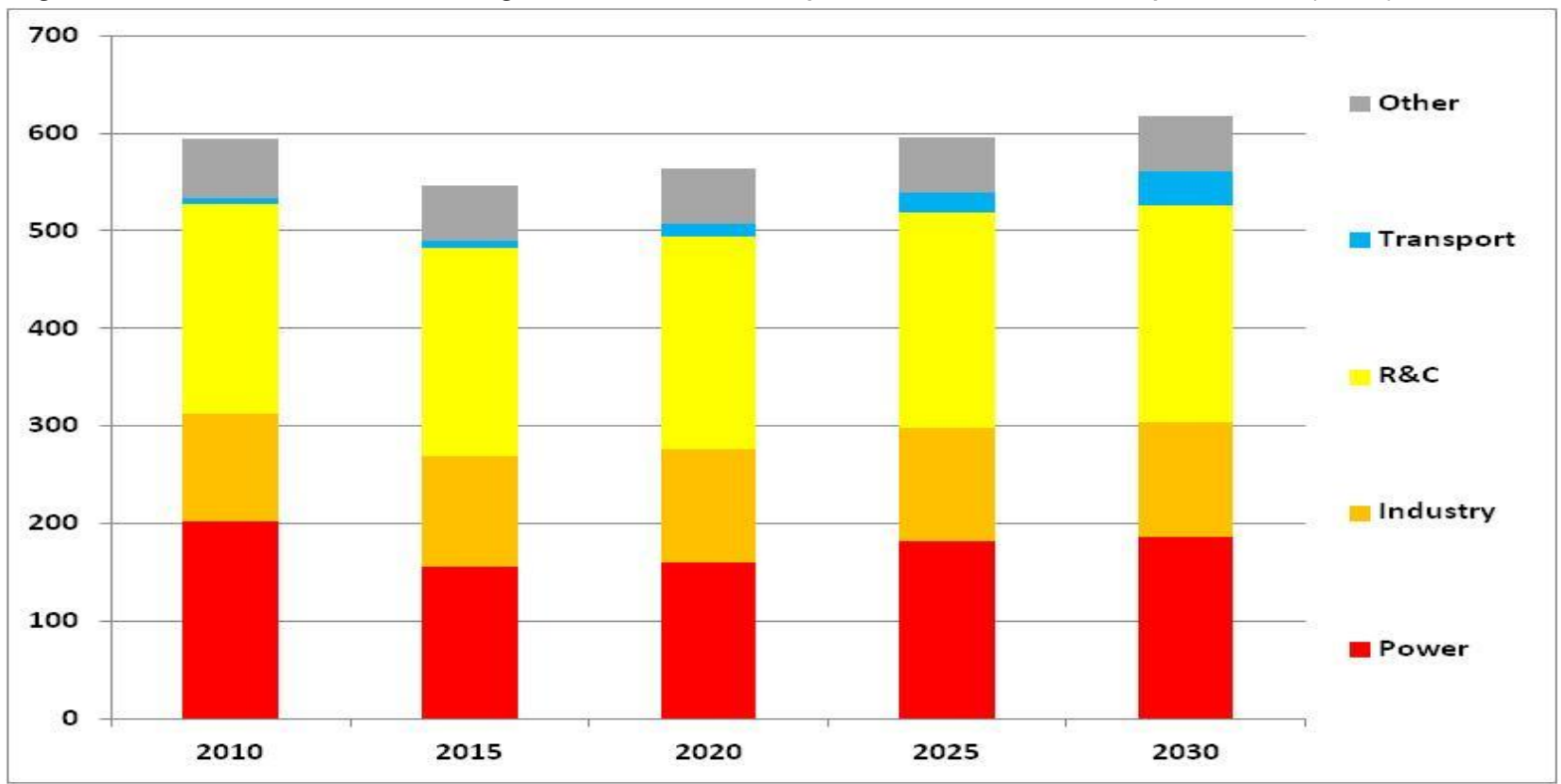

Source: 2010: IEA (2013a); scenario 2015-2030: Author's assumptions 

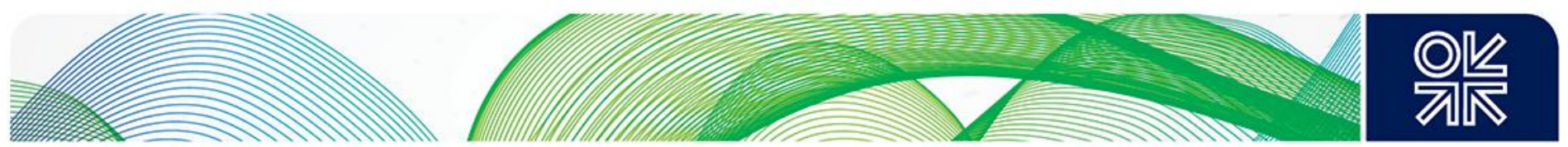

The most interesting result shown by these scenarios is that European gas demand does not seem to be doomed, however it does not seem to return to 2010 levels until after 2020/2025. It shows cautious optimism, but good news nonetheless with some limited but sustained growth in the 2020s.

The additional volumes of gas consumed between 2010 and 2030 amount to about $24 \mathrm{Bcm}$ compared to the 2010 level, representing an increase of about $0.19 \%$ per year on average $(-0.5 \%$ in $2010-2020$ and $0.9 \%$ in 2020-2030). This difference in time is partly explained by the power sector which provides some growth post 2020 after declining steadily in the 2010s and by growth expected in the transport sector also post 2020. It is important to note that this pessimistic result reflects the decline that has already happened in 2010-2013 (about $58 \mathrm{Bcm}$ ). As a result, our scenario is more optimistic if the period considered is 2013-2030 with $88 \mathrm{Bcm}$ of additional gas demand in 35 countries in Europe compared to the 2013 level.

\subsubsection{The power and the transport sector as the key drivers}

Our bottom up approach gave a surprising result for both the residential and commercial and the industrial sectors which keep the same shares in total gas consumption in 2010 and in 2030 [Figure 46]. Declines in gas volumes consumed in the residential and commercial sector in the mature markets of North West Europe (except France) and Italy are compensated by growth in Southern Europe and more particularly Turkey. The same result was replicated in the industrial sector, where the major west European markets register a decline which is more than surpassed by the growth in Turkey alone. The other markets show small variations, positive or negative as detailed in Appendix 2.

Figure 46: Author's scenario: share by sectors in 2010 and in 2030 in Europe with 35 countries,(\%)

2010

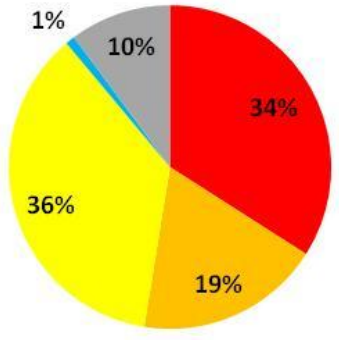

2030

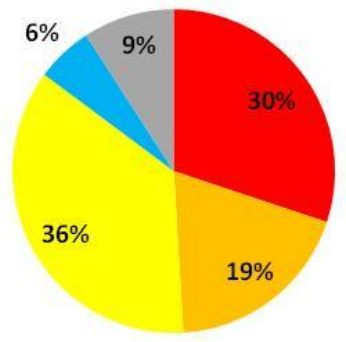

Source: 2010: IEA (2013a); scenario 2030: Author's assumptions

In general, the non-power sectors (the industrial sector, the residential and commercial sector but also the transport sector) are rarely the centre of attention. However, one rising sector post 2020 appears to be the transport sector [Figure 47] specifically in a few markets (Italy, Germany, France, Spain, Switzerland and Turkey), although significant growth will only happen if strong political support starts/continues. This sector will add about $30 \mathrm{Bcm}$ between 2010 and 2030 in this scenario but still represents only about $5.6 \%$ of total demand at the end of the period, much smaller than the major sectors. 
Figure 47: Author's scenario for natural gas demand in the transport sector in Europe with 35 countries, 2010-2030, evolution by country (Bcm)

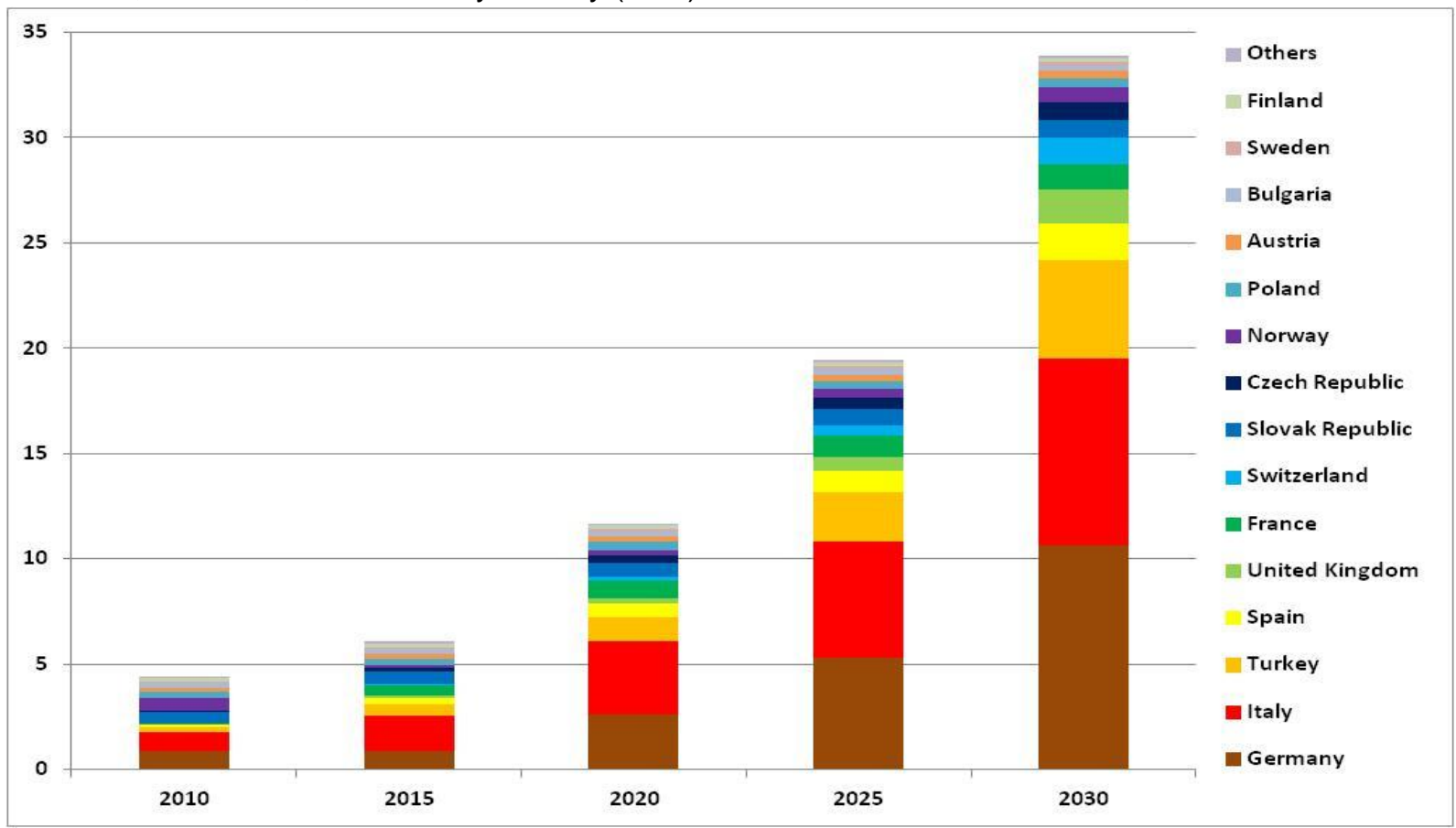

Source: 2010: IEA (2013a); scenario 2015-2030: Author's assumptions

The power sector is also part of the growth story. However, the expansion of renewables and the general overcapacity created will continue to push gas-fired plants out of the merit order for most of the 2010s even if the situation starts to improve in some markets (see Appendix 2). The impacts of the LCPD/IED and nuclear phase out will start to make a difference at the regional level for gas in the power sector in the 2020s, as seen in Figure 48. Gas used for power diminishes by $2.3 \%$ /year on average in $2010-2020$ but grows by $1.5 \%$ in $2020-2030$ when much nuclear capacity gets retired and coal starts to decline in the mix.

The major markets for gas in the power sector remain the same: Spain, the UK, Italy, Turkey, Germany, France, Belgium and the Netherlands $(80.8 \%$ of the gas consumed in $2010,81.7 \%$ in 2030). What happens in these markets will influence the results at the regional level and special attention will need to be paid to the evolution of energy policies and environmental measures taken in these eight countries.

As surprising as it may sound, Spain is the country that registers the major growth in our scenario, while the UK also sees some volume increases in the power sector post 2015 (although it does not recover to 2010 levels). Belgium, France, Poland and Turkey also register an augmentation. If nuclear does not get developed in the 2020s in Turkey, the country would then account for the biggest increase if the gap gets -even partly- filled by gas-fired plants. Between 2010 and 2030, the sharpest decline happens in the Netherlands, Germany, Italy and the UK even if some of these countries actually register growth in the 2020s (it is not sufficient to compensate the slump of the early 2010s). 

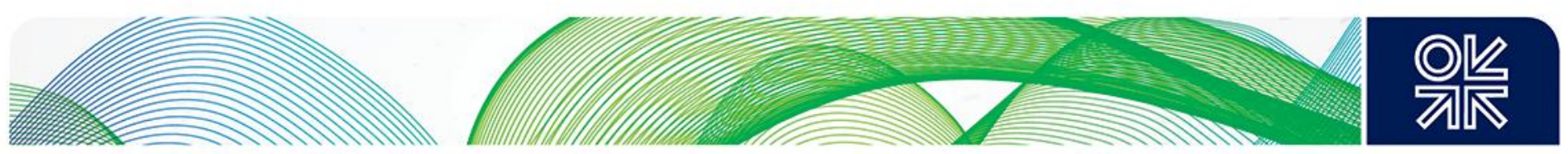

Figure 48: Author's scenario for natural gas demand in the power sector in Europe with 35 countries, 2010-2030, evolution by country (Bcm)

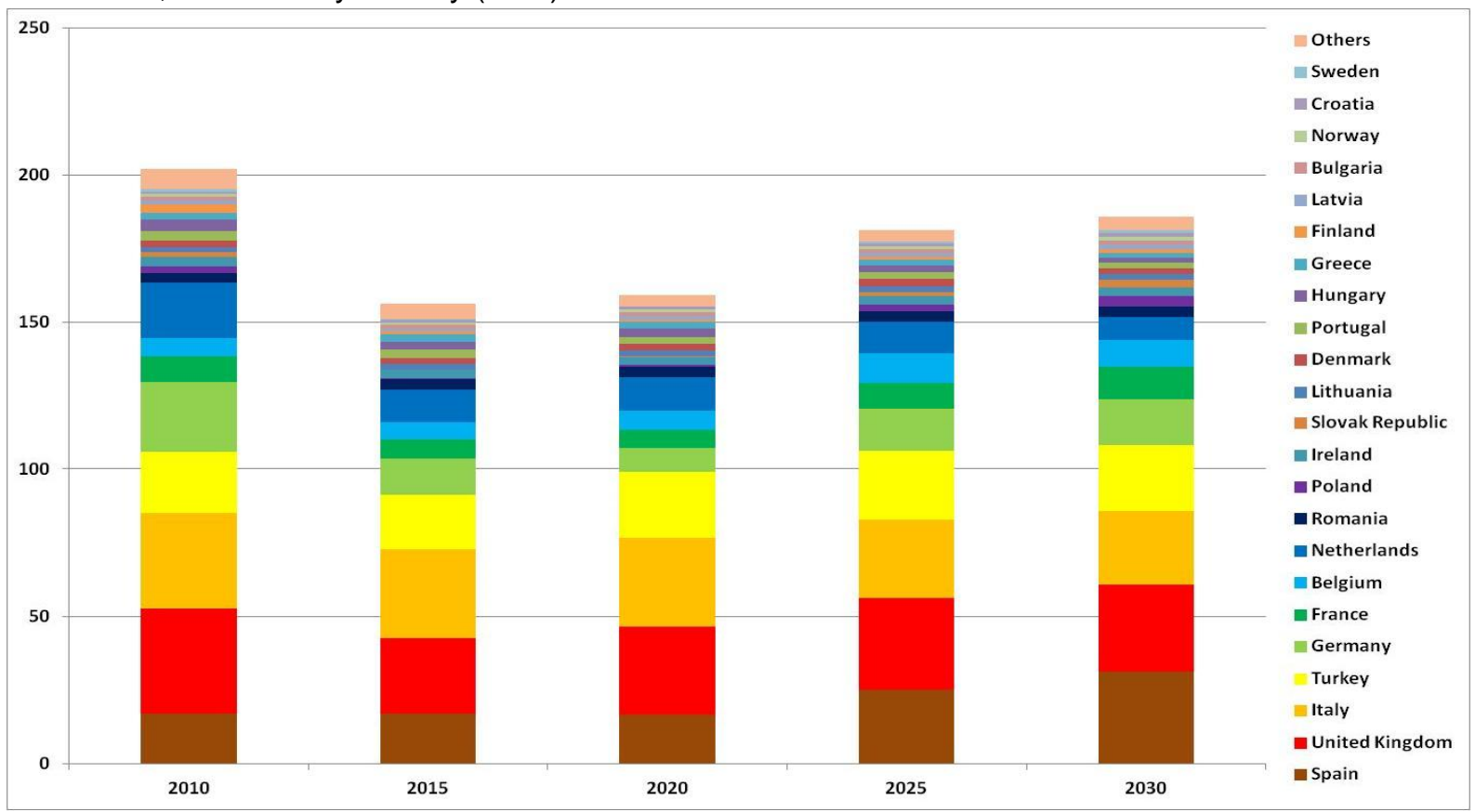

Source: 2010: IEA (2013a); scenario 2015-2030: Author's assumptions

\subsubsection{The major markets keep their market share}

The representation of natural gas demand (all sectors) by country in 2010 and in 2030 show important similarities as the major markets in 2010 remain the main consumers in 2030 [Figure 49].

Figure 49: Author's scenario for natural gas demand in 2010-2030, by country (Bcm)

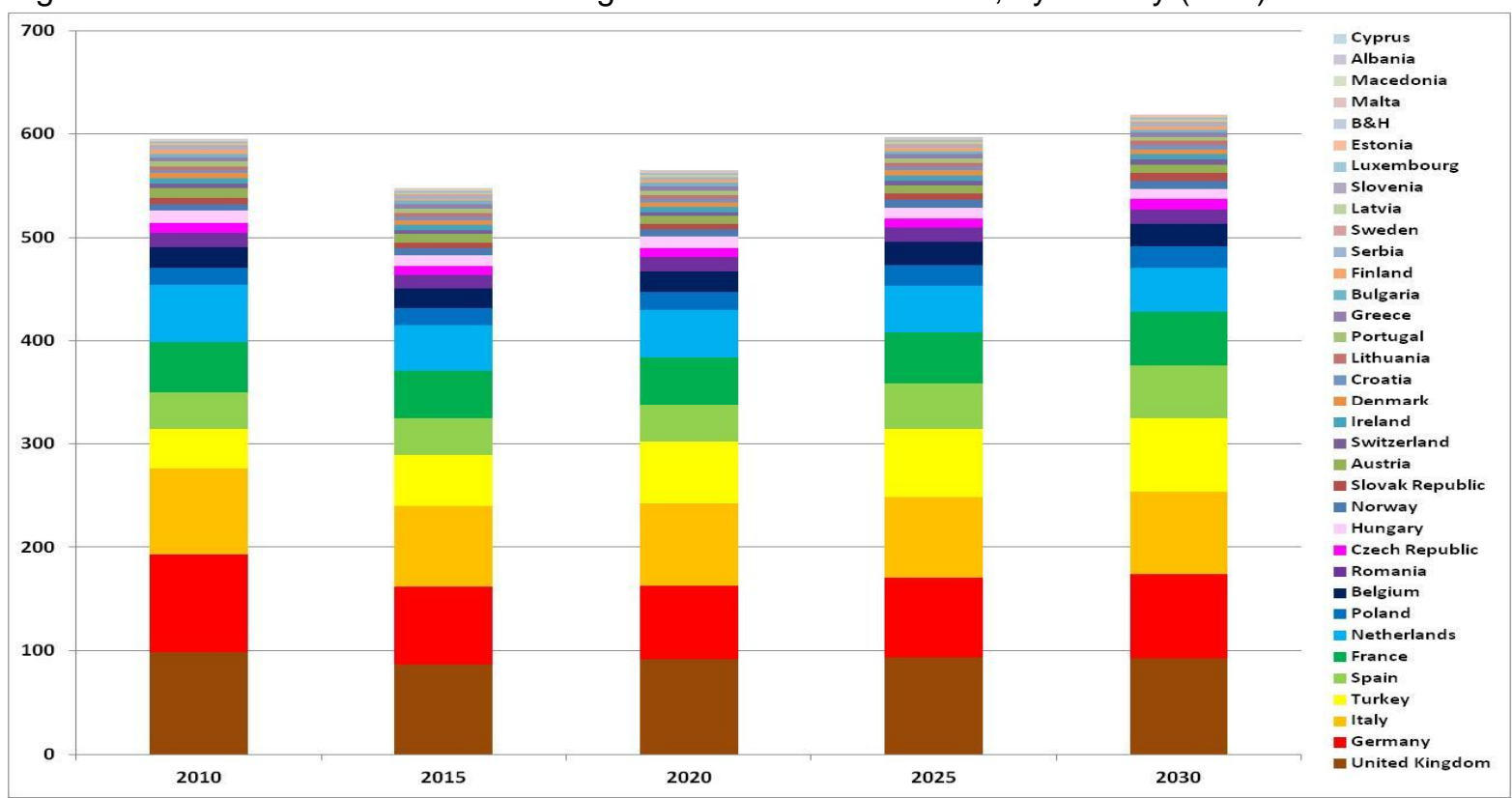

Source: 2010: IEA (2013a); scenario 2015-2030: Author's assumptions 

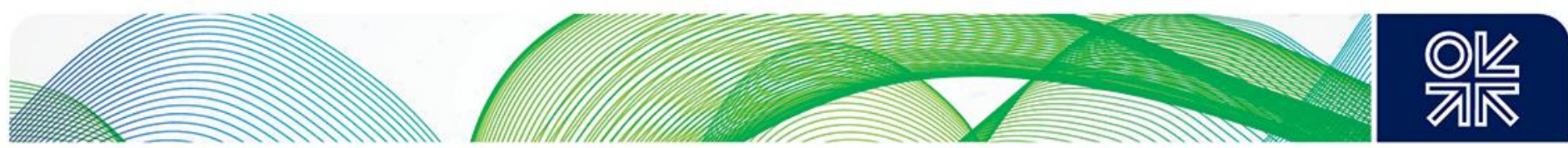

The first three major markets remain the UK, Germany and Italy although they all lose market shares in the period considered. This loss is almost complexly compensated by the growth of gas demand in Turkey, which becomes the fourth major consumer in 2030. The Netherlands becomes the seventh market after Spain and France. The seven biggest countries continue to account for more than three quarters of the total gas consumed in 35 European countries in 2030 [Figure 50].

Figure 50: Author's scenario: share per country for natural gas demand in 2010- 2030 (\%)

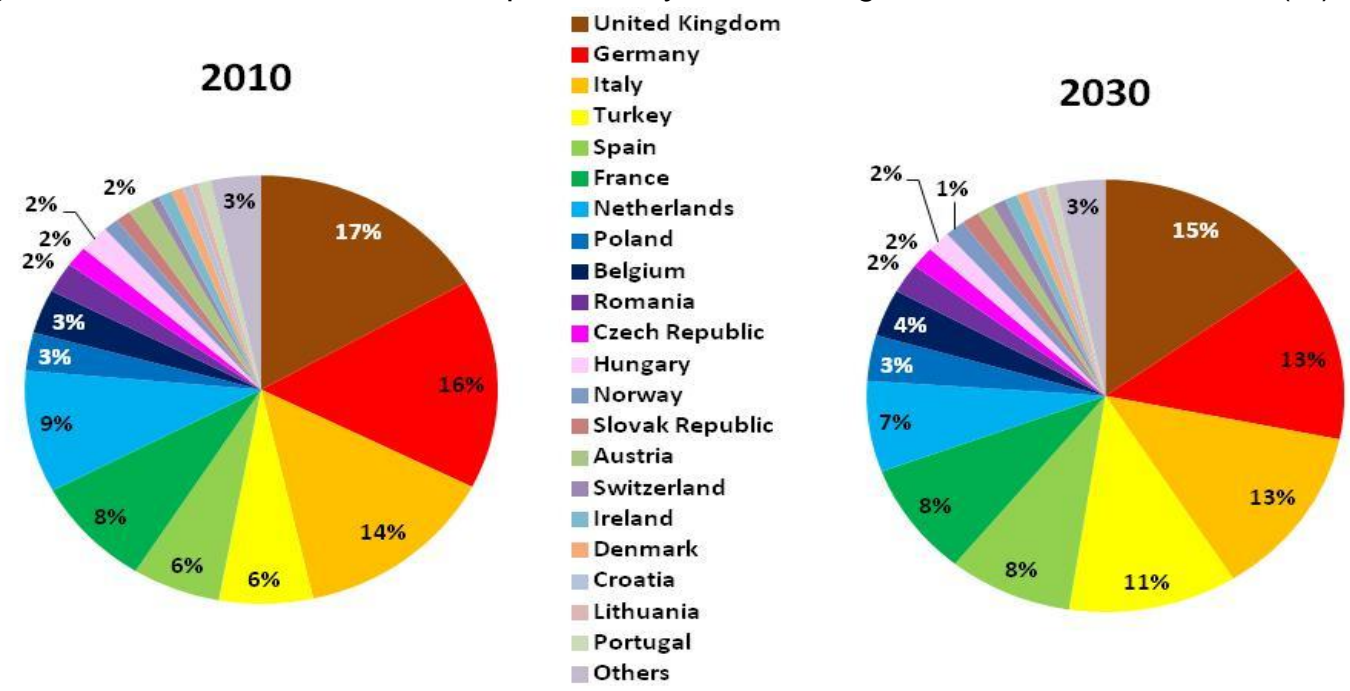

Source: 2010: IEA (2013a); scenario 2030: Author's assumptions

However, some differences exist in the net evolution of each sector of the major markets in the period considered as seen in Figure 51. It must be stressed that some of the decline shown in this figure may have already happened between 2010 and 2013, such as in the Netherlands power sector for instance as seen later in Appendix 2. If we look at the period 2010-2030 as a whole, then gas demand in Germany, the UK, Italy and the Netherlands will decline mostly due to the power sector where gasfired plants will not be competitive with other plant (coal, nuclear and/or renewables depending on the market) and/or imports from neighbouring countries. In these four markets, all the sectors register a decline or a stagnation apart from the transport sector which shows the only potential for growth apart from the Netherlands. Turkey, France and Spain will consume additional volumes of gas in all sectors apart from the industrial but with major differences. Growth is focused in the non-power sectors in Turkey, especially residential and commercial but also the industrial sector, while gas for power does not grow due to the development (and strong political commitments) to other types of generation coal, renewables or even nuclear. In Spain, the shutdown of several GW of coal plants and the phasing out of nuclear will leave some room for the fairly new CCGTs in the generation mix. Growth is more balanced in France, which will need additional gas-fired plants in its mix especially to meet peak demand in winter but also is expected to continue the development of gas in the residential and commercial sector. A more detailed picture of this author's assumptions for the national markets on key drivers, evolution of the generation mix and scenario for additional gas demand up to 2030 is provided for the 35 countries in Appendix 2. 
Figure 51: Author's scenario, natural gas demand changes by sector in selected countries, 2010 to $2030(\mathrm{Bcm})$

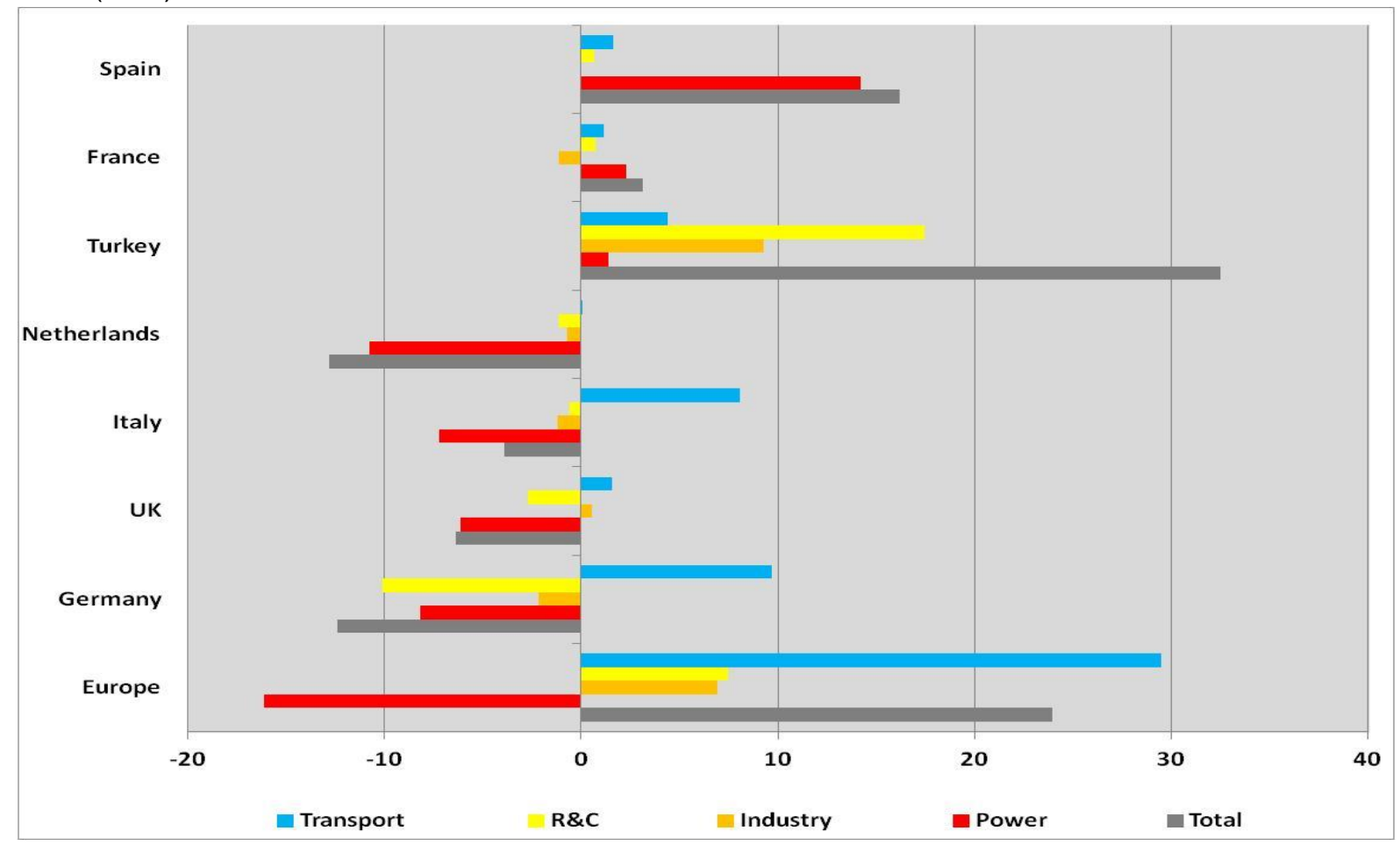

Source: Author's assumptions

So what does this mean in terms of additional imports? While indigenous production has been used to cover most of Europe's gas needs, demand has risen faster than production. Indigenous production has been in decline since early $2000 \mathrm{~s}$, but still supplied $52.2 \%$ of the gas requirements in OECD Europe in 2012 [Figure 52].

Figure 52: Gas production by country vs demand in OECD Europe, 1971 -2012 (MMcm)

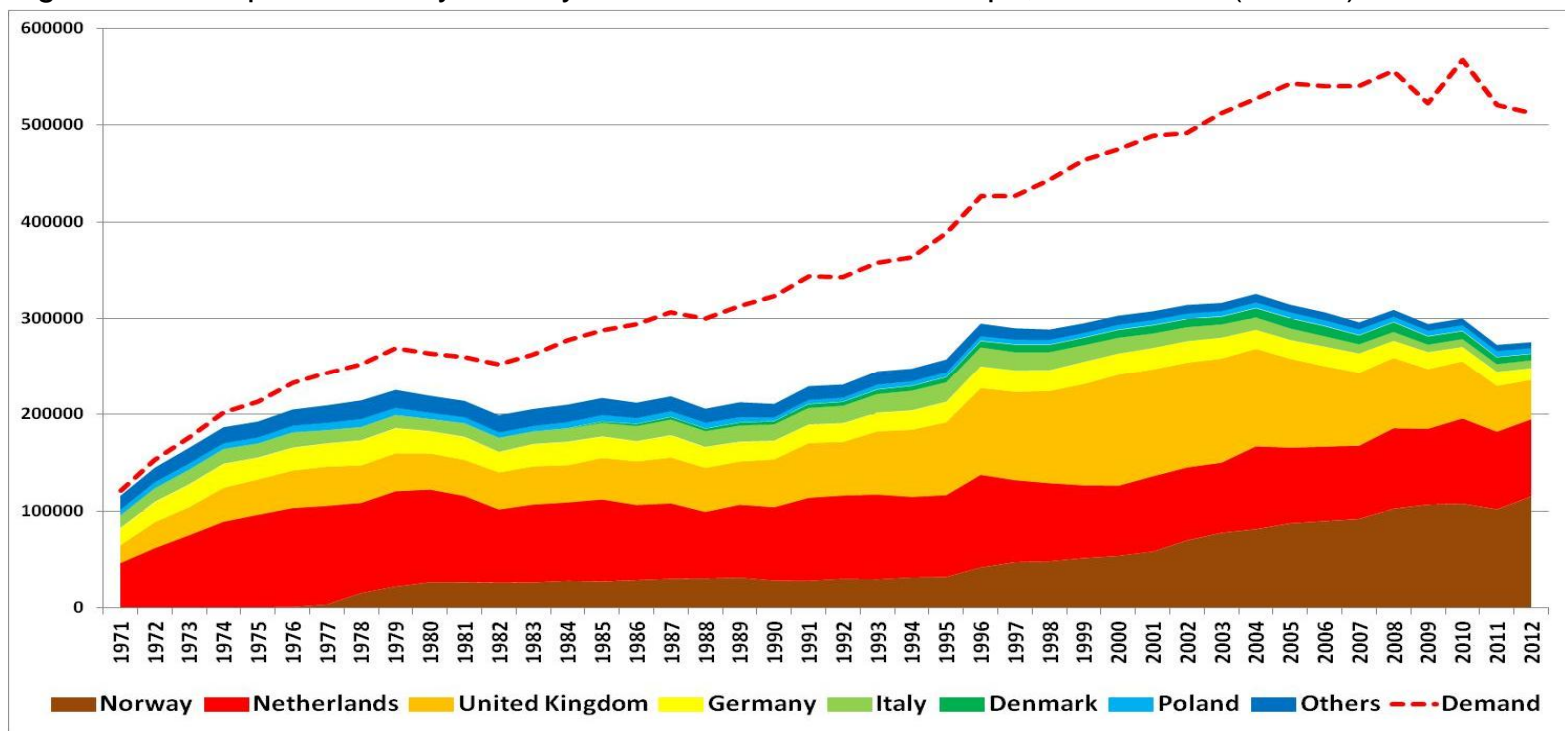

Source: IEA (annual data_a) 
Production has started to decrease everywhere, apart from Norway. Prospects for a substantial increase in output are limited in the period considered in this paper. Even in Norway, the IEA expects a slow decline post $2020 .{ }^{98}$ As a result, import dependency will continue to rise even in a scenario of slow gas demand growth.

There is no lack of import capacity, especially with new pipelines and LNG terminals being planned, even if actual gas volumes exported to Europe will depend on several interlinked factors such as new LNG supply from Australia, East Africa, Russia, US and Canada, and Asian demand. In 2012, the contracted supply was still higher than the level of demand by about $85 \mathrm{Bcm}$ in Europe with 35 countries. However, additional gas will need to be secured by the end of the 2010 s rising to about 50 Bcm by 2020 according to this author's estimates.

\footnotetext{
${ }^{98}$ Production was $114 \mathrm{Bcm}$ in 2012 (IEA - 2013a). The IEA expects an increase to $121 \mathrm{Bcm}$ by 2020, but then a decline to 115 Bcm by 2030 (IEA, WEO 2013, p.109).
} 


\section{Conclusions}

Natural gas demand in 35 countries in Europe fell from 586 Bcm in 2008 to just over 528 Bcm in 2013 from early estimates and shows little sign of recovery. The situation in the seven major markets is even worse with gas demand still 5-26\% below 2008 levels apart from in Turkey. While the economic situation, which has been crippling energy demand since 2009, is showing signs of recovery for the 2010s, the future of gas demand in the region is uncertain. The highest growth of gas consumption in the 2000s happened in the power sector, but this sector has been the main driver of decline since 2011 due to a combination of factors such as flat power demand, rising share of renewables in the generation mix and an unfavourable coal-gas competition which has put gas-fired plants at a disadvantage in the merit order. The power sector is no longer synonym of certain additional gas demand as previously thought in the scenarios designed in the 2000 s, and in a majority of countries, it will not be.

A large share of the renewables in the energy mix needs to be seen as a longer term enduring change even with the revision of support schemes for renewable energy currently happening across Europe due to binding 2020 targets. The proposed 2030 target approach will increase the importance of national policies, in particular in relation to the development of natural gas in the region, but the ongoing trend means that if the gas industry wants its presence in the power sector to endure, it will need to adapt to new market fundamentals. The more renewables, the less the annual average load factor of thermal generation, especially if electricity demand growth does not pick up again rapidly. Reduced operating hours and an increasing number of plant start-ups and shut-downs in order to balance renewable energy supply is something new, but power generators with gas-fired capacity will need to adapt to the new role of gas in power generation and create a new business model.

Gas demand growth in the power sector will only happen if (much) more competitive gas prices can help it compete with coal as the place of nuclear and renewables in the merit order is not affected by changes in fuel prices. The relationship between coal and gas prices could be reversed, even if this possibility is not envisaged in this paper in the timeframe considered (2030). Higher $\mathrm{CO}_{2}$ prices are not expected this side of 2020 but the new system proposed in January 2014 could trigger double digit prices sometime in the 2020s, but with still a high degree of uncertainty. As coal plants are retired due to the LCPD/IED/EU ETS, this relationship becomes less and less relevant in most countries in the 2020s and gas generation becomes more and more a factor of renewable (including hydropower) availability and the retirement/building of new nuclear plants. About half of the existing baseload capacity will face closure in our timeframe (nuclear phase out, impacts of the LCPD/IED on coal plants, old plants needing to be shut down). Much will depend on how the gap between power demand and renewables is filled (and how big the gap is), but this is a possible sign of improvement for gas in the power generation sector, which could even start in the mid-2010s.

Our scenarios show about $24 \mathrm{Bcm}$ of additional volumes of gas consumed above 2010 levels between 2010 and 2030, as demand falls from $594 \mathrm{Bcm}$ in 2010 to $564 \mathrm{Bcm}$ in 2020 and then rises to $618 \mathrm{Bcm}$ in 2030. This represents an increase of about $0.19 \% /$ year on average $(-0.5 \%$ in $2010-2020$ and $0.9 \%$ in 2020-2030). Only $24 \mathrm{Bcm}$ in two decades may seem very pessimistic, but one must not forget the sharp decline that already happened in 2010-2013. If we look at the data during this period, then our scenario show an additional $88 \mathrm{Bcm}$ between 2013 and 2030 in Europe. The use of gas in the power generation sector is part of the growth story: demand diminishes by $2.3 \%$ per year on average in 2010-2020 - but it must be stressed that most of the decline expected in the 2010s has 
already happened between 2010 and 2013, and demand grows by $1.5 \%$ in 2020-2030 when much nuclear capacity gets retired and coal starts to decline in the mix. While this sector will register some growth between 2015 and $2030(+30 \mathrm{Bcm})$, nonetheless, gas for power demand does not come back to 2010 levels $(202 \mathrm{Bcm})$ by $2030(186 \mathrm{Bcm})$. The second side of the growth story comes from the transport sector which is expected to add about $30 \mathrm{Bcm}$ between 2010 and 2030, although this will only happen if strong political support starts/continues. This is an important growth, but even in this scenario, this sector still represents only about $5.6 \%$ of total demand at the end of the period, much smaller than the other three major sectors. The industrial and the residential and commercial remain fairly flat until 2030. These regional results hide wide differences at the national level among the 35 countries looked at in this study.

The scenarios represent this author's views at the time of writing the paper (late 2013/early 2014). They will need to be updated as policies/prices/generation mix evolve, but the main conclusion of this research is that the outlook for the gas industry includes the potential for modest future growth from 2013 levels but it is unlikely to see a return to 1990s / 2000s growth rates. It will not be an easy road, and the European gas industry will need to adapt to the new energy mix and market fundamentals if it is to survive. With these caveats the future is likely to be one of slow growth (as in any mature markets), and the story will be very different in each national market. 


\section{Appendix 1: Natural gas demand in Europe}

Table 3: Natural gas consumption (observed) in 35 European countries in 2008 and 2012/2013, Bcm

\begin{tabular}{|c|c|c|c|c|c|c|c|}
\hline & $\begin{array}{c}\text { Consumption } \\
\text { in } 2008 \text {, in } \\
\mathrm{bcm}\end{array}$ & $\begin{array}{c}\text { Consumption } \\
\text { in 2012, in } \\
\text { bcm }\end{array}$ & $\begin{array}{c}\text { Consumption } \\
\text { in } 2013^{*} \text {, in } \\
\text { bcm }\end{array}$ & $\begin{array}{c}\text { Difference } \\
\text { between } \\
\text { consmption in } \\
2008 \text { and } \\
2012 \text {, in \% }\end{array}$ & $\begin{array}{c}\text { Difference } \\
\text { between } \\
\text { consmption in } \\
2008 \text { and } \\
2013 \text {, in \% }\end{array}$ & $\begin{array}{c}\text { Share of total } \\
\text { European } \\
\text { consumption } \\
\text { in } 2013 \text {, in } \%\end{array}$ & $\begin{array}{c}\text { Cumulated } \\
\text { share of total } \\
\text { European } \\
\text { consumption } \\
\text { in 2013, in \% }\end{array}$ \\
\hline 1 Germany & \begin{tabular}{c|}
92.3 \\
\end{tabular} & 87.2 & \begin{tabular}{l|l|}
88.8 \\
\end{tabular} & -5.5 & \begin{tabular}{|c|}
-3.8 \\
\end{tabular} & 16.8 & 16.8 \\
\hline \begin{tabular}{l|l}
2 & United Kingdom
\end{tabular} & \begin{tabular}{c|c}
99.1 \\
\end{tabular} & 78.1 & 77.3 & $-21,2$ & -22.0 & 14.6 & 31.4 \\
\hline 3 |ltaly & 84.9 & 74.9 & 70.0 & -11.8 & $-17,6$ & 13.3 & 44.7 \\
\hline 4 Netherlands & 48.5 & 46.0 & 46.5 & -5.2 & $-4,1$ & 8.8 & 53.5 \\
\hline 5 Turkey & 36.6 & 45.2 & 45.6 & 23.5 & 24.6 & 8.6 & 62.1 \\
\hline \begin{tabular}{l|l}
6 & France \\
\end{tabular} & 46.1 & 44.1 & 43.3 & -4.3 & -6.1 & 8.2 & 70.3 \\
\hline \begin{tabular}{l|l} 
Spain \\
\end{tabular} & 40.3 & 32.5 & 29.9 & $-19,4$ & -25.8 & 5.7 & 76.0 \\
\hline 8 Poland & \begin{tabular}{c|c|}
16.3 \\
\end{tabular} & 18.1 & 18.2 & 11.0 & 11.7 & 3.4 & 79.4 \\
\hline \begin{tabular}{|l|l}
9 Belgium \\
\end{tabular} & 17.5 & 17.9 & 17.7 & 2.3 & 1.1 & 3.4 & 82.8 \\
\hline \begin{tabular}{l|l}
10 & Romania \\
\end{tabular} & 16.0 & 13.6 & 12.5 & -15.0 & -21.9 & 2.4 & 85.2 \\
\hline \begin{tabular}{l|l}
11 & Hungary \\
\end{tabular} & 13.1 & 10.2 & 9.3 & -22.1 & -29.0 & 1.8 & 86.9 \\
\hline 12 Austria & 9.4 & 9.0 & 8.5 & -4.3 & -9.6 & 1.6 & 88.5 \\
\hline \begin{tabular}{|l|l}
13 & Czech Republic \\
\end{tabular} & 8.7 & 8.3 & 8.4 & -4.6 & -3.4 & 1.6 & 90.1 \\
\hline \begin{tabular}{l|l|}
14 Norway \\
\end{tabular} & 5.8 & 6.2 & 6.3 & 6.9 & 8.6 & 1.2 & 91.3 \\
\hline \begin{tabular}{l|l}
15 & Slovakia \\
\end{tabular} & 6.3 & 5.3 & 5.8 & -15.9 & -7.9 & 1.1 & 92.4 \\
\hline 16 |reland & 5.2 & 4.7 & 4.7 & -9.6 & -9.6 & 0.9 & 93.3 \\
\hline \begin{tabular}{l|l|}
17 & Portugal \\
\end{tabular} & 4.7 & 4.6 & 4.3 & -2.1 & -8.5 & 0.8 & 94.1 \\
\hline 18 Greece & 4.2 & 4.4 & 3.8 & 4.8 & -9.5 & 0.7 & 94.8 \\
\hline \begin{tabular}{l|l}
19 & Denmark \\
\end{tabular} & 4.6 & 3.9 & 3.7 & -15.2 & -19.6 & 0.7 & 96.2 \\
\hline \begin{tabular}{|l|l|}
20 & Switzerland \\
\end{tabular} & 3.4 & 3.6 & 3.7 & 5.9 & 8.8 & 0.7 & 96.9 \\
\hline 21 Finland & 4.7 & 3.7 & 3.5 & -21.3 & -25.5 & 0.7 & 95.5 \\
\hline \begin{tabular}{l|l|}
22 & Croatia \\
\end{tabular} & 3.2 & 3.0 & 3.0 & -6.3 & -6.3 & 0.6 & 98.0 \\
\hline $23 \mid$ Lithuania & 3.2 & 3.4 & 2.8 & 6.3 & -12.5 & 0.5 & 97.4 \\
\hline \begin{tabular}{l|l}
24 & Bulgaria \\
\end{tabular} & 3.5 & 2.7 & 2.7 & -22.9 & -22.9 & 0.5 & 98.5 \\
\hline \begin{tabular}{l|l|}
25 & Serbia \\
\end{tabular} & 2.5 & 2.4 & 2.4 & -4.0 & -4.0 & 0.5 & 99.0 \\
\hline \begin{tabular}{l|l|}
26 & Latvia \\
\end{tabular} & 1.7 & 1.5 & 1.5 & -11.8 & -11.8 & 0.3 & 99.2 \\
\hline \begin{tabular}{l|l}
27 & Sweden \\
\end{tabular} & 0.8 & 1.1 & 1.1 & 37.5 & 37.5 & 0.2 & 99.6 \\
\hline \begin{tabular}{|l|l|}
28 & Luxembourg \\
\end{tabular} & 1.3 & 1.2 & 1.0 & -7.7 & -23.1 & 0.2 & 99.4 \\
\hline \begin{tabular}{l|l}
29 & Slovenia \\
\end{tabular} & 1.1 & 0.9 & 0.8 & -18.2 & -27.3 & 0.2 & 99.8 \\
\hline \begin{tabular}{l|l}
30 Estonia \\
\end{tabular} & 0.9 & 0.7 & 0.7 & -22.2 & -22.2 & 0.1 & 99.9 \\
\hline \begin{tabular}{l|l|}
31 & Bosnia \& Herzegovina \\
\end{tabular} & 0.4 & 0.3 & 0.3 & -25.0 & -25.0 & 0.1 & 100.0 \\
\hline \begin{tabular}{l|l|}
32 & Macedonia \\
\end{tabular} & 0.1 & 0.1 & 0.1 & 0.0 & 0.0 & 0.0 & 100.0 \\
\hline 33|Albania & 0.1 & 0.0 & 0.0 & $\mathrm{n} / \mathrm{a}$ & $\mathrm{n} / \mathrm{a}$ & 0.0 & 100.0 \\
\hline \begin{tabular}{|l|l|l|}
34 & Cyprus \\
\end{tabular} & 0.0 & 0.0 & 0.0 & $n / a$ & $n / a$ & 0.0 & 100.0 \\
\hline \begin{tabular}{|l|l|}
35 & Malta \\
\end{tabular} & 0.0 & 0.0 & 0.0 & $n / a$ & $n / a$ & 0.0 & 100.0 \\
\hline TOTAL Europe, 35 countries & 586.5 & 538.8 & 528.2 & -8.1 & -9.9 & 100 & - \\
\hline
\end{tabular}

* 2013 are estimates

Source: IEA (2013a), Table 3, pp.II.8-9, IEA (Monthly data) and author's estimates 


\section{Appendix 2: General assumptions and national markets' specifics}

The purpose of this appendix is to provide additional details on individual European markets considered in this paper. Because we have used a bottom-up approached, we had to build scenarios for each sector in each country. The following pages provide a quick overview of the national markets with information on:

1. The energy background: TPES mix (focusing on fossil fuels and nuclear only), gas demand (total consumption and in the three main sectors - only: residential and commercial (R\&C), industrial and power) and the impacts of the economic crisis since 2008, and finally on the power sector including the mix and -where the data exists- assumptions on the use of gasfired plants.

2. Targets and assumptions used to build up the scenarios: GDP expectations taken from the IMF scenarios, a quick review of its energy policies and environmental targets that will impact gas consumption up to 2030, and finally a review of our scenario on the evolution of the generation mix (which in this context means the mix of indigenous power generation and does not take into account the level or fuel origins of imports).

3. Gas demand in 2010 and the scenario for 2015, 2020, 2025 and 2030 according to our assumptions. We have decided to focus on 5-year evolutions, however, in order to not misread the results, one must not forget the sharp decline in gas demand that already happened in 2010-2013 in most countries (see Appendix 1).

4. The scenarios represent this author's views at the time of writing the paper (late 2013/early 2014). They will need to be updated as policies/prices/generation mix evolve.

All the assumptions are informed judgements made by this author based on existing data, trends, policies or any other reliable information or reports available in the public domain. The following paragraphs provide some general statements and the subsequent pages look at some in greater details.

1. Assumptions on GDP growth have been made up to 2030 based on the average growth estimated by the IMF between 2010 and 2018.

2. Assumptions on fuel price competitiveness (coal, gas and $\mathrm{CO}_{2}$ ) have been made and applied to each country's specific generation mix and characteristics. In general, gas prices remain unattractive compared to coal prices for the majority of the period, albeit with a softening at the end of the 2010s due to lower gas prices [that makes gas more attractive] and an expected decline of $\mathrm{CO}_{2}$ prices as back-loaded emissions are put back in the system [that makes gas less attractive].

3. Assumptions on environmental targets / policies are based on existing policies and those that could be put in place during the period. The targets are used as an indication of where the country is aiming but they have not been replicated per se in the assumptions, as it already appears that some countries are likely to miss them.

4. Assumptions on power demand, industry growth, and population are based on historic trends and national data/projections when available.

5. It is difficult to get reliable and comprehensive data on available generation capacity. Assumptions on power plant capacities have been drawn from existing capacity, plants under construction, plants that have been opted out of the LCPD/IED when information is available, phasing out for nuclear or other agreements (plants closures due to national arrangements, 
age or commercial reasons). To calculate load factors for gas-fired plants in 2008 and 2012, assumptions have been mostly based on IEA and/or Eurelectric data.

Sixteen years up to 2030 is a long time, during which many things can happen, especially in terms of fuel prices and competitiveness. Events in energy - and gas - markets are moving rapidly. It is important for readers to remember that the writing of this paper was substantially completed by early 2014 with information available at the time. 

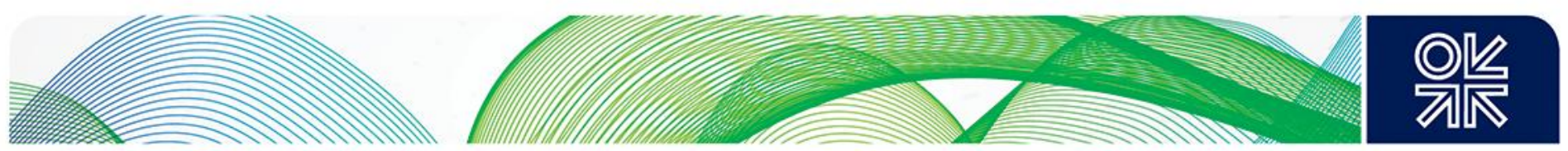

\section{Albania}

\section{Background}

Gas represented only about $0.55 \%$ of total TPES in 2011 , which was dominated by oil products and crude oil $(56 \%)$ followed by hydropower $(16 \%) .{ }^{99}$ The country was dependent on energy imports for about half of its needs, although it produced enough gas to cover its demand.

In 2012, gas demand was almost non-existent, even lower than in 2008 which culminated at $9 \mathrm{MMcm}$. In 2011 , more than $80 \%$ of the gas consumed was used in the power sector, especially in the 'other transformation' sector, which includes transfers, statistical differences, energy industry own use and losses, the rest of was consumed in the commercial sector. ${ }^{100}$

Power demand stood at 7.4 TWh in 2011, 21\% higher than 2008 levels. ${ }^{101}$ Gross electricity production represented only $56 \%$ of the country's needs. Albania has a long historical reliance on hydropower $\left(99 \%\right.$ of the electricity generation mix in 2011). ${ }^{102}$

\section{Targets and assumptions}

Albania has not been in recession since 2000, even if GDP growth has slowed since the economic crisis of 2009. According to the IMF world economic outlook of November 2013, expectations for growth remain between 1.5 and 2.5\%/year until the late 2010s [Figure 53].

Figure 53: GDP annual growth in Albania (\%), in constant prices, 2000-2018 (forecast from 2008)

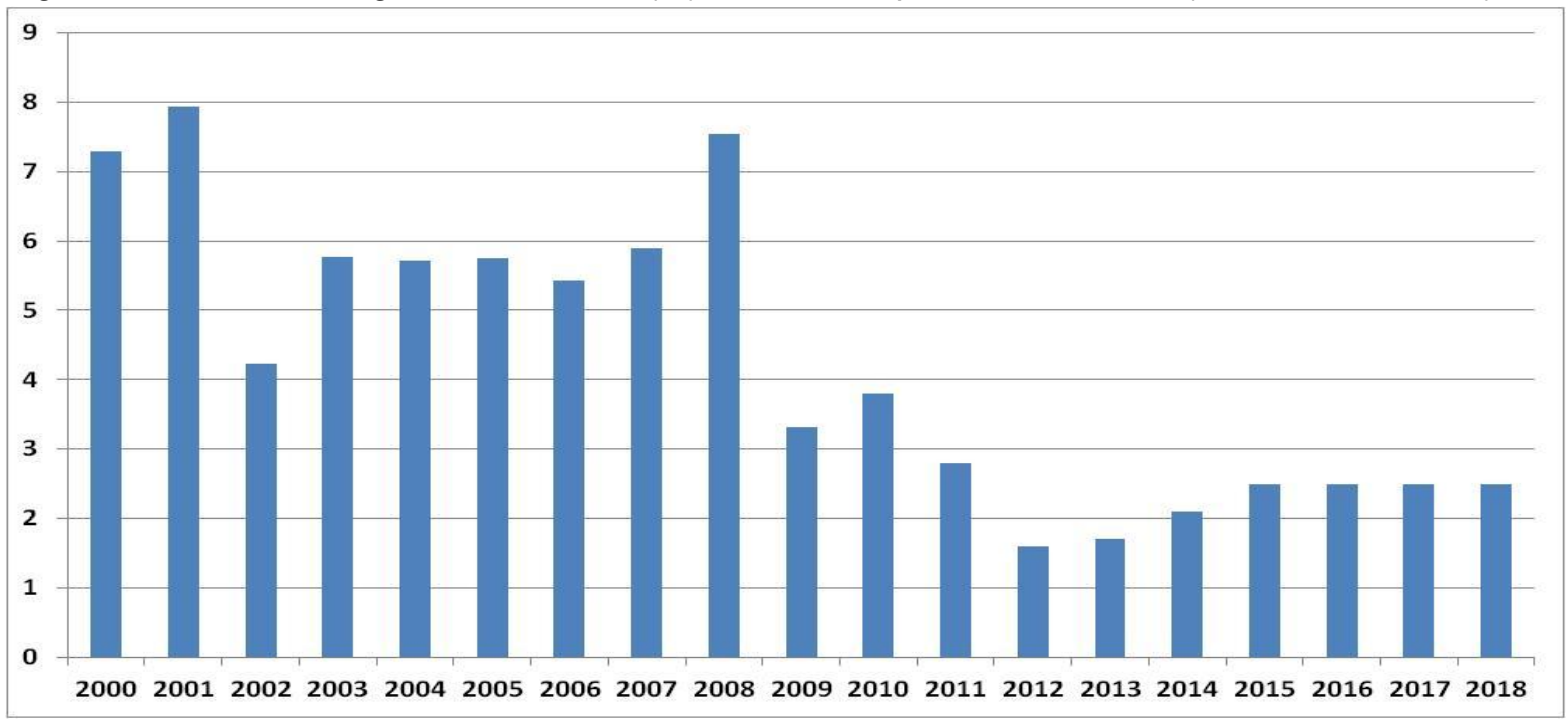

Source: IMF (2013)

Albania is not part of the European Union, nonetheless, its National Energy Efficiency Action Plan 2010-2018 is consistent with the EU goals on energy efficiency. By 2018, the targets of energy savings are $-22 \%$ in the residential sector, $-19 \%$ in services, $-25 \%$ in the industry, $-31 \%$ in transport

\footnotetext{
99 IEA (2013c), p.II.57

100 IEA (2013c), p.II.57

${ }^{101}$ IEA (2010b) and IEA (2013e), Table 1.1, p.III.6

102 IEA (2013e), Table 1.2, p.III.10
} 
and $-3 \%$ in agriculture compared to energy consumption in 2008. The National Energy Strategy published in 2003 also focused on security of supply and sustainable development of the economy. ${ }^{103}$

\section{Scenario}

Our scenarios are based on continued sustained growth for power demand up to 2030 and a generation mix to remain dominated by hydropower, despite the difficulty of meeting (rising) power demand from the industrial and residential and commercial sectors caused by the variable hydrological conditions. We do not expect gas-fired plants to be built, but rather an increase of energy import dependence to meet the country's needs. In our scenario, natural gas demand in Albania remains very small at about $15 \mathrm{MMcm}$ by 2030 .

\footnotetext{
${ }^{103}$ For more information, see http://www.iea.org/countries/non-membercountries/albania/
} 

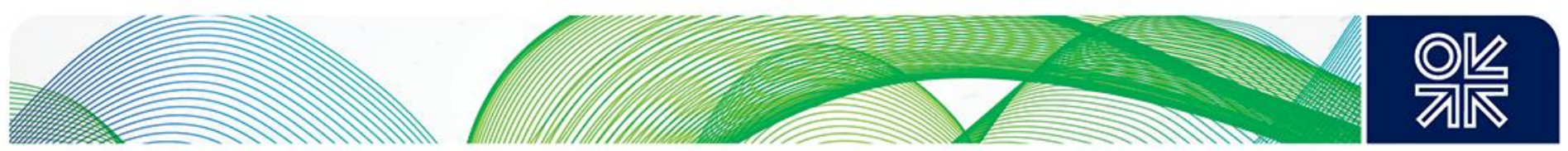

\section{Austria}

\section{Background}

In 2012, gas had the second largest share of the TPES at 22.5\%, well below oil at almost $35 \%$ and above nuclear and coal (both a 10\% share). The country is dependent on energy imports, including natural gas with indigenous production covering only about $21 \%$ of its gas needs. ${ }^{104}$

Total gas consumption dropped to about $9 \mathrm{Bcm}$ in 2012, which was about $4.3 \%$ below its 2008 precrisis level. The power sector was the largest consumer (about $34 \%$ of demand in 2011), before the industrial sector (28\%) and R\&C (26\%). Only the power sector has increased from pre-crisis levels (+9\% compared to 2008). ${ }^{105}$

Power demand was at $66.5 \mathrm{TWh}$ in 2011, 3.2\% above 2008 levels. Gross production fulfilled almost all the country's needs (99\%) and rose above 68 TWh in 2012. ${ }^{106}$ Austria has a very flexible and potentially variable generation mix which is dominated by hydropower with a $63 \%$ share in 2012 , followed by gas (14\%) and coal $(9 \%)$. Renewables (excluding hydro) represented only about $4 \%$ of the total. ${ }^{107}$

If the assumptions on available gas-fired capacity in 2008 and 2012, which are based on IEA and Eurelectric data, are correct, ${ }^{108}$ then the average load factor of the gas-fired power plants in 2012 was about $23 \%$, down from about $32 \%$ in 2008 (30\% in 2011).

\section{Targets and assumptions}

Apart from a decline in 2009, GDP growth is expected to remain positive in the 2010s albeit limited between 1 and 2\% annually according to the IMF November 2013 outlook [Figure 54].

Figure 54: GDP annual growth in Austria (\%), in constant prices, 2000-2018 (forecast from 2012)

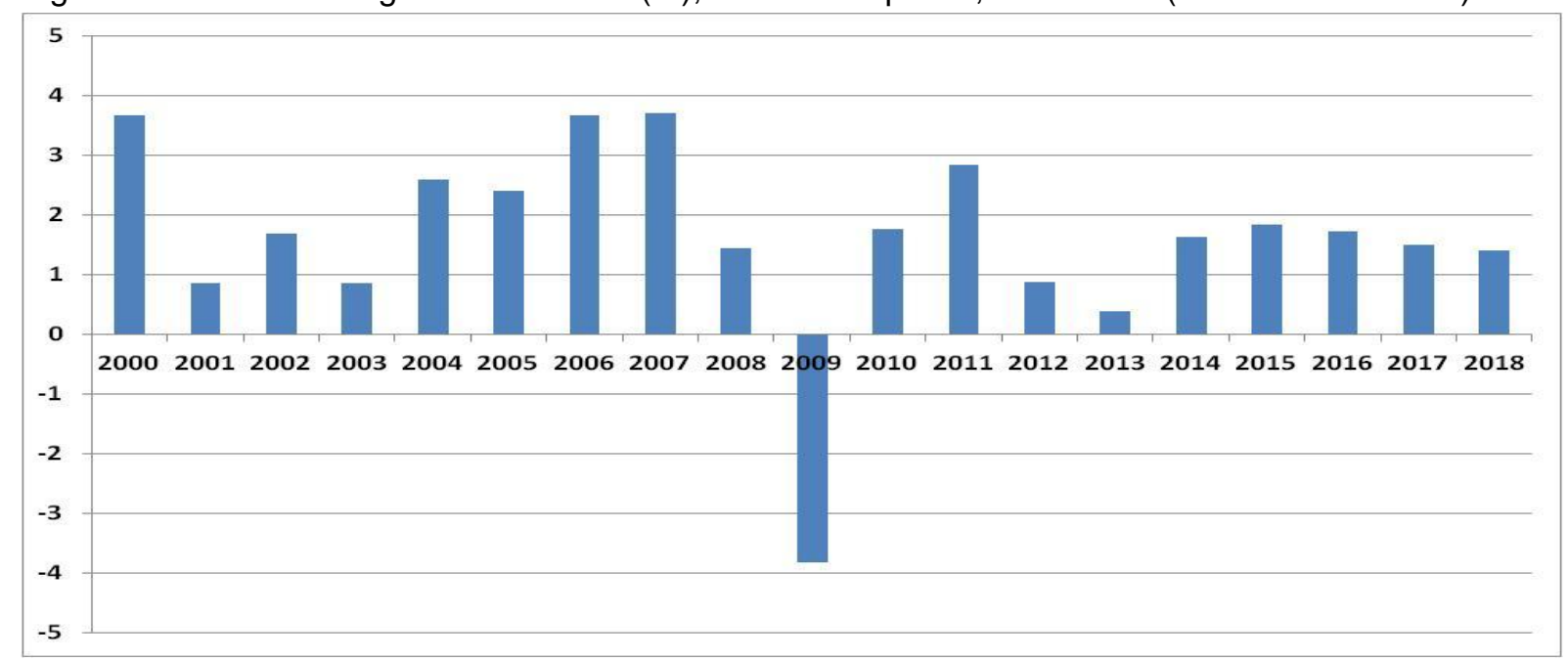

Source: IMF (2013)

\footnotetext{
${ }^{104}$ IEA (2013a), Country data, table 1

105 IEA (2010a) and IEA (2013a), Country data, table 3

${ }^{106}$ IEA (2010b) and IEA (2013e), Part III, tables 1.1 and 1.2

107 IEA (2013e), Part III, Country data, table 3

${ }^{108}$ IEA (2013e), Part III, table 2.12 and Eurelectric (2012), table 3.1.1.3.
} 

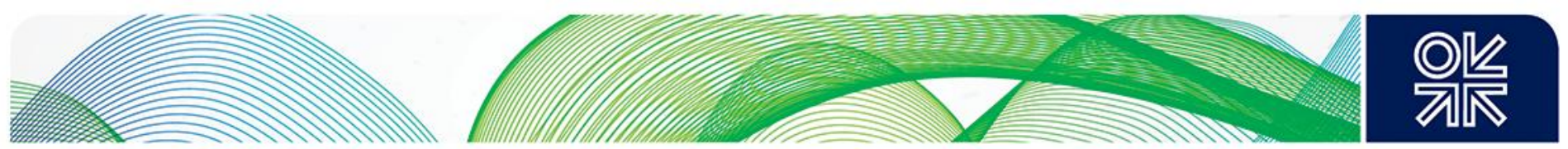

Austria's energy policy was outlined in The Climate Change Bill introduced in 2011. The target for renewable energy sources is to increase to $34 \%$ of gross final energy consumption by 2020 (in the 2005 base year this share was $24.4 \%$ ), which would be achieved by using $13 \%$ less energy and 18 $\%$ more renewables. Austria seems to be on track to meet its renewable target, notably due to its large share of hydropower in electricity generation. Non-hydro renewables generation only amounted to $4 \%$ of the generation mix in 2012 despite higher feed-in tariffs introduced in 2009 that led to a boom in wind and PV. Adjustments were made to the Green Electricity Bill (the original version was passed in 2002) in 2011, but the annual budget for the support of new green electricity capacities still reached $€ 50$ million in 2013 . The country also counts on $20 \%$ higher energy efficiency by 2020 as opposed to a business-as-usual scenario (22\% in transport, $12 \%$ in heating and cooling and $5 \%$ in electricity). Finally, Austria aims to reduce its GHG emissions by at least $16 \%$ by 2020 from 2005 emissions for sectors not in the EU ETS. It seems that the country is not on track to meet its 2020 non-ETS target unless additional measures are taken. ${ }^{109}$

\section{Scenario}

If Austria manages to develop additional renewable energy (including hydropower) into its system, the future of gas for power generation in the country seems fairly bleak as seen in Figure 55.

Figure 55: Scenario for power generation mix in Austria, up to 2030, in GWh

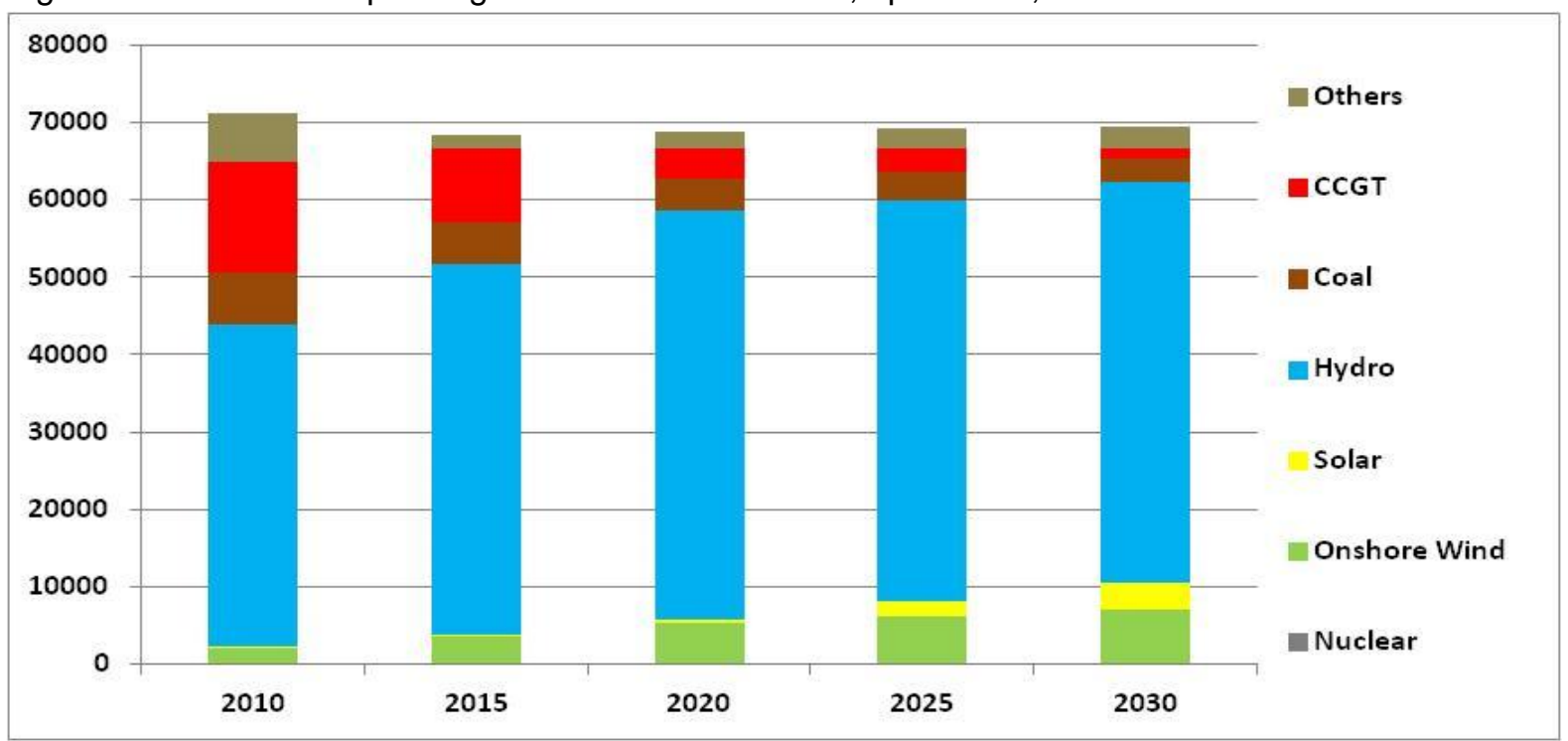

Source: 2010: IEA (2013e), table 3 for each country; scenario: Author

If this scenario happens in the power sector, then total gas demand in the country will drop sharply over the next 15 years or so as shown in Figure 56. Gas consumption would then decline from about $10 \mathrm{Bcm}$ in 2010 (9 Bcm in 2012) to just above $7 \mathrm{Bcm}$ by 2030.

\footnotetext{
${ }^{109}$ For more information, see the National Renewable Energy Action Plan to the European Commission and Ecologic Institute \& Eclareon (Austria)
} 
Figure 56: Scenario for natural gas demand in Austria, up to 2030, in $\mathrm{Bcm}$

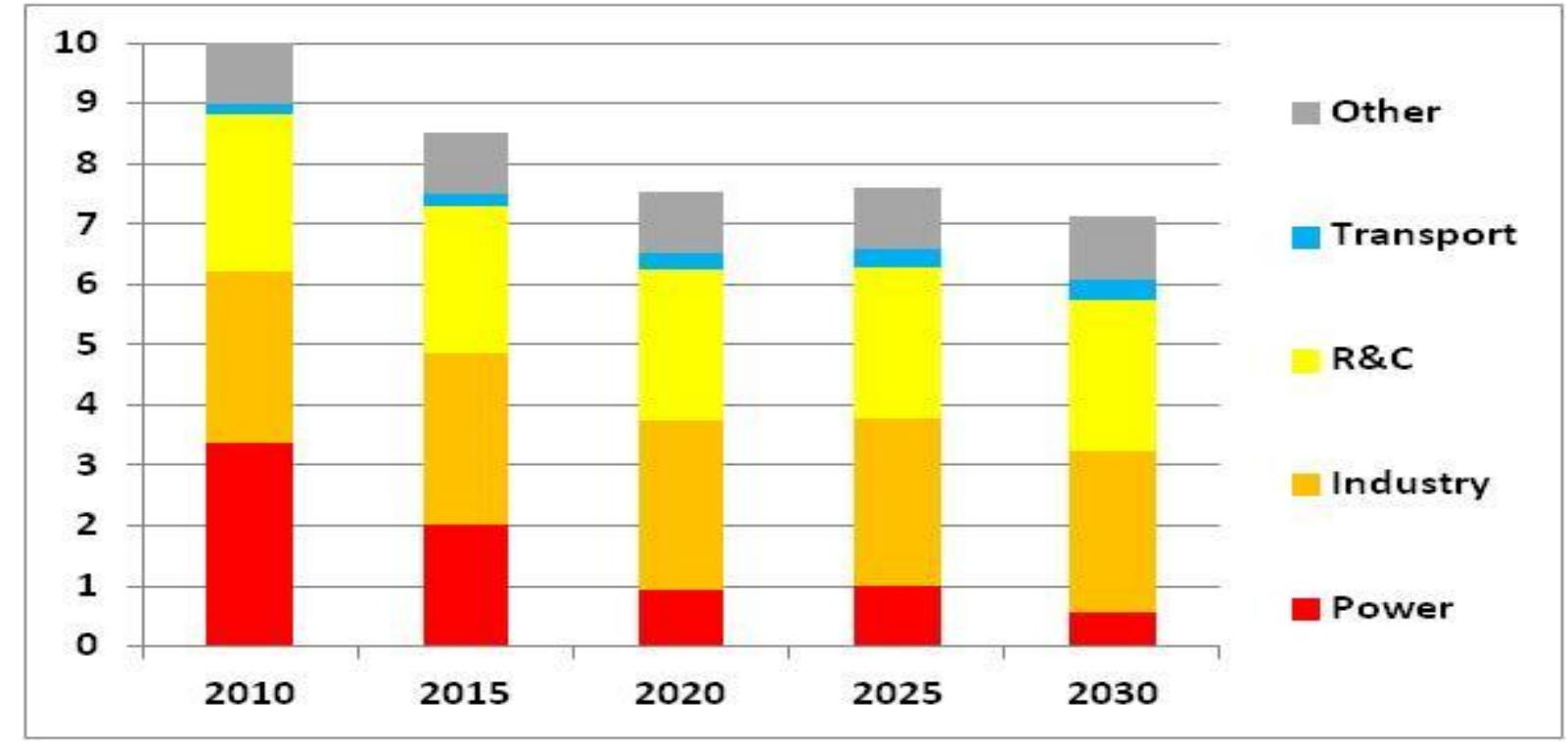

Source: 2010: IEA (2013a), table 3 for each country; scenario: Author 

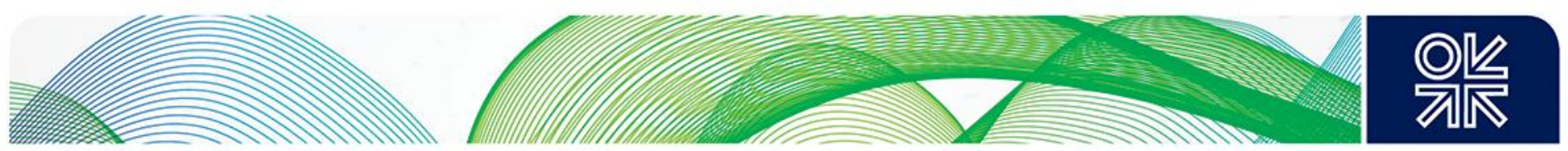

\section{Belgium}

\section{Background}

In 2012, TPES was dominated by oil ( $40 \%$ share), followed by gas $(25 \%)$ and nuclear (18\%). The country is dependent on energy imports, including the totality of its natural gas requirements. ${ }^{110}$

Total gas consumption was about $18 \mathrm{Bcm}$ in 2012, just $2.3 \%$ above its pre-crisis level (2008). The industrial sector was the largest consumer (34\% of demand in 2011), before the power sector (29\%) and R\&C (27\%). The industrial sector had increased by a substantial $11 \%$ compared to $2008 .{ }^{111}$

Power supply reached 87 TWh in 2011, 2.9\% below 2008 levels. Gross production was higher at about 90 TWh (although it dropped to 79 TWh the following year), but peak demand often necessitates imports from neighbouring countries. ${ }^{112}$ In 2012, nuclear dominated the electricity generation mix with a $51 \%$ share, followed by gas $(26 \%)$, coal $(7 \%)$ and renewables $(6 \%$, excluding hydro). ${ }^{113}$

If the assumptions on available gas-fired capacity in 2008 and 2012, which are based on Eurelectric and Elia data, are correct, ${ }^{114}$ then the average load factor of the gas-fired power plants in 2012 was about 36\%, down from about 52\% in 2008 (54\% in 2011).

\section{Targets and assumptions}

GDP growth is expected to recover slowly from the impacts of economic downturn with annual changes ranging between 1 and 1.5\% up to 2018 according to the IMF November 2013 outlook [Figure 57].

Figure 57: GDP annual growth in Belgium (\%), in constant prices, 2000-2018 (forecast from 2012)

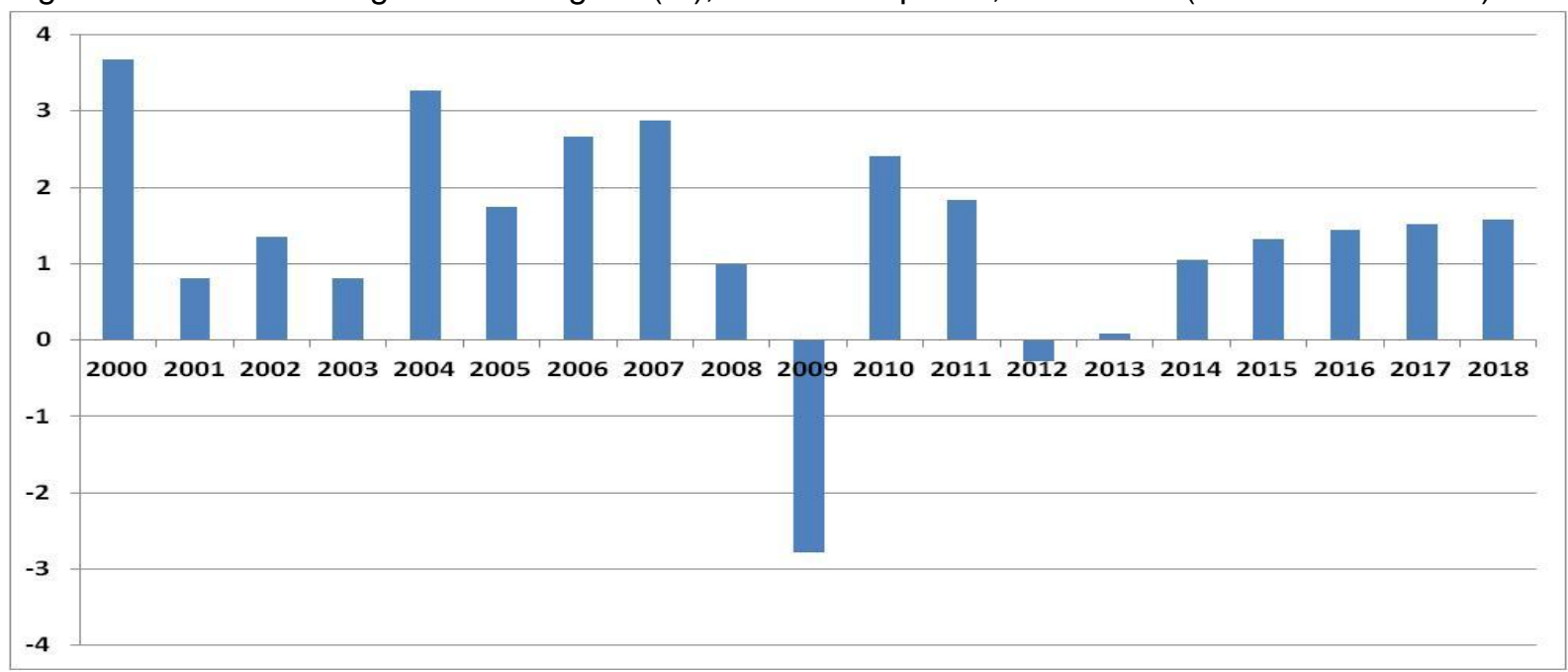

Source: IMF (2013)

The energy and environmental policies are mainly decided at the regional level, while the federal government is competent for nuclear energy, off-shore wind energy, main infrastructure, and tariffs or

\footnotetext{
${ }^{110}$ IEA (2013a), Country data, table 1

111 IEA (2010a) and IEA (2013a), Country data, table 3

112 IEA (2010b) and IEA (2013e), Part III, tables 1.1 and 1.2

113 IEA (2013e), Part III, Country data, table 3

${ }^{114}$ Eurelectric (2012), table 3.1.1.3. ; System operator Elia: http://www.elia.be/en/grid-data/data-download
} 

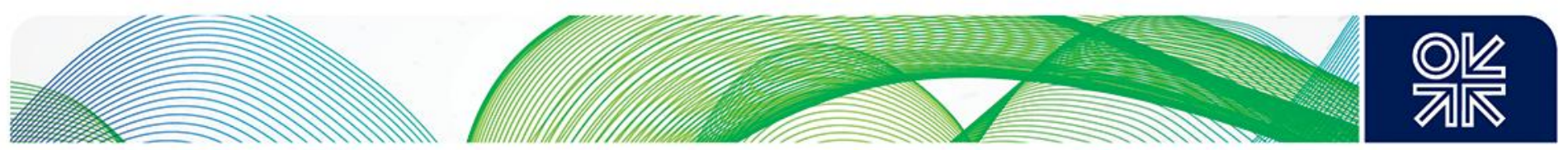

fiscal incentives. These various levels of powers can lead to unclear division of competences or even different priorities within the regions and between the regions and the federal state. ${ }^{115}$

The national target for energy from renewable sources in gross final consumption in 2020 is $13 \%$, and $20.9 \%$ in electricity (up from $2.7 \%$ in 2005 ). ${ }^{116}$ The country also has a target of an $18 \%$ reduction in primary energy consumption by 2020 relative to the Primes model 2007 baseline (53.3 MMtoe). ${ }^{117}$ There is no agreement between the regions on how to share the emissions reduction and the renewables targets for the period 2012-2020 as of mid-2013. These targets will probably be missed if no new measures are put in place. The energy policy priorities of the Belgian government were also delayed -and probably complicated- by the $2010-11$ political crisis that paralyzed the country for almost two years.

The phasing-out of nuclear energy between 2015 and 2025 may prove to be an important -(possibly insurmountable)- challenge. As Belgium prepares to scale back its dependence on nuclear generation, it will need new generation capacity in the 2010s in order to ensure the security of its electricity supply. ${ }^{118}$ In mid-2013, the federal government passed an energy plan to guarantee subsidies for offshore wind capacity and for gas-fired generation. A tender has been launched early 2014 for 800 MW gas-fired capacity ${ }^{119}$ and the capacity built as a result of this tender could be operational by 2018 at the earliest due to construction lead-times.

\section{Scenario}

The results of our scenarios are somewhat intriguing for Belgium as the country may need to add 2-3 coal plants in the 2020s to meet its demand if it does not turn to major additional imports. This is on the condition that such plants will be authorised to be built in the country, which is not certain. Nonetheless, it seems that the role of gas will need to increase in order to make up for the loss of nuclear power, which fulfilled more than half of the country's gross generation in 2012 and that will need to be phased out by 2020 as seen below in Figure 58 .

\footnotetext{
115 Several regional policies have been implemented to combat climate change albeit with different objectives such as environmentally friendly energy production, efficient energy use, fight against energy poverty and the promotion of green jobs in Flanders and reduction of energy consumption and development of renewable energy in Wallonia and Brussels. Source: Ecologic Institute \& Eclareon (Belgium), p.1

${ }^{116}$ For more information, see the National Renewable Energy Action Plan to the European Commission

117 http://ec.europa.eu/energy/efficiency/eed/reporting en.htm

118 In July 2012 Belgium's Council of Ministers announced that Doel 1 and 2 were to close in 2015 after 40 years of operation, while Tihange 1, which will also celebrate its 40th anniversary in 2015, is to be permitted to operate to 2025 to avoid the risk of blackouts. The other four Belgian reactors will reach 40 years in 2022 and 2025. Source: http://www.worldnuclear.org/info/Country-Profiles/Countries-A-F/Belgium/

${ }^{9}$ ICIS Heren (November 2013)
} 
Figure 58: Scenario for power generation mix in Belgium, up to 2030, in GWh

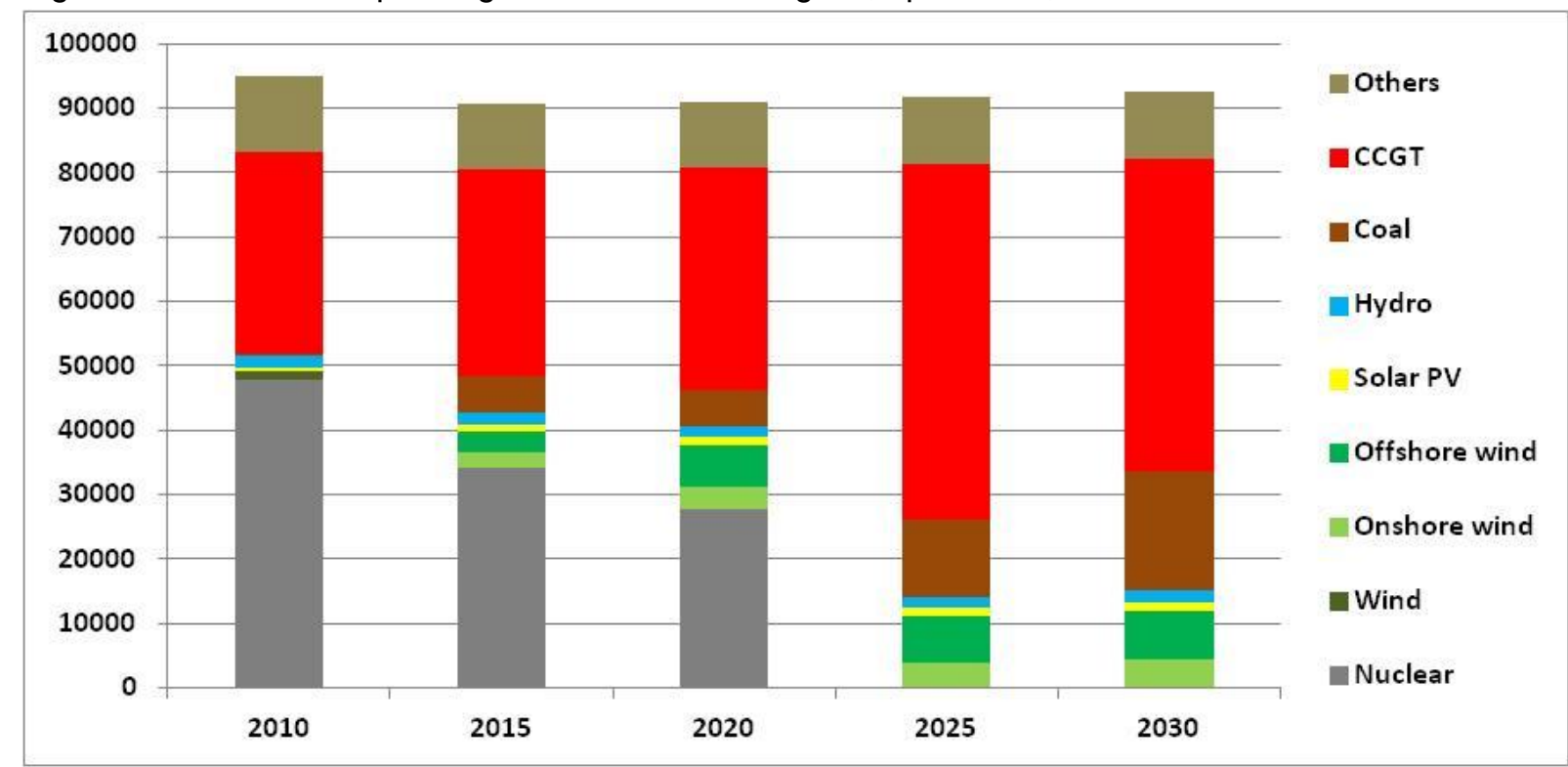

Source: 2010: IEA (2013e), table 3 for each country; scenario: Author

If this scenario happens in the power sector, then this will have an important impact for total gas demand in the country, which could exceed $20 \mathrm{Bcm} /$ year sometime in the 2020s. The industrial and $\mathrm{R} \& \mathrm{C}$ sectors also register some changes, but at a much smaller scale as shown below in Figure 59.

Figure 59: Scenario for natural gas demand in Belgium, up to 2030, in Bcm

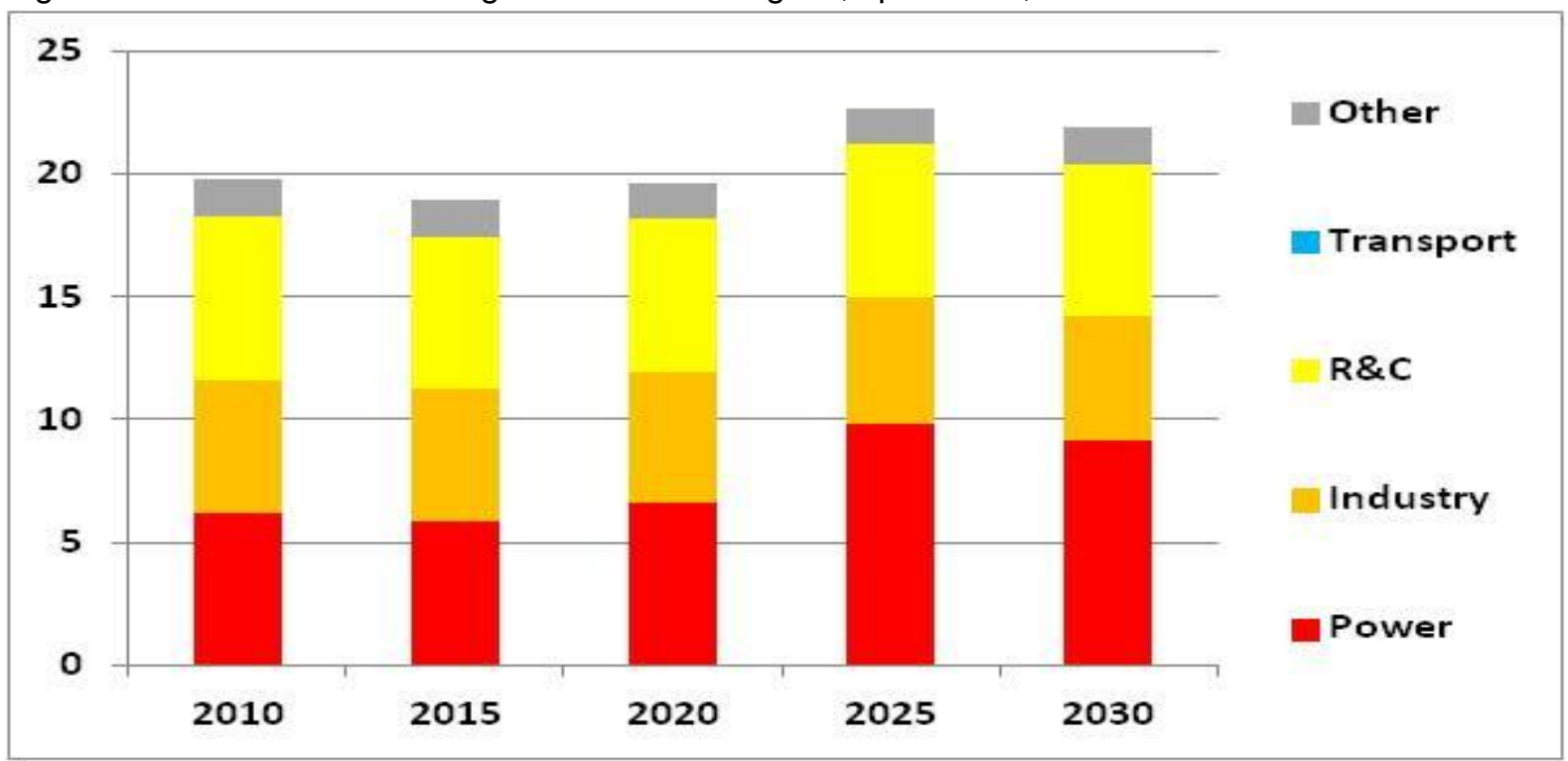

Source: 2010: IEA (2013a), table 3 for each country; scenario: Author 

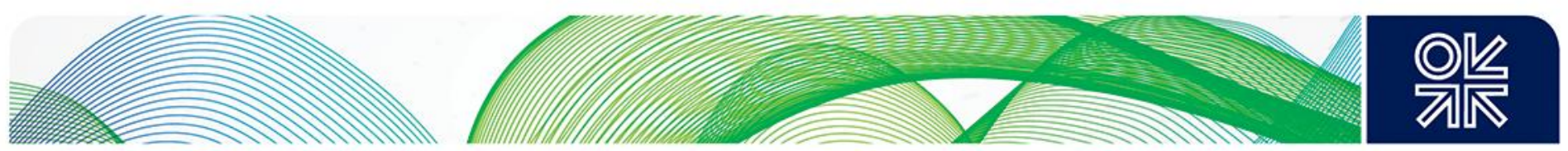

\section{Boznia and Herzegovina (B\&H)}

\section{Background}

Gas represented only about $3 \%$ of total TPES in 2011 , which was dominated by coal with a $67 \%$ followed by oil $(24 \%) .{ }^{120}$ The country was dependent on energy imports for about $35 \%$ of its needs, and for $100 \%$ of its gas requirements.

In 2012, gas demand was $300 \mathrm{MMcm}, 25 \%$ down on 2008. In 2011, 42\% of the gas consumed was used in the industrial sector, $28 \%$ in the power sector and $19 \%$ was consumed in the R\&C sector. ${ }^{121}$

Power demand stood at 12.7 TWh in 2011, 26\% more than 2008 levels. ${ }^{122}$ Gross electricity production fulfilled the country's needs and more. In terms of electricity generation mix, B\&H has a strong reliance on coal $(71 \%$ in 2011$)$, followed by hydro $(29 \%) .{ }^{123}$

\section{Targets and assumptions}

After some difficult years following the 2009 recession, GDP growth is expected to recover in 20132014 and reach high levels at around 3-4\% in 2015-2018 according to the IMF November 2013 outlook [Figure 60].

Figure 60: GDP annual growth in B\&H (\%), in constant prices, 2000-2018 (forecast from 2012)

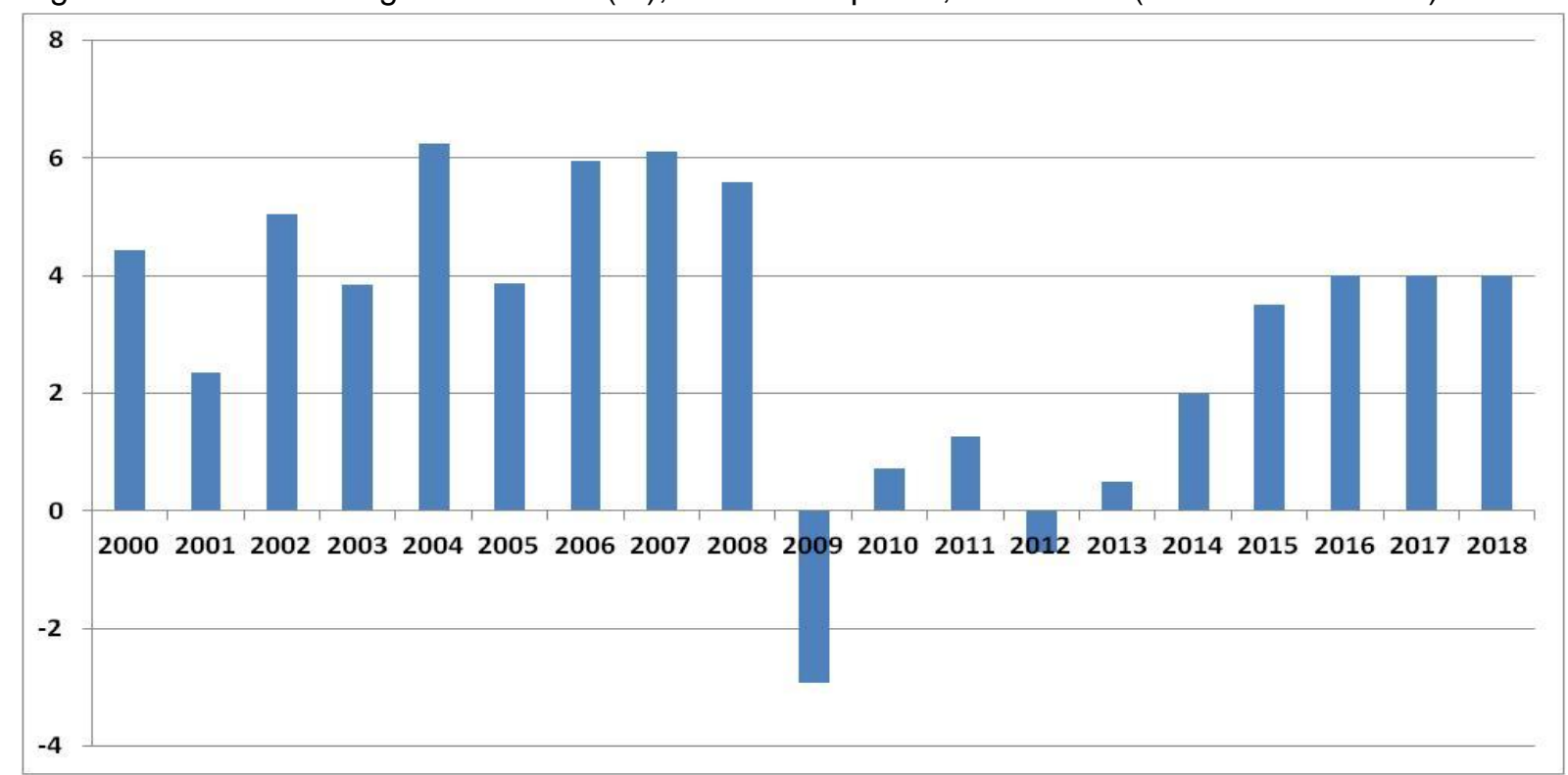

Source: IMF (2013)

The National Environmental Action Plan (NEAP), in force since 2003, sets the aims of increasing energy efficiency and usage of renewable energy sources (hydro, solar, wind and geothermal energy). The Book on incentives for generation of electricity from RES and efficient co-generation was published on January 2012 with the main objective to stimulate an increase of electricity generation

\footnotetext{
120 IEA (2013c), p.II.57

121 IEA (2013c), p.II.57

122 IEA (2010b) and IEA (2013e), Table 1.1, p.III.6

123 IEA (2013e), Table 1.2, p.III.10
} 
from renewable sources, promote efficient cogeneration and increase their participation in gross final consumption of electricity. ${ }^{124}$

\section{Scenario}

In our scenario, natural gas demand remains small at about $300 \mathrm{MMcm} / \mathrm{year}$ by 2030 . 

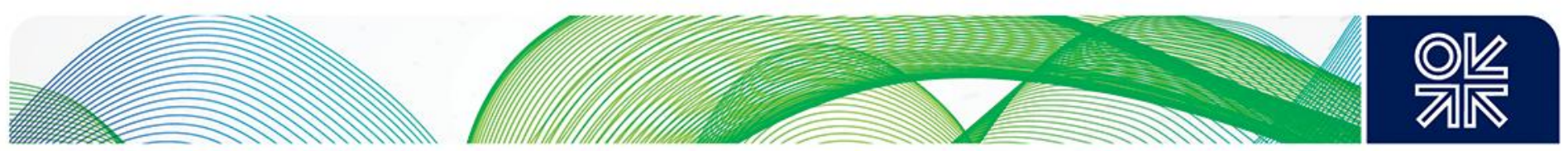

\section{Bulgaria}

\section{Background}

In 2011, gas represented $14 \%$ of total TPES, far behind coal (42\%), nuclear (22\%) and oil (19\%). ${ }^{125}$ The country was dependent on energy imports for about $36 \%$ of its needs, and for $87 \%$ of its gas requirements.

In 2012, gas demand was $2.7 \mathrm{Bcm}, 23 \%$ lower than in 2008. In $2011,42 \%$ of the gas consumed was used in the power sector, $32 \%$ in the industrial sector and $5 \%$ only was consumed in the R\&C sector. ${ }^{126}$

Power demand stood at 34 TWh in $2011,1.4 \%$ less than in $2008 .{ }^{127}$ Gross electricity production fulfilled more than $50 \%$ of the country's needs. In terms of electricity generation mix, Bulgaria has a strong reliance on coal (54\% in 2011), followed by nuclear (32\%). Gas only accounted for $4 \%$ of the $\mathrm{mix}$, the rest was fulfilled by hydro and renewables. ${ }^{128}$

If the assumptions on available gas-fired capacity in 2012, which are based on Eurelectric, are correct, ${ }^{129}$ then the average load factor of the gas-fired power plants in 2012 was about $59 \%$.

\section{Targets and assumptions}

Bulgaria enjoyed strong economic growth in the 2000s, with a recession limited to 2009. GDP growth is expected to recover in post 2014 at about 2-3\% in 2015-2018 according to the IMF November 2013 outlook [Figure 61].

Figure 61: GDP annual growth in Bulgaria (\%), in constant prices, 2000-2018 (forecast from 2012)

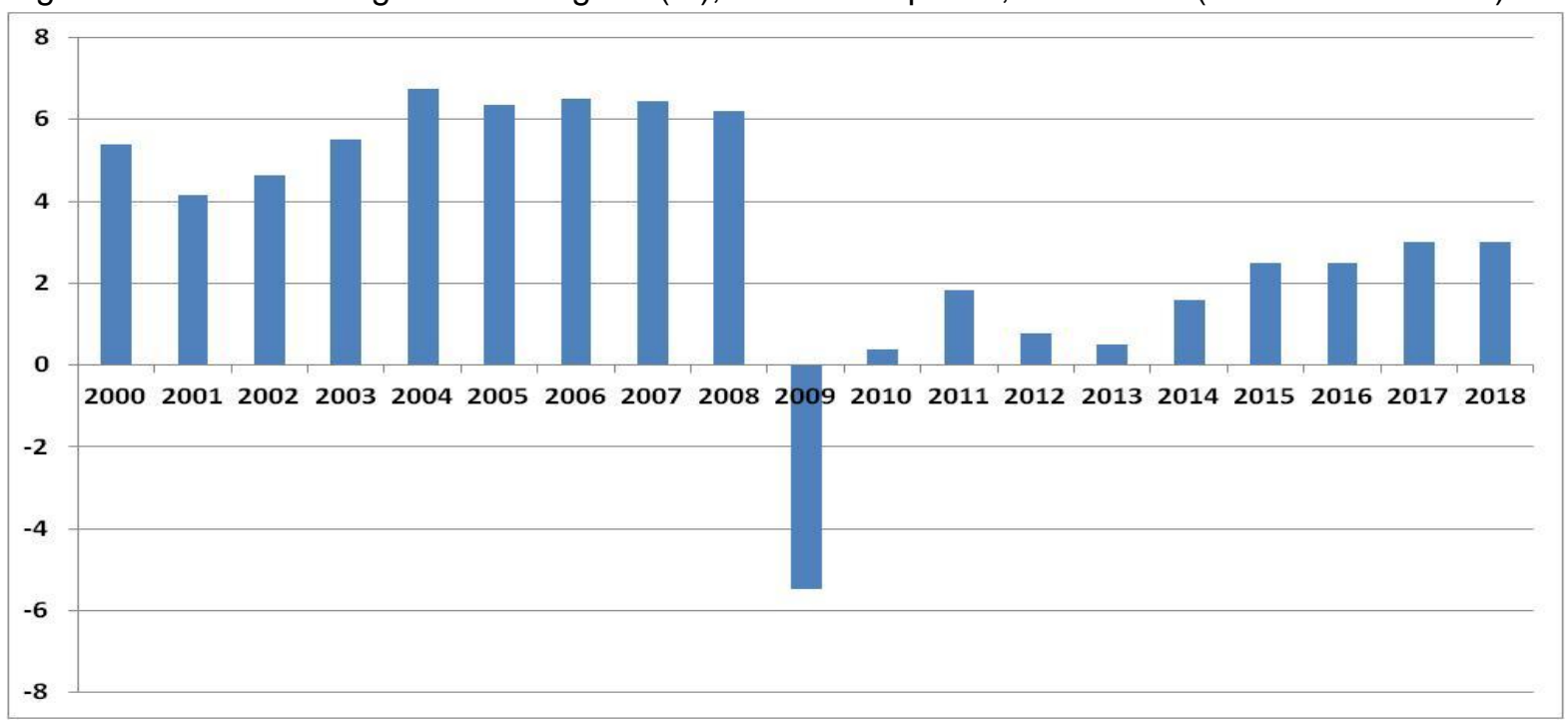

Source: IMF (2013)

The national energy policies focus on increased use of renewable energy sources and the implementation of energy efficiency measures. The overall renewable energy target by 2020 is a $16 \%$

\footnotetext{
125 IEA (2013c), p.II.57

126 IEA (2013c), p.II.57

${ }^{127}$ IEA (2010b) and IEA (2013e), Table 1.1, p.III.6

${ }^{128}$ IEA (2013e), Table 1.2, p.III.10

${ }^{129}$ Eurelectric (2012), table 3.1.1.3.
} 
share of energy generated from renewable sources in gross final energy consumption, which means a share of $24 \%$ of heat consumption, $21 \%$ of electricity demand, $8 \%$ of energy demand in the transport sector thanks to attractive incentives such as a feed-in tariff system or long-term power purchase agreements. ${ }^{130}$ The national emission target for GHG emissions for Bulgaria is a $20 \%$ increase in 2020 compared to the 2005 level. Bulgaria set a target to increase energy efficiency by $25 \%$ until 2020 (5 MMtoe primary energy savings in 2020) and to reduce energy intensity by $50 \%$ by 2020 compared to 2005 levels. ${ }^{131}$

\section{Scenario}

Natural gas is not expected to play an increasing role in power generation in Bulgaria in the period considered, nor in the other sectors. In our scenario, natural gas demand remains fairly small at about 3.3 Bcm by 2030.

\footnotetext{
${ }^{130}$ For more information, see http://www.iea.org/policiesandmeasures/climatechange/?country=Bulgaria, 

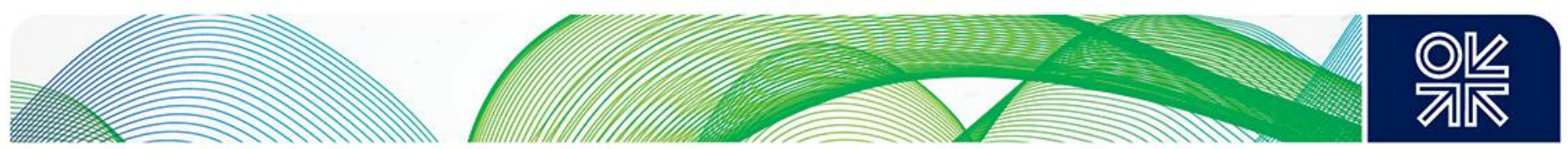

\section{Croatia}

\section{Background}

Gas represented an important share of the total TPES at 30\% in 2011, behind oil (43\%) but ahead of coal $(8 \%)$ and hydro $(5 \%){ }^{132}$ The country was dependent on energy imports for more than half of its needs, although its indigenous production helped it cover about three quarters of its gas needs.

In 2012, gas demand was about $3 \mathrm{Bcm}$, even lower than in $2008(-6 \%)$. In 2011, about 38\% of the gas consumed was used in the power sector, $27 \%$ in R\&C and about $18 \%$ in the industrial sector. ${ }^{133}$

Power demand stood at 18 TWh in 2011 , slightly below 2008 levels. ${ }^{134}$ Gross electricity production represented about $60 \%$ of the country's needs. In terms of electricity generation mix, Croatia is reliant on hydropower (43\% in 2011), coal and gas (24\% each), while renewables represented only about $2 \%{ }^{135}$

\section{Targets and assumptions}

Croatia faced difficult times with negative GDP changes between 2009 and 2013 but growth is expected back from 2014 and to plateau at about 2-3\% until 2018 according to the IMF world economic outlook of November 2013 [Figure 62].

Figure 62: GDP annual growth in Croatia (\%), in constant prices, 2000-2018 (forecast from 2012)

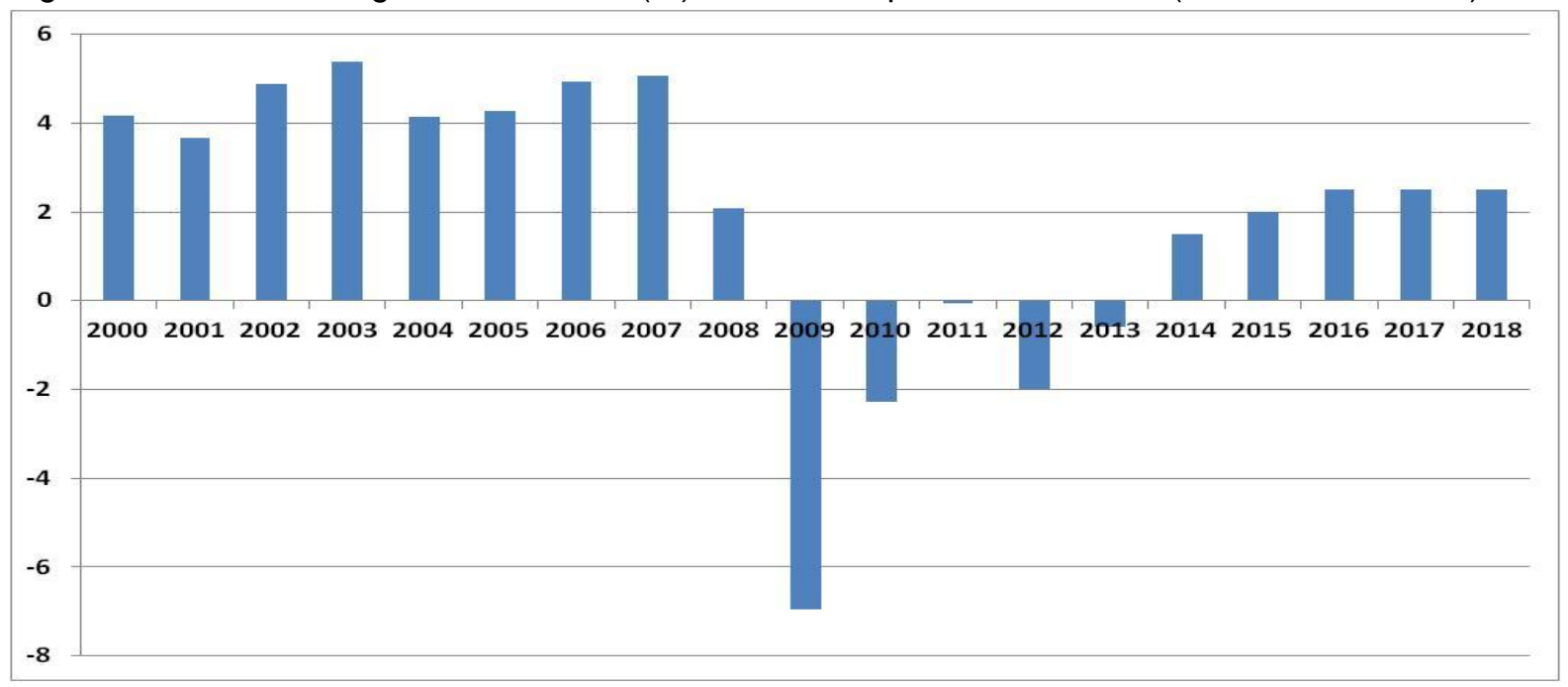

Source: IMF (2013)

Croatia has adopted several climate change policies following its accession to the EU in July 2013. The focus seems to be on nuclear energy, CCS, renewables and better efficiency. The national targets outlined in the National Energy Strategy 2009-2020 are to increase the share of renewable energy by $20 \%$ in annual gross energy consumption by 2020 in order to cut GHG emissions, improve security of energy supply and increase national energy generation in order to be self-sufficient (a feed-in tariff system entered into force in January 2013 for electricity generated from renewable

\footnotetext{
132 IEA (2013c), p.II.57

133 IEA (2013c), p.II.57

134 IEA (2010b) and IEA (2013e), Table 1.1, p.III.6

135 IEA (2013e), Table 1.2, p.III.10
} 
energy plants); to reduce GHG emissions by $20 \%$ by 2020 from the 1990 level (the country seems to be on-track to achieve this goal and more); and to reduce final energy consumption by $9 \%$ by $2016 .{ }^{136}$ It is worth noting that in the Effort Sharing Decision (ESD), ${ }^{137}$ Croatia can increase its emissions not covered by the EU ETS by 11\% compared to 2005.

\section{Scenario}

In our scenario, natural gas demand remains small at about $4 \mathrm{Bcm}$ by 2030 .

\footnotetext{
${ }^{136}$ For more information, see the National Renewable Energy Action Plan to the European Commission and Ecologic Institute \& Eclareon (Croatia); 


\section{Cyprus}

\section{Background}

TPES in 2011 was largely dominated by oil at $95 \%$, while gas was not present. ${ }^{138}$ The country was dependent on energy imports for almost $100 \%$ of its energy needs.

Power demand reached 4.7 TWh in 2011, a level almost identical to 2008 levels. ${ }^{139}$ Gross electricity production fulfilled the country's needs and slightly more. In terms of electricity generation mix, Cyprus has a strong reliance on oil (96\% in 2011), the rest was met by renewables $(4 \%) .{ }^{140}$

\section{Targets and assumptions}

After some difficult years following the 2009 recession, GDP growth is expected to recover post 2015 to about 2\% per year until the end of the period considered (2018) in the IMF November 2013 outlook [Figure 63].

Figure 63: GDP annual growth in Cyprus (\%), in constant prices, 2000-2018 (forecast from 2012)

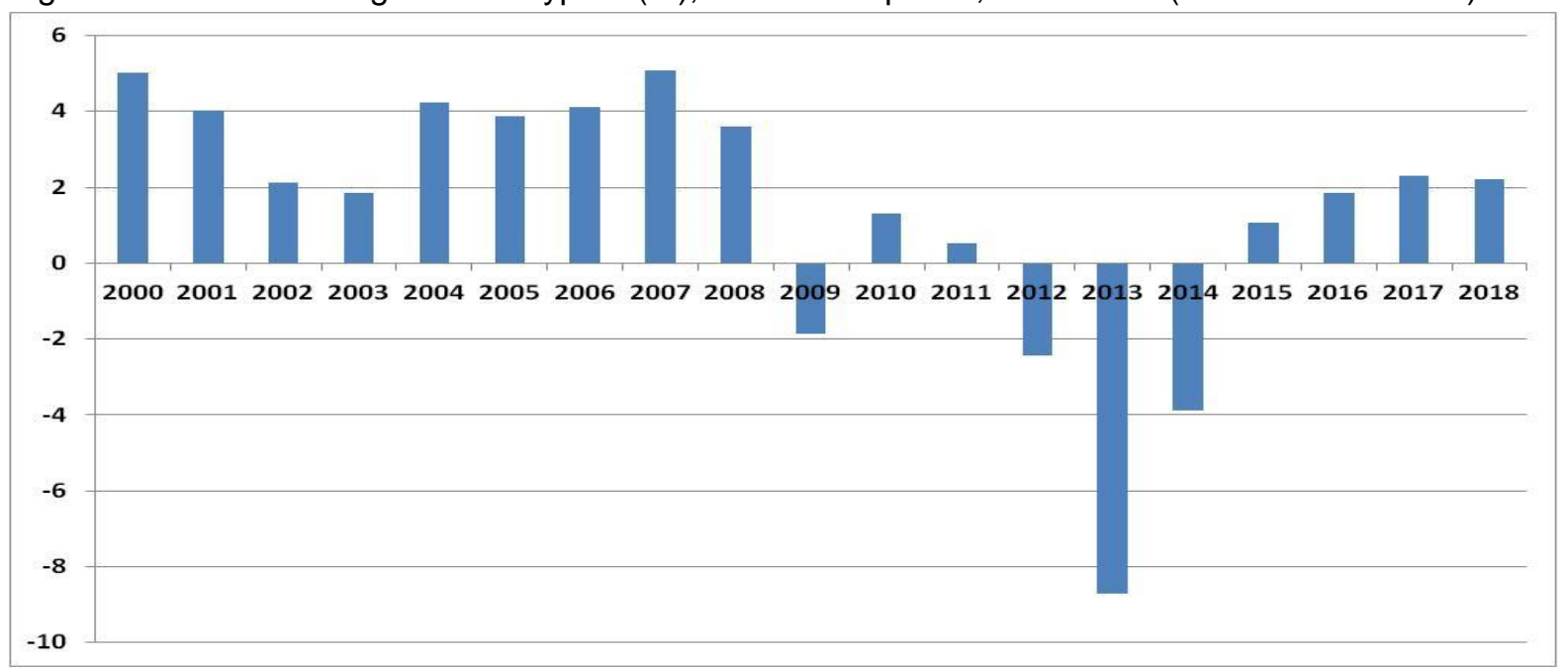

Source: IMF (2013)

The major focus of the energy policy is on the exploitation of new found gas reserves, and not necessarily on climate changes issues despite updated support mechanisms for renewables and energy efficiency and GHG emissions reduction in the transport sector. By 2020, the country has a renewable energy target of $13 \%$ in gross final energy consumption up from $7.8 \%$ in 2010 (distributed as follows: heating and cooling: $23.5 \%$, electricity: $16 \%$, and transport: $5 \%$ ), and GHG emissions reduction target of $5 \%$ compared to 2005 according to the ESD, which seems to be on track as $2013 .{ }^{141}$ Finally, the country has a target of $14.4 \%$ energy reduction in 2020 compared to a reference scenario. ${ }^{142}$

\footnotetext{
138 IEA (2013c), p.II.57

139 IEA (2010b) and IEA (2013e), Table 1.1, p.III.6

140 IEA (2013e), Table 1.2, p.III.10

${ }^{141}$ For more information, see http://www.iea.org/countries/non-membercountries/cyprus/

the National Renewable Energy Action Plan to the European Commission and Ecologic Institute \& Eclareon (Cyprus)

http://www.iea.org/policiesandmeasures/renewableenergy/?country=Croatia

http://ec.europa.eu/energy/efficiency/eed/reporting en.htm
} 


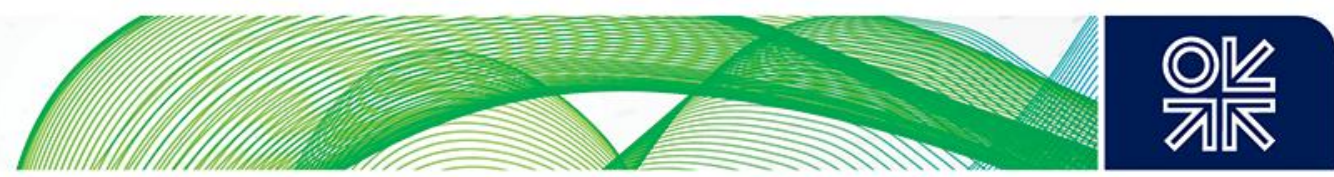

\section{Scenario}

Natural gas is not expected to play an increasing role in power generation in Cyprus in the period considered even if the country intends to convert some of its CCGTs running on diesel oil to gas at a later stage. The level of gas demand, if any, is insignificant in our scenario. 

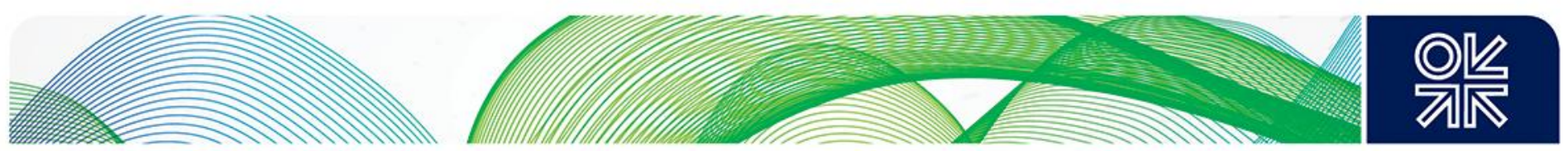

\section{Czech Republic}

\section{Background}

In 2012, TPES was dominated by coal (41\% share), followed by oil (20\%), nuclear (19\%) and gas $(16 \%)$. The country is dependent on energy imports for about one third of its needs, including for almost the totality of its natural gas requirements $(98 \%) .{ }^{143}$

Total gas consumption was about $8.3 \mathrm{Bcm}$ in 2012 , about $4.6 \%$ below its pre-crisis level (2008). The $R \& C$ sector was the largest consumer (48\% of demand in 2011), before the industrial sector (31\%) and finally the power sector (14\%). The latter is fairly small but registered a small increase from precrisis levels (2008). ${ }^{144}$

Power supply was about 63 TWh in 2011, 3.4\% below 2008 levels. Gross production was higher at about 87.5 TWh (it remained at this level the following year). ${ }^{145}$ In 2012, coal dominated the electricity generation mix with a $53 \%$ share, followed by nuclear (35\%). Hydro, renewables and gas were far behind with $2-3 \%$ share each. ${ }^{146}$

If the assumptions on available gas-fired capacity in 2008 and 2012, which are based on Eurelectric data, are correct, ${ }^{147}$ then the average load factor of the gas-fired power plants in 2012 was about $38 \%$, probably way down from 2008 levels when the gross production was twice higher.

\section{Targets and assumptions}

According to the IMF November 2013 outlook [Figure 64], GDP declined in 2009, 2012 and 2013 but is expected to recover slowly from the impacts of economic downturn with annual changes at around 2\% between 2015 and 2018 .

Figure 64: GDP annual growth in Czech Republic (\%), in constant prices, 2000-2018 (forecast from 2012)

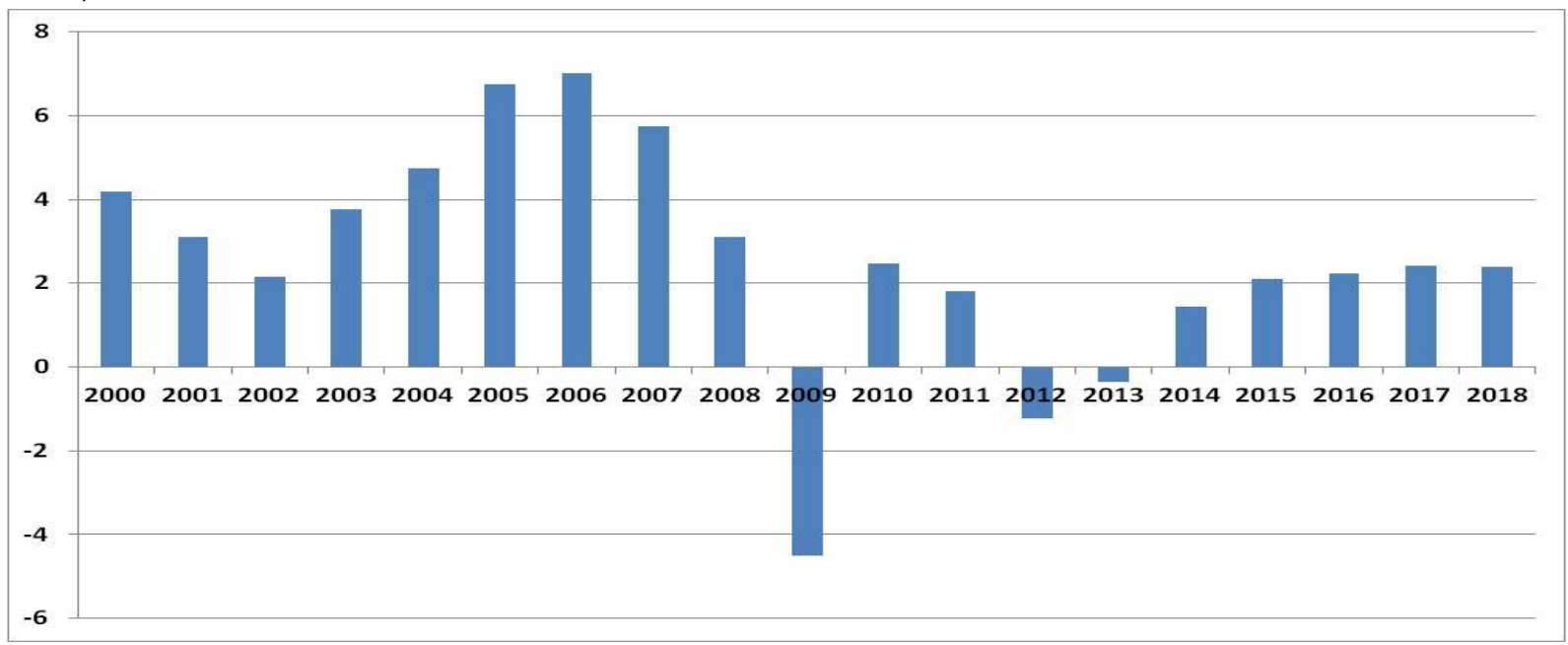

Source: IMF (2013)

\footnotetext{
${ }^{143}$ IEA (2013a), Country data, table 1

144 IEA (2010a) and IEA (2013a), Country data, table 3

${ }^{145}$ IEA (2010b) and IEA (2013e), Part III, tables 1.1 and 1.2

146 IEA (2013e), Part III, Country data, table 3

${ }^{147}$ Eurelectric (2012), table 3.1.1.3.
} 

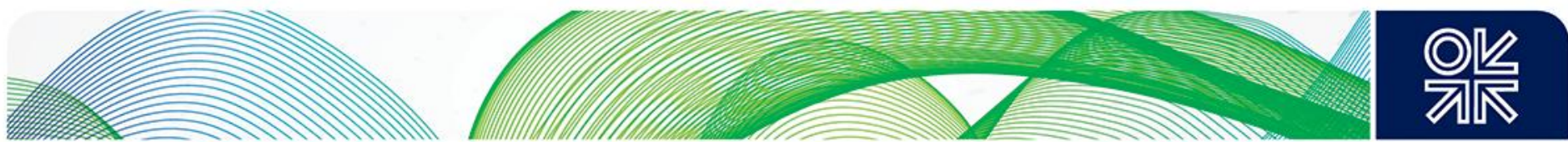

The national strategic energy policy sets the measures to reach the 2020 target of $13.5 \%$ of renewable in gross final energy consumption by 2020 (heating and cooling: $14 \%$, electricity: $14 \%$ and transport: $11 \%$ ). It is worth noting that as in other countries, the National Renewable Energy Action Plan of August 2012 aims to reduce renewable energy development in order to keep some control on electricity prices for the consumers. At the same time, the country wants to increase its energy security by producing $80 \%$ of its electricity needs and plans also to lessen its dependence on coal. No new coal plants are foreseen and a progressive closure of potentially one third of the outdated capacity is possible by 2030 amid tighter emission rules. ${ }^{148}$ The role of natural gas in electricity generation is expected to grow but this could be hampered as the country also aims to increase nuclear power with three additional reactor units at Czech utility ČEZ's Temelín and Dukovany plants. ${ }^{149}$

\section{Scenario}

Indeed, our scenario shows that if nuclear remains high in Czech Republic and if the gas price does not become significantly more competitive with coal prices, coal generation will remain high despite the closure of about a third of the coal capacity by 2030 as seen in Figure 65. Gas-fired plant capacity does not increase significantly and the small fleet runs at fairly high load factors and gas acts as the marginal fuel in the generation mix.

Figure 65: Scenario for power generation mix in Czech Republic, up to 2030, in GWh

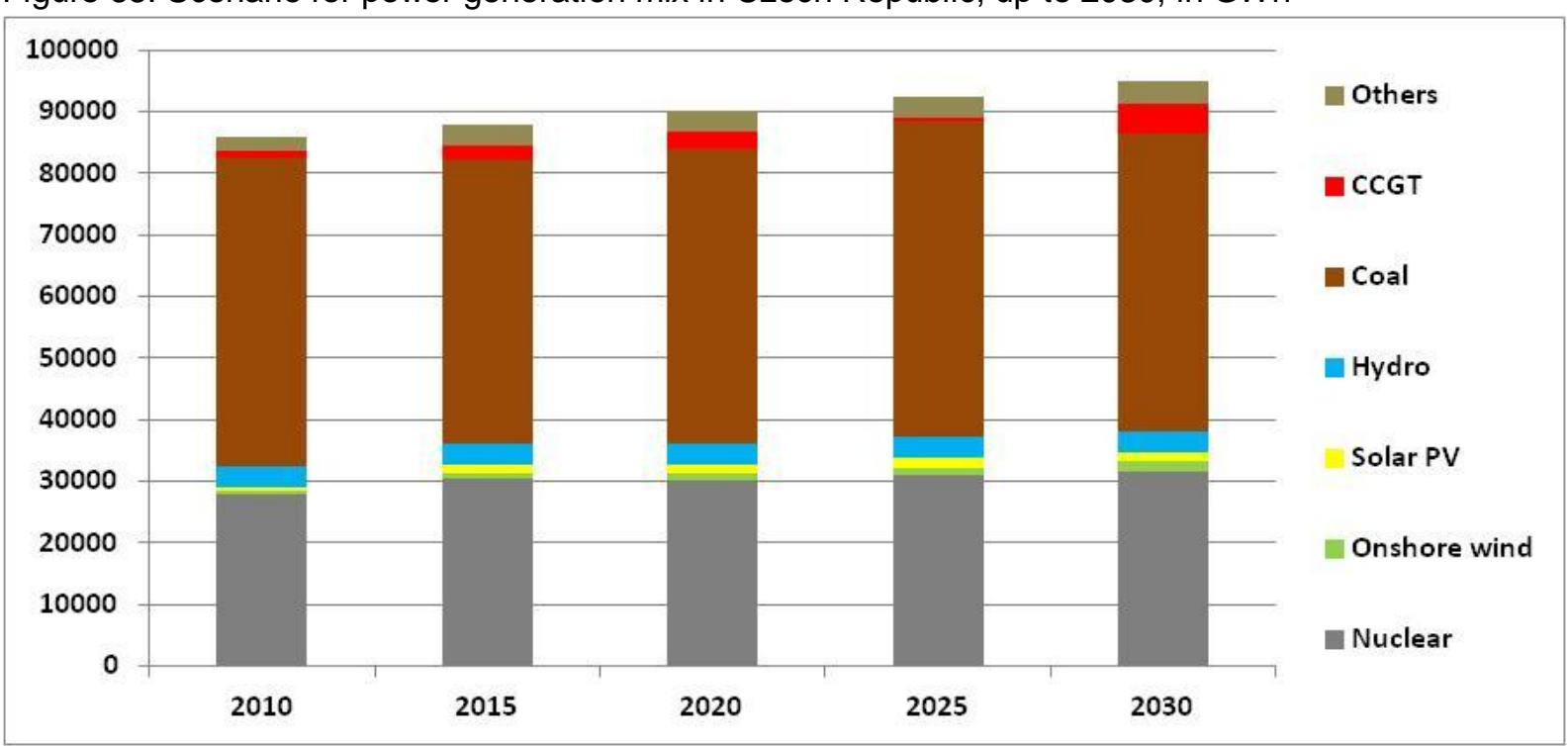

Source: 2010: IEA (2013e), table 3 for each country; scenario: Author

Total gas demand is expected to slowly recover to 2010 level sometime in the 2020 s depending on the variations in the power and transport sectors post 2025 as shown in Figure 66.

\footnotetext{
148 For more information, see the National Renewable Energy Action Plan to the European Commission https://www.iea.org/Textbase/npsum/czechrep2010SUM.pdf ; Ecologic Institute \& Eclareon (Czech Republic)

${ }^{49}$ CEZ said on April 102014 that it was scrapping the planned construction of two new reactors at its Temelin nuclear plant due to "turbulent" conditions in the European energy sector. Source: Shale gas new today (April 2014)
} 
Figure 66: Scenario for natural gas demand in Czech Republic, up to 2030, in Bcm

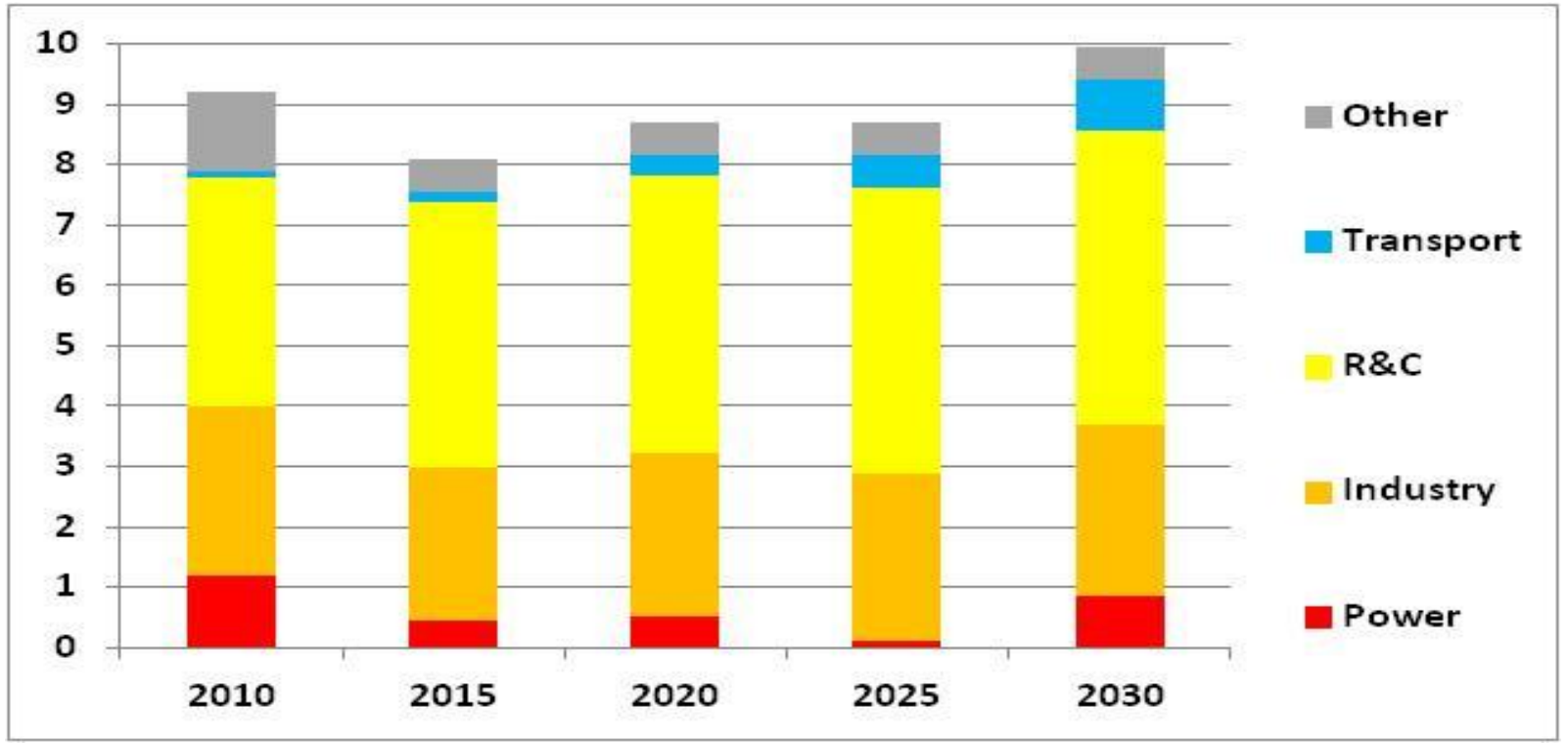

Source: 2010: IEA (2013a), table 3 for each country; scenario: Author 

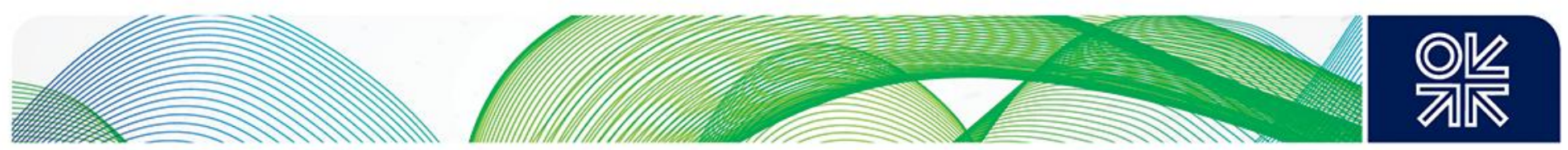

\section{Denmark}

\section{Background}

In 2012, oil still represented the largest share of the TPES (36\% share), followed by gas (20\%) and coal (14\%). The country produces all its own energy and is a net exporter of natural gas. ${ }^{150}$

Total gas consumption was just below $4 \mathrm{Bcm}$ in 2012, about $15 \%$ below its pre-crisis level (2008). The power sector was by far the largest consumer (42\% of demand in 2011), before the R\&C sector $(22 \%)$ and finally the industrial sector $(19 \%){ }^{151}$

Power supply was about 35 TWh in 2011, 5.4\% below 2008 levels. Gross production was similar (it declined to $30 \mathrm{TWh}$ the following year). ${ }^{152}$ In 2012, coal and renewables (excluding hydro) dominated the electricity generation mix with a $35 \%$ share each, followed by gas $(14 \%) .{ }^{153}$

If the assumptions on available gas-fired capacity in 2008 and 2012, which are based on Eurelectric and IEA data, are correct, ${ }^{154}$ then the average load factor of the gas-fired power plants in 2012 was about $19 \%$, down from about $30 \%$ in 2008 .

\section{Targets and assumptions}

According to the IMF November 2013 outlook [Figure 67], GDP declined in 2008, 2009 and 2012 but is expected to recover slowly from the impacts of economic downturn with annual changes at around $2 \%$ between 2015 and 2018.

Figure 67: GDP annual growth in Denmark (\%), in constant prices, 2000-2018 (forecast from 2012)

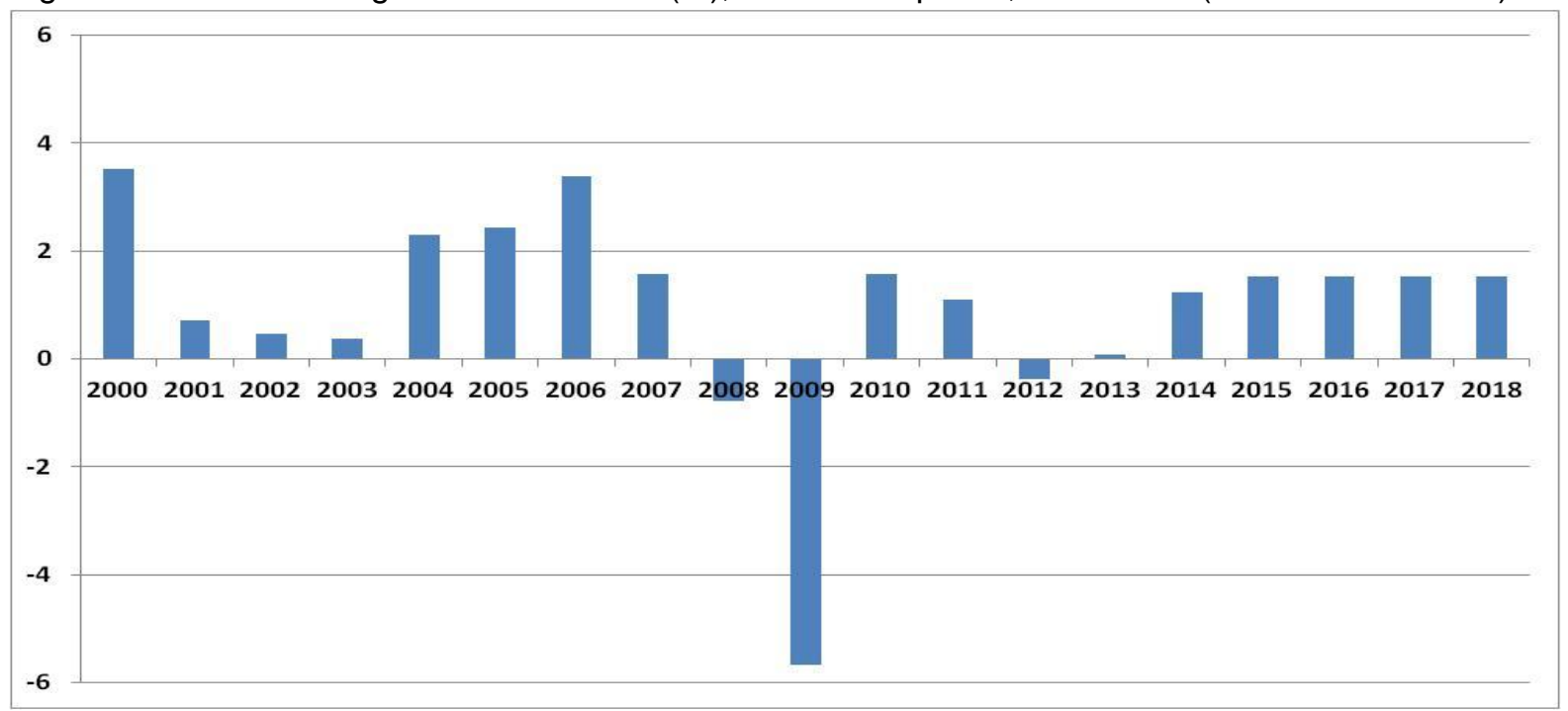

Source: IMF (2013)

Development of renewable energy in the mix and energy savings are high on the government's agenda. In its Energy Agreement 2012-2020, Denmark sets an ambitious target of 35\% renewable energy by 2020 (50\% wind in electricity consumption) together with a longer term domestic target of

\footnotetext{
150 IEA (2013a), Country data, table 1

151 IEA (2010a) and IEA (2013a), Country data, table 3

152 IEA (2010b) and IEA (2013e), Part III, tables 1.1 and 1.2

153 IEA (2013e), Part III, Country data, table 3

154 IEA (2013e), Part III, table 2.12; Eurelectric (2012), table 3.1.1.3.
} 
$100 \%$ renewables in the energy and transport sectors by 2050 . The country expect to reduce its energy consumption by $7.6 \%$ compared to 2010 , and a $34 \%$ decline of GHG emissions by 2020 compared to 1990 is also on the table, with good chances of being fulfilled. ${ }^{155}$

\section{Scenario}

Our scenario shows the generation mix evolving toward more and more renewables into the system and a sharp decline of the use of coal while natural gas seems to make up for the gap before being somewhat eroded by renewables [Figure 68].

Figure 68: Scenario for power generation mix in Denmark, up to 2030, in GWh

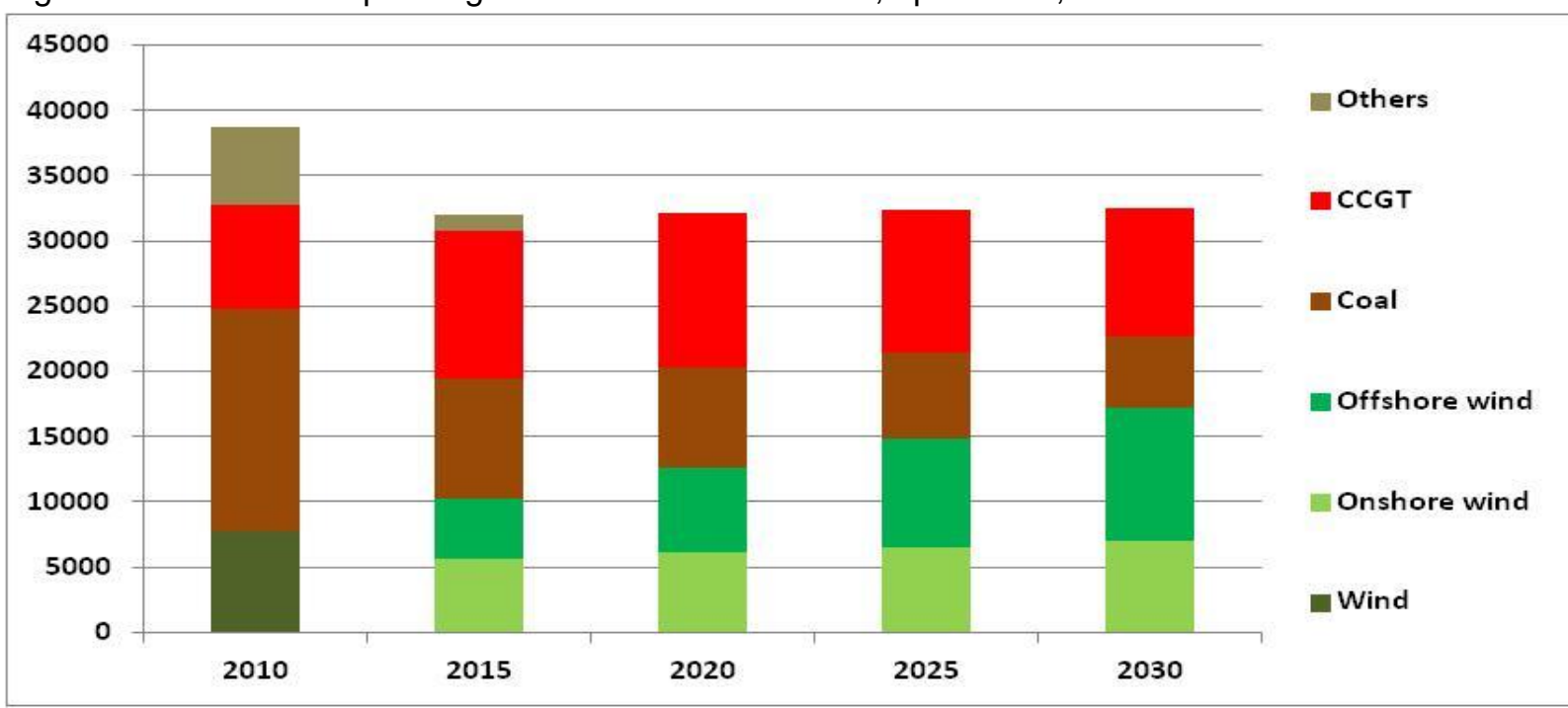

Source: 2010: IEA (2013e), table 3 for each country; scenario: Author

In this scenario, gas demand in Denmark will get back to 2010 level sometime in the late 2010s, however, post 2025 is a question mark as shown in Figure 69.

\footnotetext{
${ }^{155}$ For more information, see the National Renewable Energy Action Plan to the European Commission and Ecologic Institute \& Eclareon (Denmark)
} 
Figure 69: Scenario for natural gas demand in Denmark, up to 2030, in Bcm

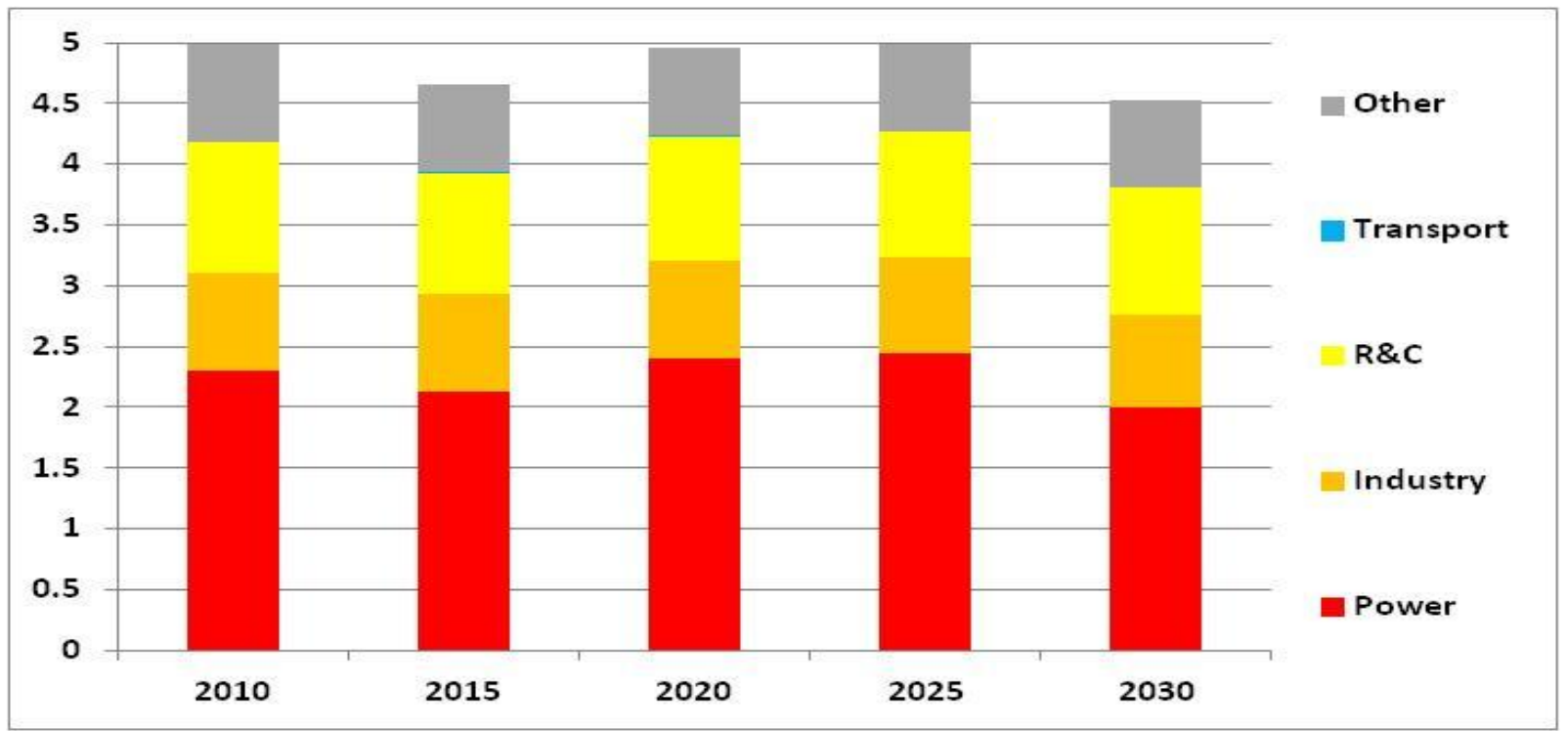

Source: 2010: IEA (2013a), table 3 for each country; scenario: Author 

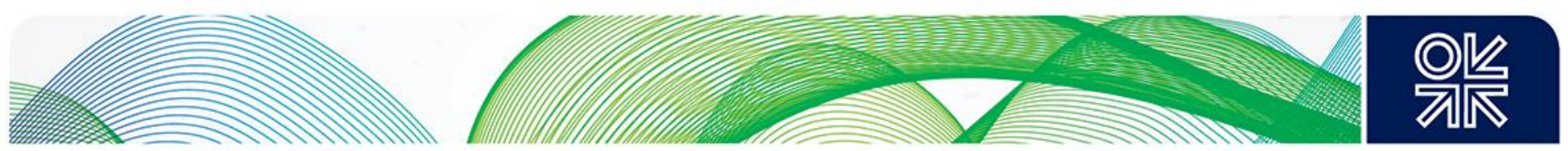

\section{Estonia}

\section{Background}

In 2011, Estonia's TPES was dominated by coal (70\% share), while gas only accounted for $10 \%$ and coal for $9 \%$. ${ }^{156}$ The country was dependent on energy imports, including for $100 \%$ of its gas requirements.

In 2012, gas demand was about $700 \mathrm{MMcm}$, about $22 \%$ less than in 2008. In 2011, the power sector consumed $57 \%$ of the gas consumed, $23 \%$ in the industrial sector and $16 \%$ in the R\&C sector. ${ }^{157}$

Power demand was just over 8 TWh in 2011, 6\% less than the 2008 levels. ${ }^{158}$ Gross electricity production fulfilled the country's needs and more $(+59 \%)$. In terms of electricity generation mix, Estonia has a strong reliance on coal (86\% in 2011), while gas only accounted for $1 \% .{ }^{159}$

\section{Targets and assumptions}

After a period of recession in 2008 and 2009, GDP growth returned in 2010 and is expected to get back to sustained levels of growth in the 2010s according to the IMF November 2013 outlook [Figure 70].

Figure 70: GDP annual growth in Estonia (\%), in constant prices, 2000-2018 (forecast from 2012)

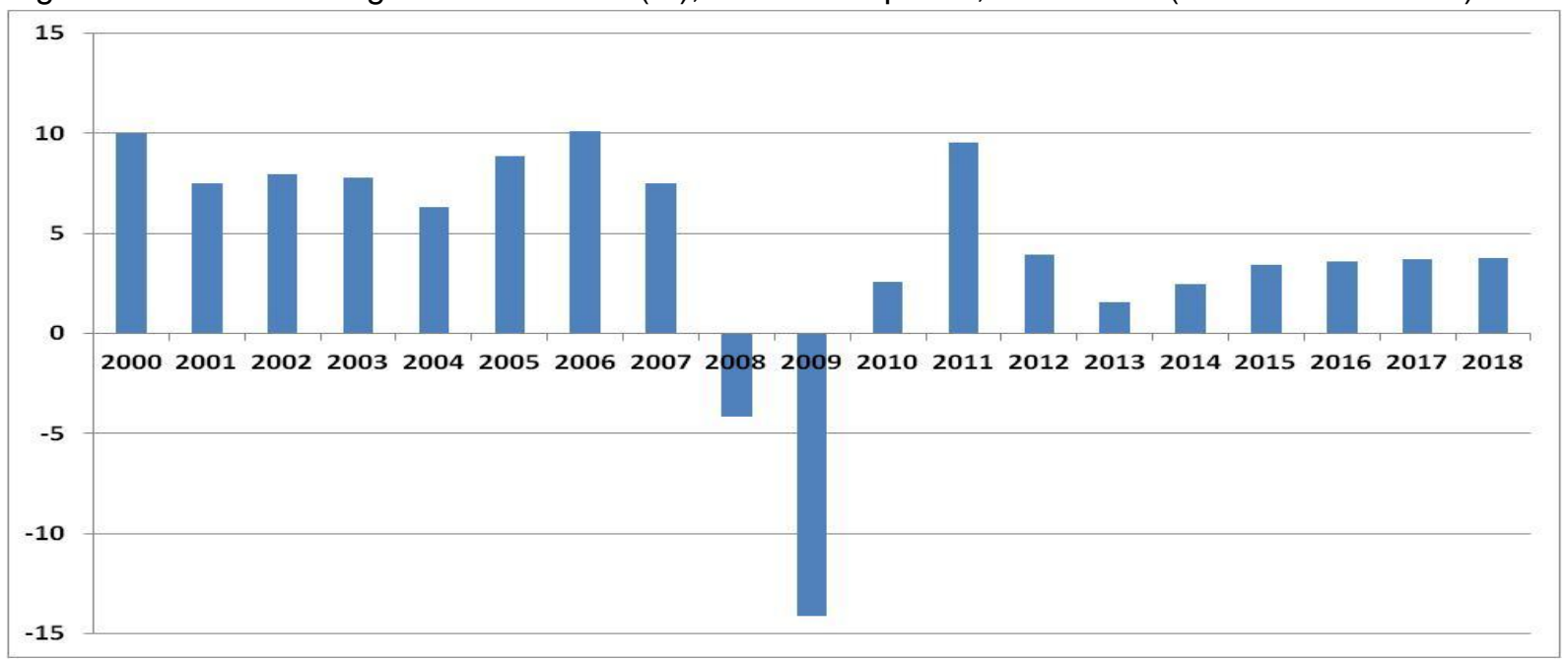

Source: IMF (2013)

The priorities of the energy policies are outlined in the Development Plan of the Estonian Energy Sector until 2020 (June 2009). Estonia has been committed to develop renewable energy which accounted for $18 \%$ of the energy consumption in 2005 . The country has a target to increase renewable energy to $25 \%$ in energy consumption by 2020 . The target for GHG emissions is to limit the increase to $11 \%$ compared to 2005 according to the ESD. High concentration of oil and inefficient fossil fuel plants in the power sector means that the energy sector is a high emitters of GHG $(70 \%$ of national emissions, which is not helped by the fact that Estonia is partially exempt from the EU ETS,

\footnotetext{
156 IEA (2013c), p.II.57

157 IEA (2013c), p.II.57

${ }^{158}$ IEA (2010b) and IEA (2013e), Table 1.1, p.III.6

159 IEA (2013e), Table 1.2, p.III.10
} 

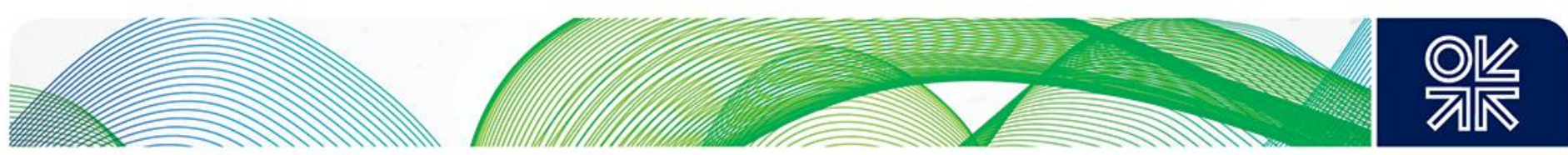

so is not fully exposed to European $\mathrm{CO}_{2}$ prices.), and the $2020 \mathrm{GHG}$ emissions targets may be missed if no additional measures are put in place. ${ }^{160}$ However, because of the Baltic countries complete dependence on Russian gas, there is reluctance in using gas for power generation, which should therefore not increase despite potential benefits for the environment. Regarding energy demand, the target is the stabilisation of final energy consumption in 2020 at the 2010 level. $^{161}$

\section{Scenario}

Our scenario shows a rather unchanging situation in the generation mix [Figure 71]. If power demand increases more than our assumptions, then additional gas could enter into the mix, but the gap could as easily be met by some renewables.

Figure 71: Scenario for power generation mix in Estonia, up to 2030, in GWh

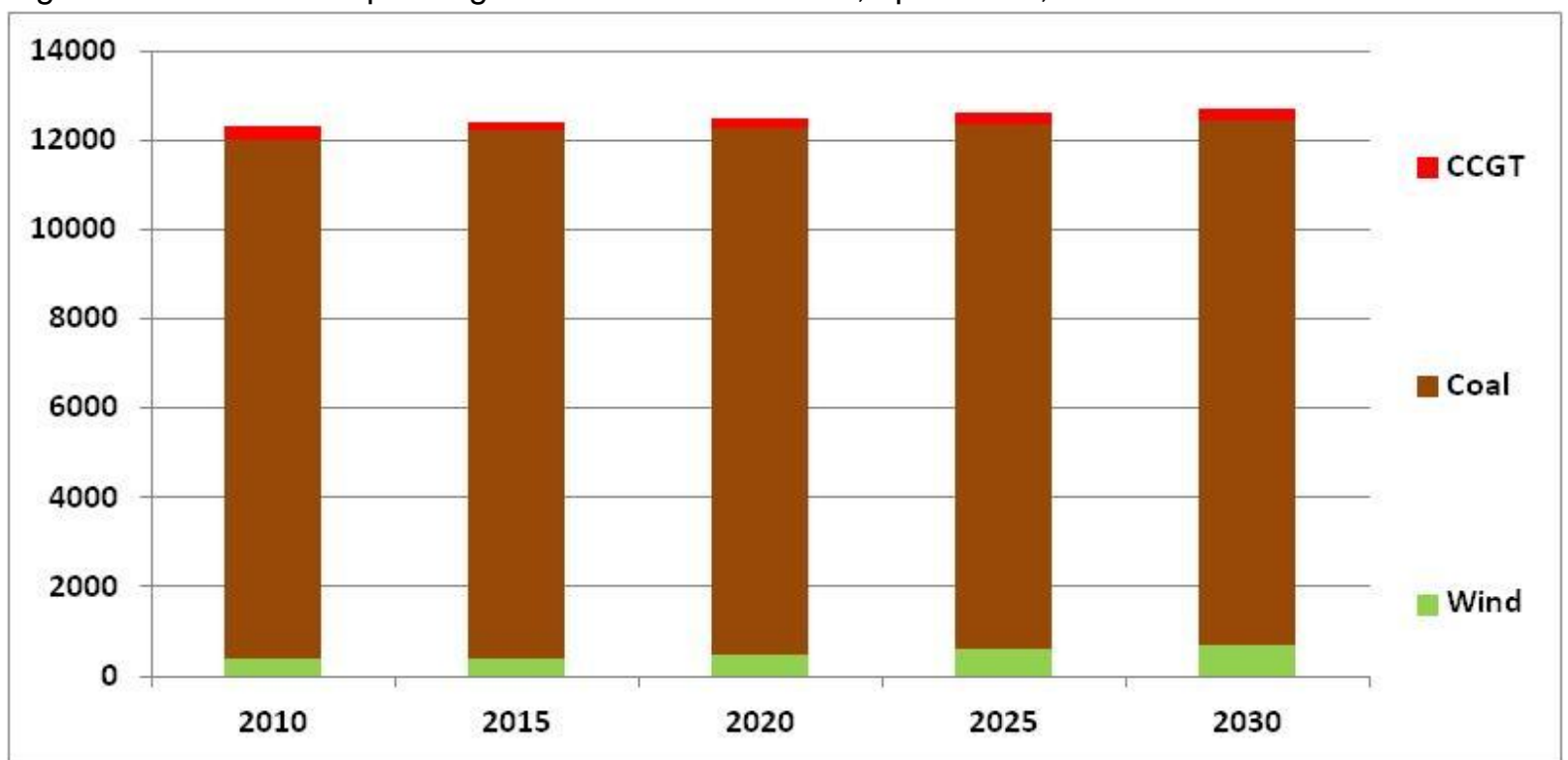

Source: 2010: IEA (2013e), table 3 for each country; scenario: Author

We expect some increase in all sectors of gas consumption, but even so, total demand will remain very low at about $1 \mathrm{Bcm}$ by 2030 as seen in Figure 72 .

\footnotetext{
${ }^{160}$ For more information, see the National Renewable Energy Action Plan and Ecologic Institute to the European Commission \& Eclareon (Estonia)

${ }^{161} \mathrm{http}: / /$ ec.europa.eu/energy/efficiency/eed/reporting en.htm
} 
Figure 72: Scenario for natural gas demand in Estonia, up to 2030, in $\mathrm{Bcm}$

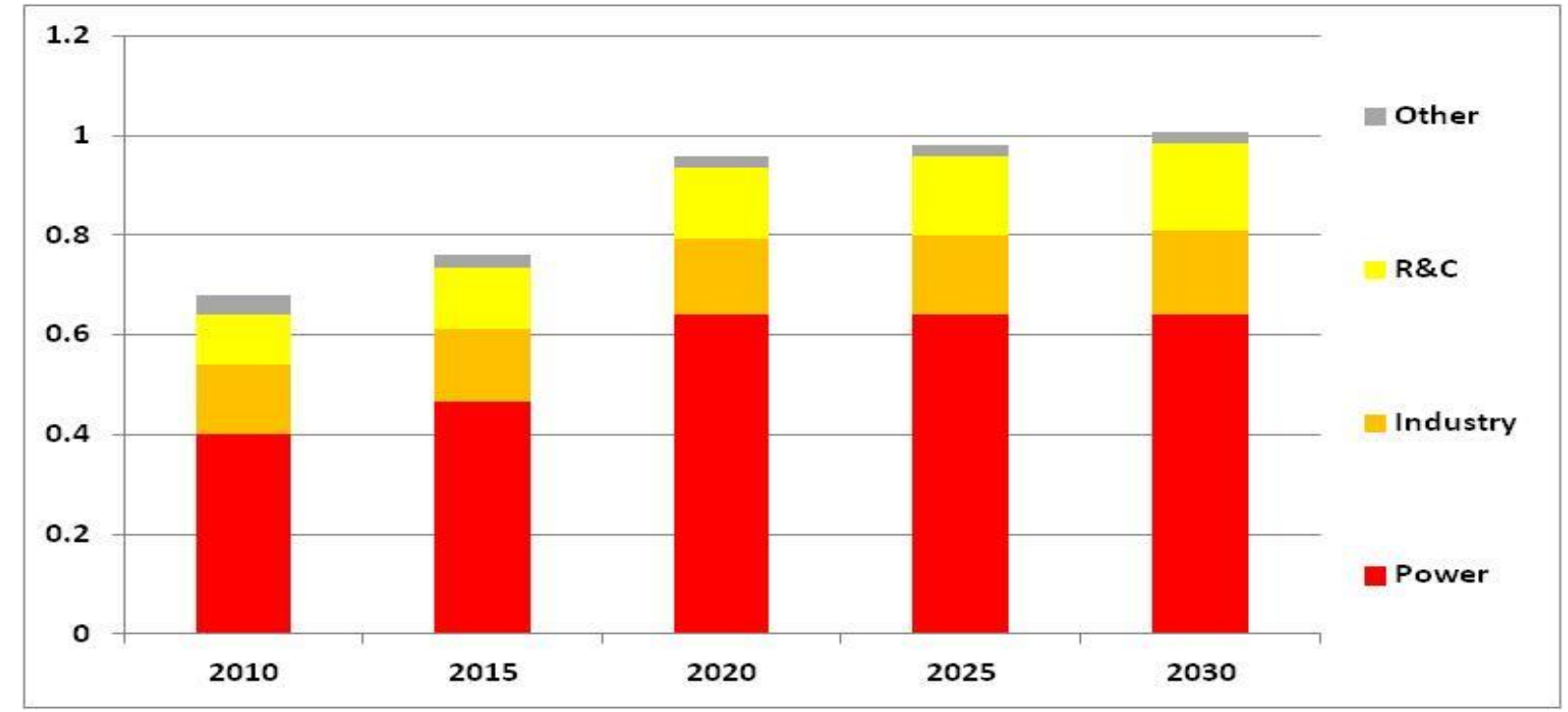

Source: 2010: IEA (2013a), table 3 for each country; scenario: Author 

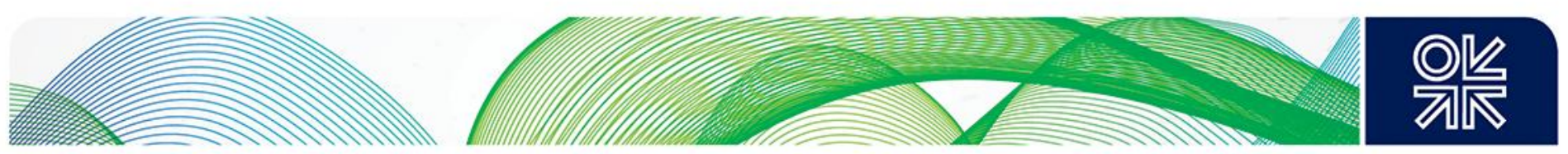

\section{Finland}

\section{Background}

In 2012, TPES was dominated by oil ( $25 \%$ share) and nuclear (18\%), followed by coal (14\%) and gas $(9 \%)$. The country is dependent on energy imports for about half of its needs, including for the totality of its natural gas requirements. ${ }^{162}$

Total gas consumption was about $3.7 \mathrm{Bcm}$ in $2012,21.3 \%$ above its pre-crisis level (2008). The power sector dominated the demand $(61 \%$ of demand in 2011$)$, before the industrial sector $(20 \%)$ and the R\&C accounted for only about $2 \% .{ }^{163}$

Power supply reached 84 TWh in 2011, 3.4\% below 2008 levels. Gross production was only 73.5 TWh (it dropped to 70.4 TWh the following year. ${ }^{164}$ In 2012, nuclear had the highest share of the electricity generation mix with a $33 \%$ share, followed by hydro $(24 \%)$, coal $(17 \%)$ and gas $(9 \%) .{ }^{165}$

If the assumptions on available gas-fired capacity in 2008 and 2012, which are based on Eurelectric and IEA data, are correct, ${ }^{166}$ then the average load factor of the gas-fired power plants in 2012 was about $31 \%$, down from about $54 \%$ in 2008 (44\% in 2011).

\section{Targets and assumptions}

GDP growth is expected to recover from the impacts of economic downturn (2008-2013) with annual changes ranging between 1.5 and 2\% from 2014 according to the IMF November 2013 outlook [Figure 73].

Figure 73: GDP annual growth in Finland (\%), in constant prices, 2000-2018 (forecast from 2012)

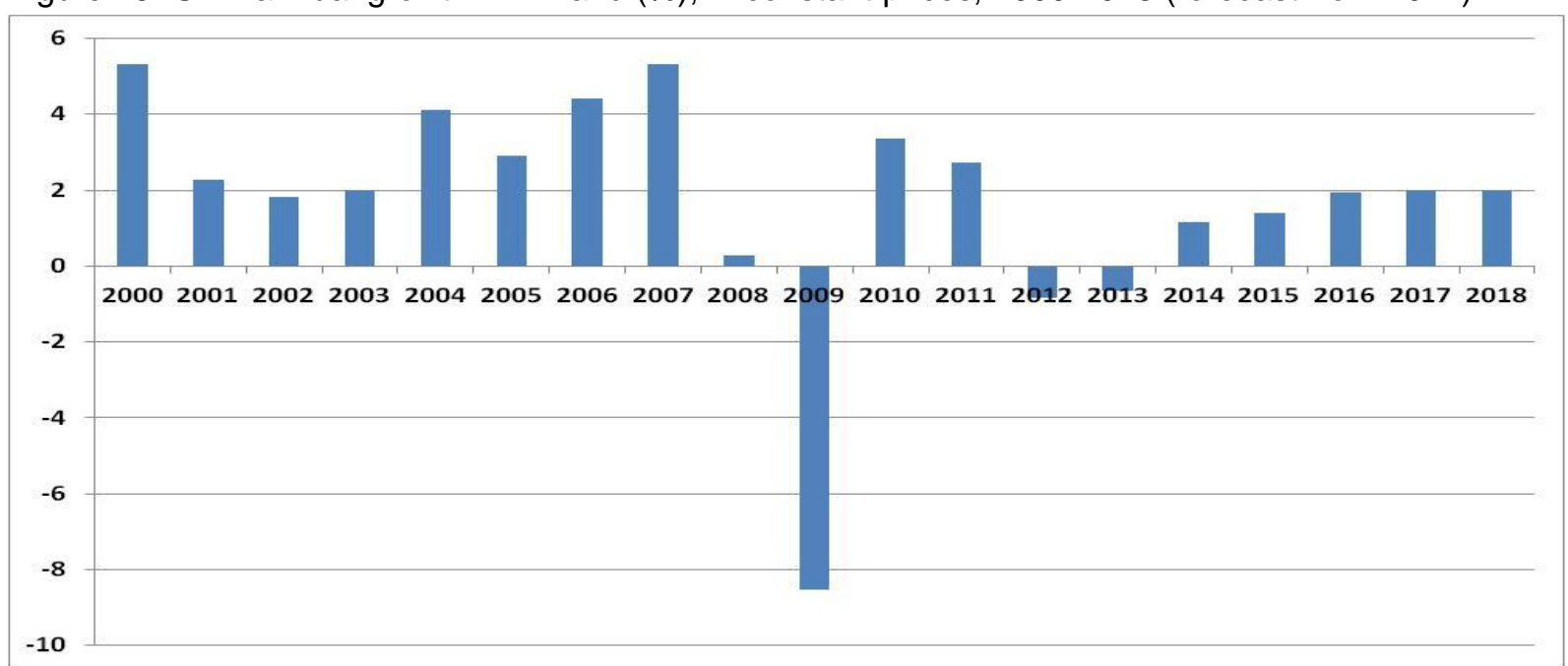

Source: IMF (2013)

Climate change is high on the government's agenda and the long-term goal is to be carbon-neutral, which is expected to be achieved by following the roadmap towards 2050, involving an increase in energy-efficiency and the use of renewable energy. The energy policy is determined by the National

\footnotetext{
162 IEA (2013a), Country data, table 1

163 IEA (2010a) and IEA (2013a), Country data, table 3

${ }^{164}$ IEA (2010b) and IEA (2013e), Part III, tables 1.1 and 1.2

165 IEA (2013e), Part III, Country data, table 3

${ }^{166}$ IEA (2013e), Part III, table 2.12; Eurelectric (2012), table 3.1.1.3.
} 

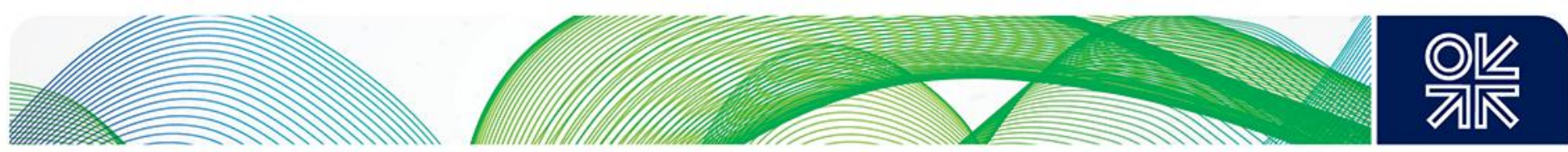

Energy and Climate Strategy of March 2013 and the programmes supplementing the previous 2008 strategy. Finland's target for renewable energy is $38 \%$ of total consumption. At the same time, it plans to reduce its GHG emissions not covered by the EU ETS by $16 \%$ compared to 2005 according to the ESD, which should be met. ${ }^{167}$ The natural gas grid covers the south and southeast of Finland, with a possibility to extend the natural gas grid to western Finland and the supply of natural gas to the Turku region.

\section{Scenario}

In our scenario, natural gas will lose market share to additional nuclear capacity. In the 2020s, the role of gas will then depend on hydropower availability and gas-coal prices competition. Coal capacity is expected to decline rapidly, but the remaining fleet could still produce some electricity and compete against gas as seen in Figure 74 .

Figure 74: Scenario for power generation mix in Finland, up to 2030, in GWh

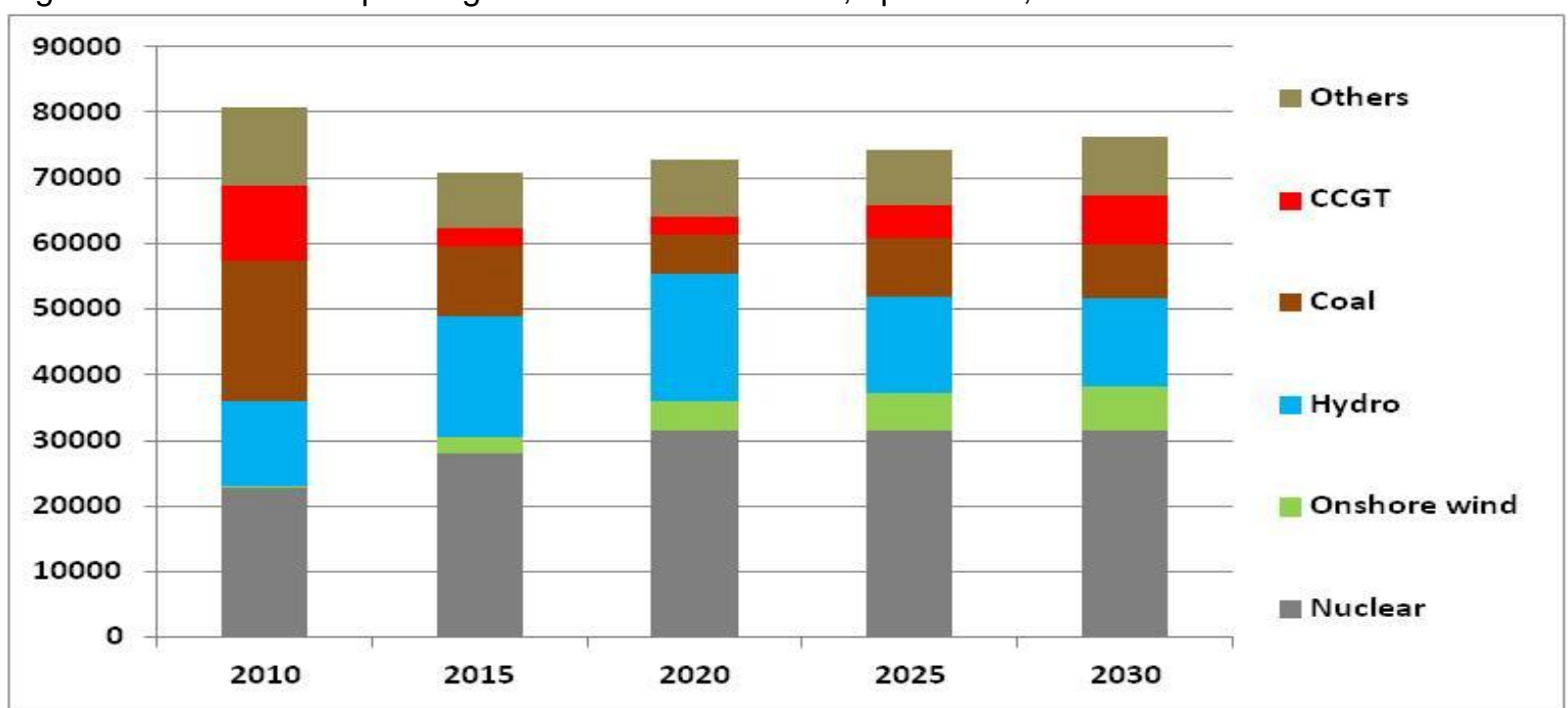

Source: 2010: IEA (2013e), table 3 for each country; scenario: Author

If this happens, then gas demand will drop significantly in the 2010s before starting to recover slowly in the 2020s as shown in Figure 75.

\footnotetext{
${ }^{167}$ For more information, see Ministry of Employment and Economy: http://www.tem.fi/en/energy ; the National Renewable Energy Action Plan to the European Commission, ; Ecologic Institute \& Eclareon (Finland)
} 
Figure 75: Scenario for natural gas demand in Finland, up to 2030, in $\mathrm{Bcm}$

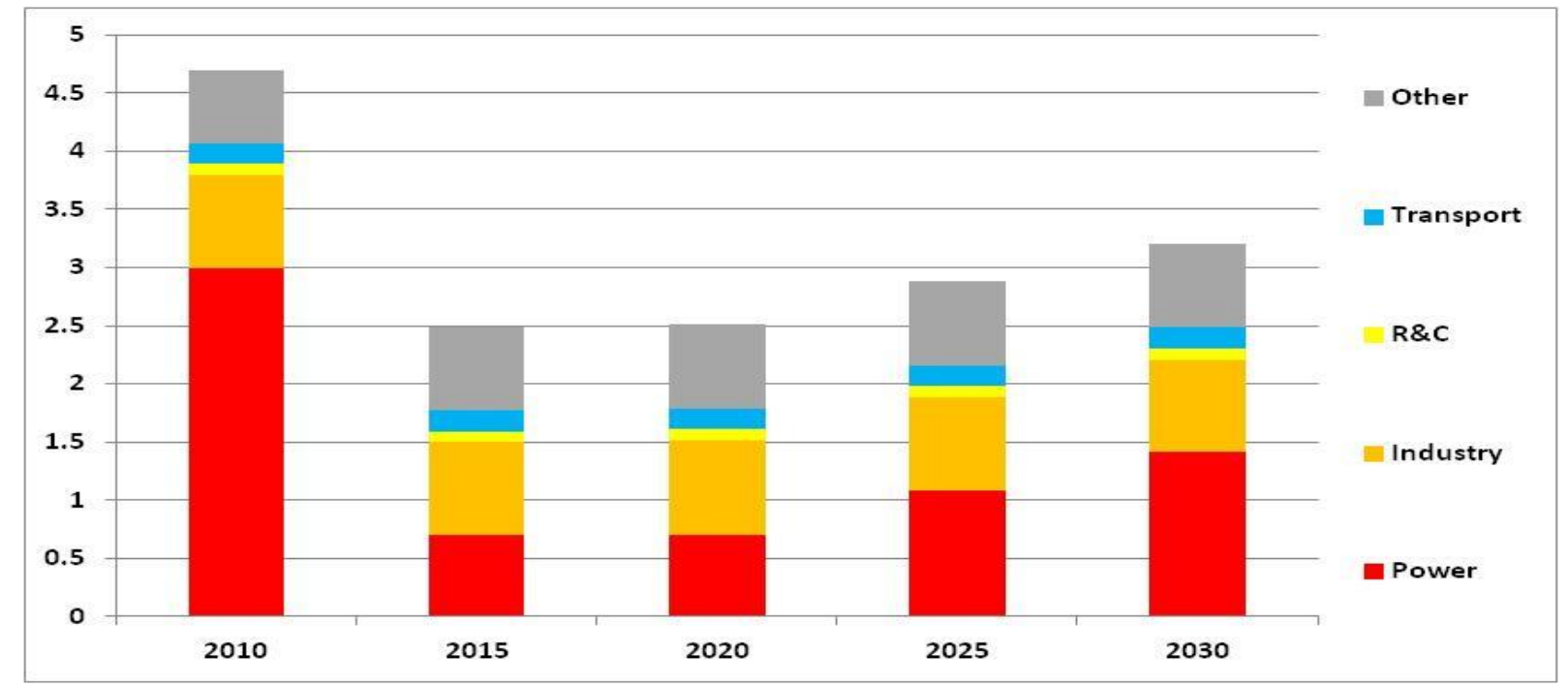

Source: 2010: IEA (2013a), table 3 for each country; scenario: Author 

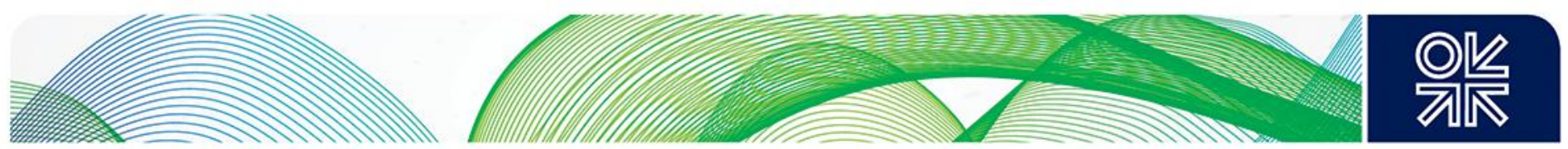

\section{France}

\section{Background}

In 2012, nuclear represented the largest share of the TPES (44\% share), followed by oil (30\%) and gas (15\%). France is import dependant for about half of its on energy needs and for almost $100 \%$ of its natural gas requirements. ${ }^{168}$

Total gas consumption was just over $44 \mathrm{Bcm}$ in 2012, about $4 \%$ below its pre-crisis level (2008). The $R \& C$ sector was the largest consumer (46\% of demand in 2011$)$, before the industrial sector $(23 \%)$ and the power sector $(21 \%) .{ }^{169}$

France is the second biggest electricity market in Europe, with power supply at about $474 \mathrm{TWh}$ in $2011,4.3 \%$ below 2008 levels. Gross production was higher than the national needs by $18 \%$ but even with 58 nuclear reactors designed to operate 24 hours a day, France doesn't have enough capacity to meet peak winter demand and imports electricity during cold snaps in winter. ${ }^{170}$ In 2012, the generation mix was largely dominated by nuclear with a $76 \%$ share, followed by hydro power $(11 \%)$. Natural gas and coal had each a $4 \%$ share. Renewables (excluding hydro) accounted for only $3 \% .{ }^{171}$ If the assumptions on available gas-fired capacity in 2008 and 2012, which are based on Eurelectric and IEA data, are correct, ${ }^{172}$ then the average load factor of the gas-fired power plants in 2012 was about $25 \%$, down from about $30 \%$ in 2008 . These plants are mostly used to make up for peak demand during winter.

\section{Targets and assumptions}

According to the IMF November 2013 outlook [Figure 76], GDP declined in 2008-2009, and after a brief recovery in 2010-2011, was expected to be very low in 2012-2013, but to recover progressively between 2014 and 2018.

Figure 76: GDP annual growth in France (\%), in constant prices, 2000-2018 (forecast from 2012)

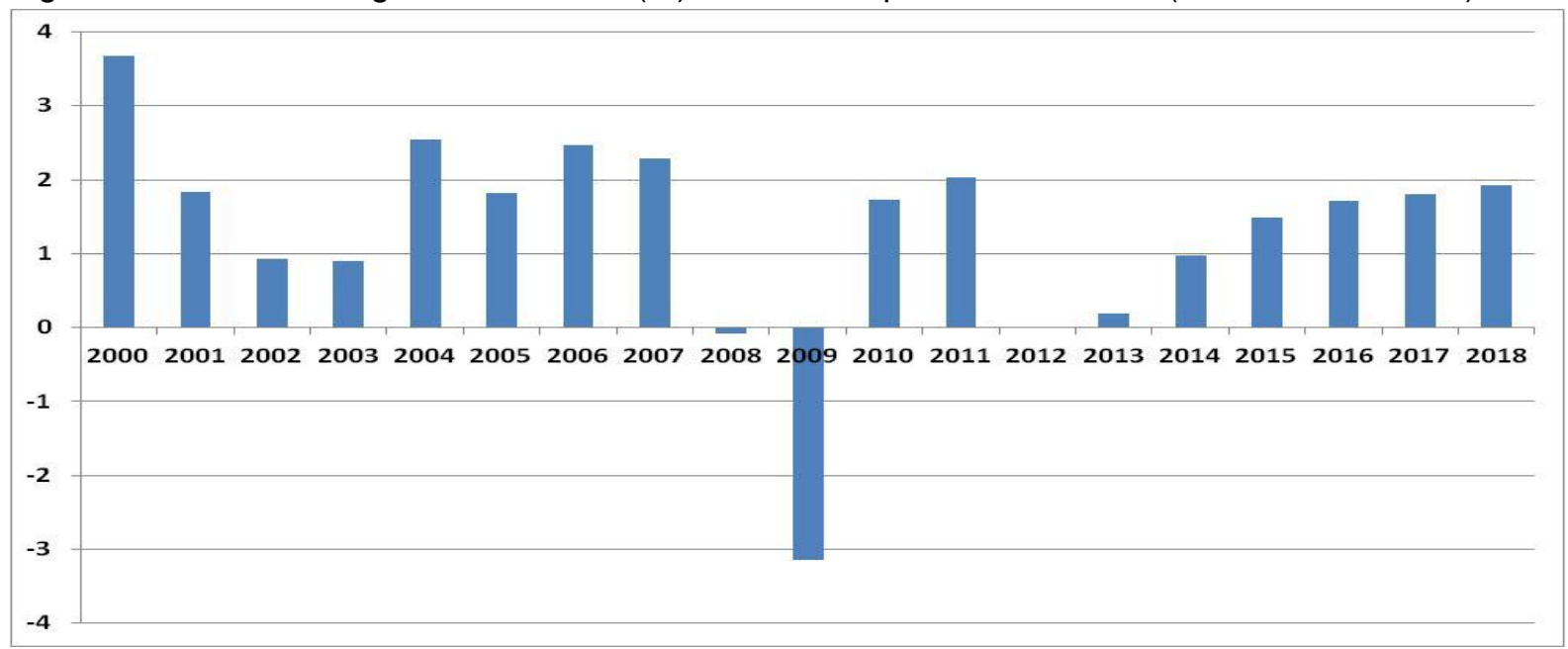

Source: IMF (2013)

\footnotetext{
${ }^{168}$ IEA (2013a), Country data, table 1

169 IEA (2010a) and IEA (2013a), Country data, table 3

170 IEA (2010b) and IEA (2013e), Part III, tables 1.1 and 1.2

171 IEA (2013e), Part III, Country data, table 3

172 IEA (2013e), Part III, table 2.12; Eurelectric (2012), table 3.1.1.3.
} 
France has entered into a national debate about its energy transition to meet its long range target to reduce $\mathrm{CO}_{2}$ emissions by $75 \%$ by 2050 (while maintaining security of supply and the competitiveness of French industry). France needs to decrease its emissions not covered by the EU ETS by $14 \%$ compared to 2005 according to the ESD. Thanks to its heavy reliance on nuclear power for electricity generation (58 nuclear reactors), France is amongst the lowest emitters of GHG, much lower than the EU average. The GHG emissions target should be met even without additional measures, although questions arise if the share of nuclear power in the electricity generation mix is cut down from $75 \%$ to $50 \%$ by 2025 as pledged by President Hollande since his presidential campaign. ${ }^{173}$ The gap is expected to be filled by renewables and better energy efficiency. However, without a much faster development of renewables (12.9\% in 2010 compared to a 2020 target of $23 \%$ ), the country will be left with extending the life of its nuclear reactors ${ }^{174}$ or may build gas-fired plants. Some gas plants are expected to be built to meet peak winter demand even if the share of nuclear power remains at $75 \% .{ }^{175}$ It is worth noting that the nuclear reactors operate on a seasonal basis, with more power being produced in winter than in the summer (France has a strong seasonality of power demand due to the electrification of the residential sector). The reactors have also displayed some good flexibility to cope with a sudden rise in wind power as shown in the early $2014 .{ }^{176}$ Although nuclear capacity is not suited to act as the main back up of renewables, this proves that it can be so used on occasion. The target for better efficiency is a $17.4 \%$ reduction of final energy consumption in $2020 .{ }^{177}$

\section{Scenario}

Natural gas could get some market share from lower coal and potentially nuclear generation in the 2020s in France as seen in Figure 77.

Figure 77: Scenario for power generation mix in France, up to 2030, in GWh

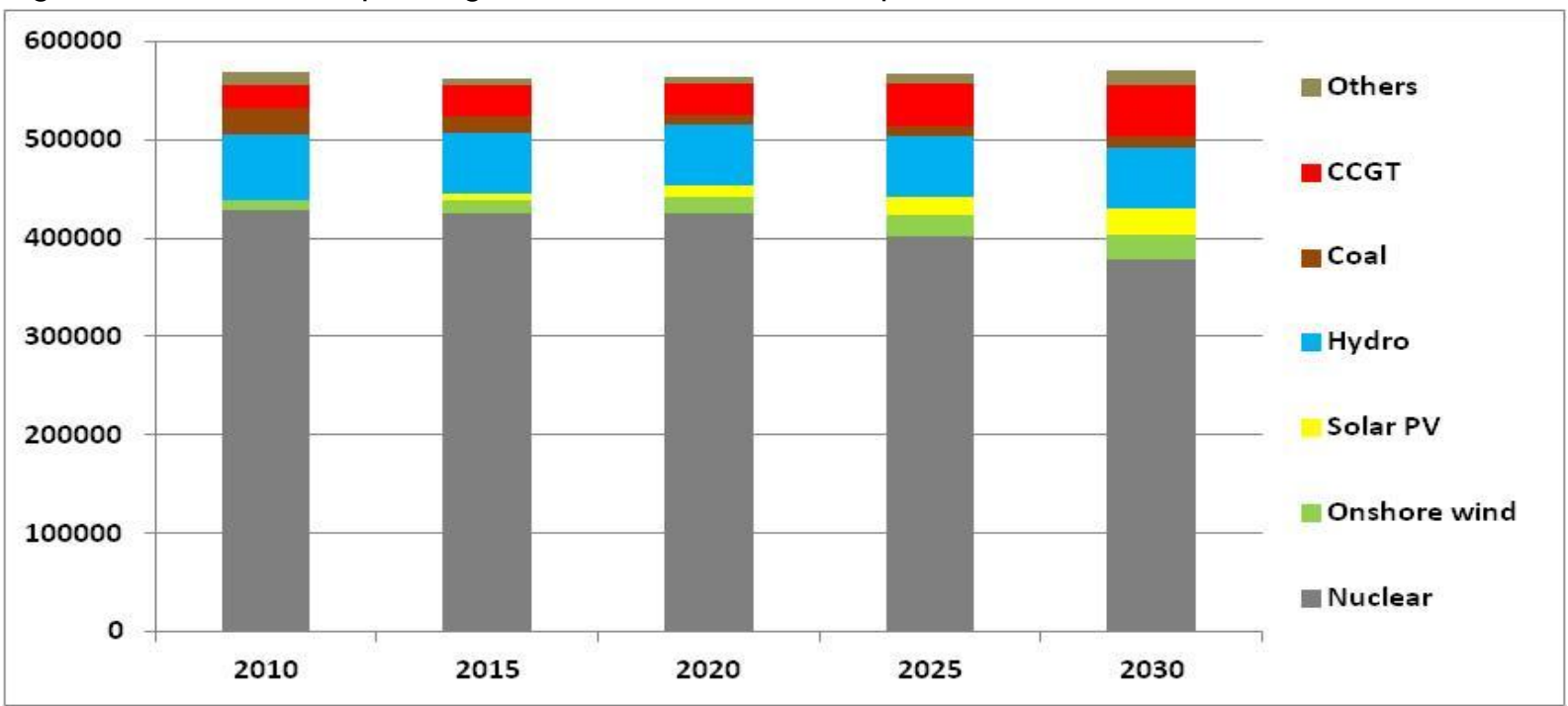

Source: 2010: IEA (2013e), table 3 for each country; scenario: Author

\footnotetext{
173 See Buchan (2014) for more information

${ }^{4}$ Flamanville is costing $€ 8.5$ billion $(1.65 \mathrm{GW})$ while 10 -year major refit will cost $€ 55$ billion for 58 reactors. Source: Argus (February 2014), p.5

${ }^{5}$ For more information, see the National Renewable Energy Action Plan to the European Commission; Ecologic Institute \& Eclareon (France)

176 See Buchan (2014), p.8

http://ec.europa.eu/energy/efficiency/eed/reporting en.htm
} 


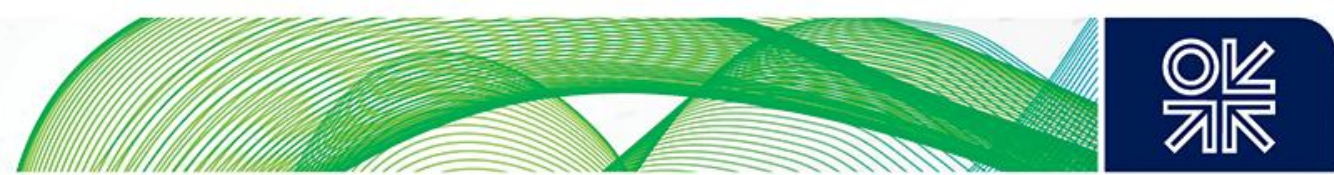

In this scenario, the power sector shows the best opportunities for additional gas demand up to 2030, as do the $R \& C$ and the transport sectors while the industrial sector is going to continue its slow decline as seen in Figure 78.

Figure 78: Scenario for natural gas demand in France, up to 2030, in $\mathrm{Bcm}$

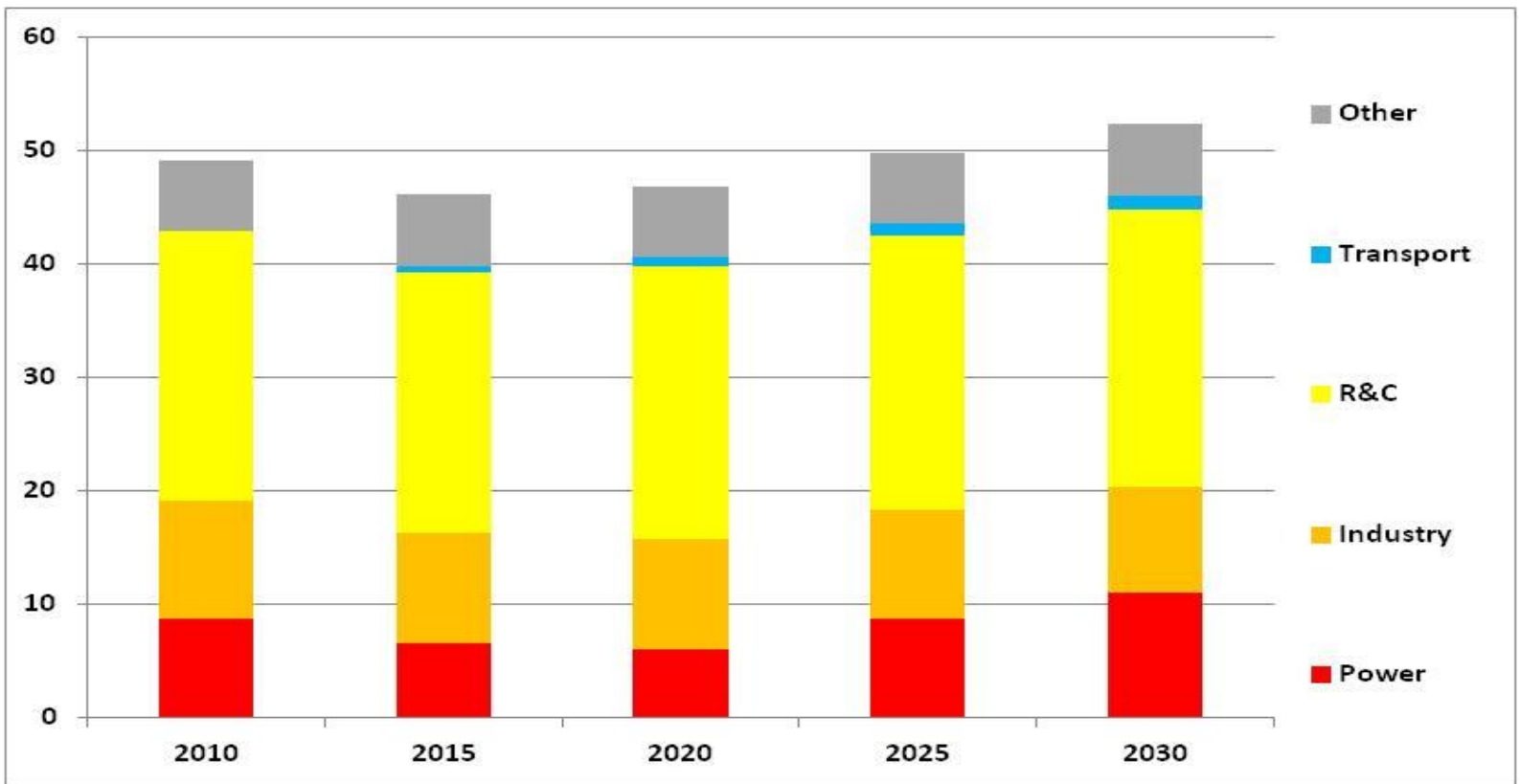

Source: 2010: IEA (2013a), table 3 for each country; scenario: Author 

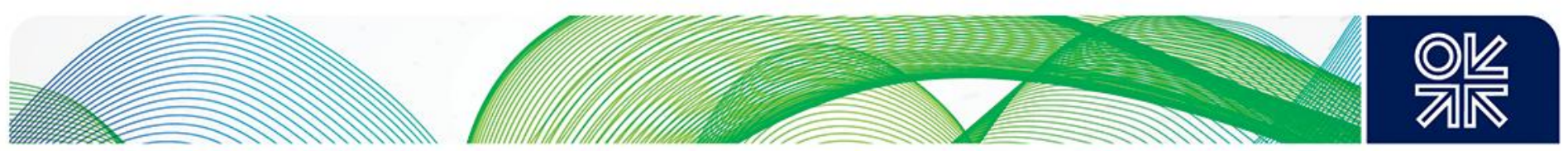

\section{Germany}

\section{Background}

In 2012, oil still represented the largest share of the TPES (33\% share), followed by coal (25\%) and gas (22\%). The country is dependent on imports for $40 \%$ of its energy needs and for up to $86 \%$ of its natural gas requirements. ${ }^{178}$

Total gas consumption was just above $87 \mathrm{Bcm}$ in 2012, about $11 \%$ below its pre-crisis level (2008). The $R \& C$ sector was the largest consumer $(41 \%$ of demand in 2011), before the industrial sector $(27 \%)$ and finally the power sector $(26 \%) .{ }^{179}$ The industrial sector has slowly recovered from the economic downturn with consumption higher by $6.8 \%$ in 2012 compared to 2008 .

Germany is the largest electricity market in Europe with power supply at about 530 TWh in 2011, $1.7 \%$ below 2008 levels. Gross production was above the country needs at $609 \mathrm{TWh}$ (it rose to 618 TWh the following year). ${ }^{180}$ In 2012, coal dominated the electricity generation mix with a $46 \%$ share, followed by nuclear $(16 \%)$, renewables (excluding hydro) $(12 \%)$ and then gas at only $11 \% .{ }^{181}$

If the assumptions on available gas-fired capacity in 2008 and 2012, which are based on Eurelectric data, are correct, ${ }^{182}$ then the average load factor of the gas-fired power plants in 2012 was about $32 \%$ (down from about $41 \%$ in 2008), however, these numbers are probably too high with load factors assumed by this author to be closer to $20-25 \%$ in 2012 .

\section{Targets and assumptions}

According to the IMF November 2013 outlook [Figure 79], GDP declined in 2009, but annual changes are expected to remain positive up to 2018 .

Figure 79: GDP annual growth in Germany (\%), in constant prices, 2000-2018 (forecast from 2012)

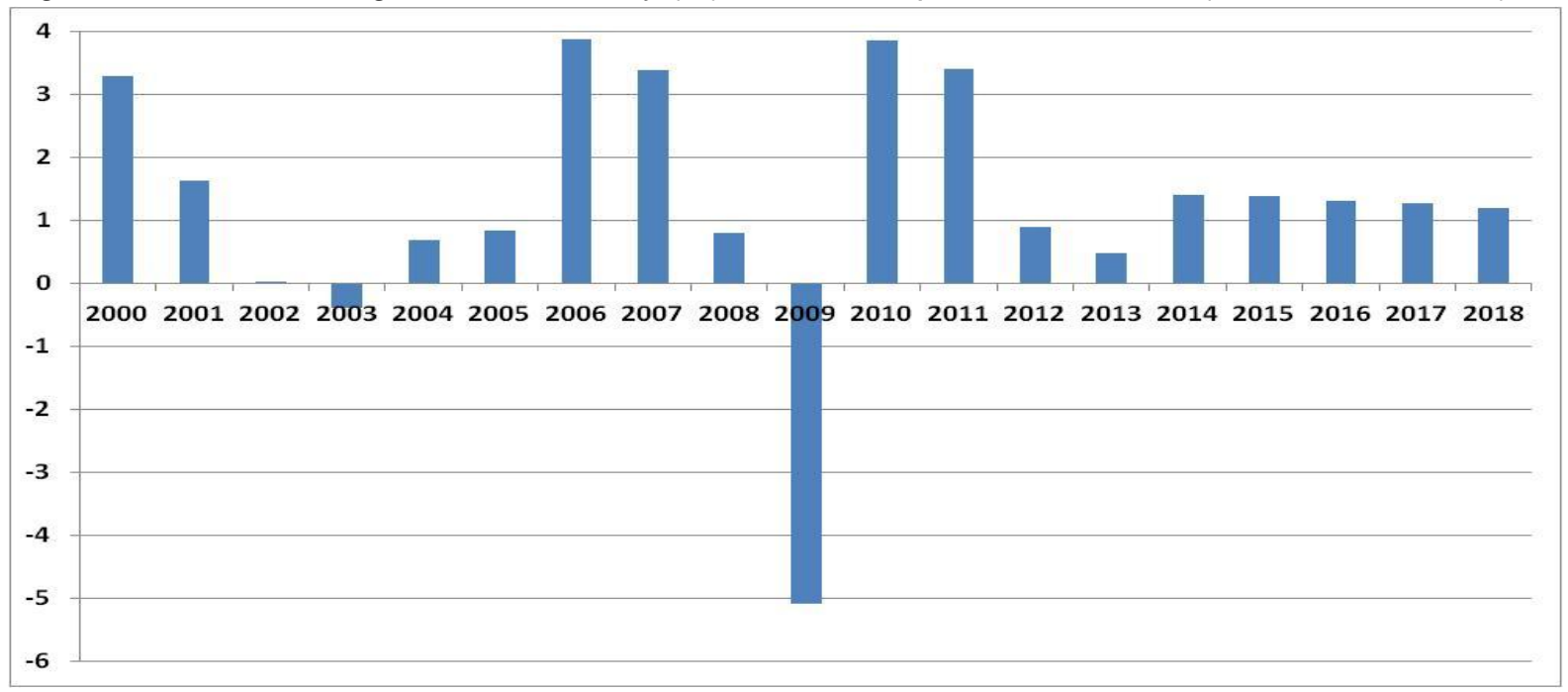

Source: IMF (2013)

\footnotetext{
${ }^{178}$ IEA (2013a), Country data, table 1

179 IEA (2010a) and IEA (2013a), Country data, table 3

180 IEA (2010b) and IEA (2013e), Part III, tables 1.1 and 1.2

181 IEA (2013e), Part III, Country data, table 3

182 Eurelectric (2012), table 3.1.1.3.
} 
The national 2020 targets are $18 \%$ for renewable in gross final energy consumption (about $35 \%$ of electricity), a reduction of $14 \%$ of GHG emissions outside the EU ETS compared to 2005 (which will probably be missed if generation from coal remains strong in the 2010s) ${ }^{183}$ and an annual improvement of energy intensity (energy productivity) by $2.1 \%$ pa on average until $2020 .{ }^{184}$

Developing renewable energies has a central role in the German energy policy. Indeed the 'Energiewende' decided in 2011 can be summarised as being the politically supervised shift of the economy from nuclear (to be phased out by 2022) and fossil fuels dependency to renewables, a path to the renewable energies era. Germany increased its renewables target of $35 \%$ of electricity supply by 2020 to $40 \%$ in late 2013 , and aims for $50 \%$ of electricity supply from renewables by 2030 . With already more than $30 \mathrm{GW}$ of wind capacity and more than $30 \mathrm{GW}$ of solar capacity, the country seems on the right path to achieve its renewable goal. The fast increase in intermittent renewable energy in the decade through 2012 intensified the need for back up plants. Interestingly, most of the intermittency $(2 / 3)$ is dealt by with flexing the generation of new lignite plants (high efficiency, lower $\mathrm{CO}_{2}$ emissions ${ }^{185}$ and flexible) with gas plants roughly responsible for the rest of it. Cross border connections also play an important role, which means that the national energy policy is starting to have serious impacts on the energy markets of its neighbouring countries.

The renewable technology to replace nuclear energy is costly and is starting to be a discussion even at political level with state guarantees expected to have amounted to $€ 17$ billion in 2013 ( $€ 14$ billion in 2012). Chancellor Angela Merkel has made reforming renewable-energy subsidies to reduce the cost of the country's switch from nuclear power the top priority of her third-term government. ${ }^{186}$ In addition Germany is also struggling to come to grips with network bottlenecks which are a major problem in Southern Germany where no more plants closures may be allowed ${ }^{187}$ until thousands of kilometres of power grids required to ensure that green energy reaches consumers are built. At baseload prices below $€ 40 / \mathrm{MWh}$ (which was the case for most of 2013), all fossil fuel generation is in financial difficulty, but it has been most difficult for gas plants where utilities have been losing money by burning gas for power since 2012. Negative spark spread, a spark vs clean dark spread at about $€ 25 / \mathrm{MWh}$ and the disappearance of the spread between mid-day electricity prices vs night prices means that gas plants can't operate for enough hours to cover their costs. Several GW of capacity of coal (and gas) plants will be shut down in the 2010s for economic reasons, ${ }^{188}$ while the LCPD and the IED will probably have no direct impact on coal plants closures post 2015. Some $8.4 \mathrm{GW}$ of nuclear closed down in 2011, 12 GW will shut down by 2022, but the phase out of nuclear will not necessarily translate into extra gas demand for power in the 2010s as new coal fired and renewable capacity and energy efficiency measures are expected to likely compensate for the permanent closure of unprofitable fossil fuels-fired plants. However the late 2010s and 2020s and beyond could a different story, especially if the difficulties in building new coal plants remain and/or if commercial CCS does not develop as the country will need to build new plants by 2019/2020 especially if action isn't taken to keep existing facilities online.

\section{Scenario}

Natural gas never played a major role in the German generation mix and its role is likely to decline in the 2010s amid over capacity due to fast growth in renewables and more attractive coal prices.

\footnotetext{
${ }^{183}$ For more information, see the National Renewable Energy Action Plan to the European Commission; Ecologic Institute \& Eclareon (Germany)

http://ec.europa.eu/energy/efficiency/eed/reporting en.htm

185 But still substantially higher than a gas CCGT

${ }^{186}$ Bloomberg (January 2014)

${ }^{7}$ German utilities have asked to shut or mothball total 42 generating units with capacity of about 11,100MW. Source: Bloomberg (February 2014)

About $15 \mathrm{GW}$ already online longer than originally scheduled, mostly hard coal, but also some lignite and gas plants.
} 
However, by the end of the 2010s and in the 2020s, gas could recover its 2010 level in the mix thanks to the phasing out of nuclear plants and slow decline of coal generation as seen in Figure 80.

Figure 80: Scenario for power generation mix in Germany, up to 2030, in GWh

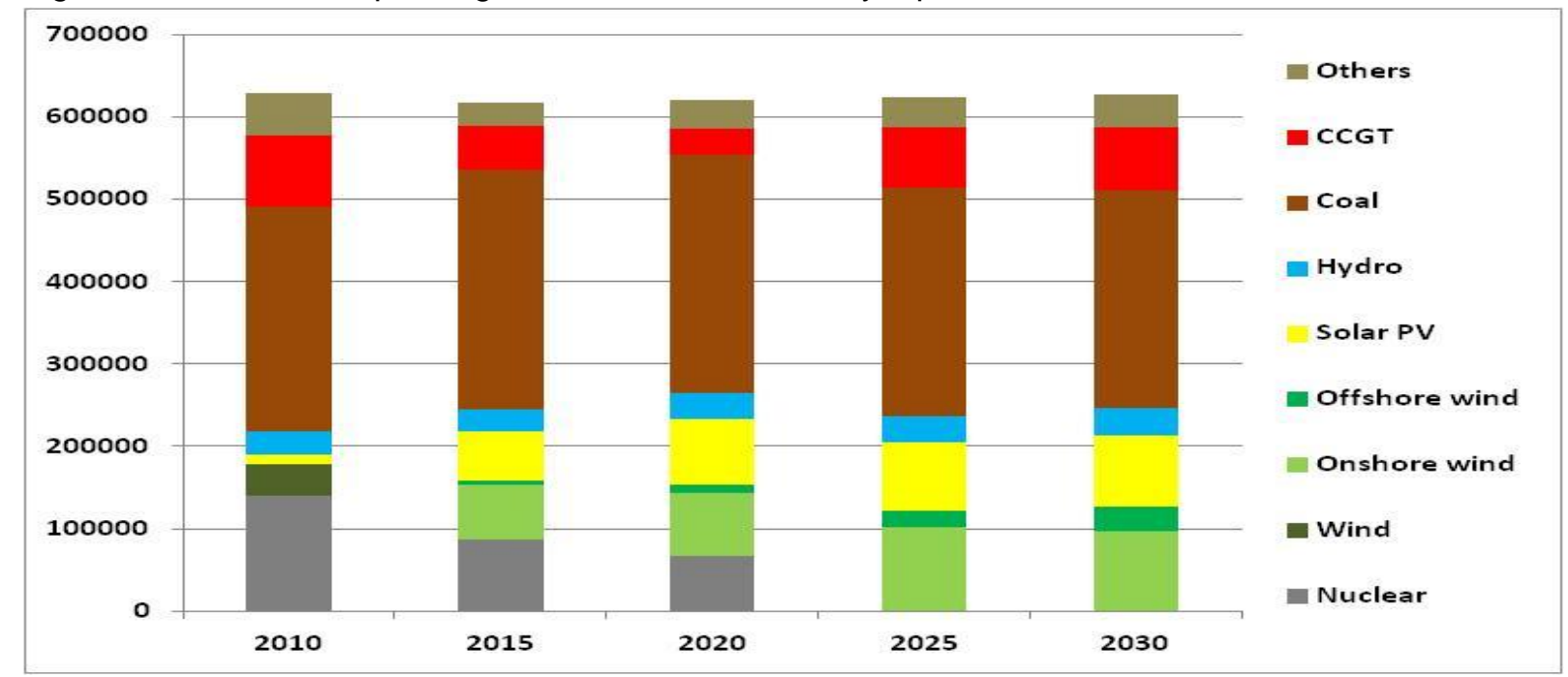

Source: 2010: IEA (2013e), table 3 for each country; scenario: Author

The power and transport sectors appear to be the key drivers to gas demand recovery in the 2020s while the industrial and $R \& C$ both show slow but steady decline as efficiency measures take their toll as in Figure 81. Strong growth in the transport sector is strongly conditioned to continued political support, it will not happen without it.

Figure 81: Scenario for natural gas demand in Germany, up to 2030, in Bcm

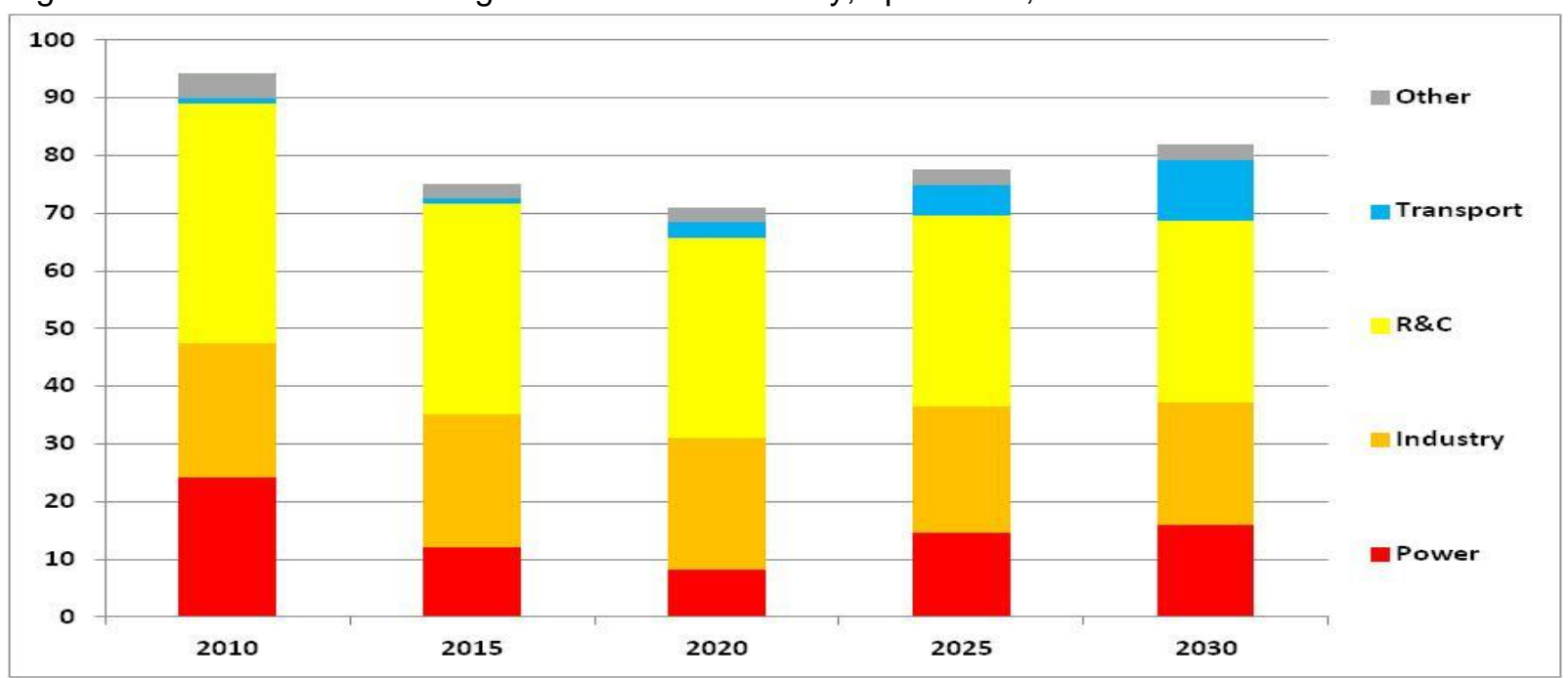

Source: 2010: IEA (2013a), table 3 for each country; scenario: Author 

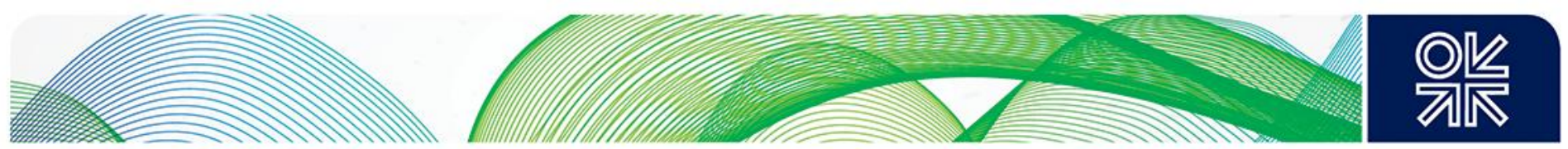

\section{Greece}

\section{Background}

In 2012, TPES was dominated by oil (45\% share) and coal (32\%), followed by gas (15\%). The country is dependent on energy imports for about $61 \%$ of its needs, including for the totality of its natural gas requirements. ${ }^{189}$

Total gas consumption was about $4.4 \mathrm{Bcm}$ in $2012,4.8 \%$ above its pre-crisis level (2008). The power sector dominated the demand $(61 \%$ of demand in 2011$)$, before the industrial sector $(14 \%)$ and the R\&C sector $13 \% .{ }^{190}$ The industrial sector strongly recovered from the economic downturn and the sector consumed $19 \%$ more gas in 2011 compared to 2008.

Power supply reached 57 TWh in 2011, 11\% below 2008 levels. Gross production was 60 TWh (and about 58 TWh the following year). ${ }^{191}$ In 2012, coal had the highest share of the electricity generation mix at $56 \%$, followed by gas (21\%), hydro (8\%) and renewables $(8 \%){ }^{192}$

If the assumptions on available gas-fired capacity in 2012, which are based on IEA data, are correct, ${ }^{193}$ then the average load factor of the gas-fired power plants in 2012 was about $37 \%$.

\section{Targets and assumptions}

After a difficult period of deep recession from 2008 to 2013, the IMF expects a recovery in GDP growth in 2014 until the end of the period considered in its November 2013 outlook [Figure 82].

Figure 82: GDP annual growth in Greece (\%), in constant prices, 2000-2018 (forecast from 2013)

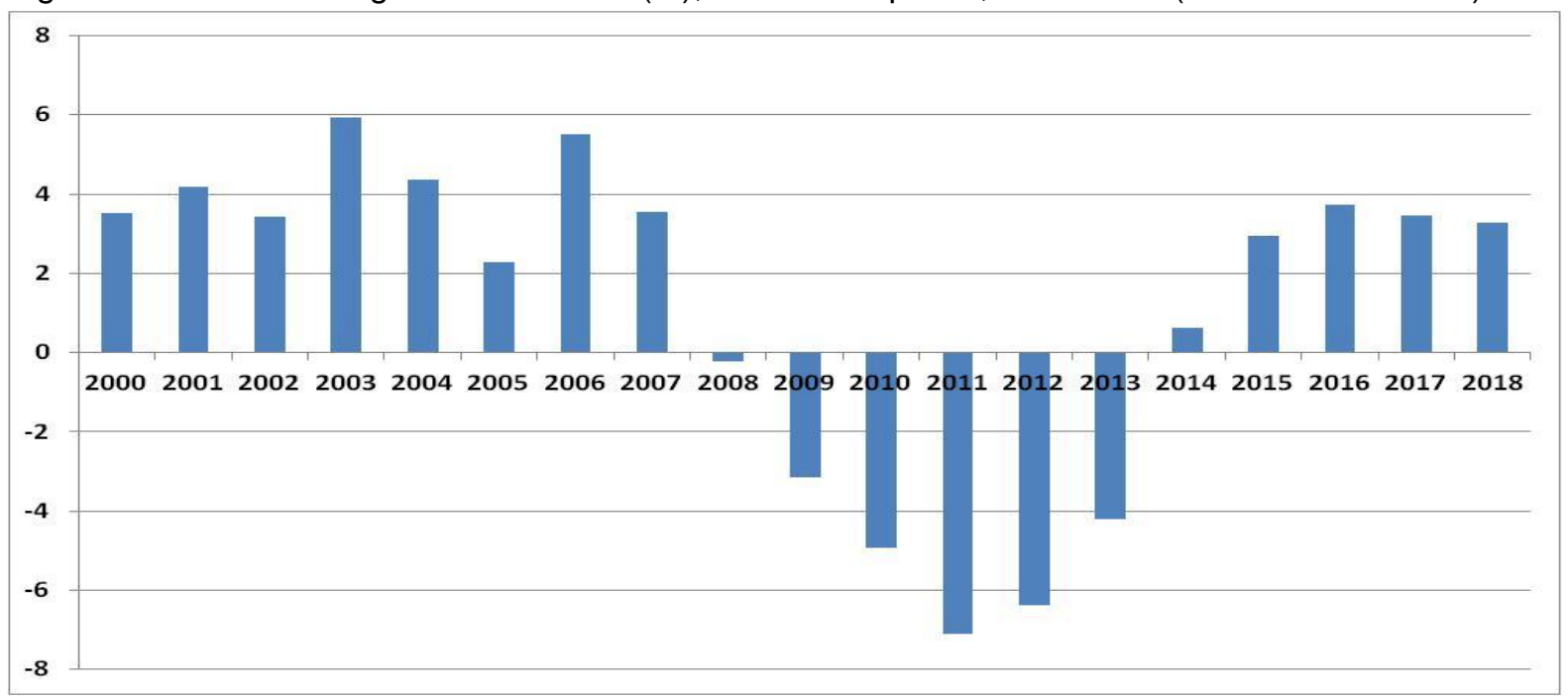

Source: IMF (2013)

Following the economic crisis that lasted longer than in the rest of Europe, climate change has not been the top priority in the country but emissions have been cut drastically as a result. The National Climate Change Programme was last revised in 2007. The EU 2020 target for renewable is $18 \%$ of

\footnotetext{
${ }^{189}$ IEA (2013a), Country data, table 1

190 IEA (2010a) and IEA (2013a), Country data, table 3

${ }^{191}$ IEA (2010b) and IEA (2013e), Part III, tables 1.1 and 1.2

192 IEA (2013e), Part III, Country data, table 3

193 IEA (2013e), Part III, table 2.12
} 
final consumption (the country has an even higher national target of $20 \%$ ), the target for GHG emissions is a reduction of $4 \%$ compared to 2005 , which seems likely to be missed without additional measures. ${ }^{194}$

\section{Scenario}

If the country manages to develop significant wind capacity, it is probable that the role of gas in the mix will not increase as previously expected in the 2000s as seen in Figure 83.

Figure 83: Scenario for power generation mix in Greece, up to 2030, in GWh

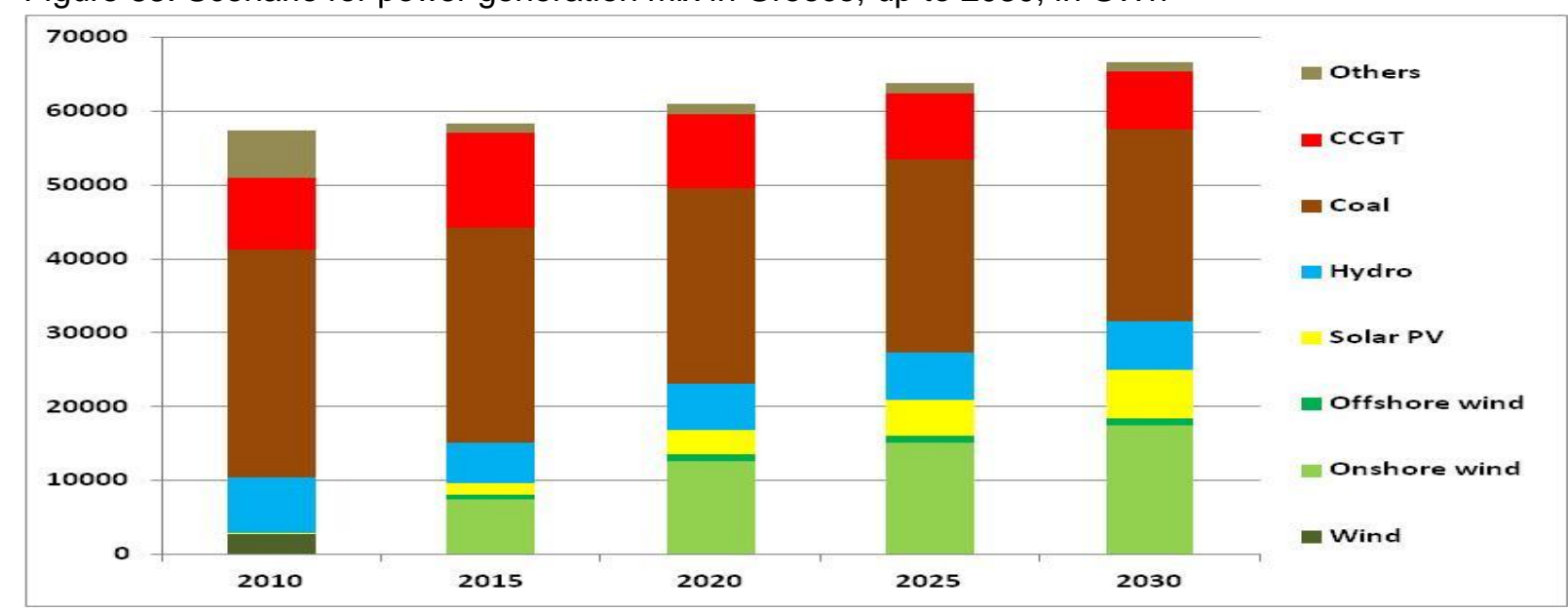

Source: 2010: IEA (2013e), table 3 for each country; scenario: Author

If this scenario happens in the power sector, then total gas demand will be influenced and will show a decline post 2015 despite slow growth in the other sectors as in Figure 84.

Figure 84: Scenario for natural gas demand in Greece, up to 2030, in Bcm

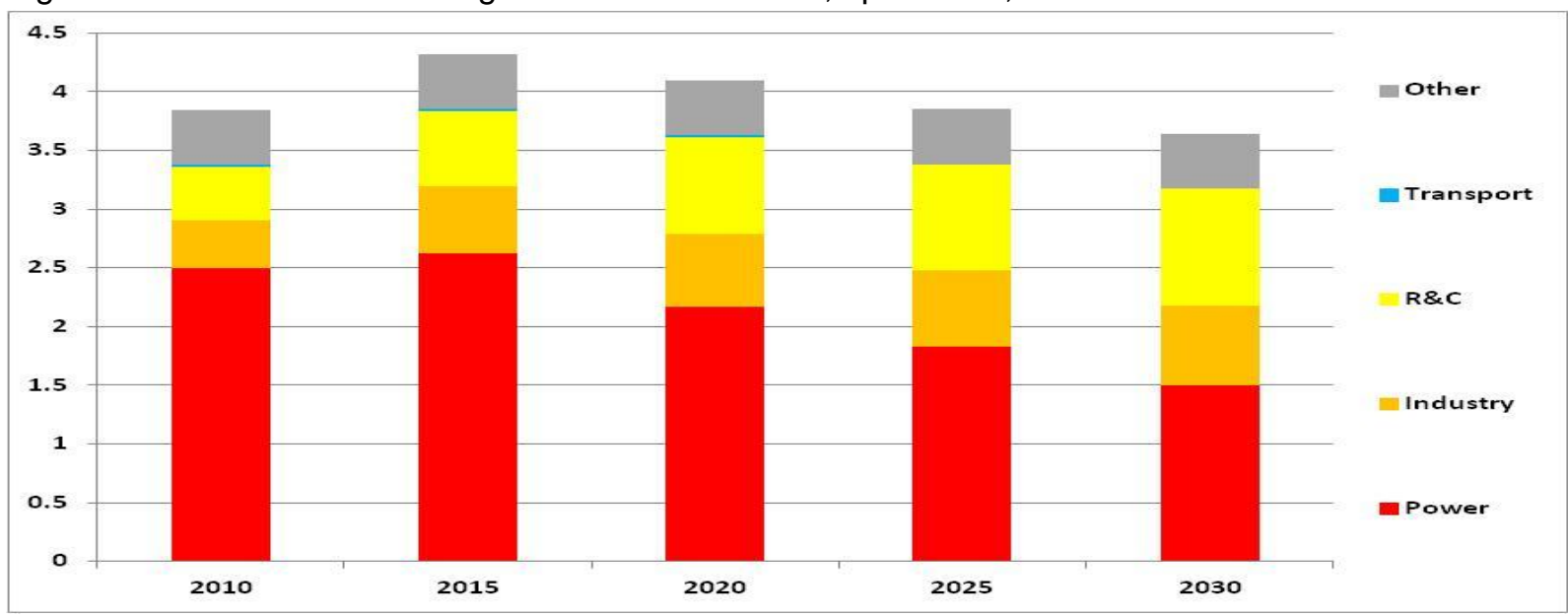

Source: 2010: IEA (2013a), table 3 for each country; scenario: Author

\footnotetext{
${ }^{194}$ For more information, see the National Renewable Energy Action Plan to the European Commission; Ecologic Institute \& Eclareon (Greece)
} 

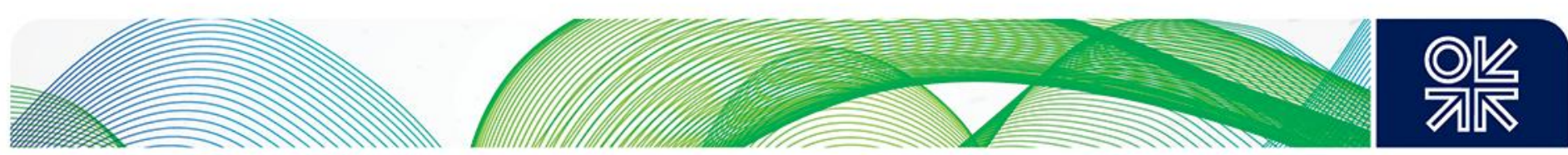

\section{Hungary}

\section{Background}

In 2012, natural gas held the largest share of the TPES (36\% share), followed by oil (24\%), nuclear $(18 \%)$ and coal (11\%). The country imports about $55 \%$ of its energy needs but almost $80 \%$ of its natural gas requirements. ${ }^{195}$

Total gas consumption was just over $10 \mathrm{Bcm}$ in 2012 , about $22 \%$ below its pre-crisis level (2008). The $R \& C$ sector was the largest consumer (50\% of demand in 2011 ), before the power sector $(29 \%)$ and the industrial sector (10\%). ${ }^{196}$

The power supply was 40 TWh in 2011, almost 3\% below 2008 levels. Gross production only fulfilled about $90 \%$ of the national needs. ${ }^{197}$ In 2012, the generation mix was dominated by nuclear with a $46 \%$ share, followed by gas (27\%) and coal (19\%). Renewables (including hydro) accounted for only $3 \%$ of the total. ${ }^{198}$

If the assumptions on available gas-fired capacity in 2008 and 2012, which are based on Eurelectric and IEA data, are correct, ${ }^{199}$ then the average load factor of the gas-fired power plants in 2012 was about $21 \%$, down from about $38 \%$ in 2008 .

\section{Targets and assumptions}

According to the IMF November 2013 outlook, after a difficult period between 2007 and 2013, GDP should start growing again at annual rates of 1.5-2\% between 2014 and 2018 [Figure 85].

Figure 85: GDP annual growth in Hungary (\%), in constant prices, 2000-2018 (forecast from 2012)

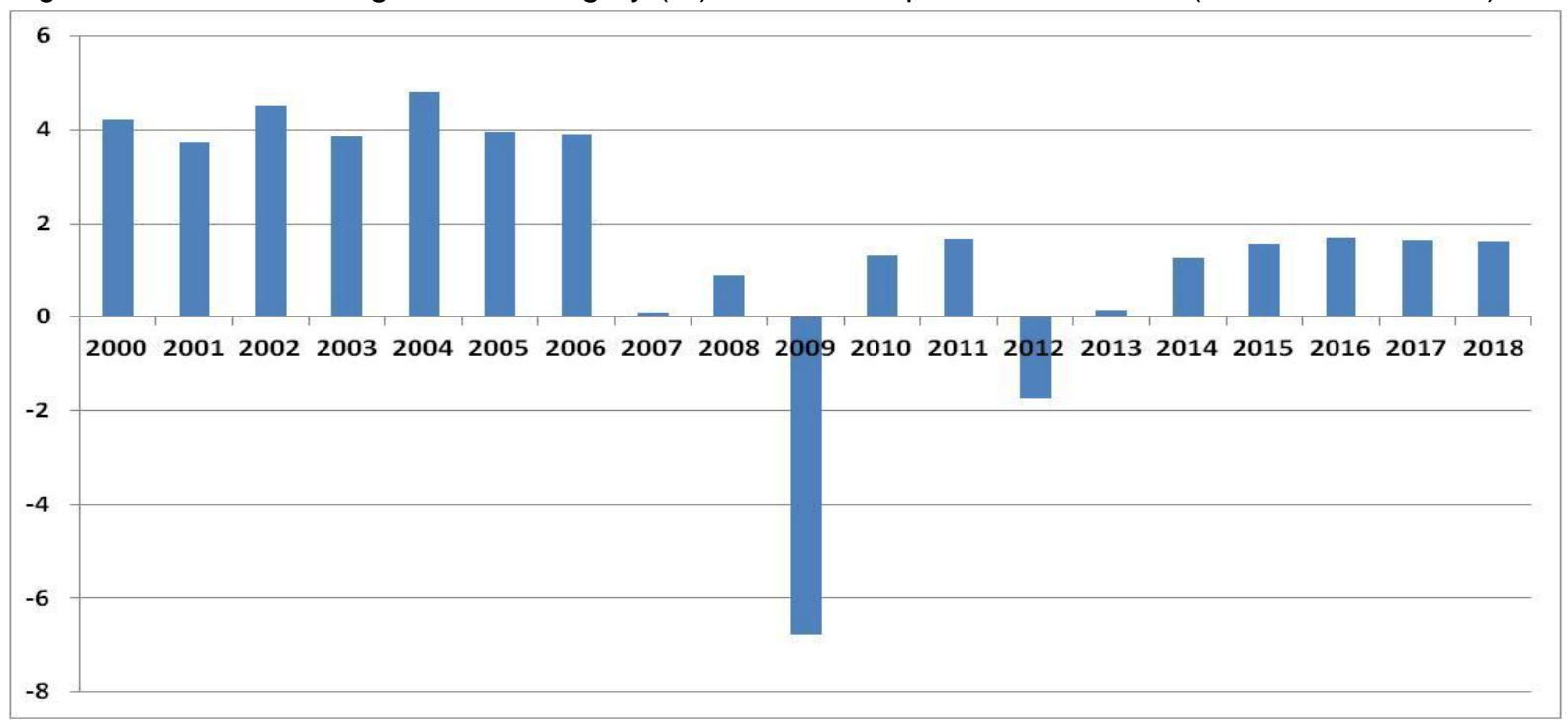

Source: IMF (2013)

\footnotetext{
195 IEA (2013a), Country data, table 1

196 IEA (2010a) and IEA (2013a), Country data, table 3

${ }^{197}$ IEA (2010b) and IEA (2013e), Part III, tables 1.1 and 1.2

198 IEA (2013e), Part III, Country data, table 3

199 IEA (2013e), Part III, table 2.12; Eurelectric (2012), table 3.1.1.3.
} 

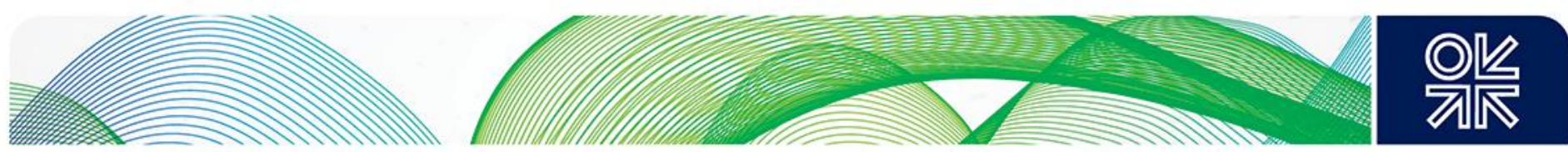

Measures to increase the role of renewables (especially in heating) and improve efficiency already exist and find their place in economic development discussions rather than energy and climate change debates. By 2020, the country can increase its emissions not covered by the EU ETS by $10 \%$ compared to 2005 according to the ESD and needs to reach $13 \%$ of its final energy consumption from renewables. Hungary also considers the expansion of its nuclear plant, including new reactors. The government has already extended by 20 years the original 30 -year lifetime of its Paks Nuclear Power plant which ended in 2012 due to the lack of alternative generation capacity. ${ }^{200}$

\section{Scenario}

Natural gas plays an important part in the generation mix, but it will see its role being contested by additional growth of hydro and/or nuclear despite the room left in the mix by the slow decline of the coal plant fleet as seen in Figure 86.

Figure 86: Scenario for power generation mix in Hungary, up to 2030, in GWh

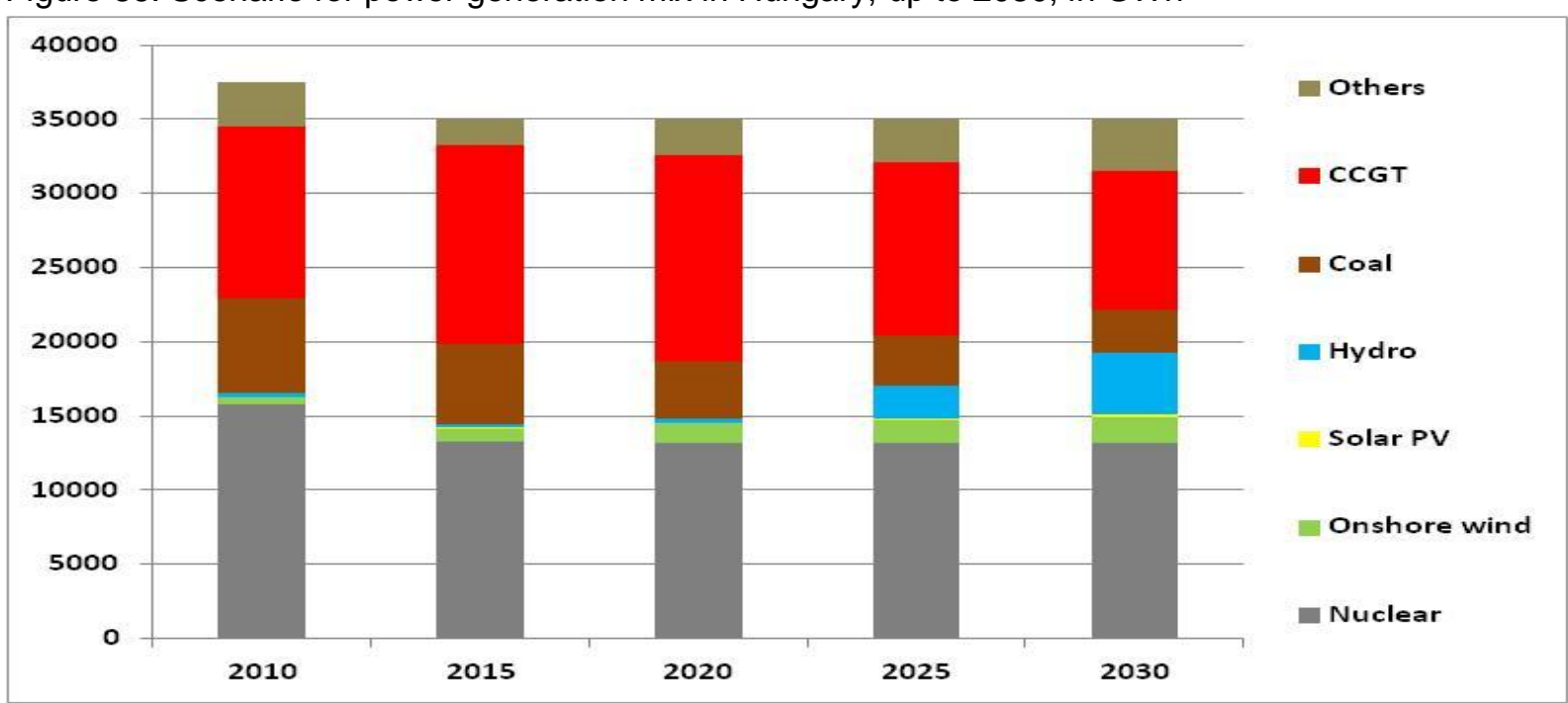

Source: 2010: IEA (2013e), table 3 for each country; scenario: Author

If this scenario happens, then gas demand will start a slow decline post 2020 until the end of the period as seen in Figure 87.

\footnotetext{
${ }^{200}$ For more information, see the National Renewable Energy Action Plan to the European Commission; Ecologic Institute \& Eclareon (Hungary)
} 
Figure 87: Scenario for natural gas demand in Hungary, up to 2030, in Bcm

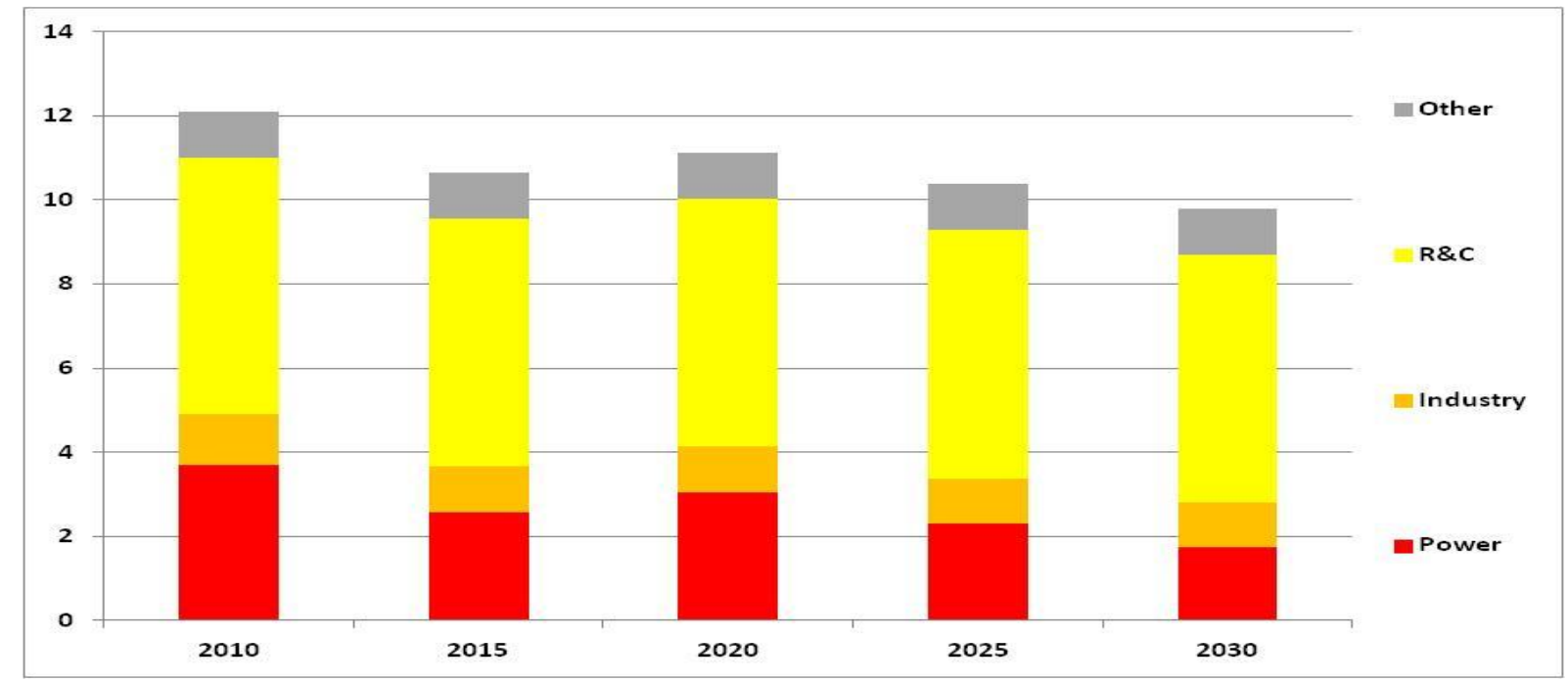

Source: 2010: IEA (2013a), table 3 for each country; scenario: Author 

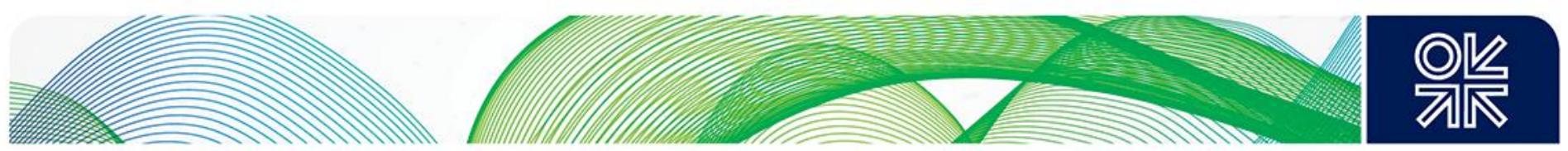

Ireland

\section{Background}

In 2012, oil still represented the largest share of the TPES (43\% share), followed by gas (30\%) and coal $(20 \%)$. The country is dependant for $90 \%$ of its energy needs $(92 \%$ of its natural gas requirements). ${ }^{201}$

Total gas consumption was about $4.7 \mathrm{Bcm}$ in 2012 , almost $10 \%$ below its pre-crisis level (2008). The power sector was the biggest consumer (61\% of demand in 2011$)$, before the R\&C sector $(27 \%)$ and finally the industrial sector (15\%). ${ }^{202}$ The latter nonetheless grew by about $22 \%$ since its pre-crisis level (2008).

Power supply was just below 27 TWh in 2011, about 5\% below 2008 levels. Gross production was similar at 27.7 TWh (flat the following year). ${ }^{203}$ In 2012, gas dominated the electricity generation mix with a $49 \%$ share, followed by coal (29\%) and renewables (excluding hydro, $14 \%$ - including hydro $18 \%)^{204}$

If the assumptions on available gas-fired capacity in 2008 and 2012, which are based on Eurelectric and IEA data, are correct, ${ }^{205}$ then the average load factor of the gas-fired power plants in 2012 was about $43 \%$ (down from $58 \%$ in 2008 according to this data).

Targets and assumptions

Ireland was in a difficult situation in 2008-2010, but it is expected that GDP growth will recover in the 2010s, especially post 2014 according to the IMF November 2013 outlook [Figure 88].

Figure 88: GDP annual growth in Ireland (\%), in constant prices, 2000-2018 (forecast from 2012)

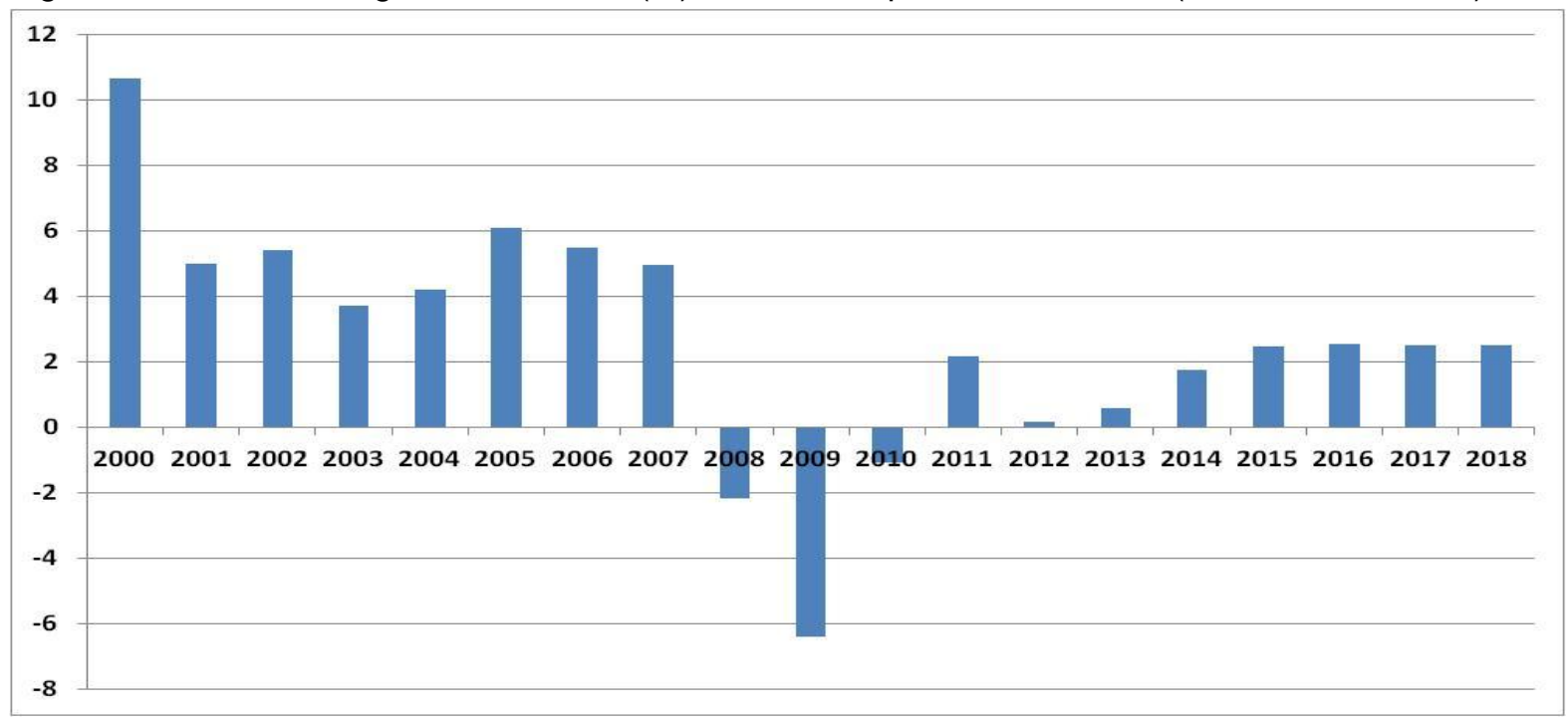

Source: IMF (2013)

\footnotetext{
201 IEA (2013a), Country data, table 1

202 IEA (2010a) and IEA (2013a), Country data, table 3

203 IEA (2010b) and IEA (2013e), Part III, tables 1.1 and 1.2

204 IEA (2013e), Part III, Country data, table 3

205 IEA (2013e), Part III, table 2.12; Eurelectric (2012), table 3.1.1.3.
} 

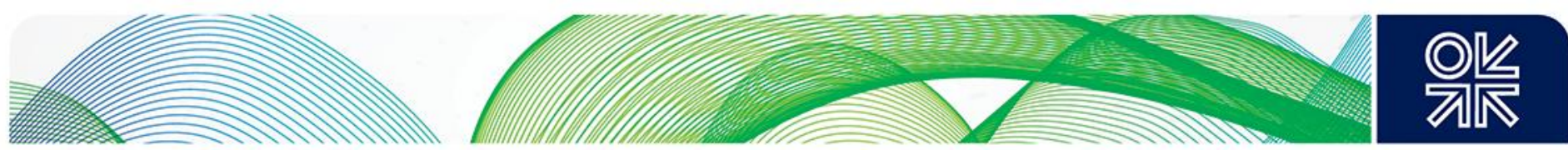

Renewable energy constitutes a core element of the energy policy which is seen as beneficial for climate change but also to ensure secure energy supply. The Irish target for renewable energy in gross final consumption is $16 \%$ by 2020 and the government has set a national target of $40 \%$ of electricity consumption from renewables by 2020 . The country needs to reduce its carbon emissions by $20 \%$ compared to 2005 and increase energy efficiency by $20 \%$ (along with a public sector energy saving target of $33 \%{ }^{206}$ ). Ireland may not be on track to meet its emission reduction target but has strong commitments in term of renewables and energy savings. ${ }^{207}$

\section{Scenario}

Natural gas will continue to play an important role in the country's generation mix even in the case of sustained renewable growth thanks to coal plant retirements and additional power demand as seen in Figure 89.

Figure 89: Scenario for power generation mix in Ireland, up to 2030, in GWh

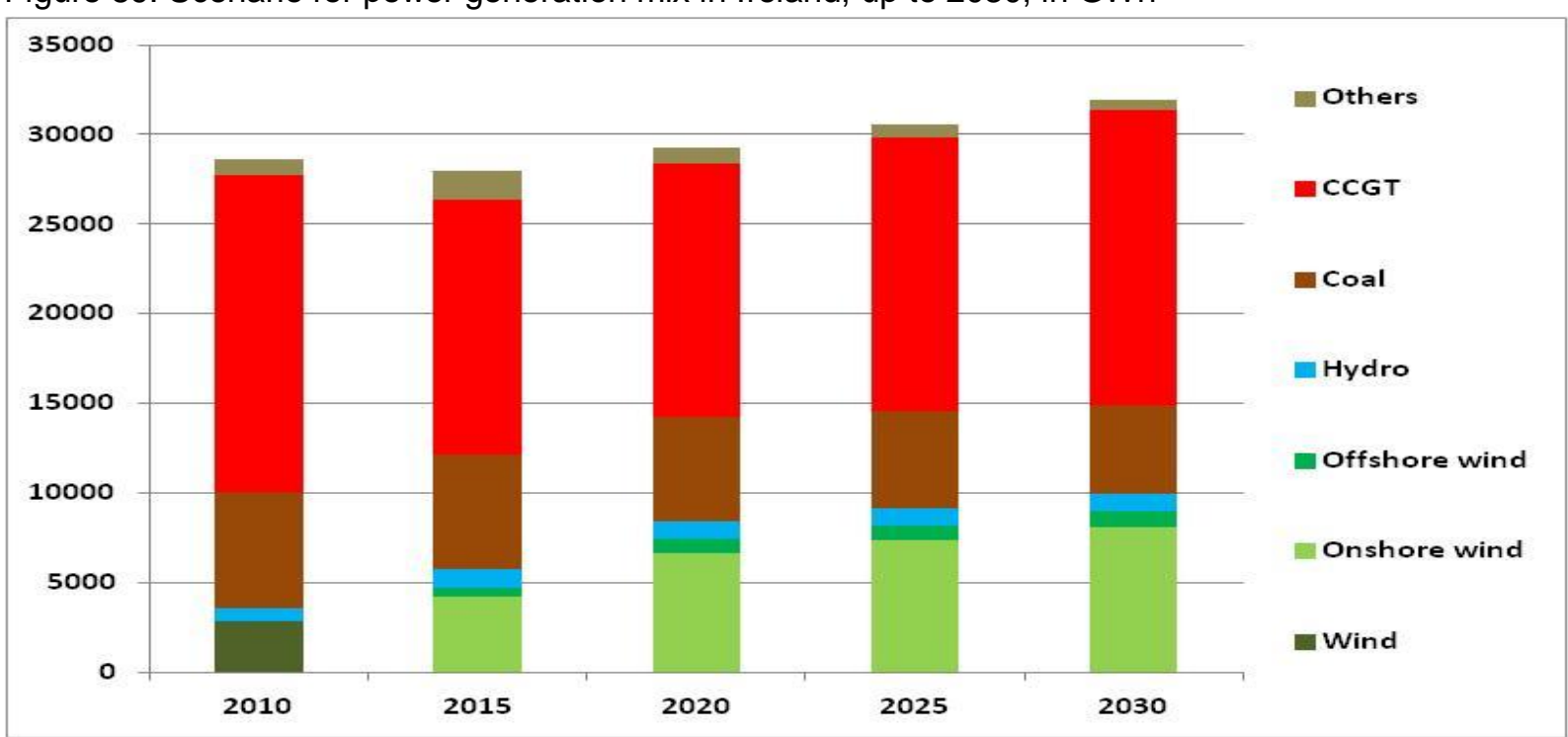

Source: 2010: IEA (2013e), table 3 for each country; scenario: Author

The crisis has had a major impact on gas consumption. The market is expected to recover slowly up to 2030 with slow growth in all three of the major sectors as shown in Figure 90.

${ }_{207}^{206} \mathrm{http} / / /$ ec.europa.eu/energy/efficiency/eed/reporting en.htm

207 For more information, see Sustainable Energy Authority of Ireland: http://www.seai.ie/Renewables/Renewable Energy Policy/, Department of Communications, Energy and Natural Resources http://www.dcenr.gov.ie/energy/energy+efficiency+and+affordability+division/national+energy+efficiency+action+plan.htm, the National Renewable Energy Action Plan to the European Commission, ; Ecologic Institute \& Eclareon (Ireland) 
Figure 90: Scenario for natural gas demand in Ireland, up to 2030, in $\mathrm{Bcm}$

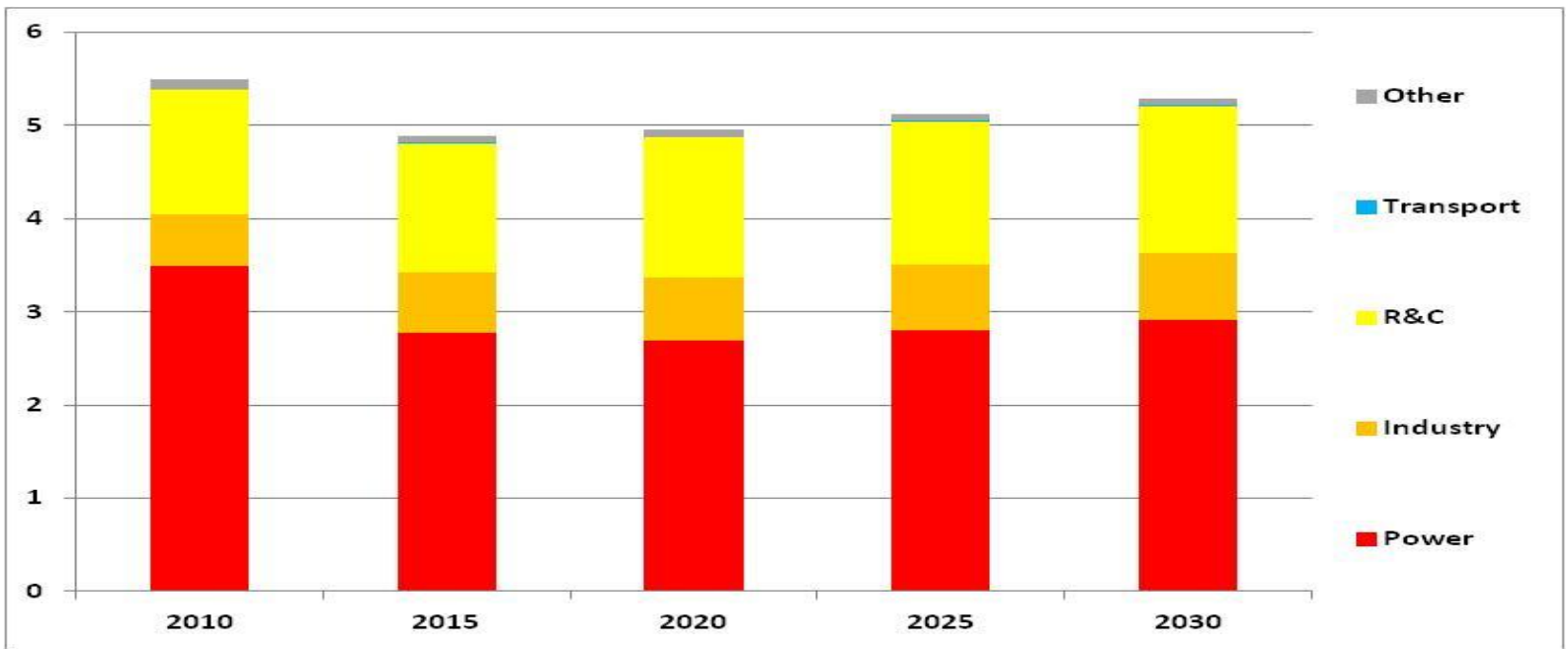

Source: 2010: IEA (2013a), table 3 for each country; scenario: Author 

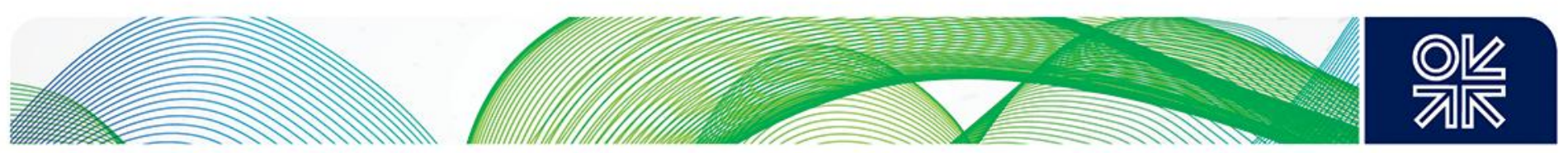

Italy

\section{Background}

In 2012, TPES was dominated by gas (39\% share), oil (35\%) and coal (10\%). The country is dependent on energy imports for about $80 \%$ of its total energy needs and $89 \%$ for its natural gas requirements. ${ }^{208}$

Total gas consumption was about $75 \mathrm{Bcm}$ in 2012, about $12 \%$ below its pre-crisis level (2008). The power and the R\&C sectors dominated gas demand with a $40 \%$ share each in 2011), far above the industrial sector $(15 \%){ }^{209}$

Power supply reached 335 TWh in 2011, 1.4\% below 2008 levels. Gross production was about $10 \%$ below (it dropped to 296 TWh the following year). ${ }^{210}$ In 2012, gas had the highest share of the electricity generation mix (46\%), followed by coal (16\%), hydro (15\%) and renewables $(13 \%) .{ }^{211}$

If the assumptions on available gas-fired capacity in 2008 and 2012, which are based on IEA data, are correct, ${ }^{212}$ then the average load factor of the gas-fired power plants in 2012 was about $29 \%$, down from about $40 \%$ in 2008 (31\% in 2011).

\section{Targets and assumptions}

Italy has been in difficult economic conditions between 2008 and 2013, despite a short recovery in 2010-2011. The IMF expects growth from 2014 onwards in its economic outlook of November 2013 [Figure 91].

Figure 91: GDP annual growth in Italy (\%), in constant prices, 2000-2018 (forecast from 2012)

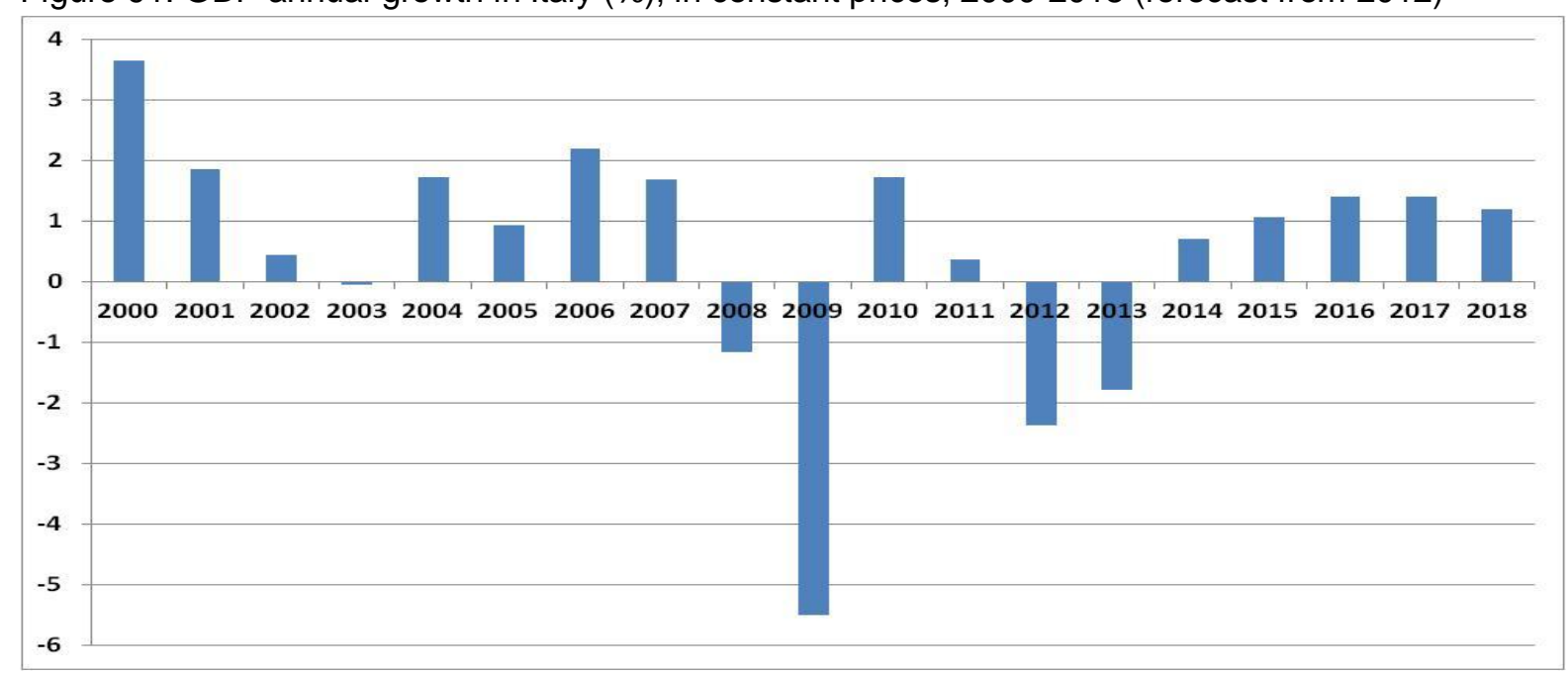

Source: IMF (2013)

The National Energy Strategy was adopted in 2013 and was designed to surpass the EU 2020 targets of renewables and efficiency. According to its EU 2020 commitments, Italy needs to increase the renewable share in gross final energy consumption to $17 \%$ in an effort to make the country less

\footnotetext{
${ }^{208}$ IEA (2013a), Country data, table 1

209 IEA (2010a) and IEA (2013a), Country data, table 3

${ }^{210}$ IEA (2010b) and IEA (2013e), Part III, tables 1.1 and 1.2

211 IEA (2013e), Part III, Country data, table 3

212 IEA (2013e), Part III, table 2.12
} 

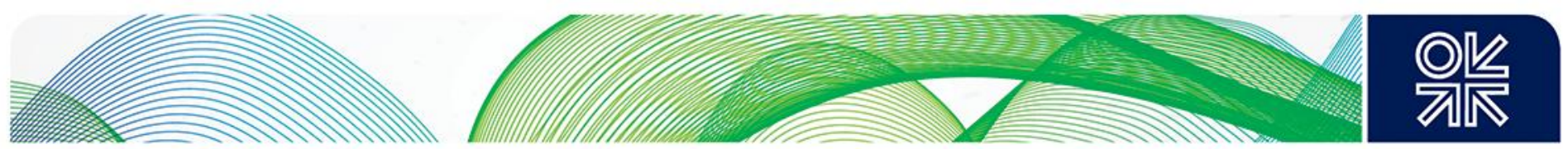

dependent on imported fossil fuels. Fast growth of wind and solar in the 2000s and early 2010s means that the country has already reached its target of a $26.4 \%$ share of renewables in electricity generation. Thanks to the $30 \mathrm{GW}$ of new gas-fired capacity (essentially CCGTs, both repowered existing plants and greenfields) that were commissioned between 2003 and 2012, the country has flexible generation that can act as back up to the renewables intermittency... even if the output from the renewables has mostly crowded out a large share of gas-fired generation. Italy also needs to increase its energy efficiency by $20 \%$ by 2020 and reduce its GHG emissions not covered by the EU ETS by $13 \%$ compared to 2005 according to the ESD. Because the National Energy Strategy was adopted before the change of government, it is unclear how much of the document will be implemented in the 2010s and which impacts can be expected on renewables, efficiency and emissions. $^{213}$

\section{Scenario}

Natural gas will remain a dominant player in the Italian generation mix but its share is going to decline because of rapid development of renewables up to 2030 as seen in Figure 92.

Figure 92: Scenario for power generation mix in Italy, up to 2030, in GWh

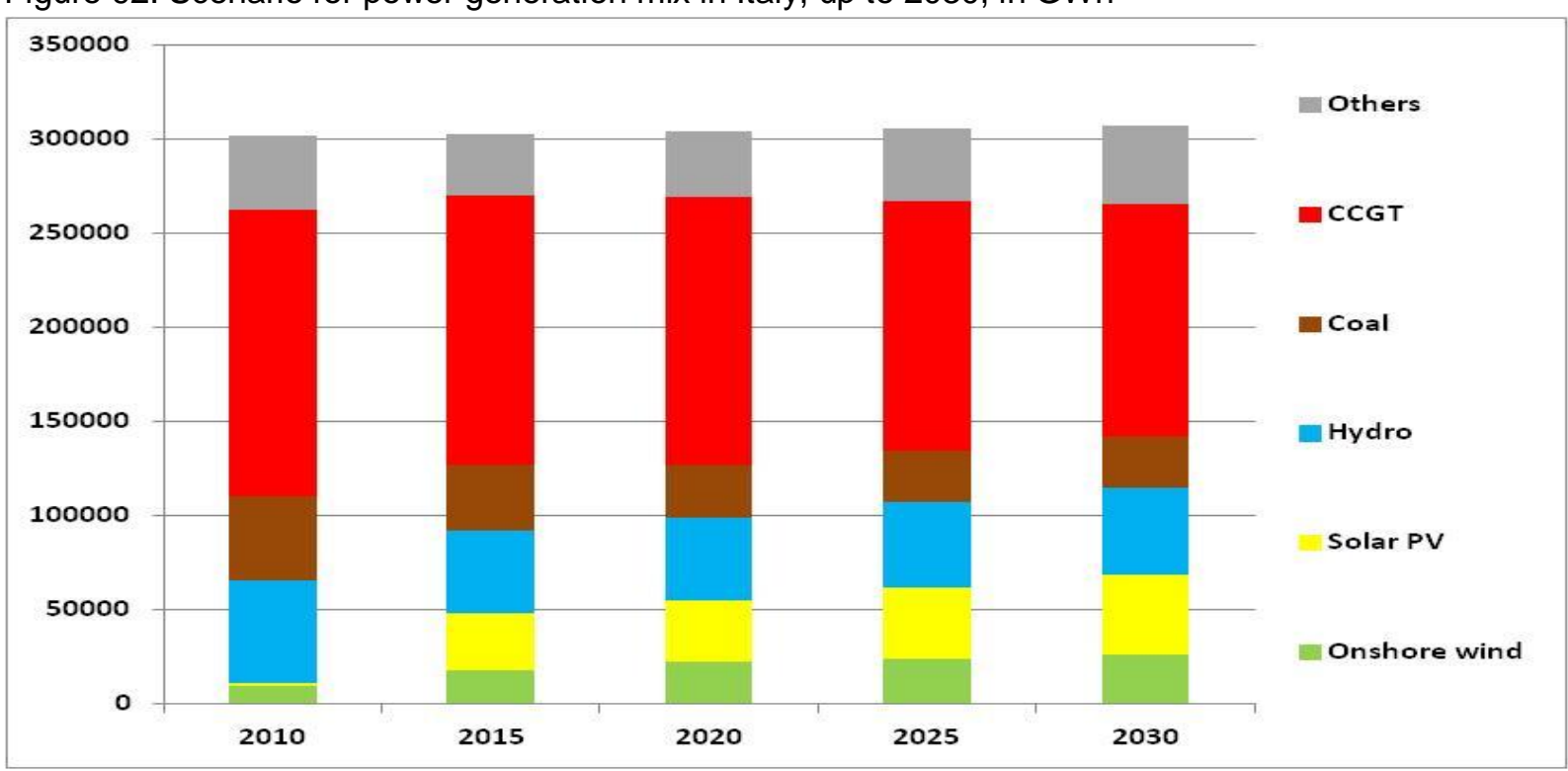

Source: 2010: IEA (2013e), table 3 for each country; scenario: Author

In our scenario, natural gas demand will experience a moderate decline up to 2030 but the split between sectors will evolve with a slow decline of the power sector which will nonetheless remain an important part of the gas consumed in the country, being replaced by additional growth in the transport sector as shown in Figure 93. The latter is conditioned to a continued strong political support.

\footnotetext{
${ }^{213}$ For more information, see Honoré (2013), the National Renewable Energy Action Plan to the European Commission, Ecologic Institute \& Eclareon (Italy)
} 
Figure 93: Scenario for natural gas demand in Italy, up to 2030, in $\mathrm{Bcm}$

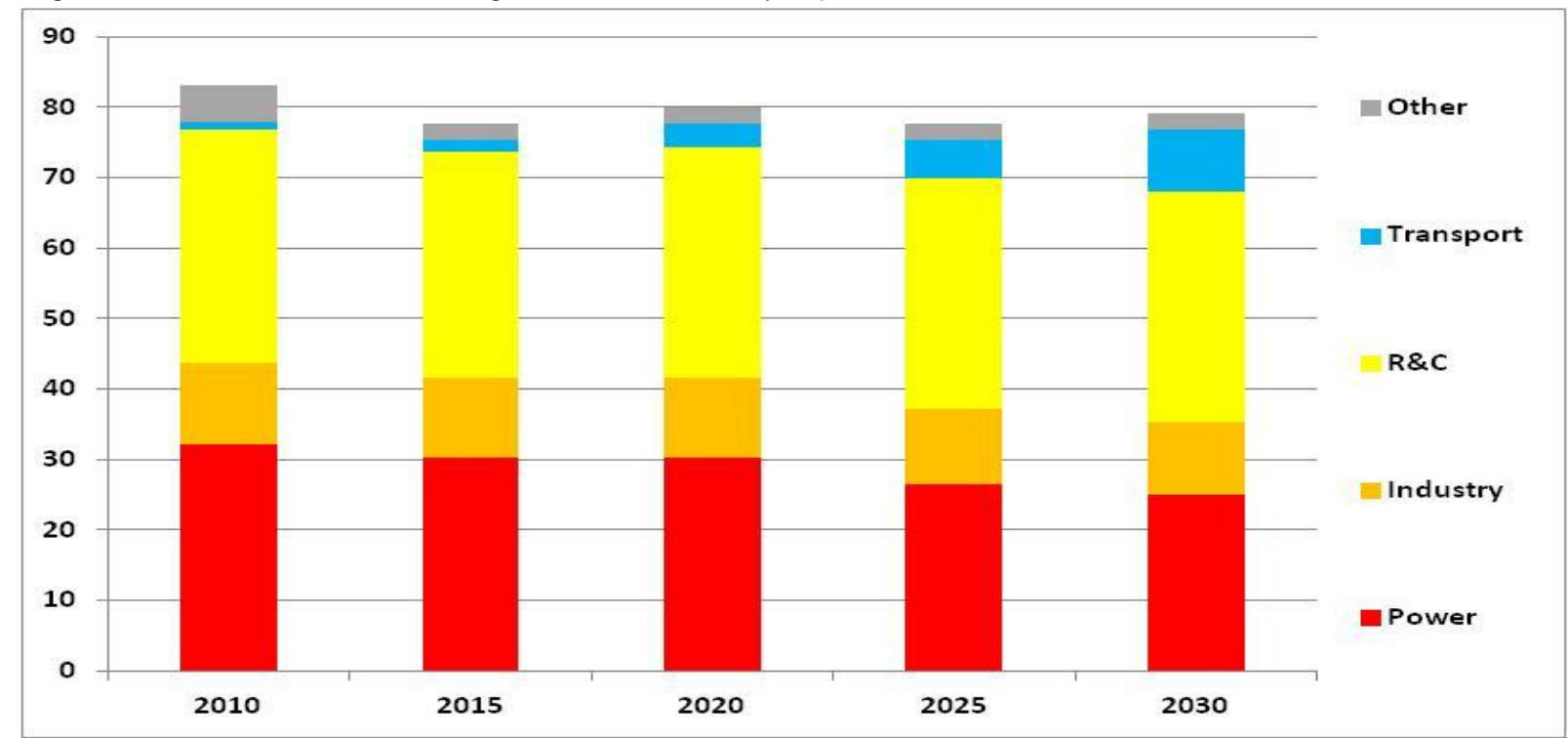

Source: 2010: IEA (2013a), table 3 for each country; scenario: Author 

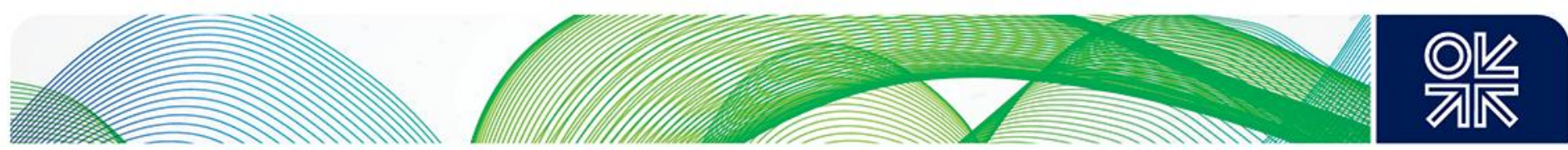

\section{Latvia}

\section{Background}

In 2011, the TPES was dominated by oil (32\%) and gas (29\%). Hydro was far behind at $6 \%$ and coal at $3 \% .{ }^{214}$ The country was dependent on energy imports for more than half of its energy needs, and for $100 \%$ of its gas requirements.

In 2012, gas demand was about $1.5 \mathrm{Bcm}$, even lower than in $2008(-12 \%)$. The power sector was predominant with $69 \%$ of the gas consumed nationally in 2011 , followed by $R \& C(16 \%)$ and industry $(13 \%) .{ }^{215}$

Power demand stood at 6.8 TWh in $2011,10.5 \%$ below 2008 levels. ${ }^{216}$ Gross electricity production was lower at 6.1 TWh. In terms of electricity generation mix, Latvia is highly reliant on both gas $(49 \%$ in 2011 ) and hydropower (47\%). Renewables represented only about $3 \% .{ }^{217}$

\section{Targets and assumptions}

Latvia saw negative economic growth in 2008-2010, but it recovered in 2011 and GDP annual growth is expected to remain positive at about $4 \%$ until 2018 according the IMF world economic outlook of November 2013 [Figure 94].

Figure 94: GDP annual growth in Latvia (\%), in constant prices, 2000-2018 (forecast from 2012)

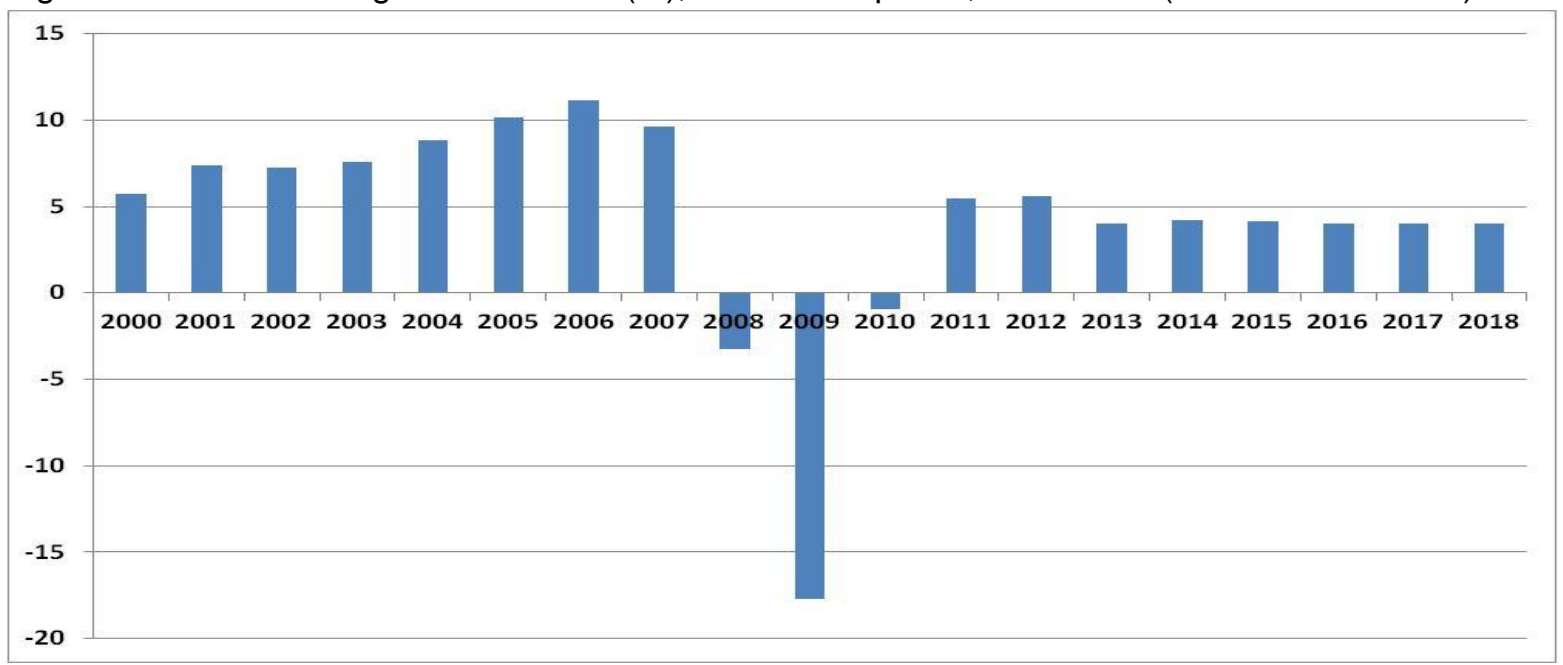

Source: IMF (2013)

Climate change is not a priority in Latvia, only in the context of improving energy security, especially in order to fulfil the bullish scenario of electricity demand. ${ }^{218}$ By 2020 , the country is committed to produce $40 \%$ of its gross final energy consumption from renewables (up from $32.6 \%$ in 2005). Slow development of renewables and rapid growth in final consumption means that the country may need new measures to reach its target. Renewable energy is also perceived as a security against import 


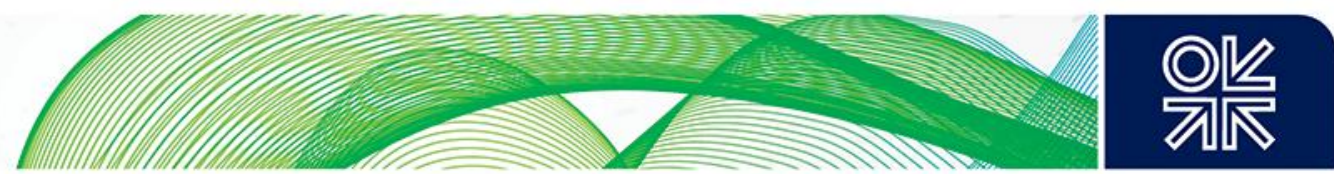

price fluctuations and is therefore seen as way to strengthen the security of supply. The country can also increase its GHG emissions not covered by the EU ETS by $17 \%$ compared to $2005 .{ }^{219}$

\section{Scenario}

In our scenario, natural gas demand remains small at just above 2 Bcm by 2030 .

${ }^{219}$ For more information, see the National Renewable Energy Action Plan to the European Commission; Ecologic Institute \& Eclareon (Latvia) 

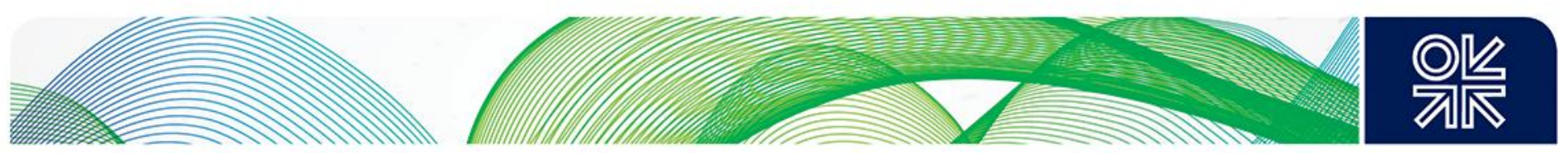

\section{Lithuania}

\section{Background}

In 2011, the TPES was dominated by gas (37\%) and oil (34\%), while coal only represented $3 \%$ of the total. ${ }^{220}$ The country was dependent on energy imports for almost $80 \%$ of its energy needs, and for $100 \%$ of its gas requirements.

In 2012, gas demand was about $3.4 \mathrm{Bcm}$, higher than in 2008 (6.3\%). The power sector was predominant accounting for $42 \%$ of the gas consumed in 2011 , followed far behind by the industrial $(10 \%)$ and $R \& C(8 \%){ }^{221}$

Power demand stood at 10.4 TWh in 2011, 5.5\% below 2008 levels. ${ }^{222}$ Gross electricity production only amounted to $4.8 \mathrm{TWh}$, although large variations exist due to its heavy reliance on hydropower. Lithuania has a strong historical reliance on hydropower, however in 2011 , gas accounted for $56 \%$ of its electricity generation mix, hydro only for $22 \%$ and renewables for $19 \%$. ${ }^{223}$

\section{Targets and assumptions}

Lithuania saw a negative GDP growth in 2009, but the economic situation recovered quickly and growth is expected to remain relatively high (3-4\%) until 2018 according the IMF world economic outlook of November 2013 [Figure 95].

Figure 95: GDP annual growth in Lithuania (\%), in constant prices, 2000-2018 (forecast from 2012)

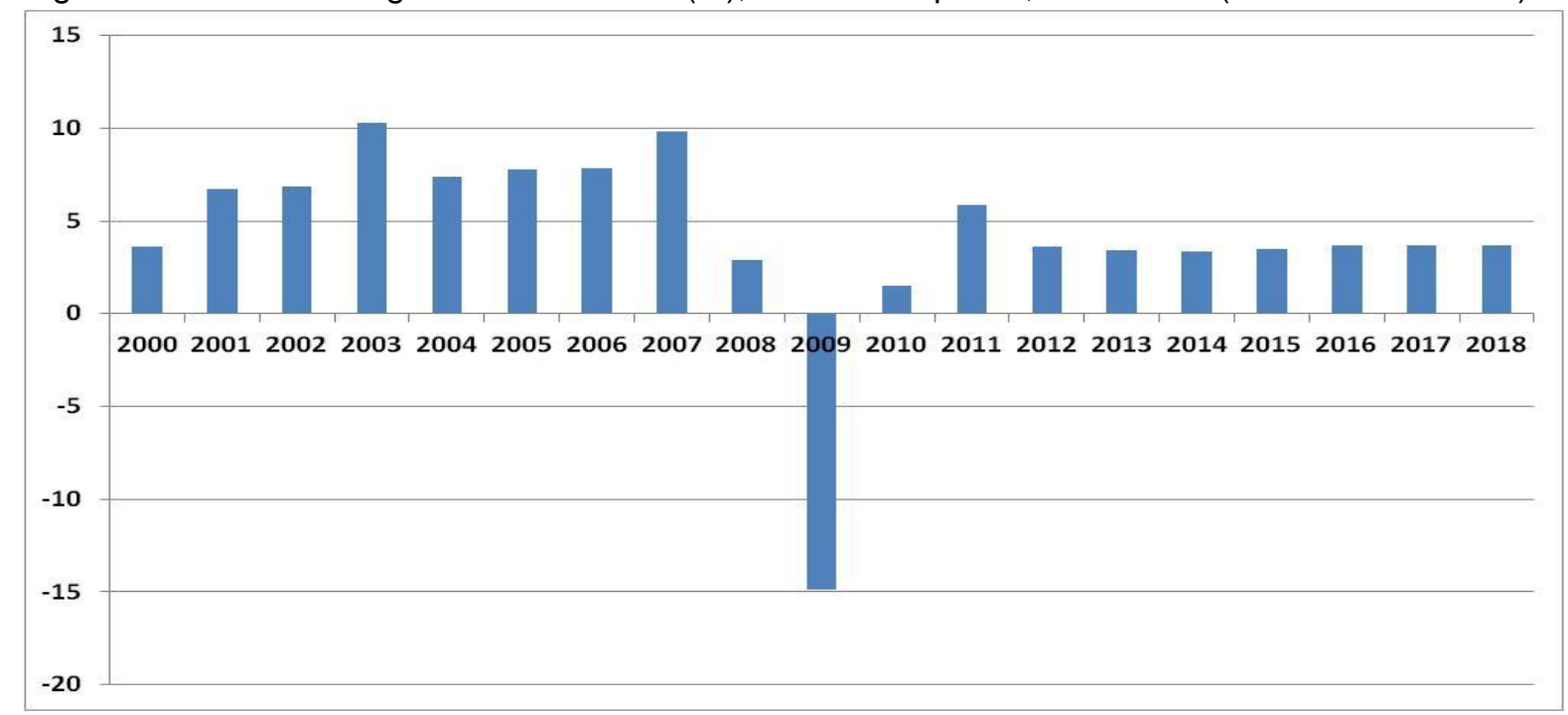

Source: IMF (2013)

Lithuania's target for renewable energy is to provide at least $23 \%$ of the country's final gross energy consumption by 2020, which would mean increasing the share of electricity produced from renewables to $21 \%$ in 2020 (10\% in transport, 36\% in heating and cooling and $50 \%$ in district heating). An LNG terminal at Klaipeda is under construction and should be completed by end 2014

\footnotetext{
220 IEA (2013c), p.II.57

221 IEA (2013c), p.II.57

222 IEA (2010b) and IEA (2013e), Table 1.1, p.III.6

${ }^{223}$ IEA (2013e), Table 1.2, p.III.10
} 
but it may not necessarily increase the use of gas in power generation if LNG deliveries are not competitive with pipeline supplies from Russia. Lithuania is partially exempt from the EU ETS, so it is not yet fully exposed to European $\mathrm{CO}_{2}$ prices. ${ }^{224} \mathrm{GHG}$ emissions in the non-ETS sectors can increase by $15 \%$ compared to 2005 levels. ${ }^{225}$ Finally, the country needs to achieve a $17 \%$ reduction in final energy use compared to the 2009 level. ${ }^{226}$

\section{Scenario}

In our scenario, natural gas demand remains small at about $4 \mathrm{Bcm}$ by 2030 .

\footnotetext{
${ }^{224}$ Platts (May 2013b), p.7

${ }^{225}$ For more information, see the National Renewable Energy Action Plan to the European Commission; Ecologic Institute \& Eclareon (Lithuania)

${ }^{226} \mathrm{http}: / /$ ec.europa.eu/energy/efficiency/eed/reporting en.htm
} 

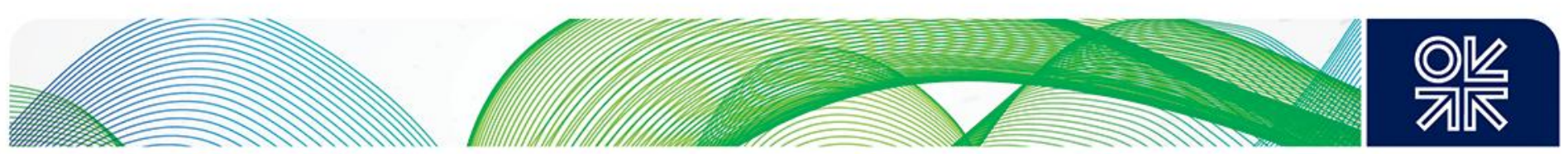

\section{Luxembourg}

\section{Background}

In 2012, TPES was dominated by oil (60\% share) and gas $(26 \%)$. The country is dependent on energy imports and has to import $100 \%$ of the natural gas it consumes. ${ }^{227}$

Total gas consumption was about $1.2 \mathrm{Bcm}$ in 2012 , almost $8 \%$ below pre-crisis level (2008). The power sector was the largest sector (41\% in 2011), followed by the $R \& C$ sector $(32 \%)$ and industry $(26 \%) .{ }^{228}$

Power supply reached 6.6 TWh in 2011, just $1.5 \%$ below 2008 levels. Gross production was about $44 \%$ below (3.8 TWh the following year). ${ }^{229}$ In 2012, gas had the highest share of the electricity generation mix (63\%), followed by hydro (32\%). Renewables accounted for $3 \%{ }^{230}$

If the assumptions on available gas-fired capacity in 2008 and 2012, which are based on Eurelectric and IEA data, are correct, ${ }^{231}$ then the average load factor of the gas-fired power plants in 2012 was about $55 \%$, down from about $58 \%$ in 2008 .

Targets and assumptions

After two consecutive reductions in GDP in 2008 and 2009, economic growth is expected to recover slowly in the 2010s as shown in the IMF economic outlook of November 2013 below [Figure 96].

Figure 96: GDP annual growth in Luxembourg (\%), in constant prices, 2000-2018 (forecast from 2012)

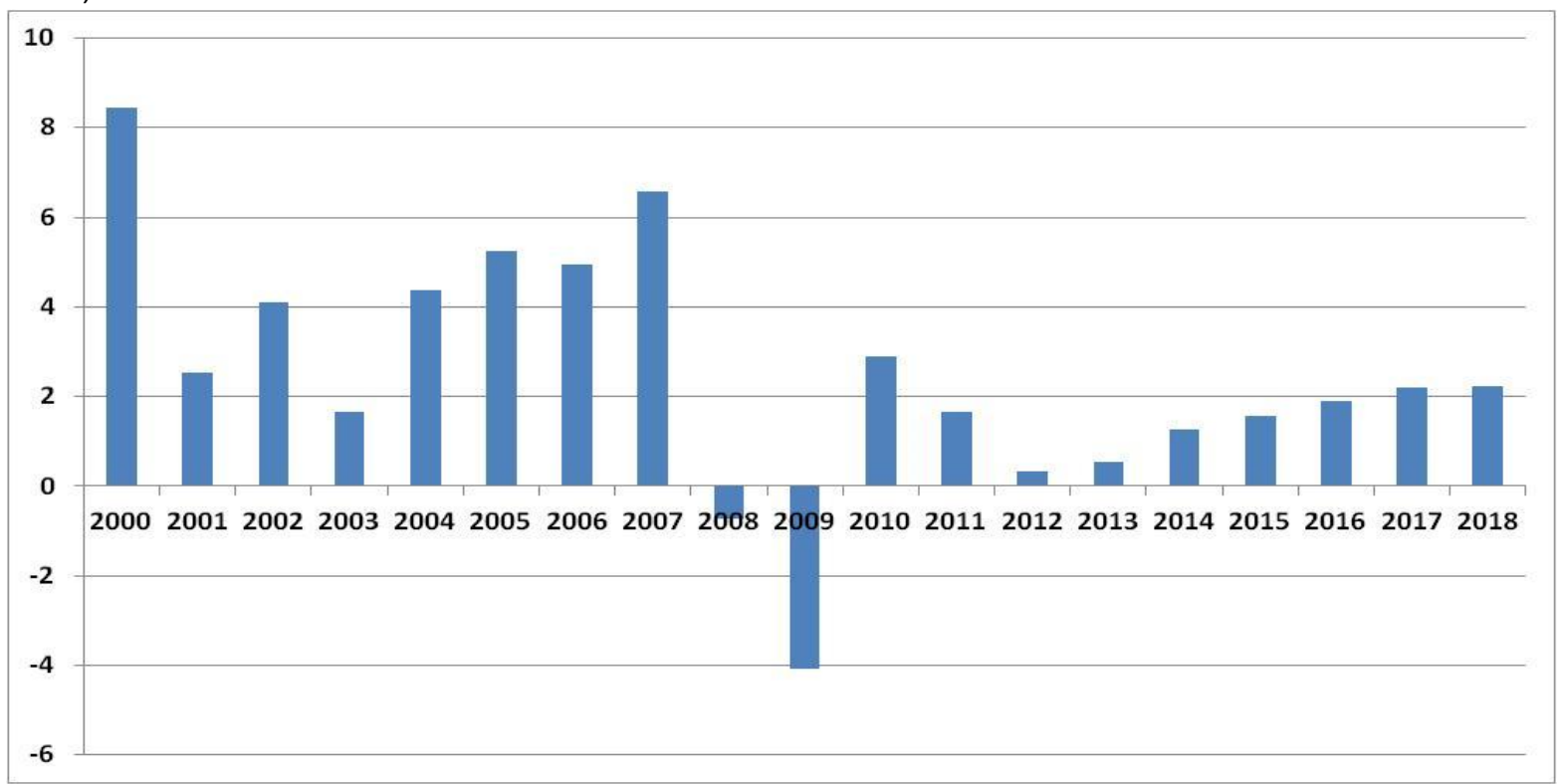

Source: IMF (2013)

\footnotetext{
227 IEA (2013a), Country data, table 1

${ }^{228}$ IEA (2010a) and IEA (2013a), Country data, table 3

${ }^{229}$ IEA (2010b) and IEA (2013e), Part III, tables 1.1 and 1.2

230 IEA (2013e), Part III, Country data, table 3

${ }^{231}$ IEA (2013e), Part III, table 2.12; Eurelectric (2012), table 3.1.1.3.
} 
Increasing the role of renewables and improving efficiency are high on the government's agenda and several measures to tackle climate change are already being implemented. Luxembourg has an EU 2020 target of $11 \%$ of gross final consumption from renewables and of $20 \%$ reduction of GHG emissions not covered by the EU ETS. ${ }^{232}$

\section{Scenario}

Additional hydro could lower the need for natural gas in the mix as seen in Figure 97.

Figure 97: Scenario for power generation mix in Luxembourg, up to 2030, in TWh

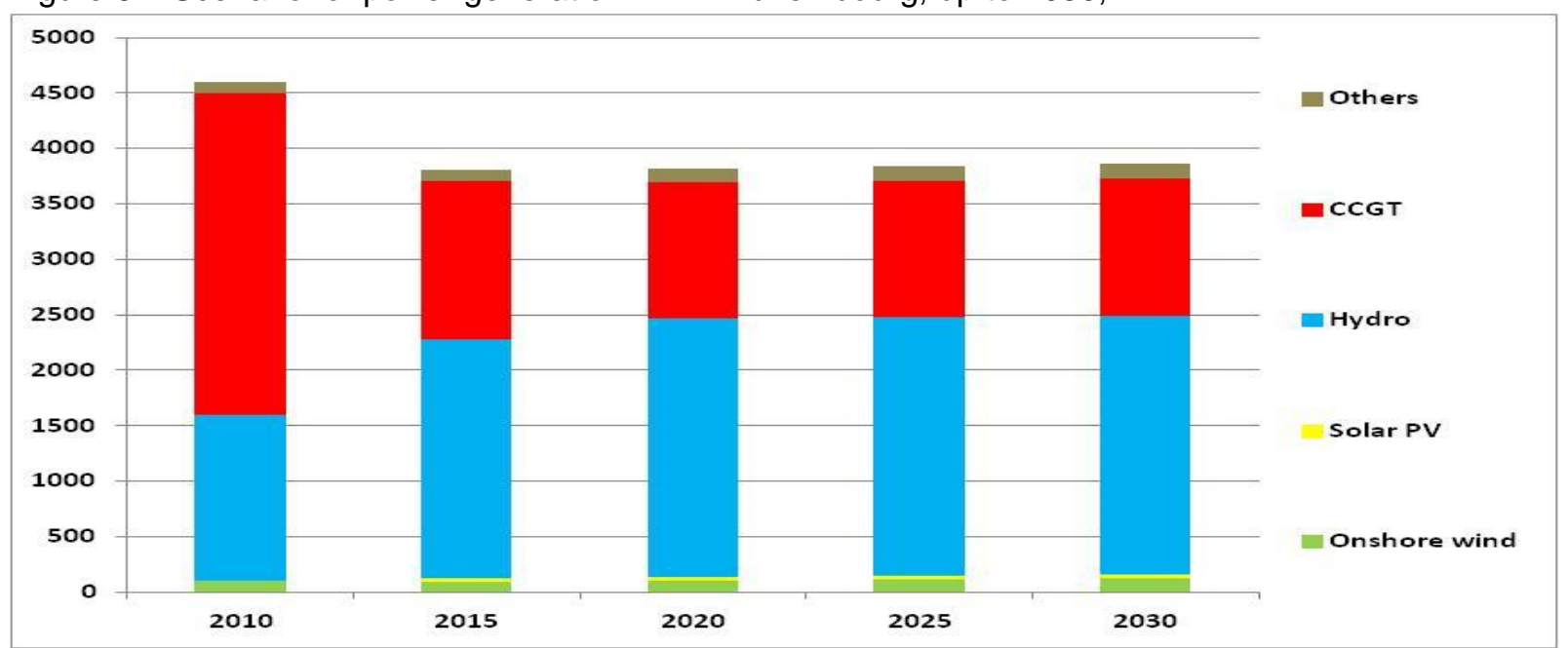

Source: 2010: IEA (2013e), table 3 for each country; scenario: Author

If this happens, total demand will decline accordingly even if with some growth in the other sectors as shown below in Figure 98.

Figure 98: Scenario for natural gas demand in Luxembourg, up to 2030, in $\mathrm{Bcm}$

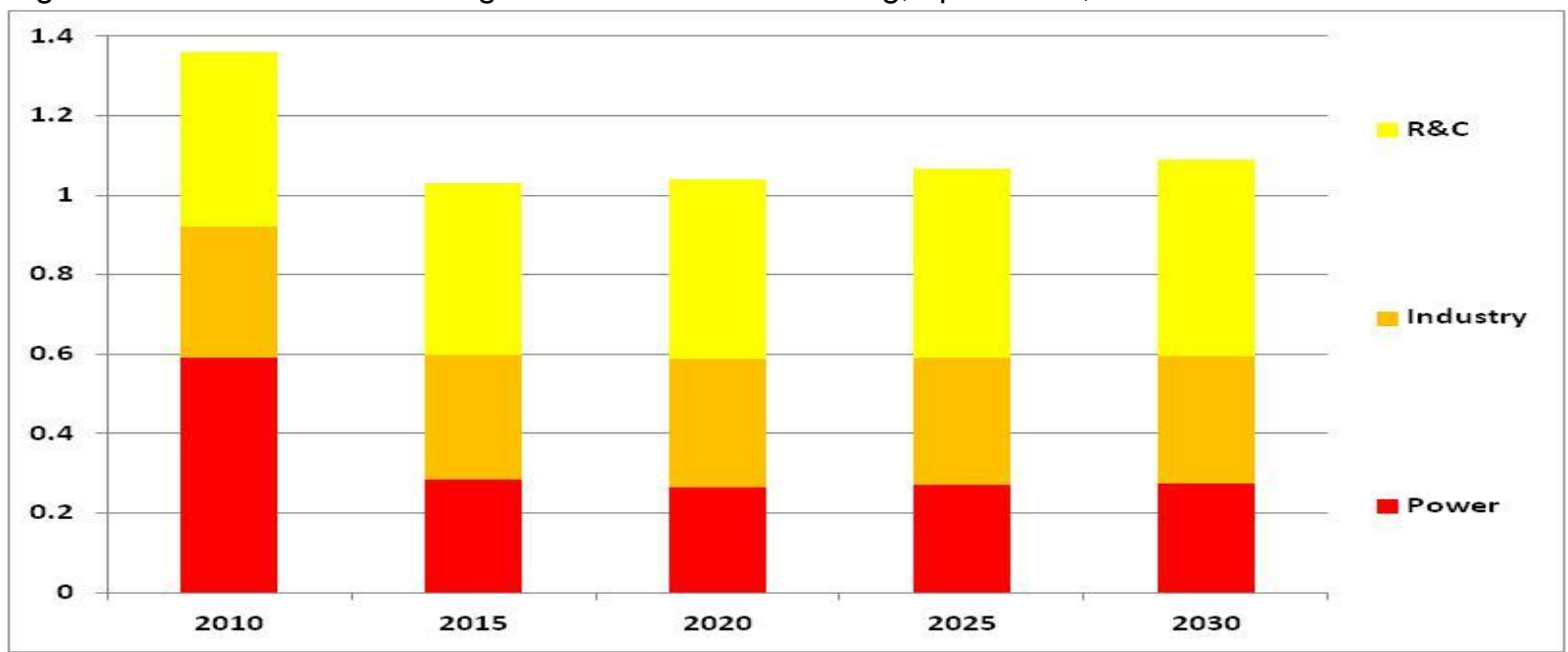

Source: 2010: IEA (2013a), table 3 for each country; scenario: Author

\footnotetext{
${ }^{232}$ For more information, see the National Renewable Energy Action Plan to the European Commission; Ecologic Institute \& Eclareon (Luxembourg)
} 

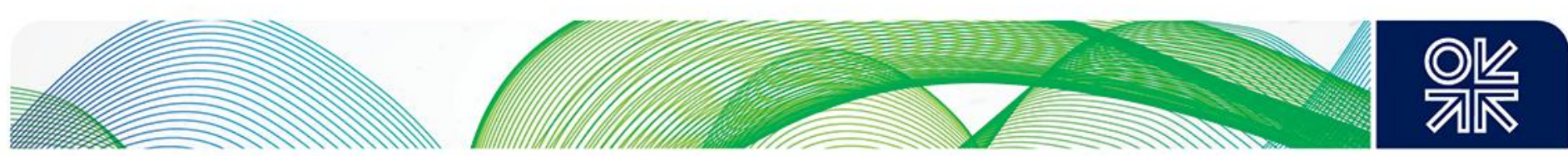

\section{Macedonia}

\section{Background}

In 2011, the TPES was dominated by coal (47\%) and oil (31\%), while gas only represented $3.5 \%$ of the total. ${ }^{233}$ The country was dependent on energy imports for just over $40 \%$ of its energy needs, and for $100 \%$ of its gas requirements.

Macedonia is a small gas market with gas demand at $100 \mathrm{MMcm}$ in 2012 (same as in 2008). The power sector was predominant accounting for $61 \%$ of the gas consumed in 2011 , followed far behind by the industrial $(37 \%)$ and $R \& C(2 \%) .{ }^{234}$

Power demand stood at 9.1 TWh in 2011, 7\% above 2008 levels. ${ }^{235}$ Gross electricity production only amounted to $6.9 \mathrm{TWh}$, with an electricity generation mix dominated by coal $(77 \%)$ followed by hydropower $(21 \%)$ while gas only accounted for $1 \% .{ }^{236}$ Even though the power sector is the largest consumer of gas in Macedonia, the country is not dependent on gas for its electricity production.

\section{Targets and assumptions}

After a decline in 2009 and 2012, GDP growth is expected to stabilise between 2-4\% annually between 2013 and 2018 according the IMF world economic outlook of November 2013 [Figure 99].

Figure 99: GDP annual growth in Macedonia (\%), in constant prices, 2000-2018 (forecast from 2012)

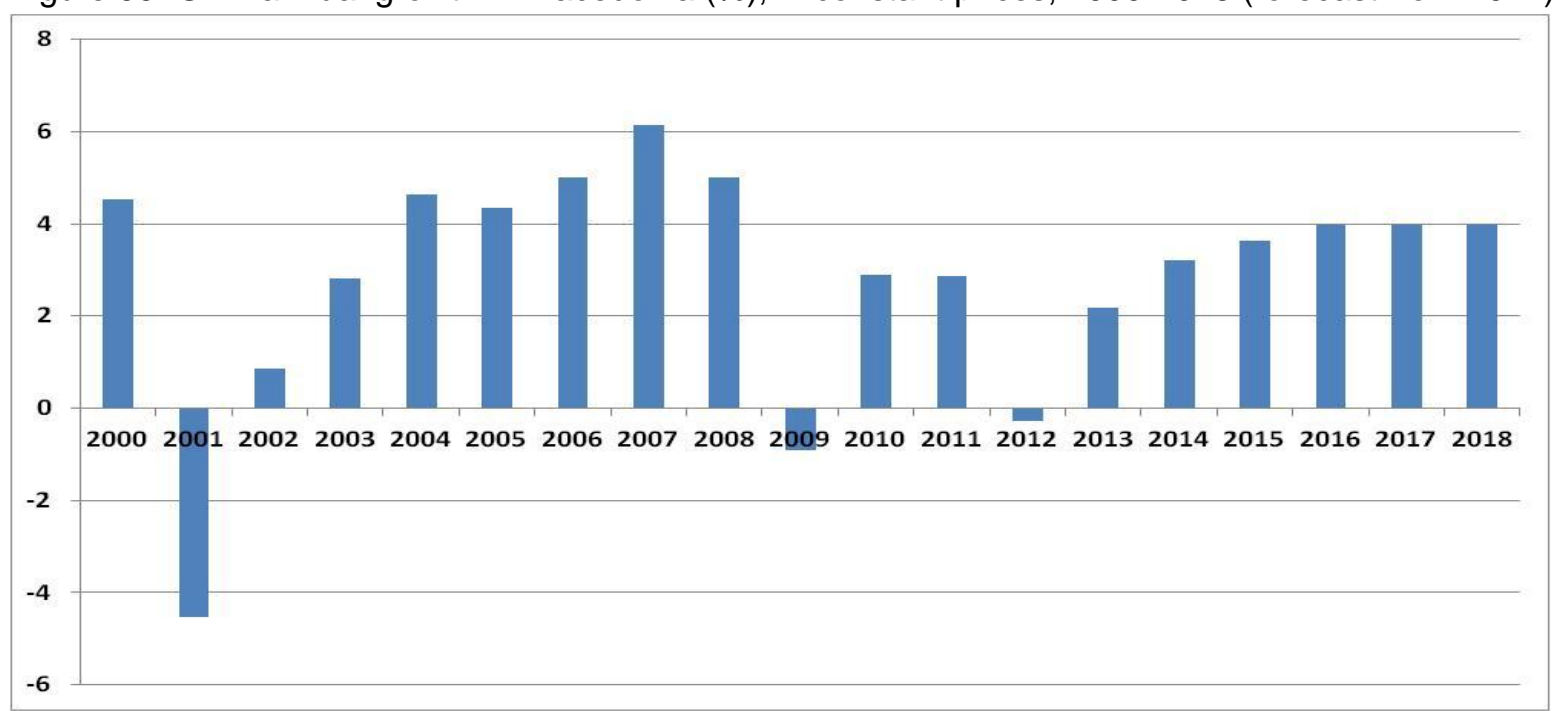

Source: IMF (2013)

\section{Scenario}

In our scenario, natural gas demand remains small at about 120 MMcm by 2030 . 

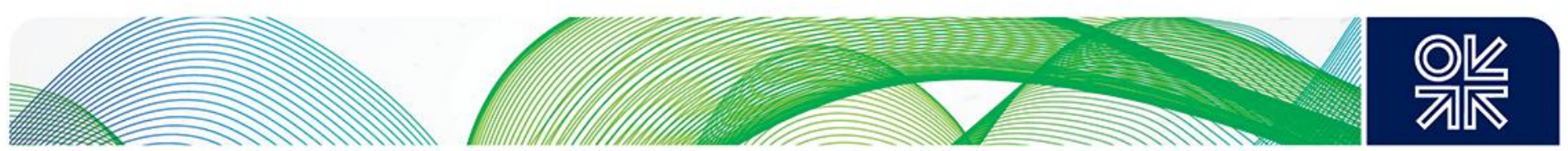

Malta

\section{Background}

TPES in 2011 was largely dominated by oil at $95 \%$, while gas was not present. ${ }^{237}$ The country was dependent on energy imports for about $94 \%$ of its energy needs.

Power demand reached 2.1 TWh in 2011, slightly below its 2008 levels. ${ }^{238}$ Gross electricity production fulfilled the country's needs and slightly more. In terms of electricity generation mix, Malta has a strong reliance on oil (almost 100\% in 2011), the rest was met by biofuels and waste. ${ }^{239}$

\section{Targets and assumptions}

After a sharp drop in 2009, GDP growth is expected to remain positive in the 2010 s (between $1-2 \%$ per year) as seen in Figure 100.

Figure 100: GDP annual growth in Malta (\%), in constant prices, 2000-2018 (forecast from 2012)

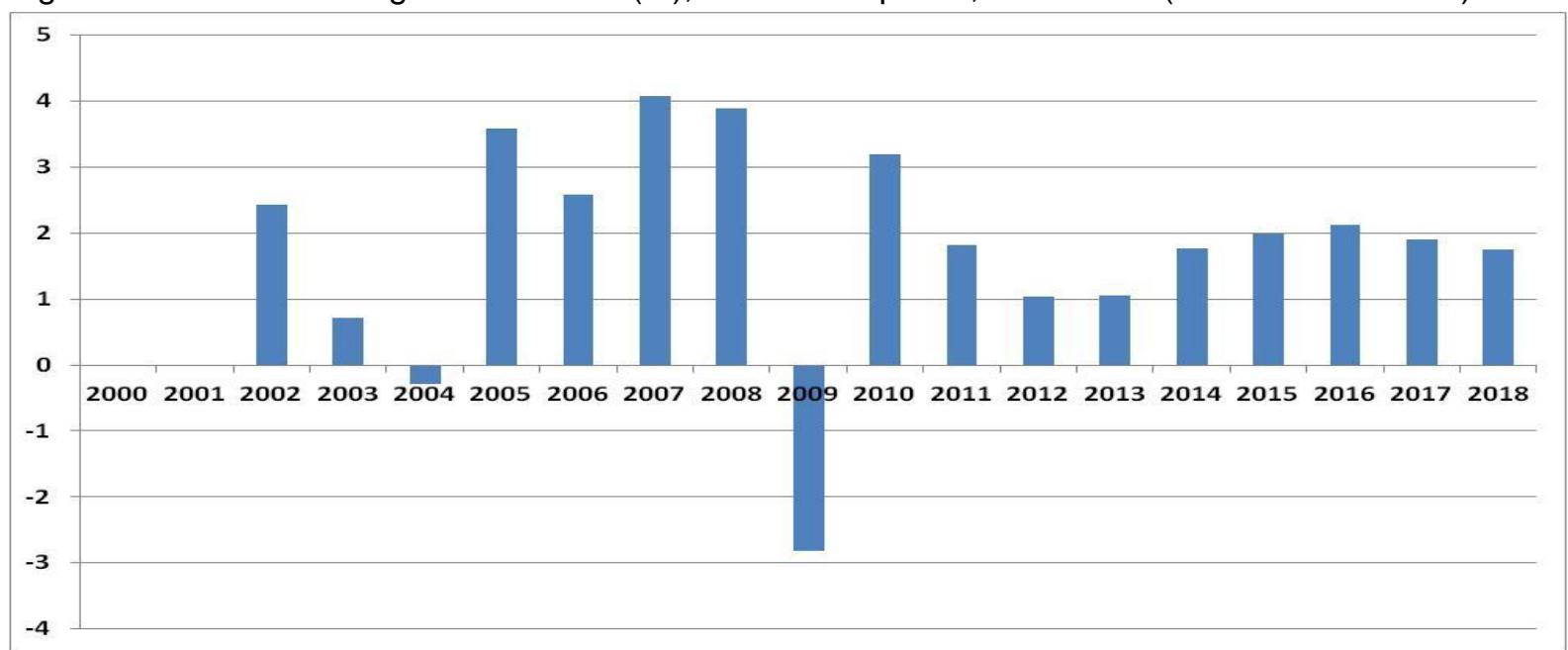

Source: IMF (2013)

The country is heavily reliant on (imported) oil and about $60 \%$ of its GHG emissions originate from the energy supply. As a consequence, one of the objectives of the energy policy is to reduce this dependence, which could be achieved thanks to a renewables increase (Malta has a target of energy from renewable sources in gross final consumption of $10 \%$ by 2020) and energy efficiency (its target is $22 \%$ energy savings by $\left.2020^{240}\right){ }^{241}$ Another option envisaged is to build a gas-fired power plant. The Maltese government plans a $215 \mathrm{MW}$ gas-fired power plant in order to reduce costs and lower emissions, which would require an LNG regasification terminal to be constructed by 2015 . An existing heavy fuel oil-fired plant at Enemalta's Delimara site may also be converted to run on natural gas. ${ }^{242}$

\footnotetext{
237 IEA (2013c), p.II.57

${ }^{238}$ IEA (2010b) and IEA (2013e), Table 1.1, p.III.6

239 IEA (2013c), p.II.194

240 http://ec.europa.eu/energy/efficiency/eed/reporting en.htm

241 For more information, see the National Renewable Energy Action Plan to the European Commission; Ecologic Institute \& Eclareon (Malta)

${ }^{242}$ Gas to Power journal (March 2014)
} 


\section{Scenario}

In our scenario, natural gas demand will develop in the power sector but remain small at about 200 MMcm by 2030. 

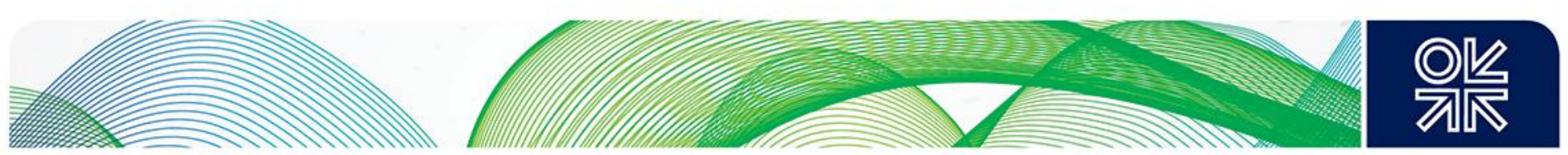

\section{Netherlands}

\section{Background}

In 2012, TPES was dominated by gas (42\% share), oil (39\%) and coal (10\%). The country imports about $17 \%$ of its total energy needs but is a net gas exporter. ${ }^{243}$

Total gas consumption was about $46 \mathrm{Bcm}$ in 2012, about $5 \%$ below its pre-crisis level (2008). The power and the R\&C sectors dominated gas demand (35\% and $30 \%$ share respectively in 2011), far above the industrial sector $(15 \%) .{ }^{244}$ The gas consumed in the power sector remained flat between 2008 and 2011, but a decline was expected by 2012/2013.

Power supply reached 118 TWh in 2011, about the same level as in 2008, while gross production was about $4 \%$ below (it dropped to 102 TWh the following year). ${ }^{245}$ In 2012, gas had the highest share of the electricity generation mix (54\%), followed by coal (27\%), renewables (excluding hydro, $5 \%$ ) and nuclear (4\%). ${ }^{246}$

If the assumptions on available gas-fired capacity in 2008 and 2012, which are based on Eurelectric data, are correct, ${ }^{247}$ then the average load factor of the gas-fired power plants in 2012 was about $35 \%$, down from about $44 \%$ in 2008 (44\% in 2011).

\section{Targets and assumptions}

After a sharp drop in 2009, GDP changes were negative again in 2012 and 2013 but the IMF expect a return to growth from 2014 onwards in its economic outlook of November 2013 [Figure 101].

Figure 101: GDP annual growth in Netherlands (\%), in constant prices, 2000-2018 (forecast from 2012)

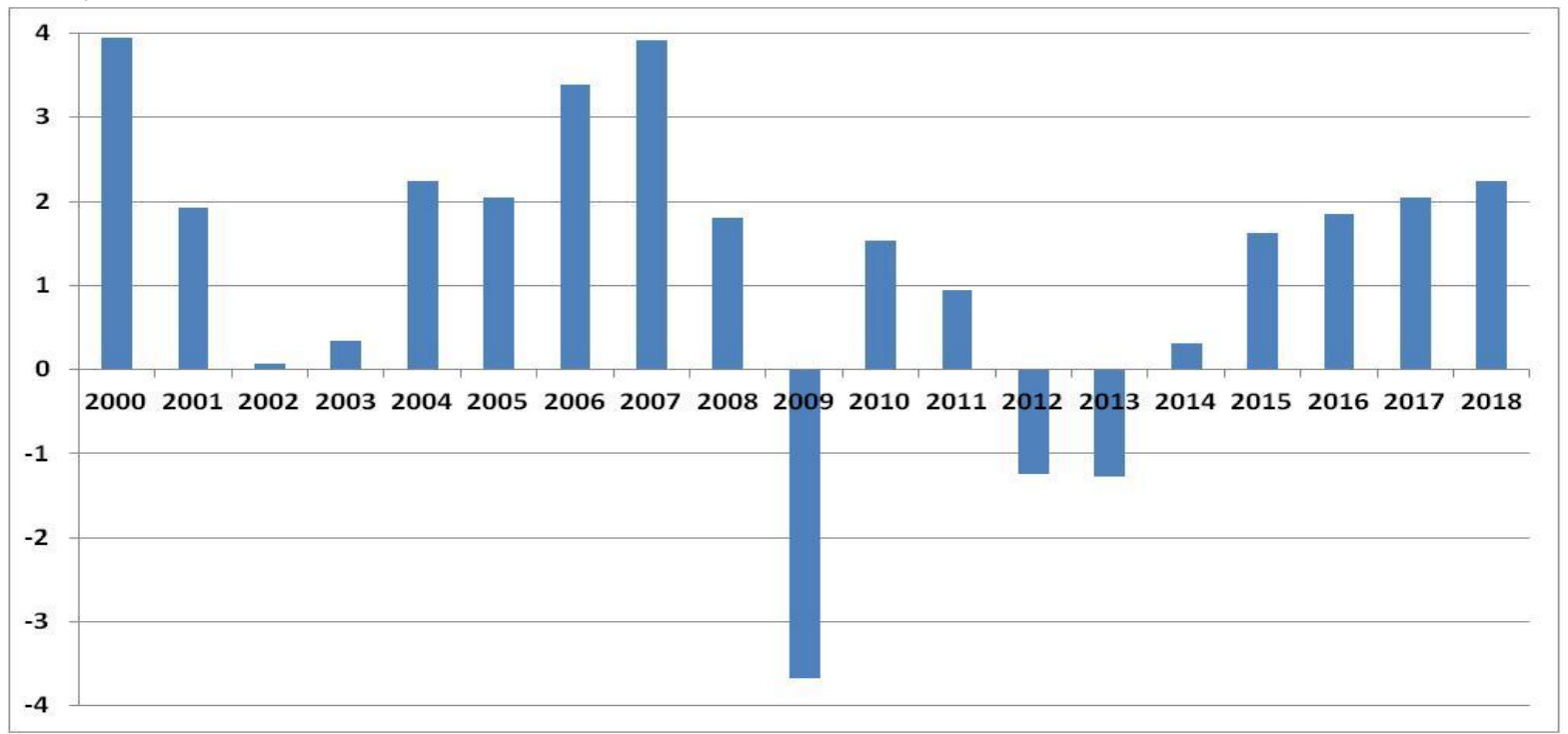

Source: IMF (2013)

\footnotetext{
${ }^{243}$ IEA (2013a), Country data, table 1

244 IEA (2010a) and IEA (2013a), Country data, table 3

${ }^{245}$ IEA (2010b) and IEA (2013e), Part III, tables 1.1 and 1.2

${ }^{246}$ IEA (2013e), Part III, Country data, table 3

${ }^{247}$ Eurelectric (2012), table 3.1.1.3.
} 

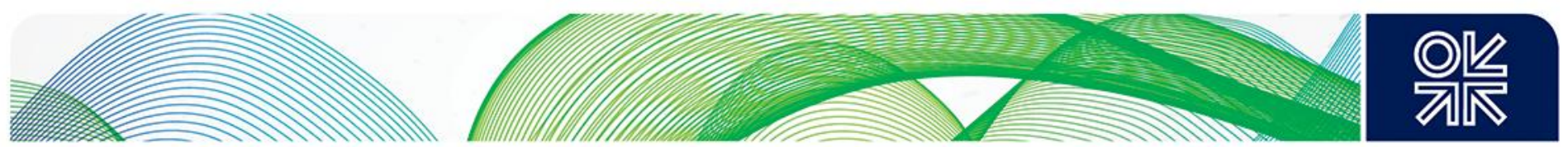

The Dutch energy policy outlines the need for the energy supply to be 'sustainable, reliable and affordable' thanks to a balanced energy mix (best value-for-money mix of green and grey energy) and nuclear power is a necessary part of the mix as it reduces dependence and does not cause $\mathrm{CO}_{2}$ emissions. The Netherlands has already put in place measures to transition to a low carbon economy focusing on energy efficiency and promoting renewable. The country's targets for 2020 are $20 \%$ reduction in $\mathrm{CO}_{2}$ emissions compared with 1990 (a target that is expected to be met), renewable energy of $14 \%$ of final energy consumption (although this may be challenging to achieve without new policies and measures) and $20 \%$ energy saving to be achieved via fiscal measures, stricter energy requirements for buildings and agreements with the private sector. By 2020, all new buildings must be energy neutral (for example using solar collectors and micro $\mathrm{CHP}$ ). The country aims to cut $\mathrm{CO}_{2}$ emissions by $80-95 \%$ by 2050 (compared with 1990). A National energy agreement was announced in July 2013. It was designed to make a substantial contribution to the Netherlands being a climateneutral economy by 2020 with the planned decommissioning of five coal plants, the first three being shut in 2015 and the other two in 2017. This measure would put a de facto limit on the possibilities for generating renewable energy from co-burning biomass in coal-fired power stations as these will be shut down. ${ }^{248}$

\section{Scenario}

The role of gas in generation has already been eroded by the competition between coal and gas prices since 2011/2012. The country has also preferred to import electricity than run its CCGTs 'out of the money'. The share of gas is expected to be further eroded in our scenario by the new efficient coal plants added in the 2010s, relative slow growth of renewables and additional nuclear sometime potentially in the 2020s as seen in Figure 102.

Figure 102: Scenario for power generation mix in the Netherlands, up to 2030, in GWh

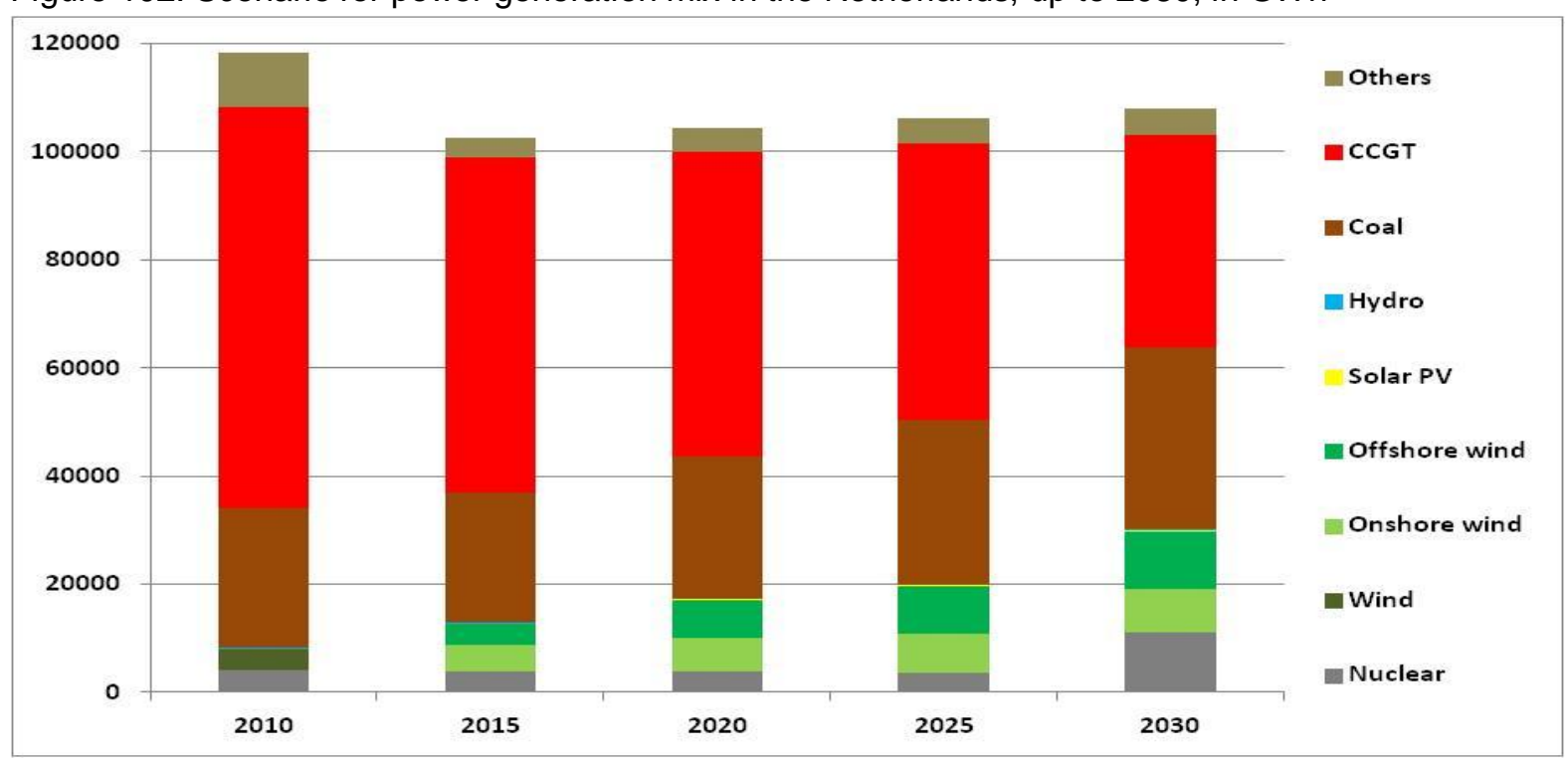

Source: 2010: IEA (2013e), table 3 for each country; scenario: Author

\footnotetext{
${ }^{248}$ For more information, see the National Renewable Energy Action Plan to the European Commission; Ecologic Institute \&
} Eclareon (Netherlands) 
All the major sectors are expected to experience a decline, which is most impressive in the power sector as shown in Figure 103. In order not to misread the figure, it is important to note that most of the decline in the power sector seen between 2010 and 2030 has already happened at the time of writing (2013). Some additional decline is expected in the late 2020s due to the arrival of additional nuclear capacity in our scenario.

Figure 103: Scenario for natural gas demand in Netherlands, up to 2030, in Bcm

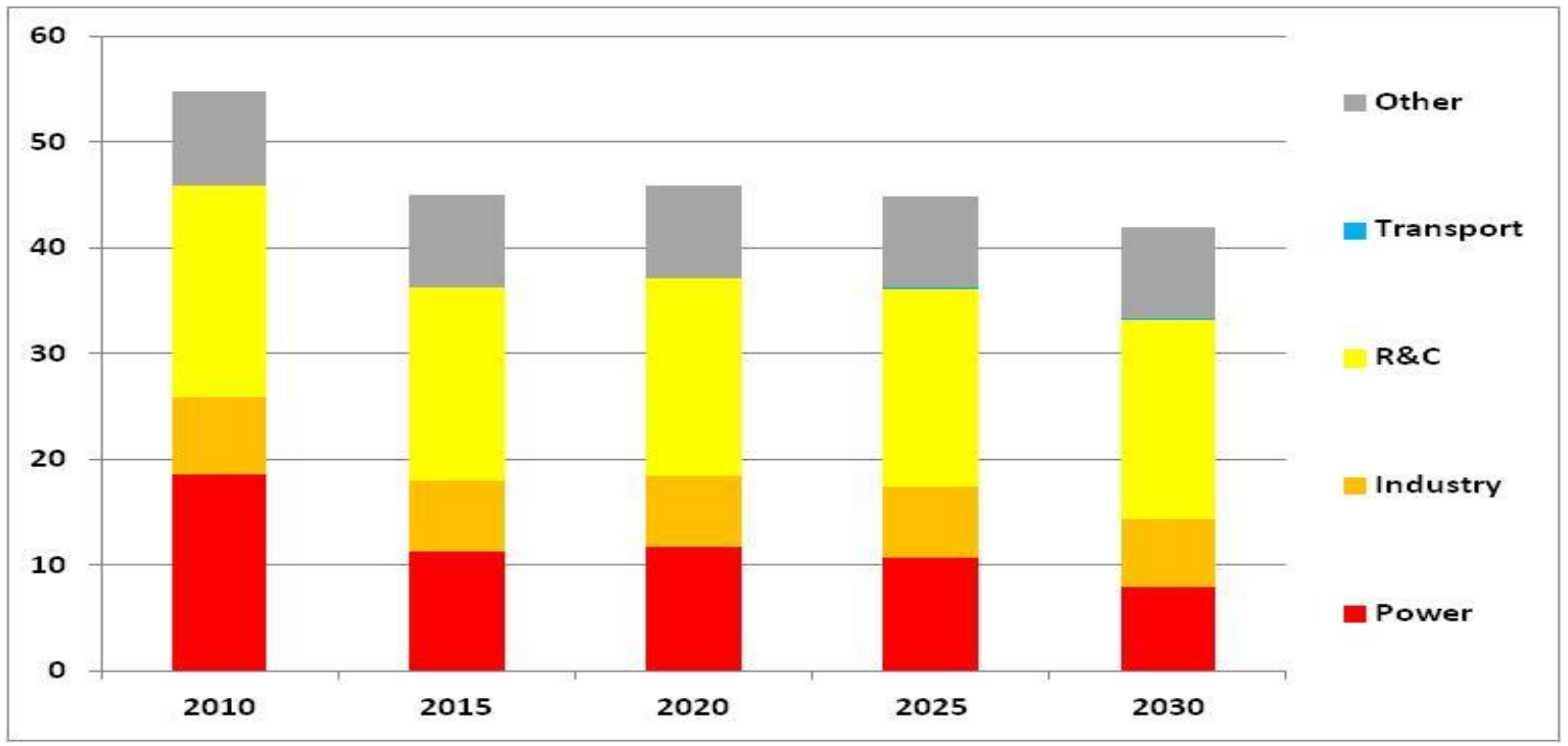

Source: 2010: IEA (2013a), table 3 for each country; scenario: Author 

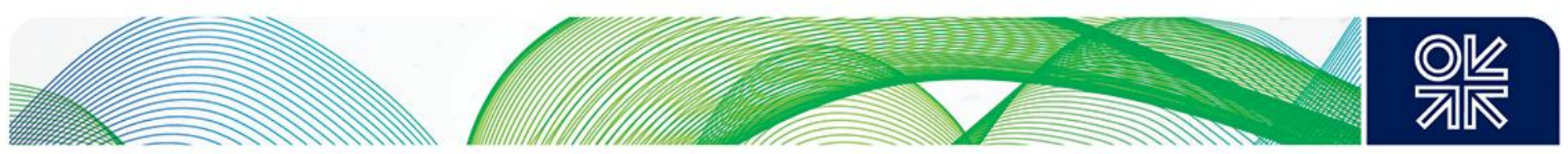

\section{Norway}

\section{Background}

In 2012, TPES was dominated by hydropower (41\% share), oil (37\%) and gas (17\%). The country is a net exporter of energy, including gas. ${ }^{249}$

Total gas consumption was about $6.2 \mathrm{Bcm}$ in 2012, about $7 \%$ above its pre-crisis level (2008). The large majority of the gas consumed was in the 'energy own use' sector for indigenous production, while the traditional sector only accounted for a small share: power (13\%), industry $(5 \%)$ and R\&C for $0.5 \%$ in 2011.250

Power supply reached 122 TWh in 2011, about 3\% below 2008 level, while gross production was about $5 \%$ above (it climbed to 148 TWh the following year due to variations in hydropower availability) ${ }^{251}$ In 2012 , the electricity generation mix was dominated by hydropower at $97 \%$, while gas accounted for $2 \%$ and renewables $1 \%{ }^{252}$

If the assumptions on available gas-fired capacity in 2008 and 2012, which are based on Eurelectric and IEA data, are correct, ${ }^{253}$ then the average load factor of the gas-fired power plants in 2012 was about $26 \%(41 \%$ in 2011$)$.

\section{Targets and assumptions}

After difficult times in 2008-2010, GDP growth is expected to recover and remain at about $2 \%$ per year until 2018 according to the IMF economic outlook of November 2013 [Figure 104].

Figure 104: GDP annual growth in Norway (\%), in constant prices, 2000-2018 (forecast from 2012)

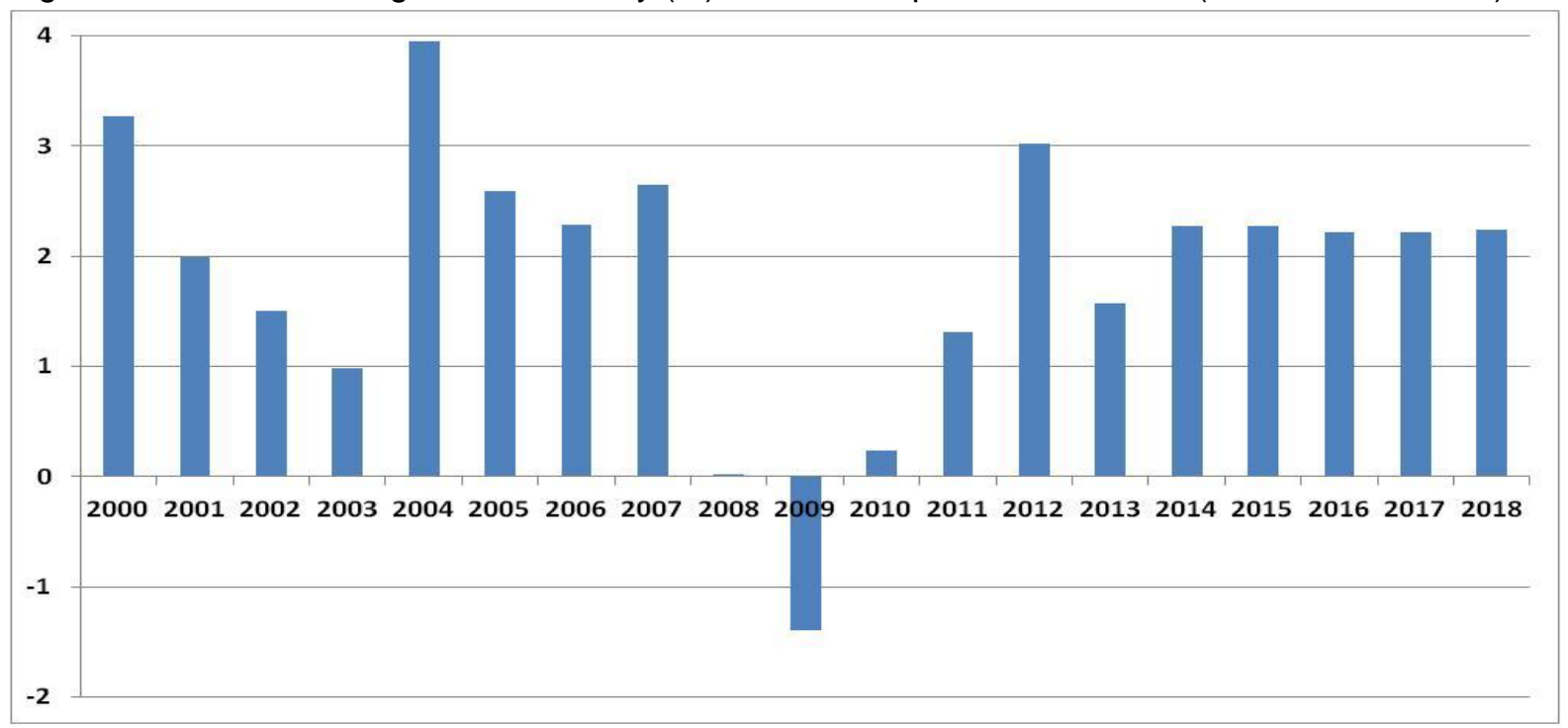

Source: IMF (2013)

\footnotetext{
${ }^{249}$ IEA (2013a), Country data, table 1

250 IEA (2010a) and IEA (2013a), Country data, table 3

${ }^{251}$ IEA (2010b) and IEA (2013e), Part III, tables 1.1 and 1.2

252 IEA (2013e), Part III, Country data, table 3

253 IEA (2013e), Part III, table 2.12; Eurelectric (2012), table 3.1.1.3.
} 
Nearly all (98\%) of Norway's electricity production comes from hydropower and renewables. The country aims at increasing the share of renewables in the energy mix by promoting the transition from fossil-fuel based energy consumption and improving energy efficiency. ${ }^{254}$

\section{Scenario}

Hydro will remain the biggest player in power generation in Norway as seen in Figure 105.

Figure 105: Scenario for power generation mix in Norway, up to 2030, in GWh

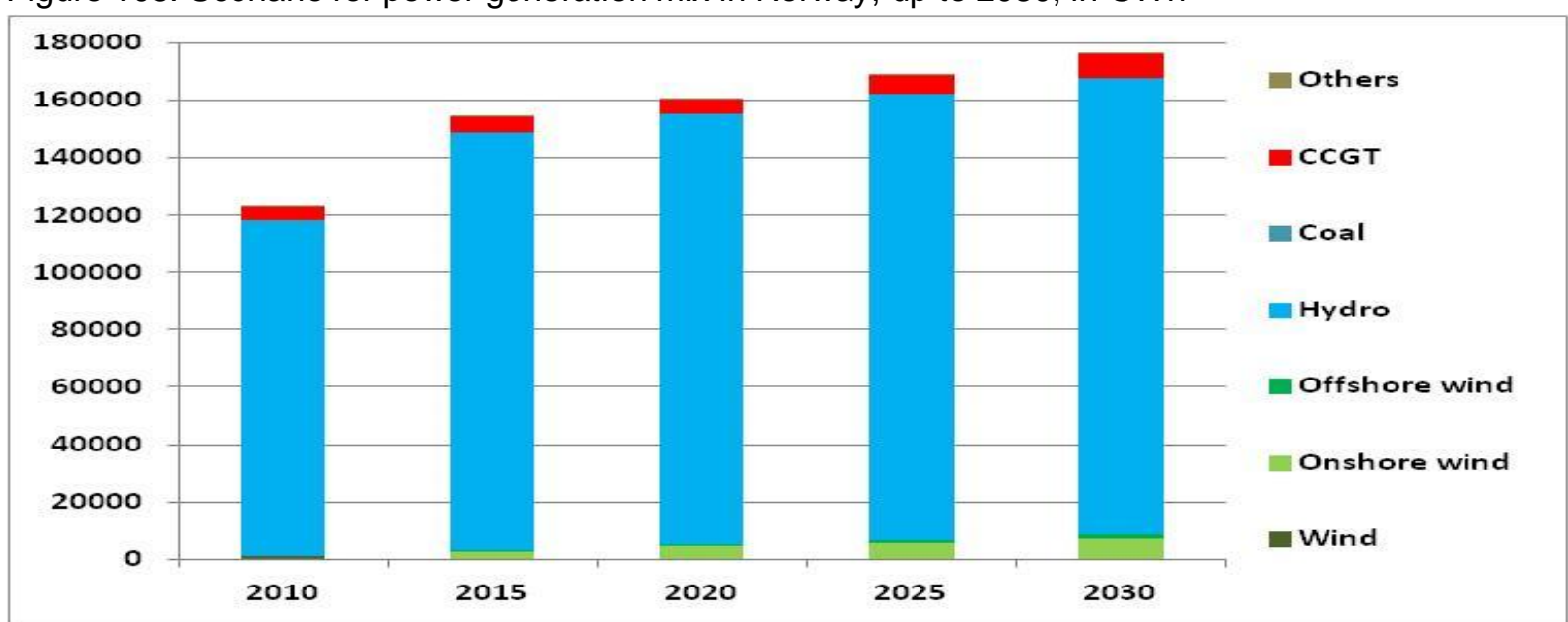

Source: 2010: IEA (2013e), table 3 for each country; scenario: Author

Some growth is expected in the transport sector -conditioned to strong political support- and in the 'industry energy own use sector' for indigenous gas production shown in 'other' in Figure 106 below.

Figure 106: Scenario for natural gas demand Norway, up to 2030, in Bcm

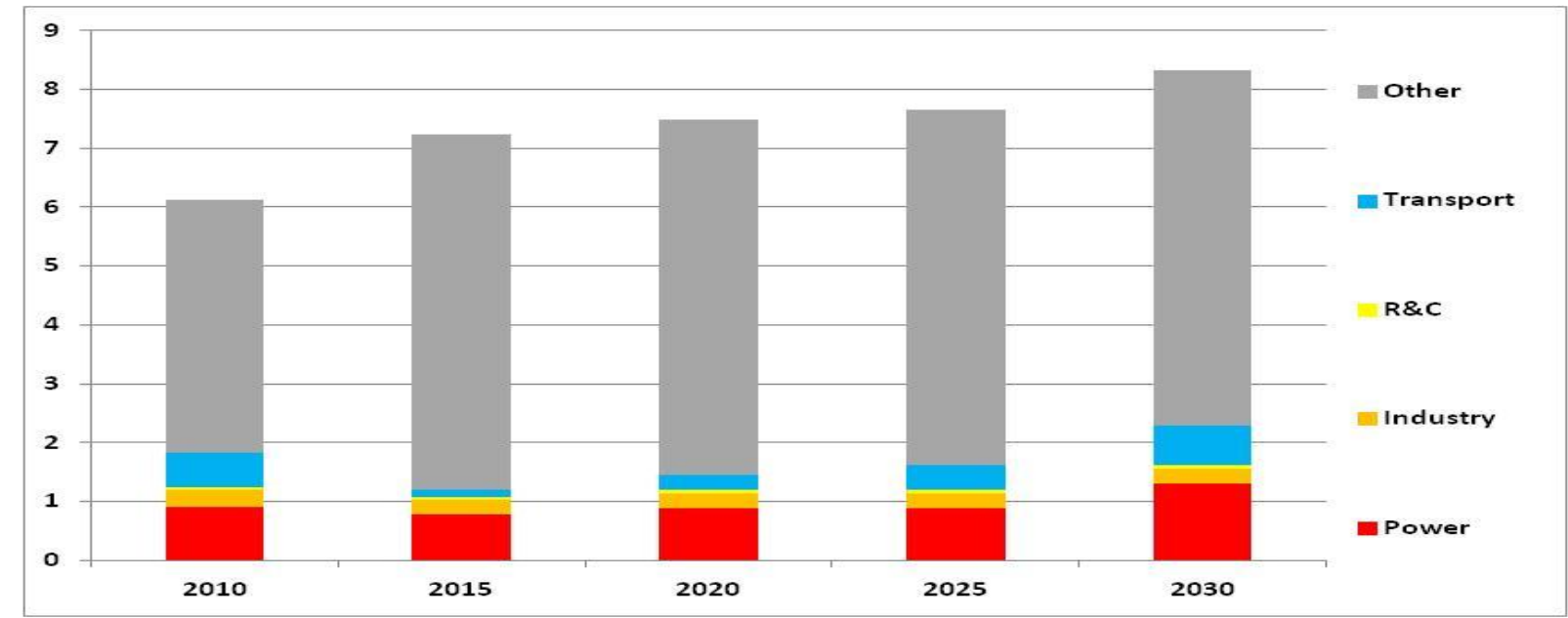

Source: 2010: IEA (2013a), table 3 for each country; scenario: Author

\footnotetext{
${ }^{254}$ For more information, see Ministry of Petroleum and Energy (2013)
} 

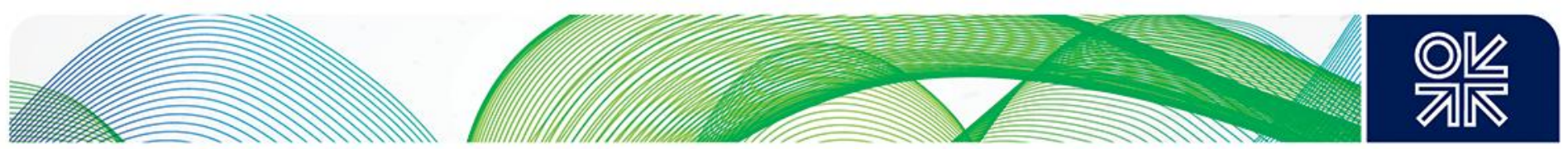

\section{Poland}

\section{Background}

In 2012, TPES was dominated by coal (52\% share), oil (25\%) and gas (14\%). The country is dependent on energy imports for about $25 \%$ of its total energy needs and for $72 \%$ of its natural gas requirements. ${ }^{255}$

Total gas consumption was about $18 \mathrm{Bcm}$ in 2012, about $11 \%$ above its pre-crisis level (2008). The $R \& C$ sector was the biggest consumer (40\% in 2011), followed by the industrial sector (25\%) and finally the power sector (12\%). Poland was never in recession and both the power sector and the industrial sector have registered strong growth since 2008 contrary to most of the other European markets $\left(+10.5 \%\right.$ and $6.5 \%$ respectively). ${ }^{256}$

Power supply reached 143 TWh in 2011, 1.8\% above 2008 levels. Gross production was about $14 \%$ higher. ${ }^{257}$ Poland has a long historical reliance on coal (84\% of the generation mix in 2012). Gas accounted for $4 \%$ of the mix, followed by renewables $(3 \%)$ and hydropower $(2 \%) .{ }^{258}$

If the assumptions on available gas-fired capacity in 2008 and 2012, which are based on Eurelectric and IEA data, are correct, ${ }^{259}$ then the average load factor of the gas-fired power plants in 2012 was above $70 \%$ (40\% in 2008).

\section{Targets and assumptions}

GDP annual growth remained positive despite the world economic downturn in 2009 and the difficulties in the following years. GDP growth is expected to continue in the 2010s as shown in the IMF economic outlook of November 2013 [Figure 107].

Figure 107: GDP annual growth in Poland (\%), in constant prices, 2000-2018 (forecast from 2012)

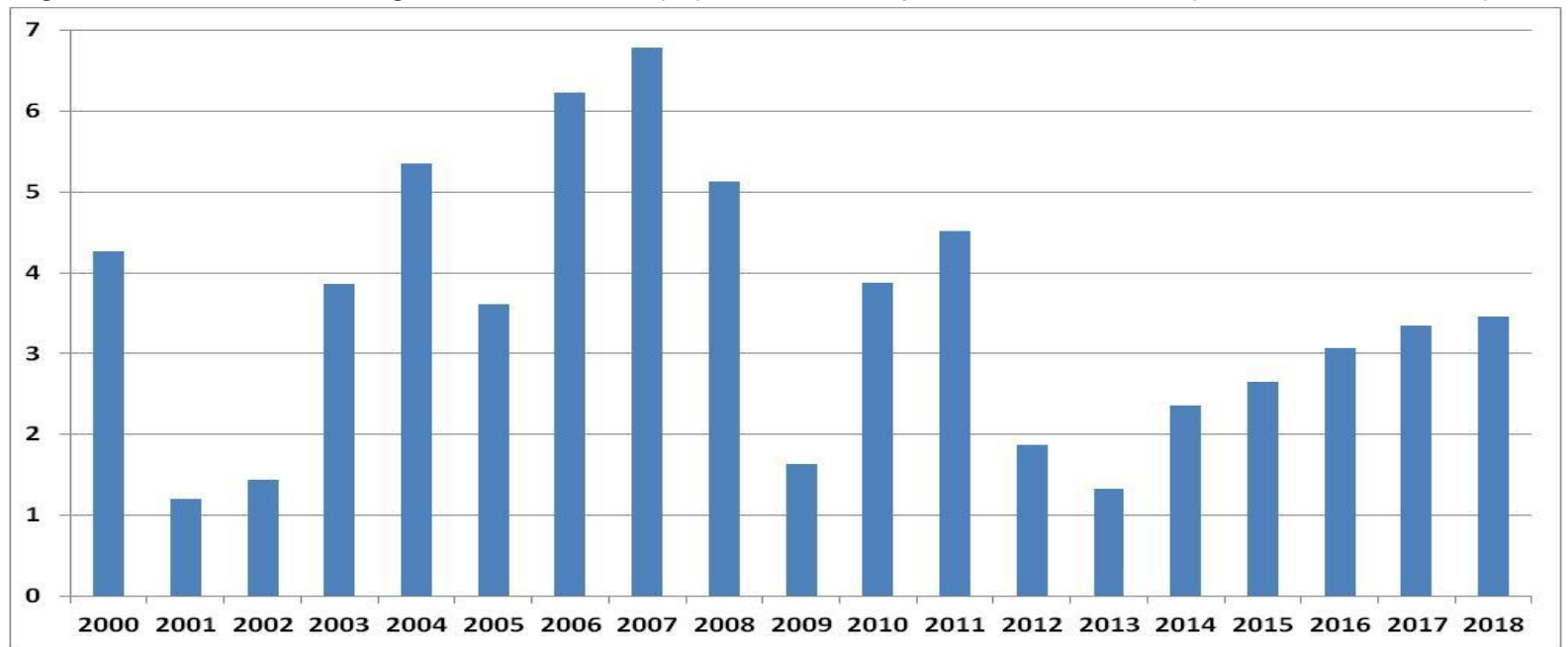

Source: IMF (2013)

\footnotetext{
255 IEA (2013a), Country data, table 1

256 IEA (2010a) and IEA (2013a), Country data, table 3

${ }^{257}$ IEA (2010b) and IEA (2013e), Part III, tables 1.1 and 1.2

258 IEA (2013e), Part III, Country data, table 3

259 IEA (2013e), Part III, table 2.12; Eurelectric (2012), table 3.1.1.3.
} 
TPES and the electricity generation are heavily reliant on coal in Poland. Climate change is not one of the main priorities of the government apart from fulfilling its EU commitments, although even these have been put into question since 2013. The main focus is on a secure and affordable energy supply, which includes support to coal in the energy mix but also the development of shale gas resources and nuclear power. While natural gas plants were envisaged in the early 2010s, most projects have been scrapped by early 2013 due to lack of financial support to build these plants. The country is expected to continue to be reliant on coal for the period considered in this study. Poland is partially exempt from the EU ETS, so it is not yet fully exposed to European $\mathrm{CO}_{2}$ prices, ${ }^{260}$ and its target regarding GHG emissions not covered by the EU ETS is to limit the increase by $14 \%$ compared to $2005 .{ }^{261}$

\section{Scenario}

Unsurprisingly, coal remains the dominant fuel in Poland. Some renewables and eventually nuclear will come into the mix, as will gas whose role is expected to grow up to 2030 as seen in Figure 108.

Figure 108: Scenario for power generation mix in Poland, up to 2030, in GWh

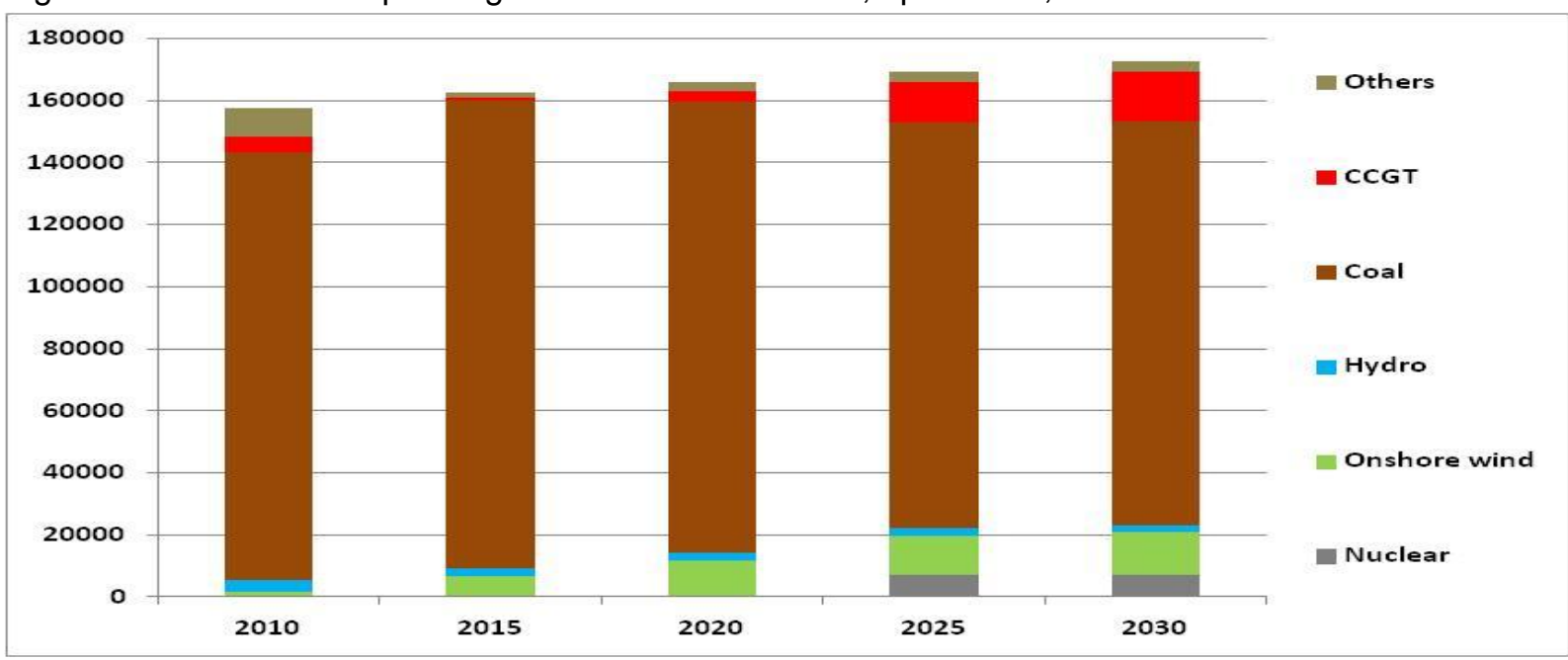

Source: 2010: IEA (2013e), table 3 for each country; scenario: Author

Growth is expected in all the sectors, but the power sector should be the key driver as shown in Figure 109.

\footnotetext{
${ }^{260}$ Platts (May 2013b), p.7

${ }^{261}$ For more information, see the National Renewable Energy Action Plan to the European Commission; Ecologic Institute \& Eclareon (Poland)
} 
Figure 109: Scenario for natural gas demand in Poland, up to 2030, in $\mathrm{Bcm}$

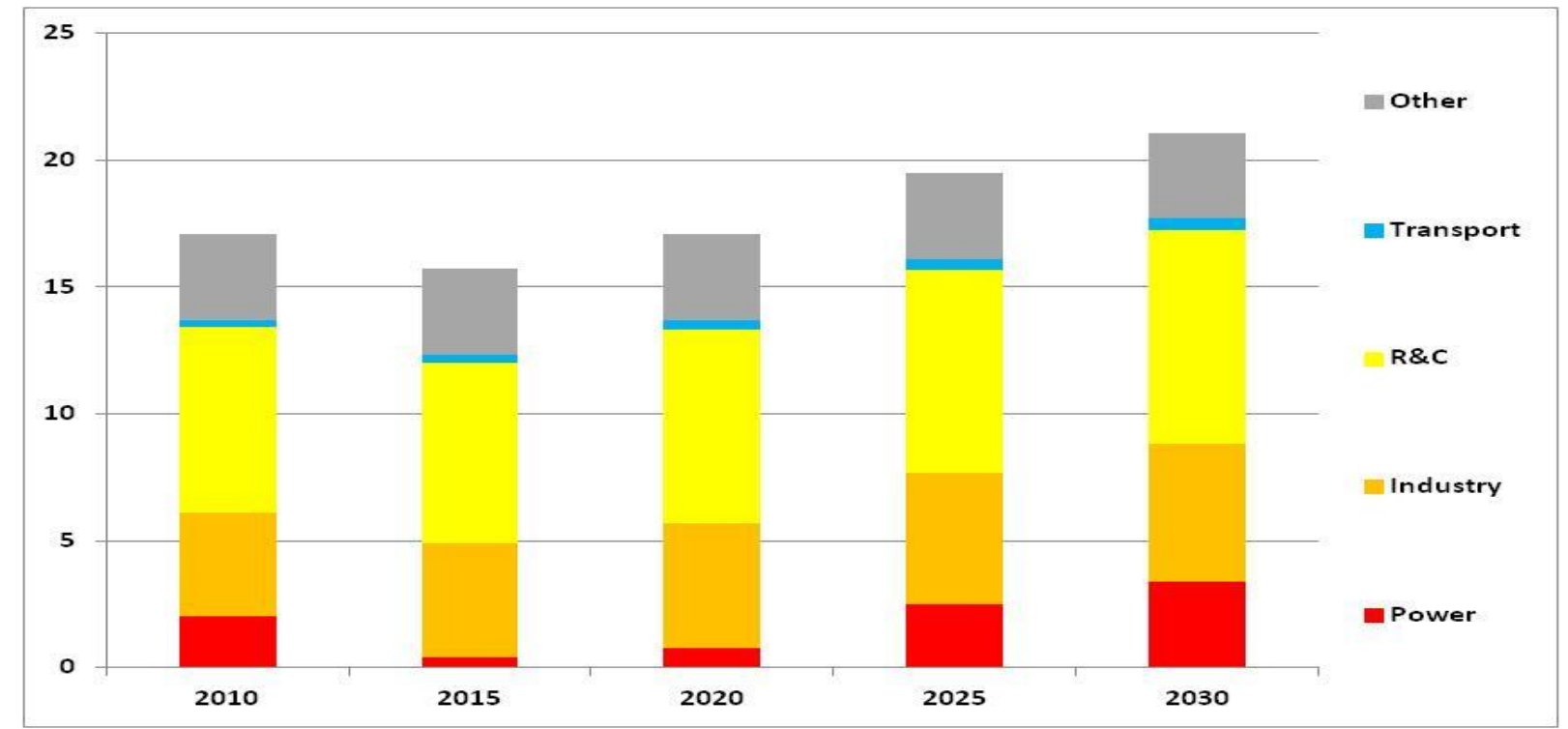

Source: 2010: IEA (2013a), table 3 for each country; scenario: Author 

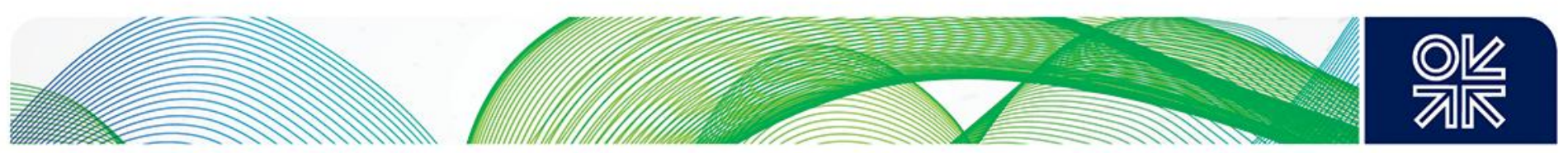

\section{Portugal}

\section{Background}

In 2012, oil still represented the largest share of the TPES (43\% share), followed by gas (18\%) and coal (13\%). The country is dependent on imports for almost $80 \%$ of its energy needs and for $100 \%$ of its natural gas requirements. ${ }^{262}$

Total gas consumption was about $4.6 \mathrm{Bcm}$ in 2012, flat from its pre-crisis level (2008). The power sector was the biggest consumer (61\% of demand in 2011), before the industrial sector $(25 \%)$ and finally the R\&C sector (10\%). ${ }^{263}$ The industrial sector has recovered from the economic downturn with a consumption higher by $13 \%$ in 2012 compared to 2008 , as did the power sector $(+7 \%)$.

Power supply was at about 53 TWh in 2011, flat from 2008 levels. Gross production was just below at 52 TWh (it dropped to 46.5 TWh the following year). ${ }^{264}$ In 2012, coal accounted for $28 \%$ of the electricity generation mix, renewables for $23 \%$, gas for $22 \%$ and hydropower at $14 \%{ }^{265}$

If the assumptions on available gas-fired capacity in 2008 and 2012, which are based on Eurelectric and IEA data, are correct, ${ }^{266}$ then the average load factor of the gas-fired power plants in 2012 was about 26\% (down from about $37 \%$ in 2011 and even $56 \%$ in 2008).

\section{Targets and assumptions}

Portugal was in economic difficulties during 2008-2013, but according to the IMF November 2013 outlook, GDP should recover post 2014 to almost $2 \%$ annual growth rates [Figure 110].

Figure 110: GDP annual growth in Portugal (\%), in constant prices, 2000-2018 (forecast from 2012)

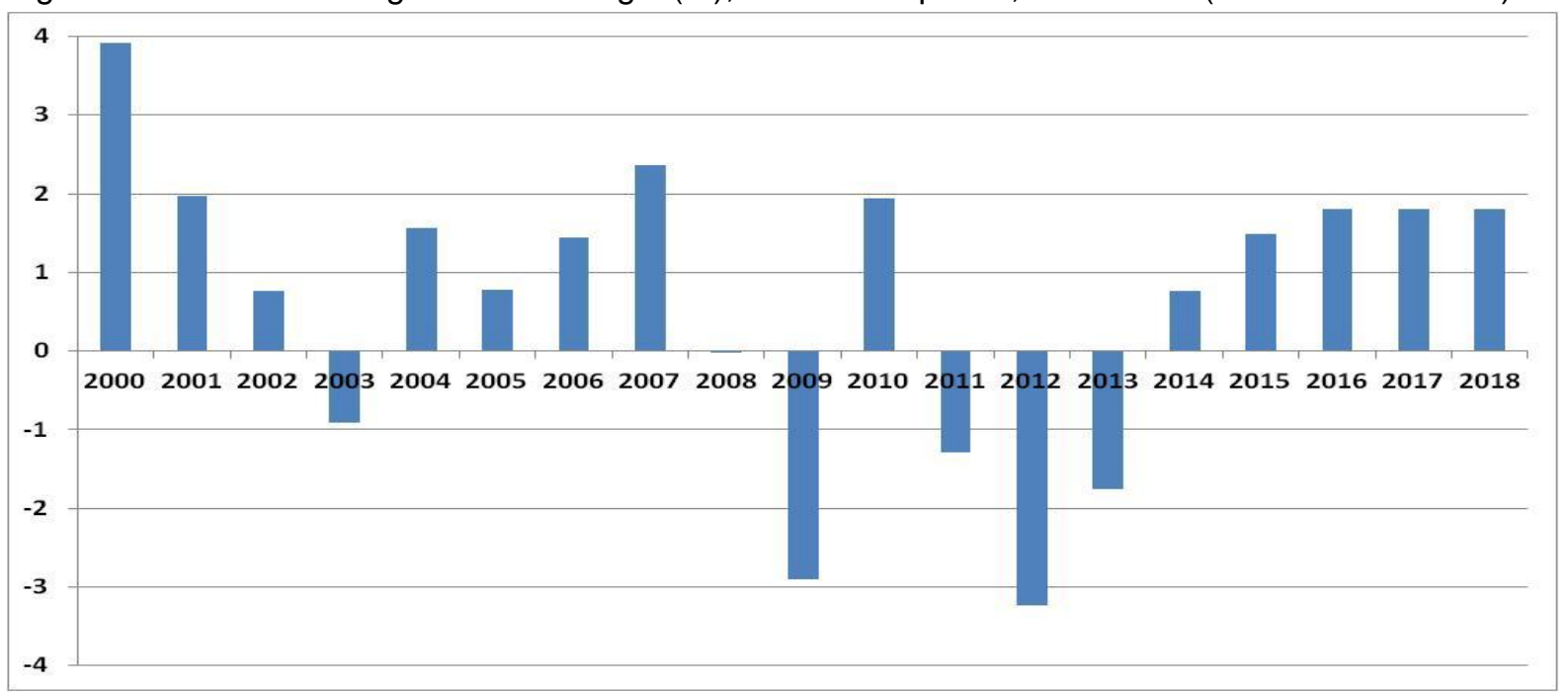

Source: IMF (2013)

\footnotetext{
262 IEA (2013a), Country data, table 1

263 IEA (2010a) and IEA (2013a), Country data, table 3

264 IEA (2010b) and IEA (2013e), Part III, tables 1.1 and 1.2

265 IEA (2013e), Part III, Country data, table 3

${ }^{266}$ IEA (2013e), Part III, table 2.12; Eurelectric (2012), table 3.1.1.3.
} 

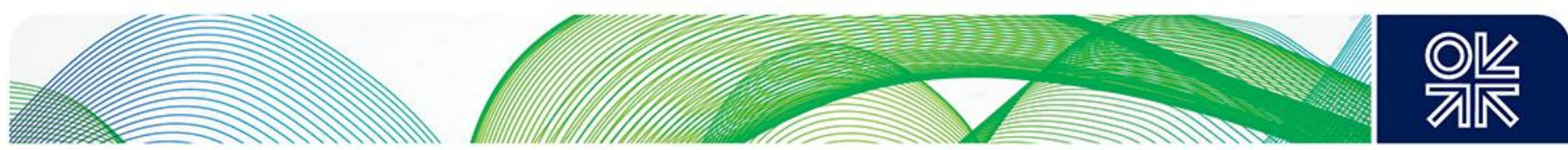

Portugal's commitments to combat climate change include a target of $31 \%$ of gross final consumption from renewables by $2020,60 \%$ of electricity and $10 \%$ of the transport sector. This will help the country to reduce its dependence on fossil fuels and energy imports. The development of renewables has been a core part of the energy policy, at least until the economic crisis changed the priorities of the government. The National Energy Strategy (2010) outlines the main priorities such as improvements of energy efficiency with a $25 \%$ reduction in consumption by 2020 and the need to diversify the TPES and reduce oil dependence. The economic crisis has lowered energy demand and de facto, related emissions. By 2020, Portugal can increase its emissions not covered under the EU ETS by $1 \%$ compared to 2005 according to the ESD, target that should be met with existing policies. ${ }^{267}$

\section{Scenario}

The role of gas in power generation will progressively be eroded by the rise of renewables, including hydropower if power demand does not pick up as seen in Figure 111.

Figure 111: Scenario for power generation mix in Portugal, up to 2030, in GWh

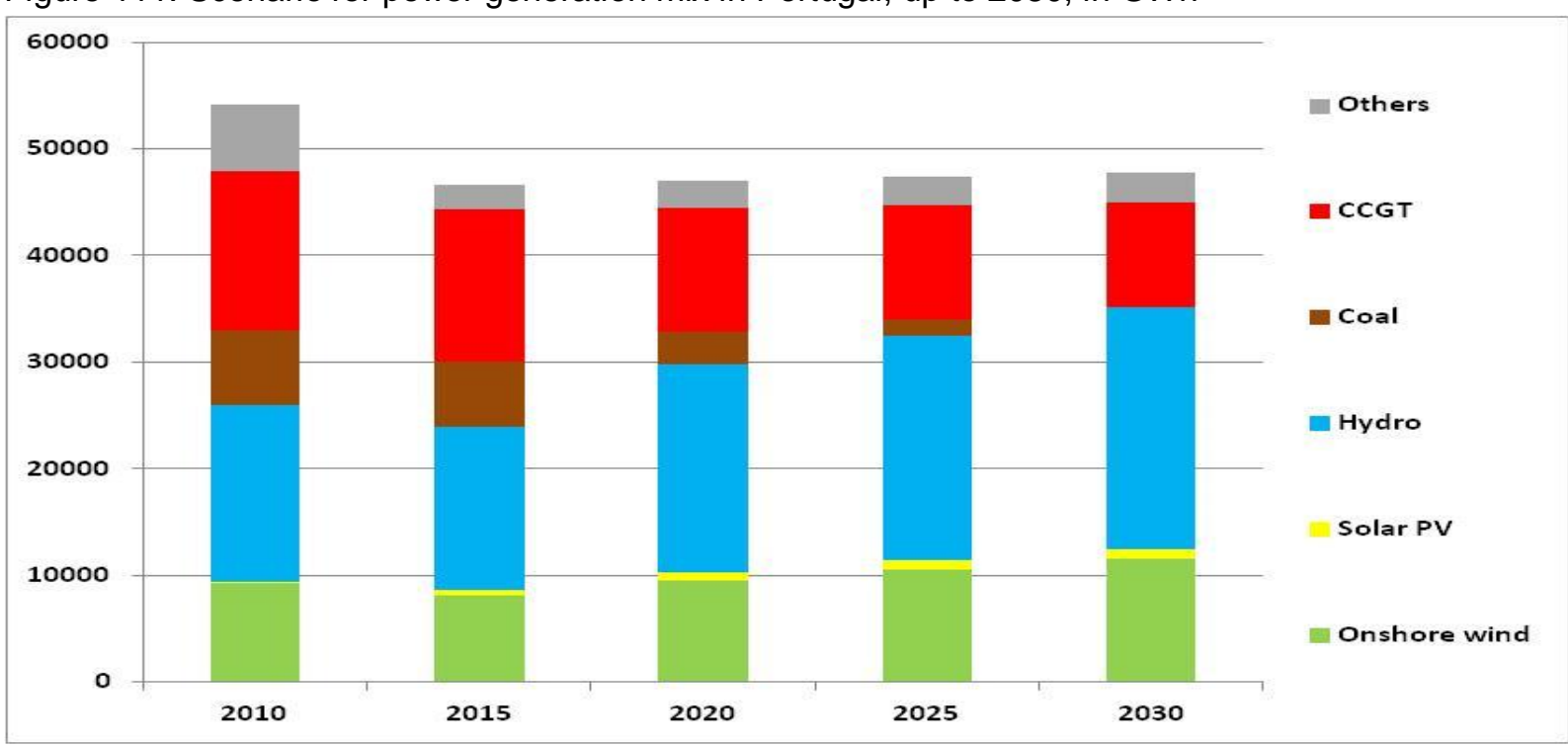

Source: 2010: IEA (2013e), table 3 for each country; scenario: Author

If this scenario happens, total gas demand will suffer and decline by about $20 \%$ by 2030 as shown in Figure 112.

\footnotetext{
${ }^{267}$ For more information, see the National Renewable Energy Action Plan to the European Commission; Ecologic Institute \& Eclareon (Portugal)
} 
Figure 112: Scenario for natural gas demand in Portugal, up to 2030, in $\mathrm{Bcm}$

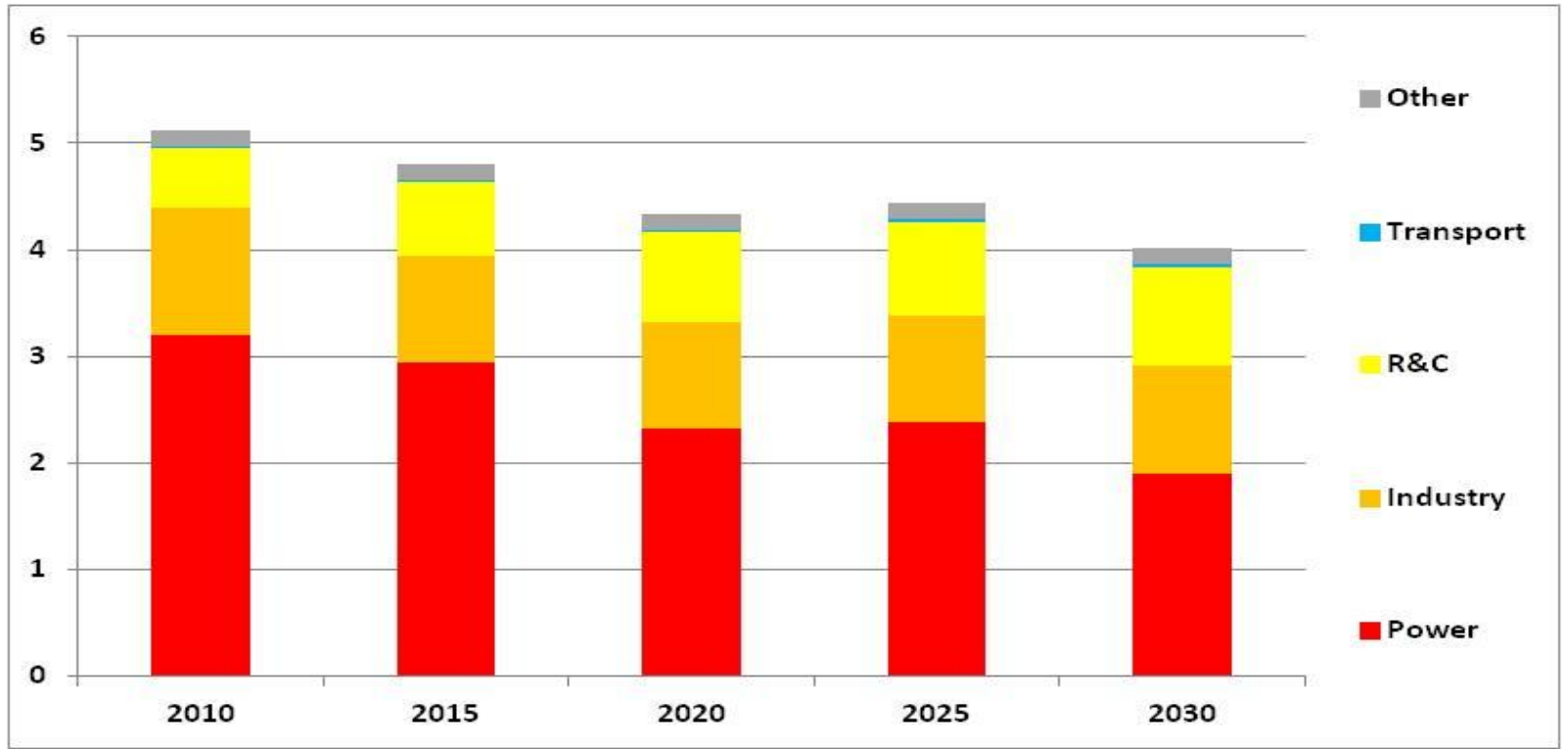

Source: 2010: IEA (2013a), table 3 for each country; scenario: Author 

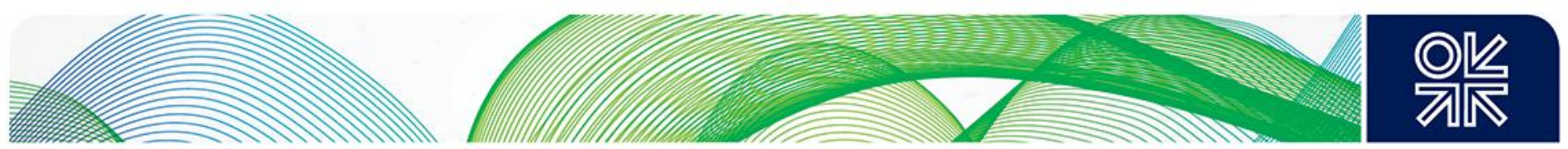

\section{Romania}

\section{Background}

In 2011, the TPES was dominated by gas (31\%), oil (24\%) and coal (23\%). Nuclear accounted for $8.5 \%$ and hydro for $3 \%{ }^{268}$ The country was dependent on energy imports for about a quarter of its energy needs, and $22 \%$ of its gas requirements.

Gas demand reached $13.6 \mathrm{Bcm}$ in 2012, $15 \%$ below 2008. The power sector was the largest consumer with $37 \%$ of the gas consumed in 2011 , followed by the industrial $(27 \%)$ and $R \& C(8 \%) .{ }^{269}$

Power demand stood at 54 TWh in 2011, 2.7\% above 2008 levels. ${ }^{270}$ Gross electricity production was higher at $62 \mathrm{TWh}$, with an electricity generation mix dominated by coal $(40 \%)$, hydropower (24\%) and nuclear (19\%), while gas only accounted for $13 \%$ and renewables for $3 \%{ }^{271}$

If the assumptions on available gas-fired capacity in 2012, which are based on Eurelectric data, are correct, ${ }^{272}$ then the average load factor of the gas-fired power plants in 2012 was above $60 \%$.

\section{Targets and assumptions}

After a decline in 2009 and 2010, GDP growth is expected to recover post 2013 and stabilise between 2-4\% annually until 2018 according the IMF world economic outlook of November 2013 [Figure 113].

Figure 113: GDP annual growth in Romania (\%), in constant prices, 2000-2018 (forecast from 2012)

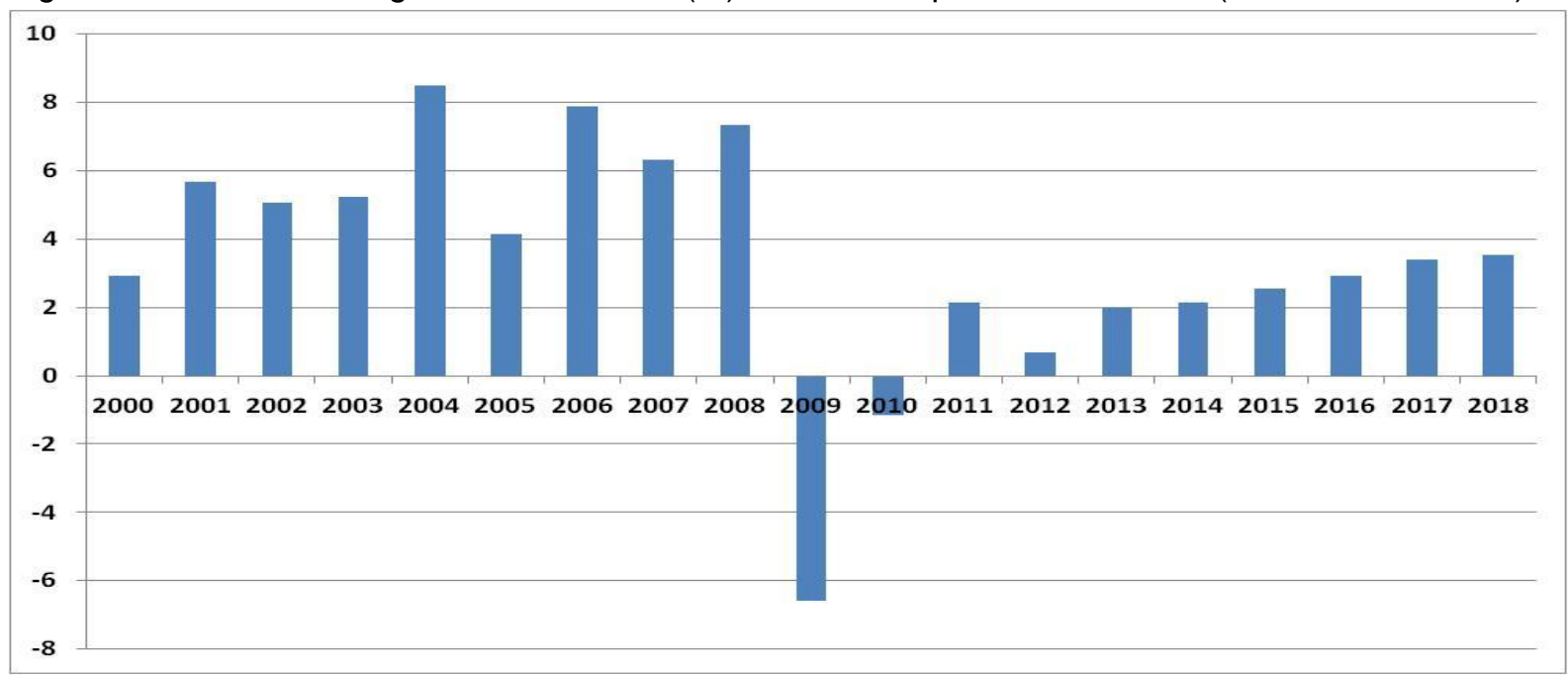

Source: IMF (2013)

Romania became a member of the EU on January 2007. The Energy Strategy for the period 20072020 followed shortly after, highlighting priorities such as the role of renewables. The country is to promote renewables in order to meet $11 \%$ of its gross final consumption by 2020 , which will also translate into $33 \%$ of electricity generation in $2010,35 \%$ in 2015 and $38 \%$ in 2020 . The national Climate Change Strategy was implemented from 2012 with additional measures to boost renewables

\footnotetext{
${ }^{268}$ IEA (2013c), p.II.57

269 IEA (2013c), p.II.57

270 IEA (2010b) and IEA (2013e), Table 1.1, p.III.6

271 IEA (2013e), Table 1.2, p.III.10

272 Eurelectric (2012), table 3.1.1.3.
} 
and reduce energy efficiency (the country's target is a reduction of $19 \%$ by $2020^{273}$ ). However, in 2013, the Romanian government approved subsidy cuts for new renewable capacities to avoid overcompensating the industry following a surge in wind and solar projects and has also delayed some certificates for existing projects until 2017 to curb costs. A large part of the $8.5 \mathrm{GW}$ of thermal capacity has exceeded its lifetime expectancies and will need to be replaced or refurbished, partly by increasing its nuclear generation capacity and building a large-scale pumped-storage hydropower plant. The national emission target for Romania under the ESD to limit the increase of GHG emissions in 2020 to $19 \%$ compared to 2005 level, a target that should be met with existing policies. $^{274}$

\section{Scenario}

Romania is a large gas market with a consumption reaching $13.6 \mathrm{Bcm}$ in 2012. However, this market has seen gas consumption decline sharply since the early 1990s and we do not foresee any key factor to reverse the trend... or continue it. In our scenario, natural gas demand remains fairly flat along the period and accounts for about $13.5 \mathrm{Bcm}$ by 2030 .

\footnotetext{
${ }^{273} \mathrm{http}: / /$ ec.europa.eu/energy/efficiency/eed/reporting en.htm

${ }^{274}$ For more information, see the National Renewable Energy Action Plan to the European Commission; Ecologic Institute \& Eclareon (Romania)
} 

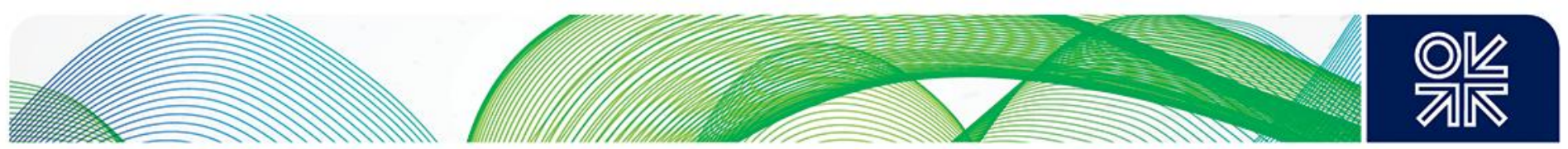

\section{Serbia}

\section{Background}

In 2011, the TPES was dominated by coal (50\%), oil (25\%) and in a lesser extent gas (12\%). ${ }^{275}$ The country was dependent on energy imports for about a third of its energy needs, but more than $80 \%$ of its gas requirements are imported.

Gas demand reached $2.4 \mathrm{Bcm}$ in $2012,4 \%$ below 2008. The power sector was the largest consumer with $38 \%$ of the gas consumed in 2011 , followed by the industrial $(33 \%)$ and $R \& C(12 \%) .{ }^{276}$

Power demand stood at 34.7 TWh in 2011, 2.4\% above 2008 levels. ${ }^{277}$ Gross electricity production was higher at $38.6 \mathrm{TWh}$, with an electricity generation mix largely dominated by coal $(75 \%)$. Hydropower accounted for $24 \%$ while gas represented only $1 \%{ }^{278}$

If the assumptions on available gas-fired capacity in 2012, which are based on Eurelectric data, are correct, ${ }^{279}$ then the average load factor of the gas-fired power plants in 2012 was $32 \%$.

\section{Targets and assumptions}

After a decline in 2009 and 2012, GDP growth is expected to recover post 2013 and stabilise at around 2-3\% annually until 2018 according the IMF world economic outlook of November 2013 [Figure 114].

Figure 114: GDP annual growth in Serbia (\%), in constant prices, 2000-2018 (forecast from 2011)

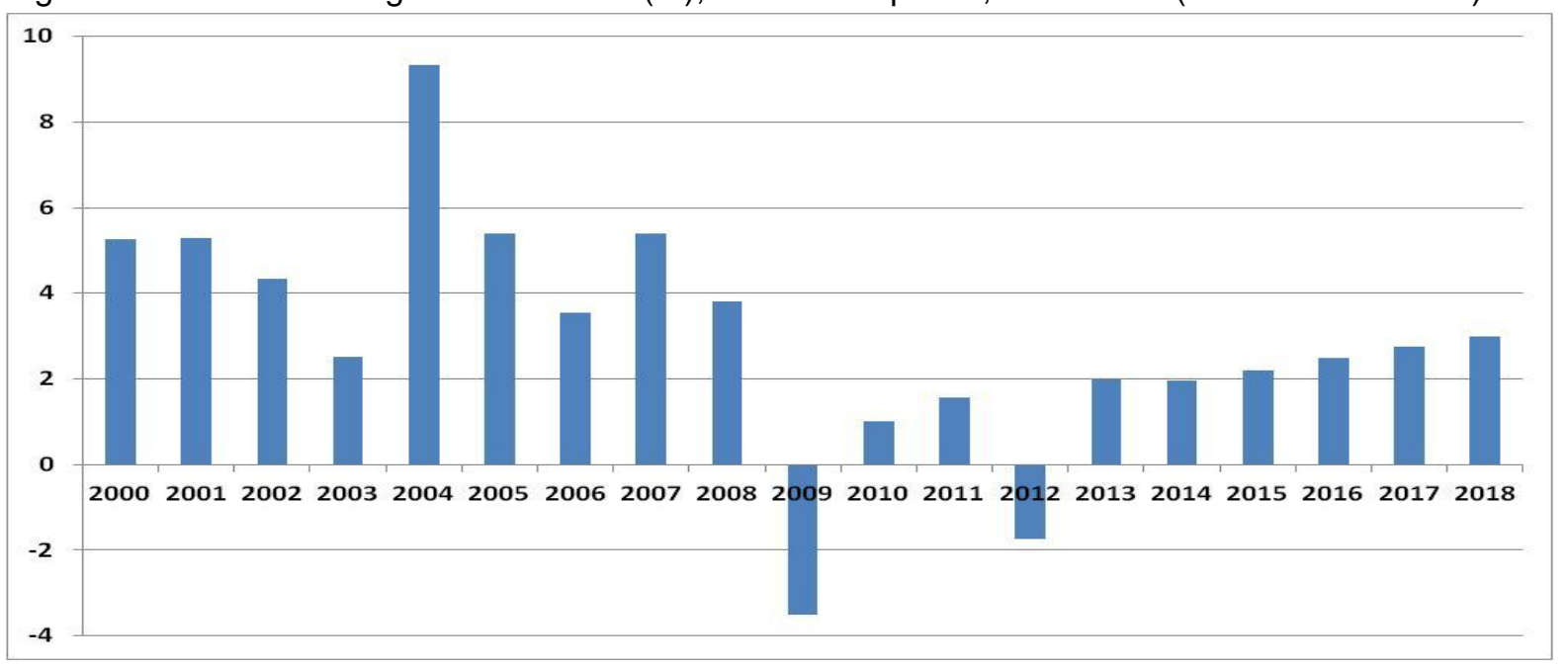

Source: IMF (2013)

Serbia is committed to increase the role of renewables to a $27 \%$ share in gross final energy consumption by 2020 . The share of renewables in the electricity sector is expected to amount to $36.6 \%$, in the heating and cooling sector to $30 \%$ and in transport $10 \%$. The country is also committed to energy savings which should amount to $10 \%$ between 2010 and $2020{ }^{280}$

\footnotetext{
${ }^{775}$ IEA (2013c), p.II.57

276 IEA (2013c), p.II.57

${ }^{277}$ IEA (2010b) and IEA (2013e), Table 1.1, p.III.6

278 IEA (2013e), Table 1.2, p.III.10

${ }^{279}$ Eurelectric (2012), table 3.1.1.3.

280 Republic of Serbia (2013)
} 


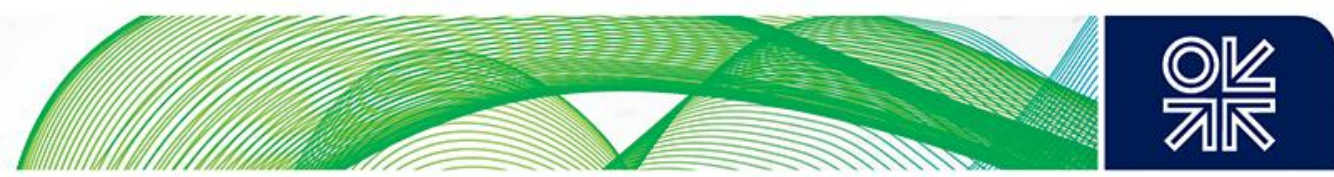

\section{Scenario}

In our scenario, natural gas demand remains fairly flat along the period and accounts for about 2.3 Bcm by 2030. 

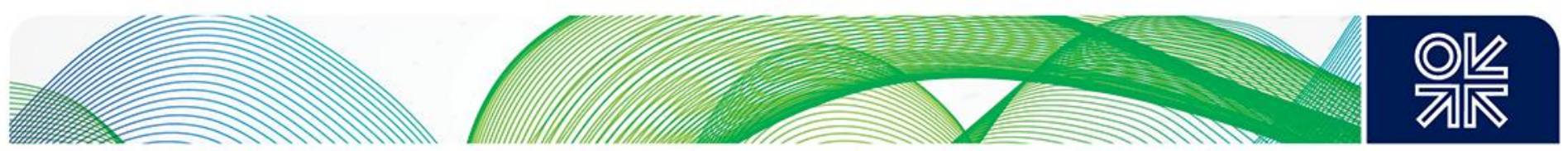

\section{Slovakia}

\section{Background}

In 2012, TPES was well balanced between gas at $26 \%$, nuclear at $25 \%$, oil at $21 \%$ and coal at $21 \%$. The country is dependent on energy imports for about $60 \%$ of its total energy needs and for almost $100 \%$ its natural gas requirements. ${ }^{281}$

Total gas consumption was about $5.3 \mathrm{Bcm}$ in 2012 , about $16 \%$ below its pre-crisis level (2008). The $R \& C$ sector was the biggest consumer (33\% in 2011), followed by the power sector $(25 \%)$ and finally the industrial sector (20\%). The power sector registered a 13\% growth since 2008 contrary to most of the other European markets. ${ }^{282}$

Power supply reached 26.3 TWh in 2011, 2.2\% below 2008 levels. Gross production was about $10 \%$ higher. ${ }^{283}$ Slovakia's generation mix is split between nuclear $(54 \%)$, hydropower (15\%), coal (13\%), gas (10\%) and renewables (3\%). ${ }^{284}$

If the assumptions on available gas-fired capacity in 2012, which are based on Eurelectric and IEA data, are correct, ${ }^{285}$ then the average load factor of the gas-fired power plants in 2012 was about $19 \%$.

\section{Targets and assumptions}

After a sharp drop in 2009, GDP growth remained positive and is expected to continue in the 2010s at rates ranging between 2-4\% as shown in the IMF economic outlook of November 2013 [Figure 115].

Figure 115: GDP annual growth in Slovakia (\%), in constant prices, 2000-2018 (forecast from 2012)

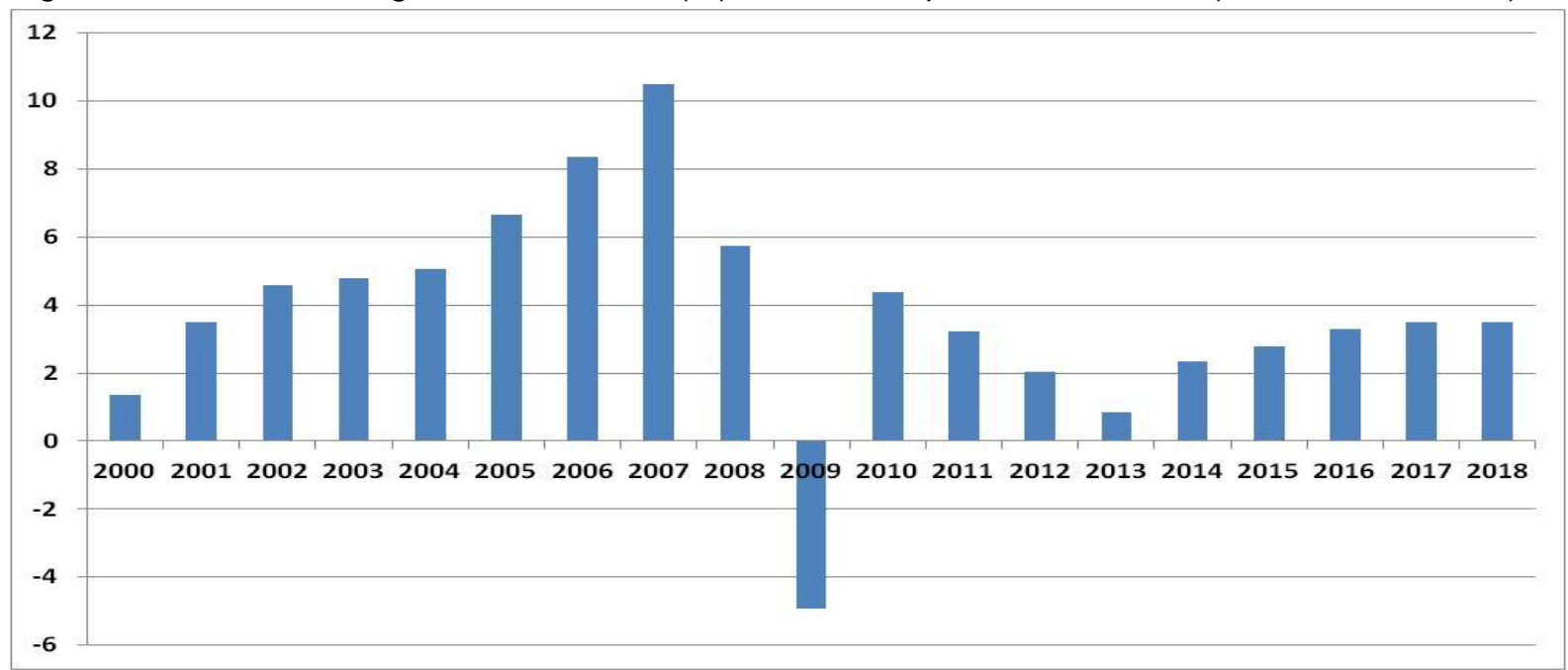

Source: IMF (2013)

Slovakia's Energy Policy (2006) focused on increasing the share of renewable energy sources in power and heat generation. This objective was strengthened following the 2009 crisis which saw gas

\footnotetext{
281 IEA (2013a), Country data, table 1

282 IEA (2010a) and IEA (2013a), Country data, table 3

${ }^{283}$ IEA (2010b) and IEA (2013e), Part III, tables 1.1 and 1.2

284 IEA (2013e), Part III, Country data, table 3

285 IEA (2013e), Part III, table 2.12; Eurelectric (2012), table 3.1.1.3.
} 
supplies from Russia cut for several days. Because of the heat sector's dependence on natural gas, developing renewables is seen in the country as an important way to increase security of supply as is nuclear power. The country has a target of a $15 \%$ share renewables in gross final consumption by 2020. However, the cost of developing renewables has become a concern during the economic crisis. By 2020, Slovakia can increase its GHG emissions not covered in the EU ETS by $13 \%$ compared to 2005 according to the ESD, which should be met with existing policies. ${ }^{286}$

\section{Scenario}

Natural gas will not have a major role in generation in the 2010s, but it may recover its share and much more when old(er) nuclear reactors are retired after 40 years of exploitation as seen in Figure 116.

Figure 116: Scenario for power generation mix in Slovakia, up to 2030, in GWh

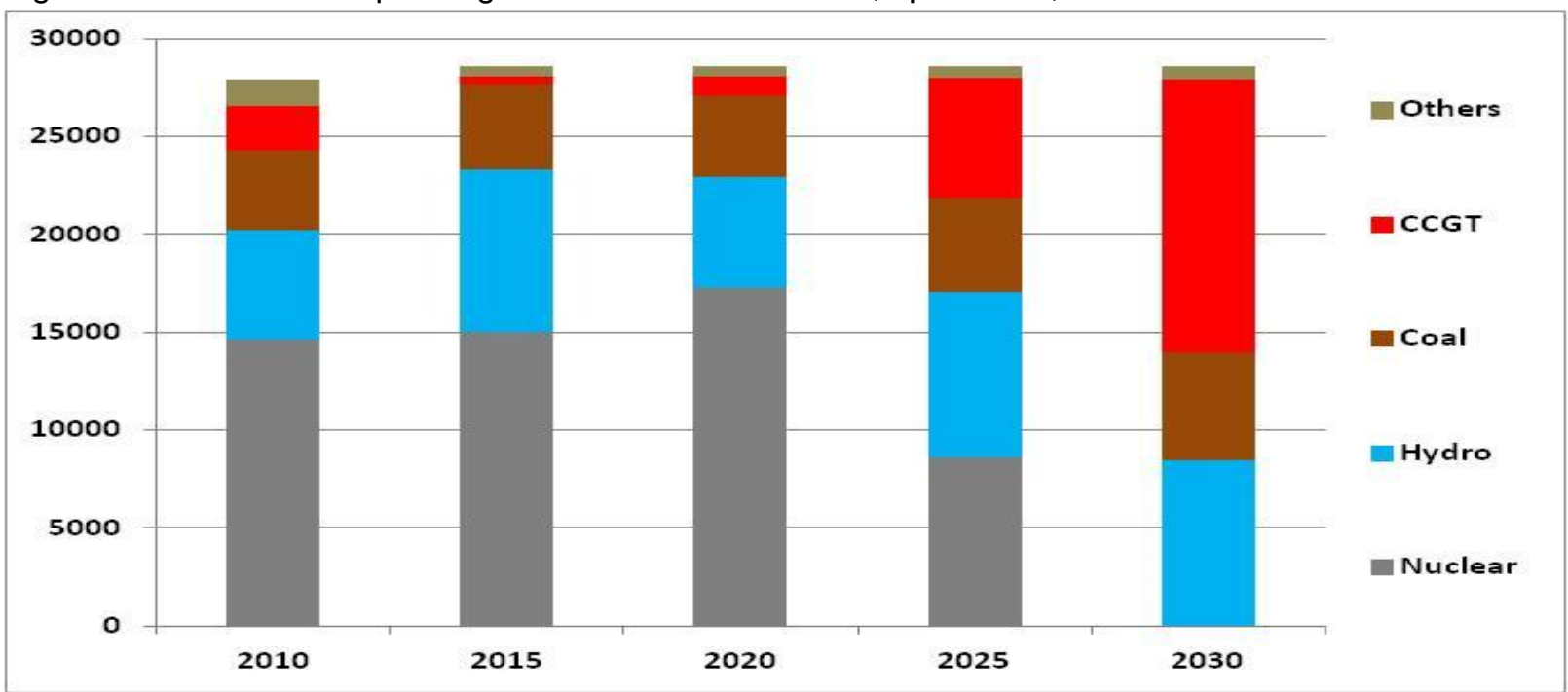

Source: 2010: IEA (2013e), table 3 for each country; scenario: Author

If this happens, we can expect gas demand to pick up in the 2020s as shown in Figure 117.

\footnotetext{
${ }^{286}$ For more information, see the National Renewable Energy Action Plan to the European Commission, ; Ecologic Institute \& Eclareon (Slovakia)
} 
Figure 117: Scenario for natural gas demand in Slovakia, up to 2030, in Bcm

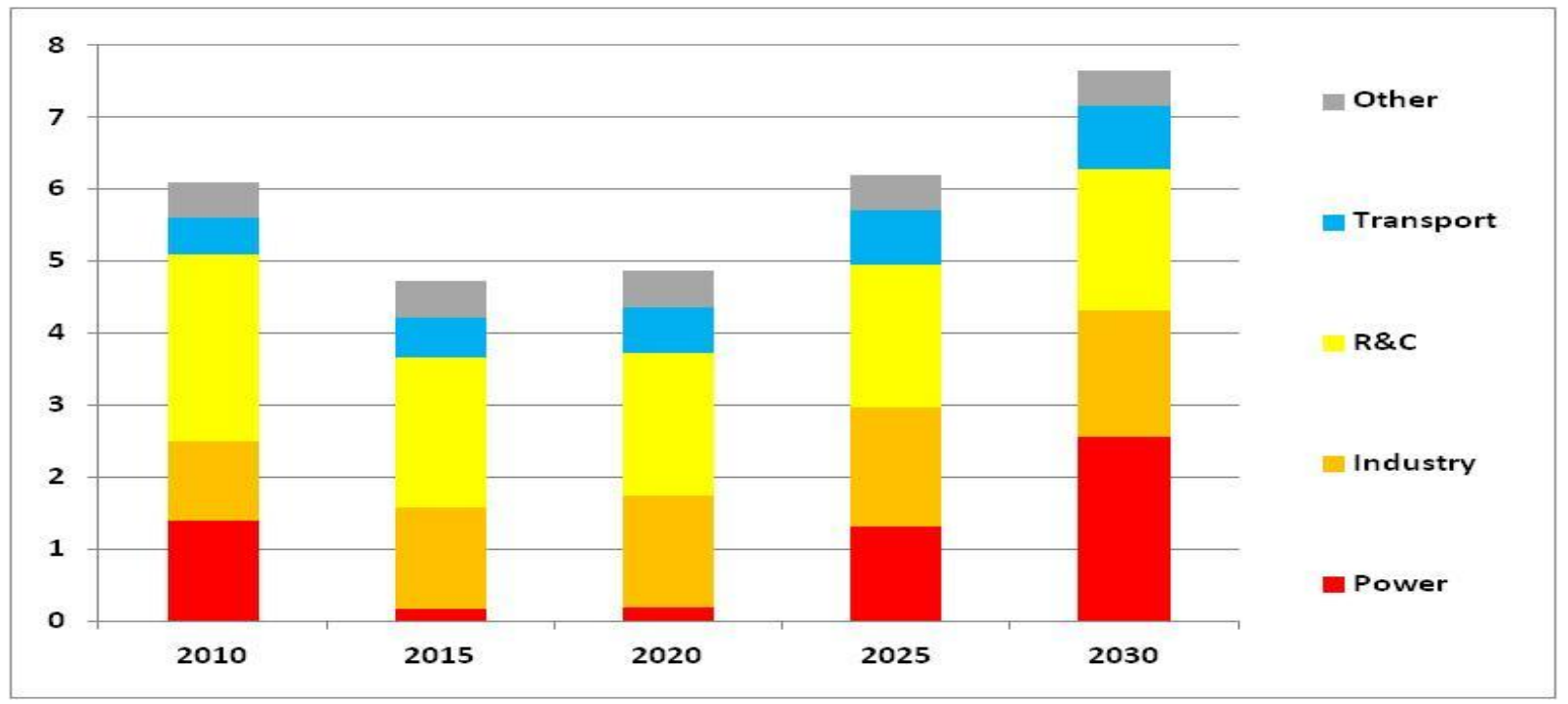

Source: 2010: IEA (2013a), table 3 for each country; scenario: Author 

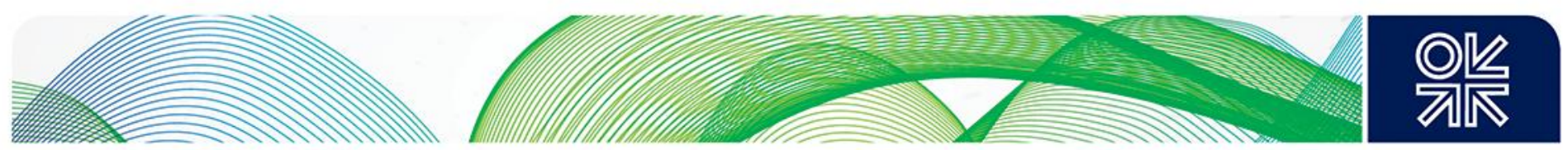

\section{Slovenia}

\section{Background}

In 2012, TPES was dominated by oil (36\%), coal (21\%) and nuclear (20\%). Gas accounted for $10 \%$ only. The country is dependent on energy imports for about half of its total energy needs and for $100 \%$ of its natural gas requirements. ${ }^{287}$

Total gas consumption was about $900 \mathrm{MMcm}$ in 2012, about $18 \%$ below its pre-crisis level (2008). The industrial sector dominated gas demand (58\% in 2011), far above the power and R\&C sectors $(21 \%) .{ }^{288}$

Power supply reached 13.5 TWh in 2011, 2.2\% below 2008 levels. Gross production was almost $20 \%$ higher (it dropped to $15.7 \mathrm{TWh}$ the following year). ${ }^{289}$ In 2012, nuclear accounted for $35 \%$ of generation, coal $(32 \%)$, hydropower $(26 \%)$, gas $(2 \%)$ and renewables $(1 \%) .{ }^{290}$

If the assumptions on available gas-fired capacity in 2012, which are based on Eurelectric and IEA data, are correct, ${ }^{291}$ then the average load factor of the gas-fired power plants in 2012 was about $9 \%$, which appears to be very low.

\section{Targets and assumptions}

After difficult economic times in the period 2009-2014, the IMF expects a return to growth by 2015 as shown in its economic outlook of November 2013 [Figure 118].

Figure 118: GDP annual growth in Slovenia (\%), in constant prices, 2000-2018 (forecast from 2012)

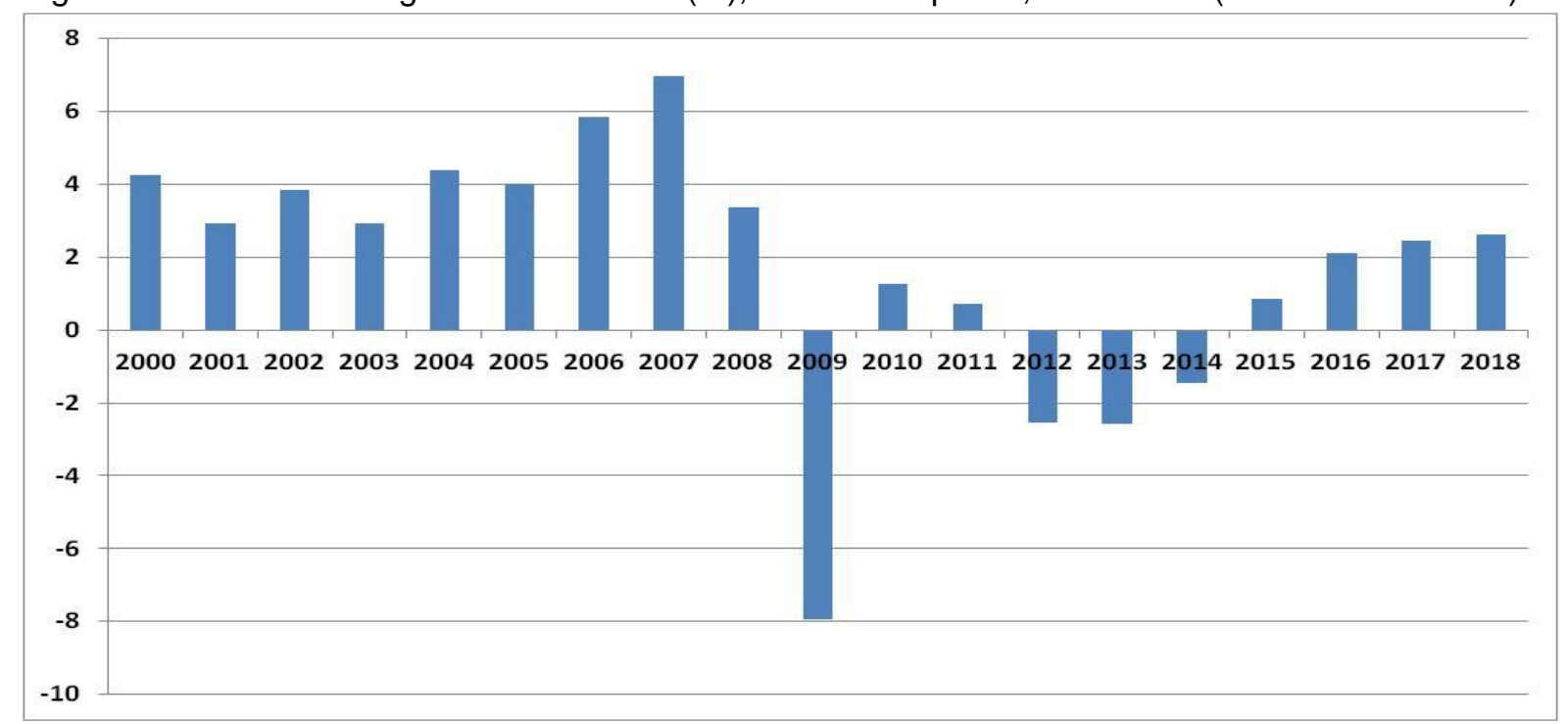

Source: IMF (2013)

As of 2014, priorities in Slovenia lie in the impacts of the economic crisis and climate change has taken a back seat. The country has a target of $25 \%$ share of renewables in gross final consumption,

\footnotetext{
287 IEA (2013a), Country data, table 1

288 IEA (2010a) and IEA (2013a), Country data, table 3

289 IEA (2010b) and IEA (2013e), Part III, tables 1.1 and 1.2

290 IEA (2013e), Part III, Country data, table 3

${ }^{291}$ IEA (2013e), Part III, table 2.12; Eurelectric (2012), table 3.1.1.3.
} 

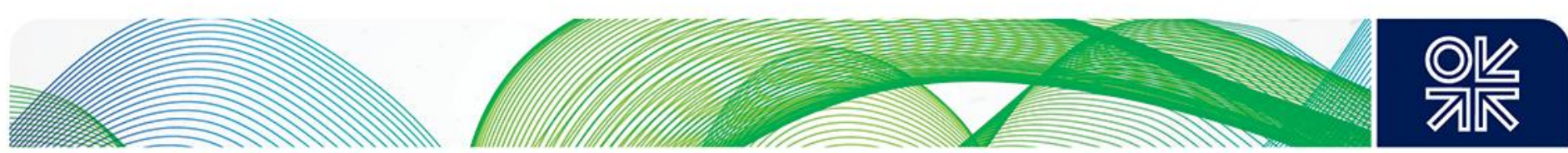

$31 \%$ of heat consumption, $39 \%$ of electricity demand and $10 \%$ in transport by 2020 . Measures to improve energy efficiencies are already in place and will be strengthened in the 2010s in order to curb energy demand growth. By 2020, the country can increase its emissions not covered by the EU ETS by $4 \%$ compared to 2005 according to the ESD, to which it seems to be on track. ${ }^{292}$

\section{Scenario}

The role of gas will be dependent on the availability of power generation in the 2010 s and on the retirement/replacement of nuclear power as seen in Figure 119.

Figure 119: Scenario for power generation mix in Slovenia, up to 2030, in GWh

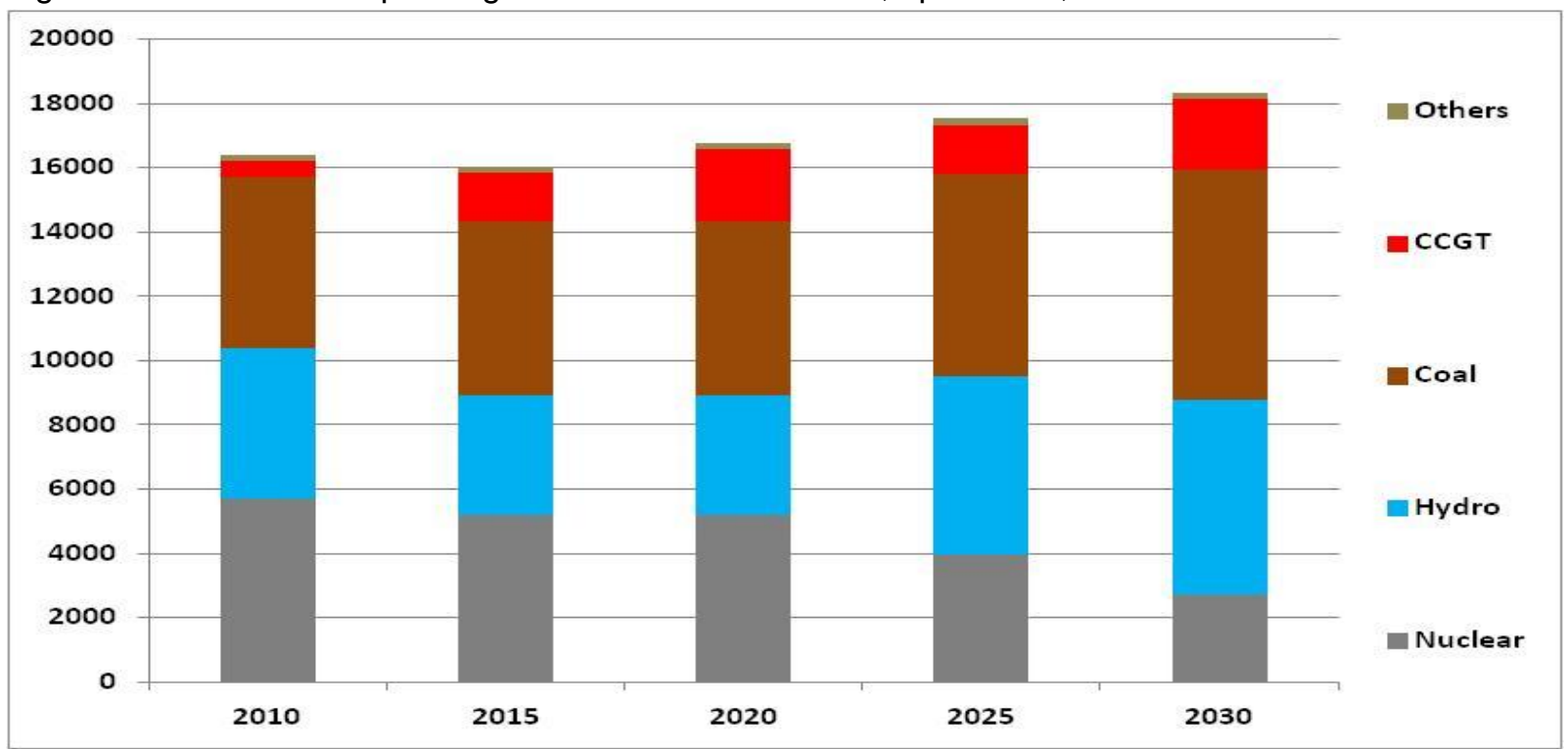

Source: 2010: IEA (2013e), table 3 for each country; scenario: Author

Total gas demand recovery will also be function of hydropower availability and nuclear energy developments as shown in Figure 120.

\footnotetext{
${ }^{292}$ For more information, see the National Renewable Energy Action Plan to the European Commission ; Ecologic Institute \& Eclareon (Slovenia)
} 
Figure 120: Scenario for natural gas demand in Slovenia, up to 2030, in Bcm

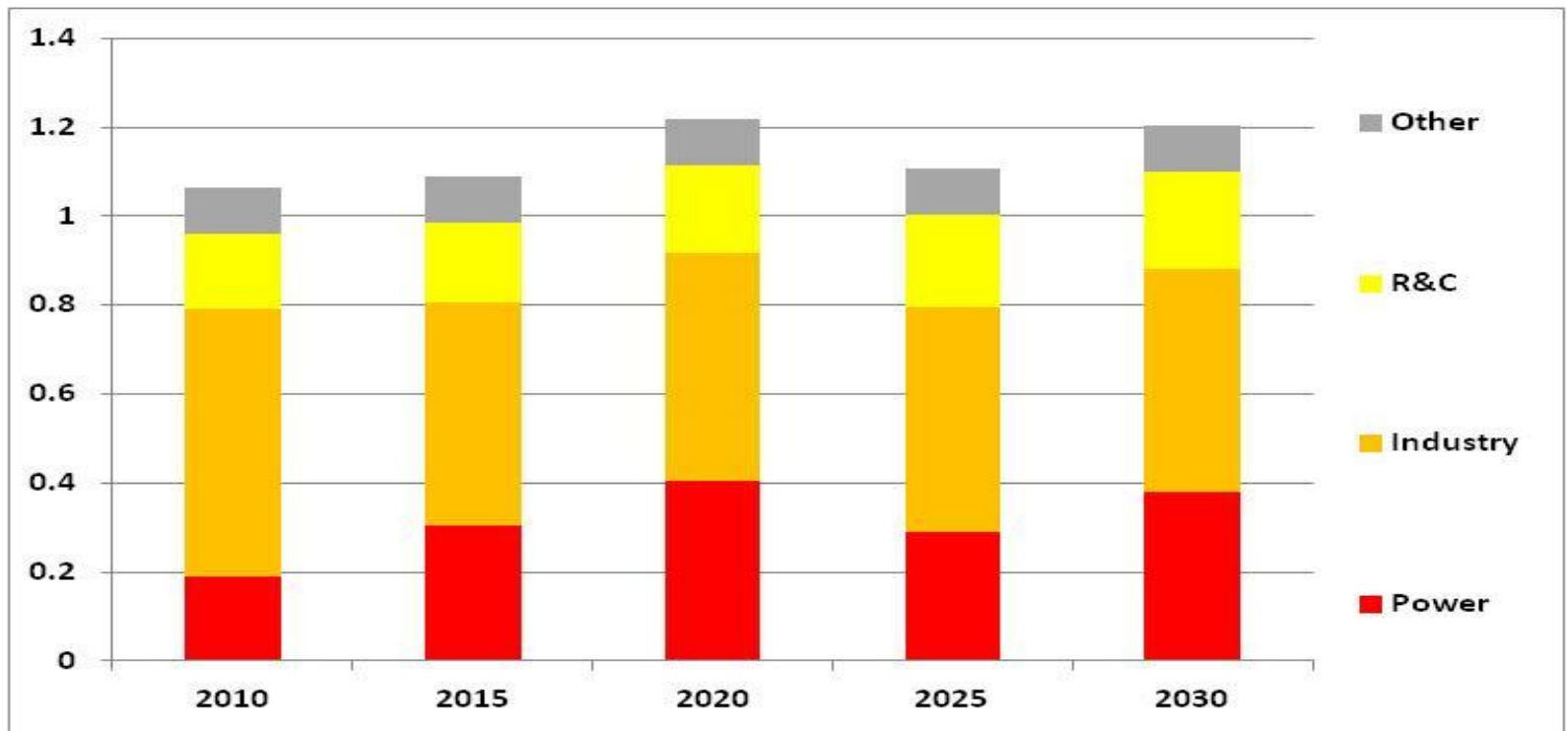

Source: 2010: IEA (2013a), table 3 for each country; scenario: Author 


\section{Spain}

\section{Background}

In 2012, oil represented the largest share of the TPES (41\% share), followed by gas (23\%), nuclear $(13 \%)$ and coal $(12 \%)$. The country is import dependant for about three quarters of its energy needs and for almost $100 \%$ of its natural gas requirements. ${ }^{293}$

Total gas consumption was just over $32.5 \mathrm{Bcm}$ in 2012 , almost $20 \%$ below its pre-crisis level (2008). The power sector was still the largest consumer in 2011 (44\%) despite a major drop since 2008, the industrial sector accounted for $26 \%$ and the R\&C sector (18\%). ${ }^{294}$

Power supply was 272 TWh in 2011, 5.2\% below 2008 levels. Gross production was 291.4 TWh (297.1 TWh the following year). ${ }^{295}$ In 2012, gas was still the predominant fuel $(25 \%)$ despite the sharp decline in CCGTs use since 2008 in Spain, followed by renewables (excluding hydro, 21\%) and nuclear (also $21 \%$ ), coal (19\%) and finally hydropower (8\%) which registers large variations from one year to another (and impacts the use of gas-fired plants). ${ }^{296}$

If the assumptions on available gas-fired capacity in 2008 and 2012, which are based on Eurelectric data, are correct, ${ }^{297}$ then the average load factor of the gas-fired power plants in 2012 was about $29 \%$ (34\% in 2011), down from about $52 \%$ in 2008. The data given by Enagás in its annual report 2013 are even worse: the utilisation rates of the $26.3 \mathrm{GW}$ of CCGTs have been on continuous decline from $52 \%$ in 2008 to $44 \%$ in $2009,33 \%$ in $2010,25 \%$ in $2011,19 \%$ in 2012 and even a disastrous $13 \%$ in 2013. ${ }^{298}$

\section{Targets and assumptions}

According to the IMF November 2013 outlook, GDP should slowly recover from the difficult times of 2009-2013 and register limited growth up to 2018 [Figure 121].

Figure 121: GDP annual growth in Spain (\%), in constant prices, 2000-2018 (forecast from 2012)

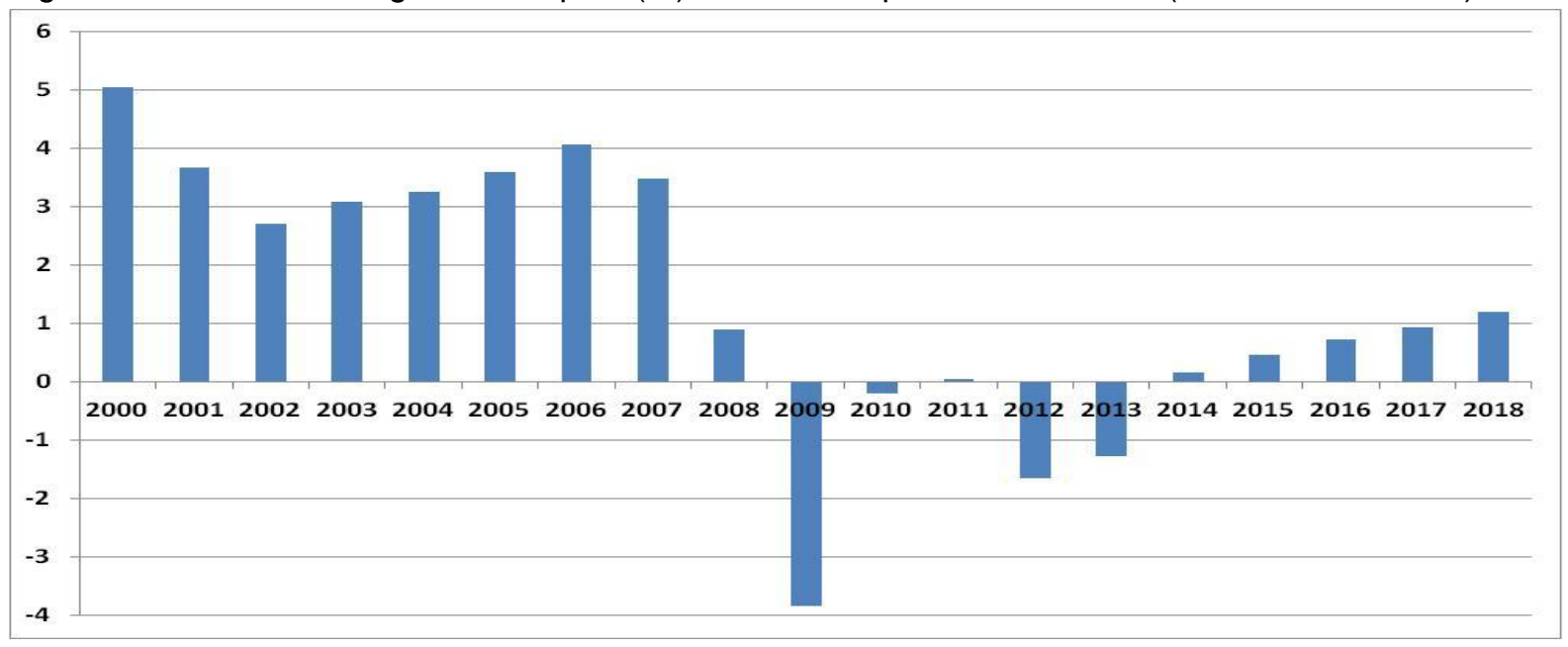

Source: IMF (2013)

\footnotetext{
293 IEA (2013a), Country data, table 1

${ }^{294}$ IEA (2010a) and IEA (2013a), Country data, table 3

${ }^{295}$ IEA (2010b) and IEA (2013e), Part III, tables 1.1 and 1.2

296 IEA (2013e), Part III, Country data, table 3

${ }^{297}$ Eurelectric (2012), table 3.1.1.3.

298 Enagas, El Sistema gasista espanol, informe 2013, pp.40-41
} 
Spain has had a strong commitment to transition toward a green economy in the 2000s, however, the economic crisis seems to have shifted the government's priorities, and there have been several reforms to cut expenditures in what used to be one of Europe's most profitable feed-in tariff and premium schemes for renewables and CHP plants. Nonetheless, the country is already a model for gas as back up for wind and solar intermittence. Important gas supply flexibility due to the variability in gas-fired generation needed to 'buffer' the changing wind generation profile as wind speed fluctuates. As a result, the demand for gas for power in Spain is less and less a factor of economic decision and more and more a factor of hydro and wind availability. Periods of peak demand and tight supply for gas can still be expected, but also increasingly, periods of low gas demand /high renewable and hydro availability which will require new forms of flexibility to balance the system.

In Spain, the 2020 targets are $20 \%$ of renewables in gross final consumption (40\% in electricity, $18.9 \%$ in heating and cooling and $13.6 \%$ in transport), a reduction of its emissions not covered by the EU ETS by $10 \%$ compared to 2005 according to the ESD (but the country seems to be on a path of missing this target) ${ }^{299}$ and $20 \%$ energy savings to be achieved by $2020 .{ }^{300}$

One question in Spain is about the future of the gas for the power sector, which after being the fastest rising sector in the 2000s has been declining sharply since 2008 due to the economic crisis, the competition with renewables and the non-competitiveness against coal plants. Is gas for power generation a doomed sector in Spain? Not necessarily. In July 2013, the new government froze the support schemes for renewables, and a much slower growth is to be expected in the 2010s. Environmental targets and European Directives (about $5 \mathrm{GW}$ of plant will close due to the LCPD, possibly more due to the IED) will reduce coal-fired capacity in the 2010 s and beyond. Additionally, incentives to burn domestic coal ${ }^{301}$ will stop at the end of 2014. Because unsubsidised generation of domestic coal is likely to be unprofitable, about $6 \mathrm{GW}$ of coal capacity (out of a total of $11 \mathrm{GW}$ ) are expected to close as the conversion to run on imported coal will be unprofitable - especially at times when the IED already requires important investments to meet the ELVs. Some $7.5 \mathrm{GW}$ of nuclear will be phased out after their ' 40 years lifetime' which will be reached for the youngest reactor in 2028 . Gas generation is and will continue to be a key tool to balance the system... but could also generate baseload generation if/when coal and nuclear shares in the generation mix start to decline in the 2010s. ${ }^{302}$

\section{Scenario}

The power generation sector in Spain has been the key driver for gas demand decline since 2008. Our scenario shows that the situation will continue to be difficult for most of the 2010s even if several factors will slowly improve the situation in the situation: slowdown of renewables additions, the impacts of the LCPD/IED and progressive phasing out of nuclear until 2028 will ease the situation for gas-fired plants up to 2030 as seen in Figure 122.

\footnotetext{
${ }^{299}$ For more information, see the National Renewable Energy Action Plan to the European Commission, ; Ecologic Institute \& Eclareon (Spain); Honoré A (2011)

${ }^{0}$ http://ec.europa.eu/energy/efficiency/eed/reporting en.htm

1 Spain as supported its mining industry by introducing the Coal Decree in 2010 whereby eight plants burning domestic coal receive payments. See Honoré A (2011) for more information
} 
Figure 122: Scenario for power generation mix in Spain, up to 2030, in GWh

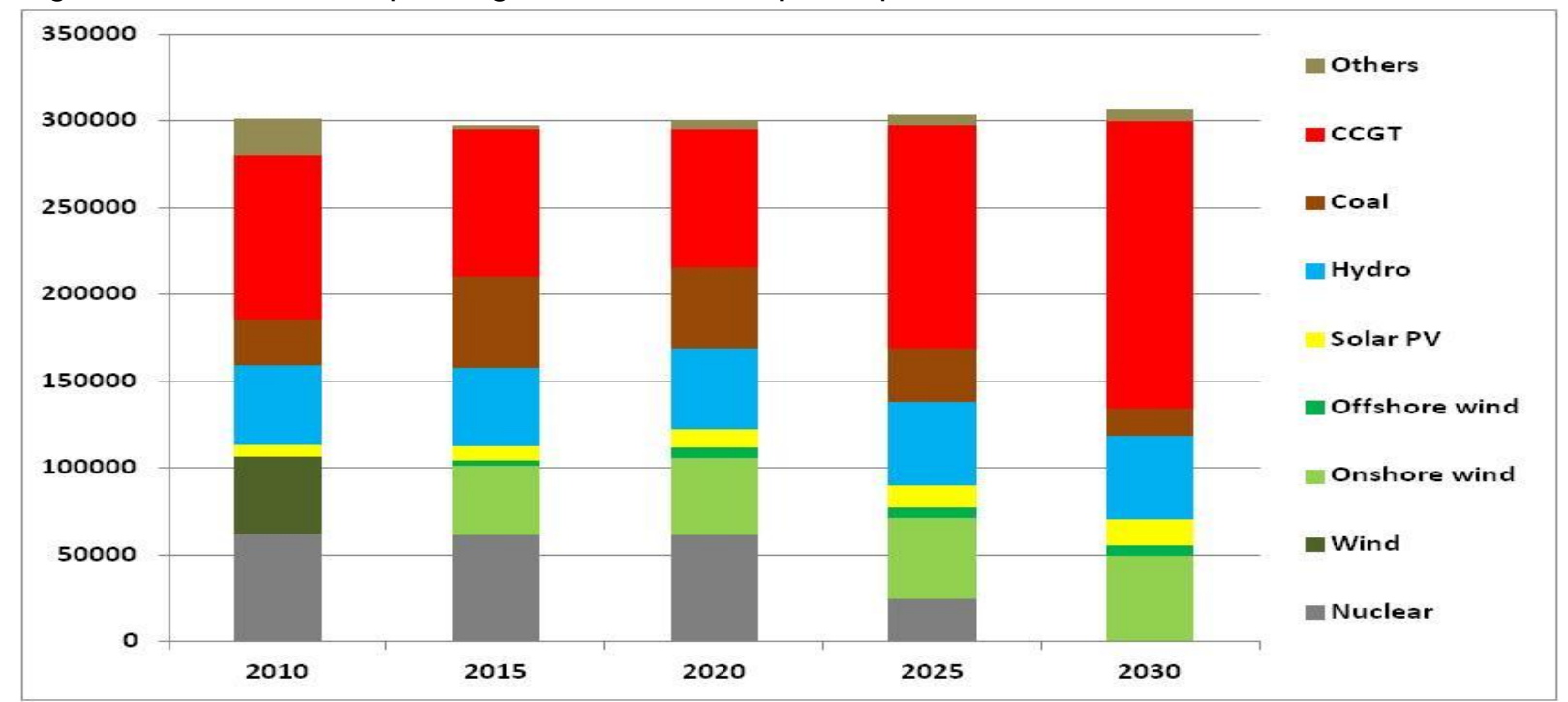

Source: 2010: IEA (2013e), table 3 for each country; scenario: Author

The future of gas consumption in Spain is still closely linked to what happens in the power sector, especially in the 2010s. One warning must be made for 2015: the level of gas demand could be lower than in the chart below if the trend seen in 2013/early 2014 continues. But if our scenario for the generation mix is realised, then total gas demand will pick up in the 2020 s and possibly reach $50 \mathrm{Bcm}$ and over as shown in Figure 123.

Figure 123: Scenario for natural gas demand in Spain, up to 2030, in Bcm

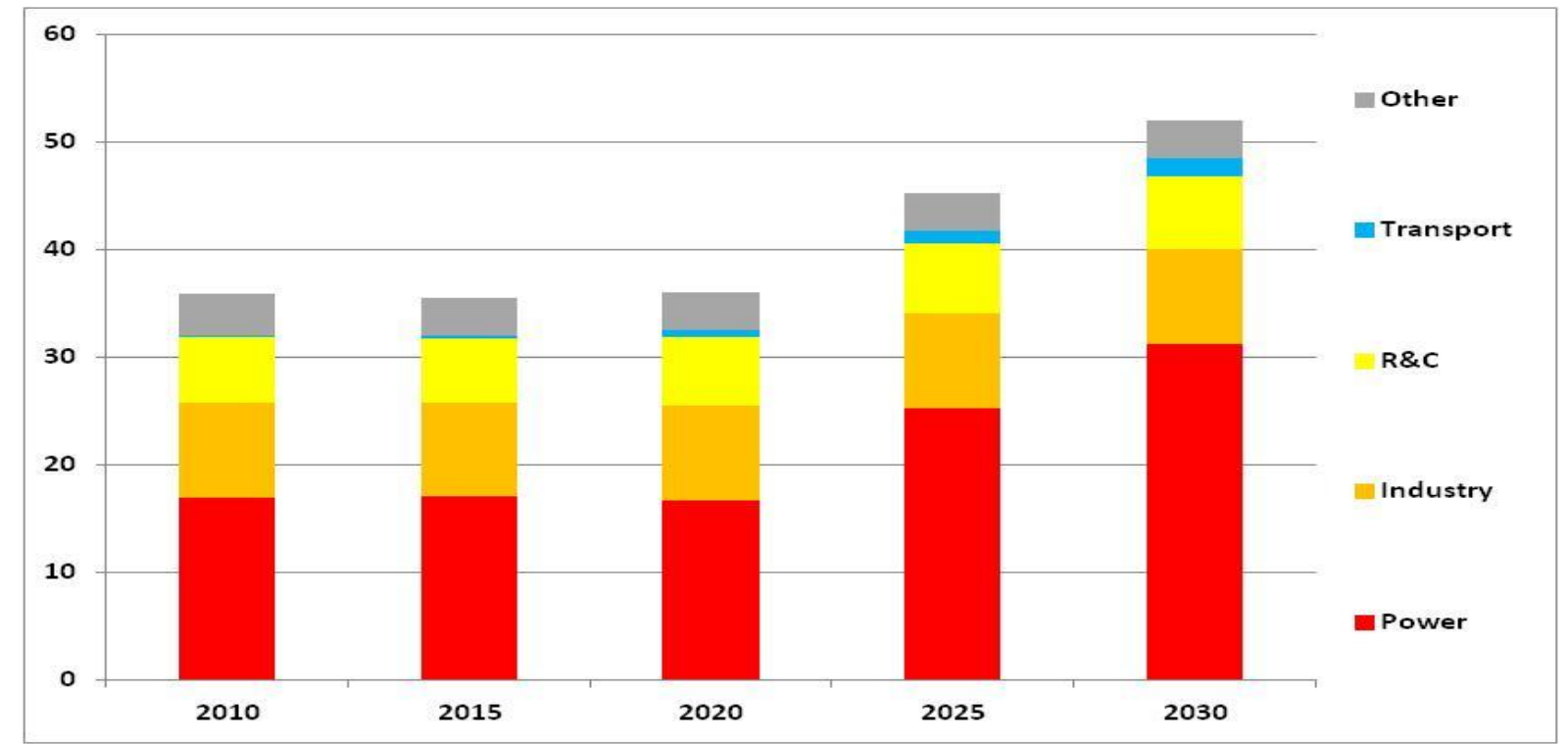

Source: 2010: IEA (2013a), table 3 for each country; scenario: Author 

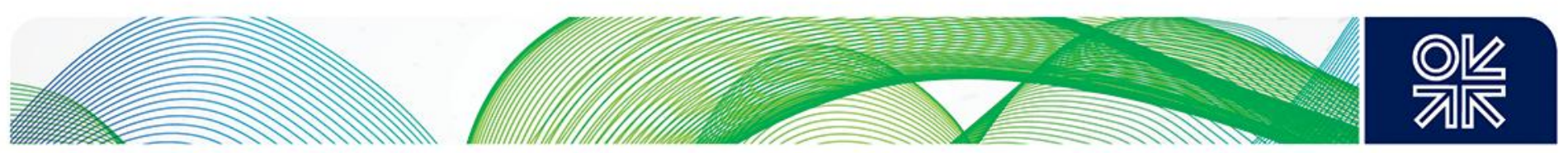

\section{Sweden}

\section{Background}

In 2012, nuclear represented the largest share of the TPES (34\% share), followed by oil (26\%), and hydropower (14\%). The share of gas was only $2 \%$. The country imported about $28 \%$ of its energy needs but was dependent for the totality of the natural gas it consumed. ${ }^{303}$

Total gas demand was about $1.1 \mathrm{Bcm}$ in $2012,37.5 \%$ above its pre-crisis level (2008) thanks to the power sector which almost doubled in the period (the industrial sector also saw some expansion). The power sector was the largest consumer in 2011 (42\%), the industrial sector accounted for $29 \%$ and the $\mathrm{R} \& \mathrm{C}$ sector $(14 \%){ }^{304}$

Power supply was 138 TWh in 2011, 3\% below 2008 levels. Gross production was 150 TWh (165 TWh the following year). ${ }^{305}$ In 2012 , hydropower was the predominant fuel (47\%), followed by nuclear (38\%). Renewables accounted for $4 \%$, gas and coal $1 \%$ each. ${ }^{306}$

If the assumptions on available gas-fired capacity in 2008 and 2012, which are based on Eurelectric data, are correct, ${ }^{307}$ then the average load factor of the gas-fired power plants in 2012 was about $18 \%$.

\section{Targets and assumptions}

According to the IMF November 2013 outlook, GDP has recovered from the difficult times of 20082009 and annual growth of about $2 \%$ to 2018 is expected [Figure 124].

Figure 124: GDP annual growth in Sweden (\%), in constant prices, 2000-2018 (forecast from 2012)

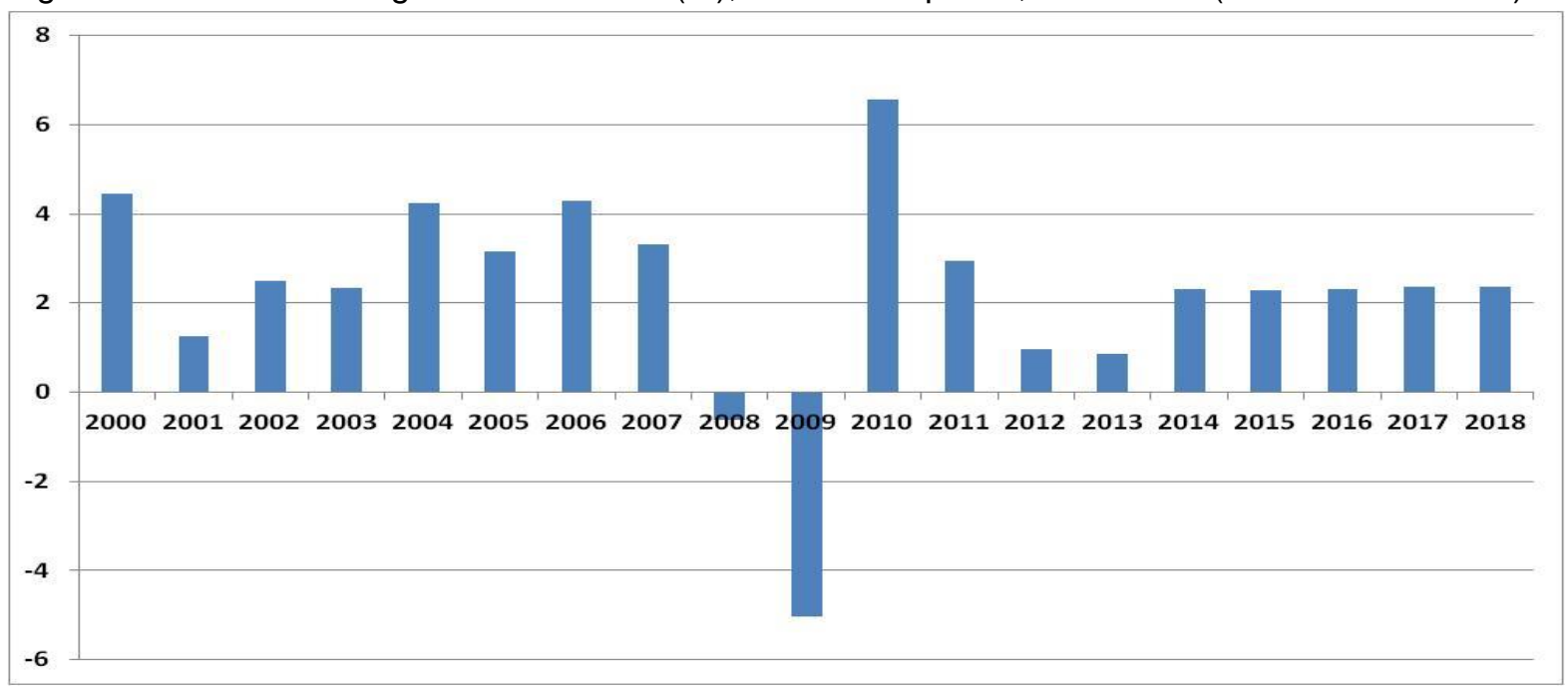

Source: IMF (2013)

Sweden already has a low carbon economy. Hydropower and nuclear account for the bulk of the electricity generation, even the heating sector is based to a large extent on district heating, and is

\footnotetext{
${ }^{303}$ IEA (2013a), Country data, table 1

304 IEA (2010a) and IEA (2013a), Country data, table 3

305 IEA (2010b) and IEA (2013e), Part III, tables 1.1 and 1.2

${ }^{306}$ IEA (2013e), Part III, Country data, table 3

${ }^{307}$ Eurelectric (2012), table 3.1.1.3.
} 
practically fossil fuel free as a result of the increased use of biomass and heat pumps. In 2009, the country proposed long term and sustainable energy and climate policy as a way out of fossil energy dependence and to promote renewable energy and more efficient energy use. The country's targets for 2020 are a reduction of 17\% in GHG emissions in the non EU ETS sectors compared to 2005 according to the ESD (on track to be met with existing measures), a minimum 50\% share of renewable energy in the energy mix, including a $10 \%$ share of renewable energy in the transport sector, $20 \%$ more efficient use of energy compared to $2008^{308}$ and a complete phase out fossil fuels in heating. The longer term priorities beyond 2020 are an action plan for renewables and for energy efficiency, nuclear replacement (by new nuclear) by 2030, vehicle stock independent of fossil fuels and, by 2050, sustainable and resource-efficient energy supply and no net emissions of GHG. The role for natural gas will at best be as a transition fuel in industry and co-generation. ${ }^{309}$

\section{Scenario}

The role of gas in power generation is not expected to increase up to 2030 as the mix continues to be dominated by hydropower/renewables and nuclear as seen in Figure 125.

Figure 125: Scenario for power generation mix in Sweden, up to 2030, in GWh

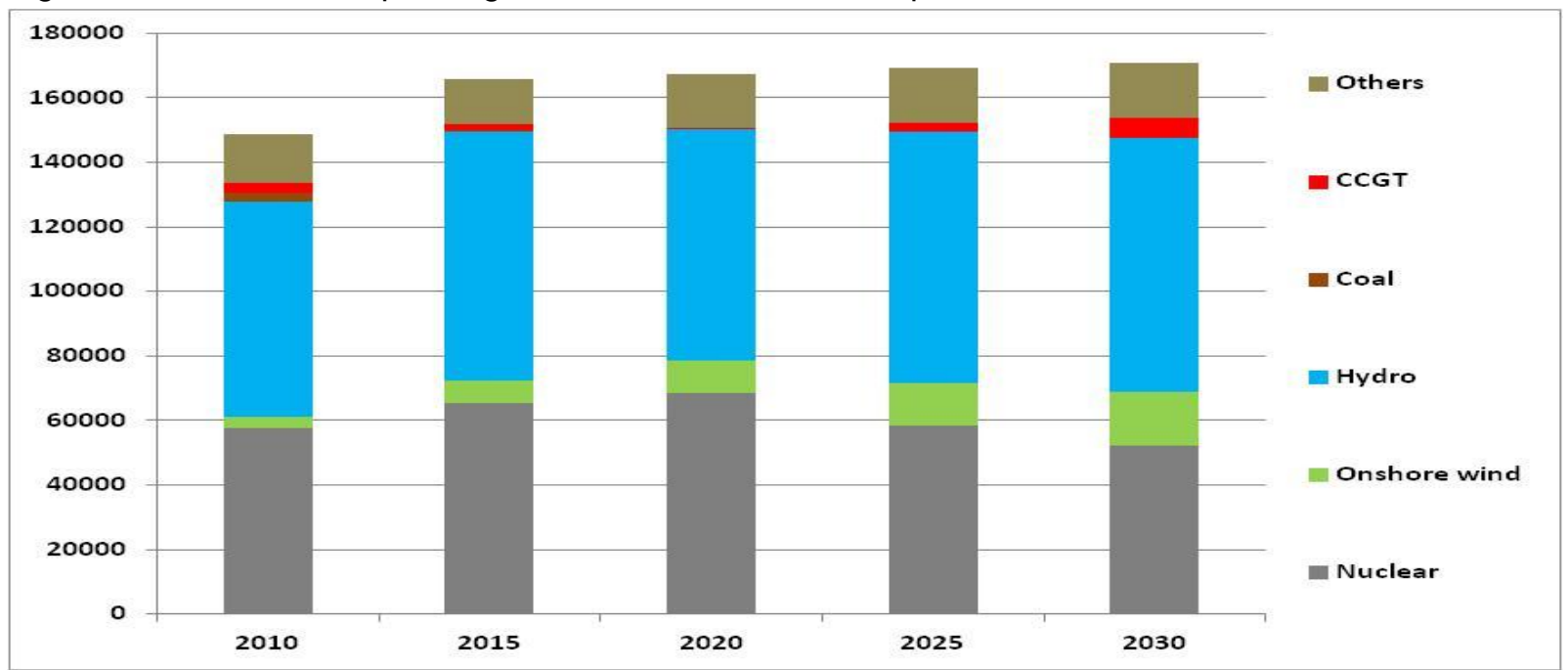

Source: 2010: IEA (2013e), table 3 for each country; scenario: Author

Despite the small changes to be expected for gas in the power generation mix, these will have important percentage impacts on the levels of total demand in this very small gas market as shown in Figure 126.

\footnotetext{
${ }^{308}$ http://ec.europa.eu/energy/efficiency/eed/reporting en.htm

${ }^{309}$ For more information, see the National Renewable Energy Action Plan to the European Commission ; Ecologic Institute \& Eclareon (Sweden)
} 
Figure 126: Scenario for natural gas demand in Sweden, up to 2030, in Bcm

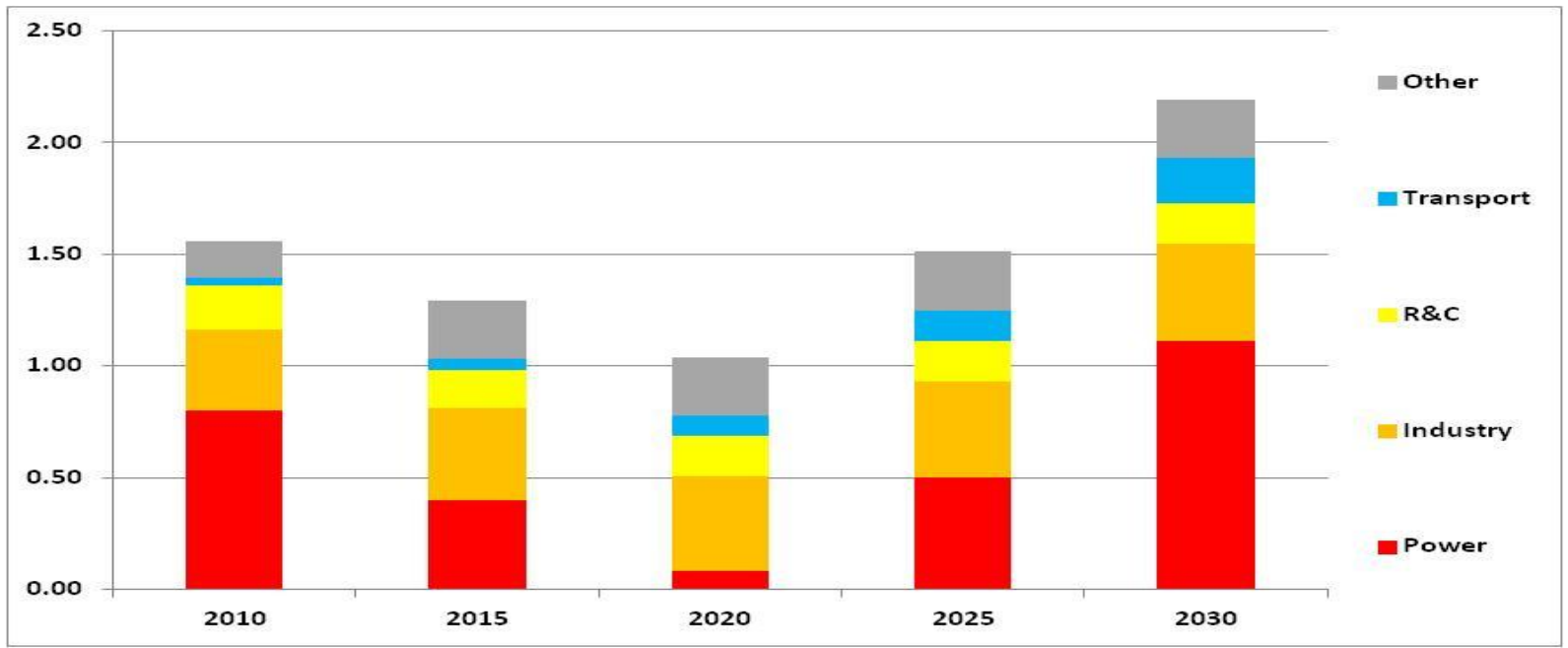

Source: 2010: IEA (2013a), table 3 for each country; scenario: Author 

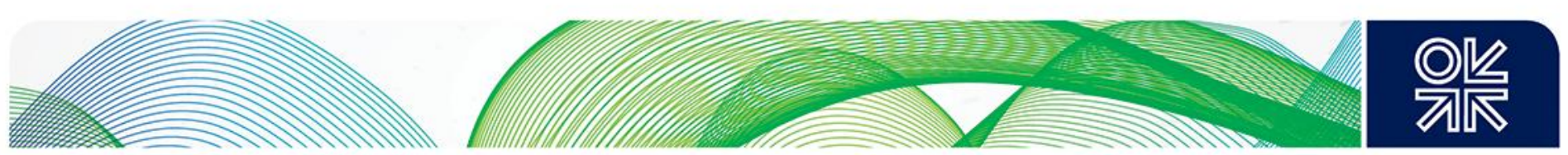

\section{Switzerland}

\section{Background}

In 2012, oil still represented the largest share of the TPES (39\% share), followed by nuclear (26\%), hydropower $(13 \%)$ and gas (12\%). The country is import dependant for about half of its energy needs and for $100 \%$ of its natural gas requirements. ${ }^{310}$

Total gas consumption was about $3.6 \mathrm{Bcm}$ in $2012,5.9 \%$ higher compared to its pre-crisis level (2008). The R\&C sector was the biggest consumer (54\% of demand in 2011 ), before the industrial sector $(31 \%)$ and finally the power sector $(7 \%){ }^{311}$

Power supply was at about 63 TWh in 2011, flat from 2008 levels. Gross production was close at 64 TWh (close to 70 TWh the following year). ${ }^{312}$ In 2012, hydropower accounted for $58 \%$ of the electricity generation mix, followed by nuclear (36\%). Natural gas accounted for only $1 \%{ }^{313}$

If the assumptions on available gas-fired capacity in 2008 and 2012, which are based on IEA data, are correct, ${ }^{314}$ then the average load factor of the gas-fired power plants in 2012 was about $42 \%$ (43\% in 2008).

\section{Targets and assumptions}

Switzerland's economy bounced back rapidly after the 2009 slump, and is expected to show annual growth close to 2\% up to 2018 according to the IMF November 2013 outlook [Figure 127].

Figure 127: GDP annual growth in Switzerland (\%), in constant prices, 2000-2018 (forecast from 2012)

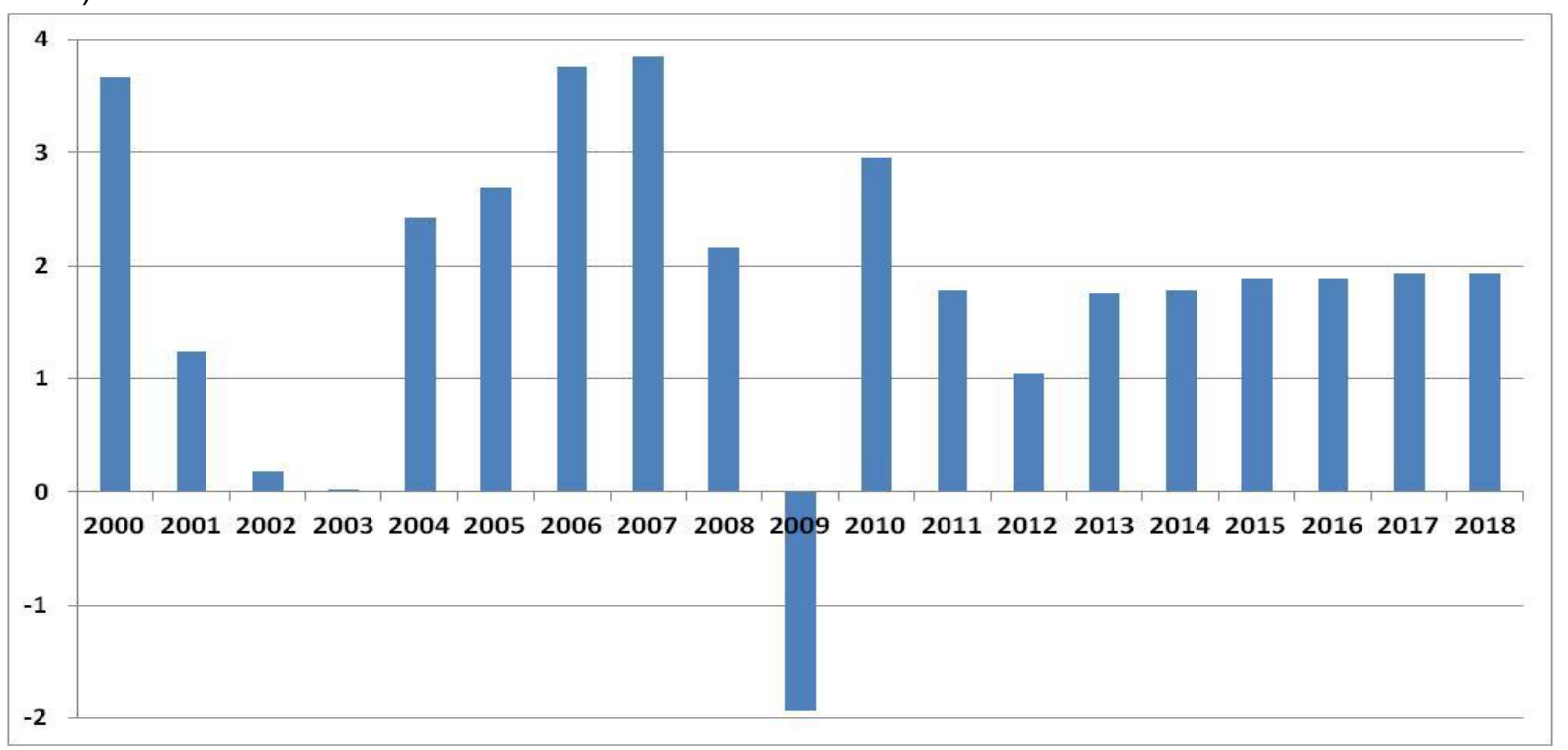

Source: IMF (2013)

\footnotetext{
310 IEA (2013a), Country data, table 1

${ }^{311}$ IEA (2010a) and IEA (2013a), Country data, table 3

312 IEA (2010b) and IEA (2013e), Part III, tables 1.1 and 1.2

313 IEA (2013e), Part III, Country data, table 3

314 IEA (2013e), Part III, table 2.12
} 

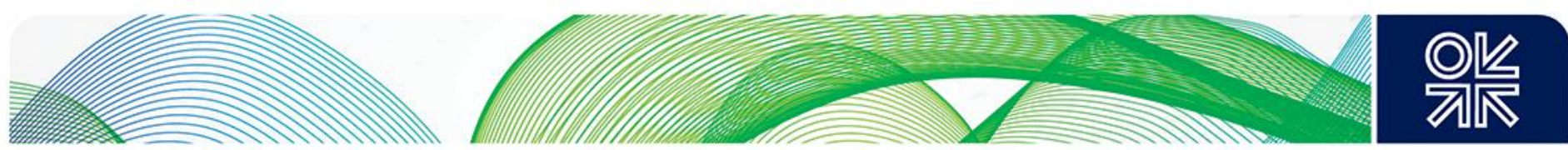

At the end of 2009 the Federal Council decided to continue with the SwissEnergy action programme until 2020. The plan outlined the following targets: general reduction in end consumption through greater energy efficiency of combustibles, motor fuel and electricity; 20\% reduction in 1990 levels of $\mathrm{CO}_{2}$ emissions and consumption of fossil fuels by 2020 and a minimum $50 \%$ increase in the share of renewable energy in total final energy consumption. Rising demand for electricity should be covered as far as possible by electricity generated from renewable sources. On 25 May 2011 the federal government declared that nuclear power would be phased out gradually in Switzerland. ${ }^{315}$

\section{Scenario}

Gas has a limited role in the power generation sector and it should continue to be dependent on hydropower variations as seen in Figure 128

Figure 128: Scenario for power generation mix in Switzerland, up to 2030, in GWh

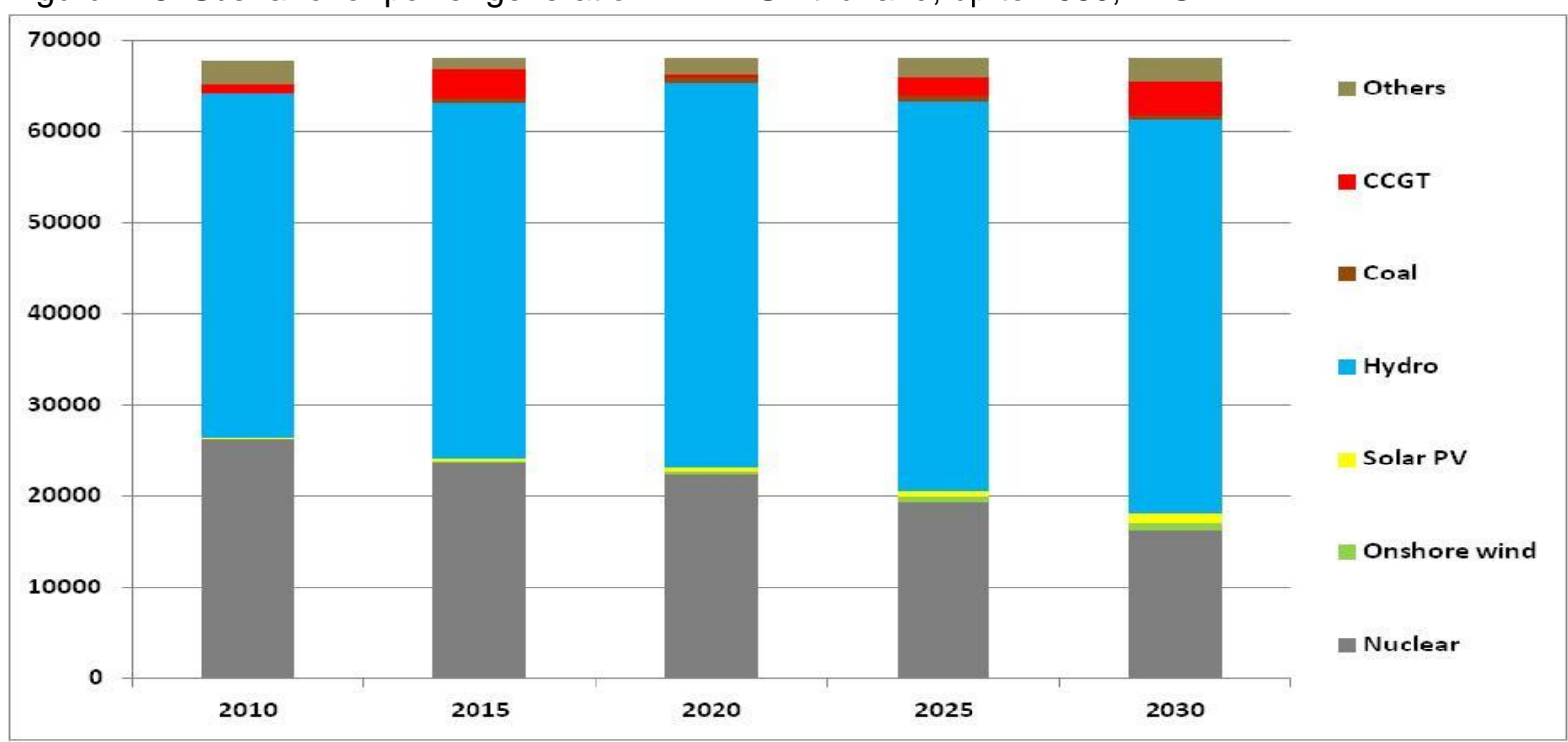

Source: 2010: IEA (2013e), table 3 for each country; scenario: Author

We expect the major changes to happen in the power sector and in the transport sector, on the condition that the latter is backed up by the adequate policies as shown in Figure 129. Switzerland will remain nonetheless a fairly small market even if growth occurs.

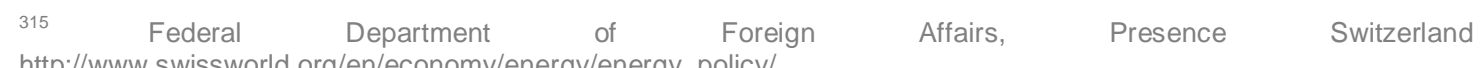


Figure 129: Scenario for natural gas demand in Switzerland, up to 2030, in Bcm

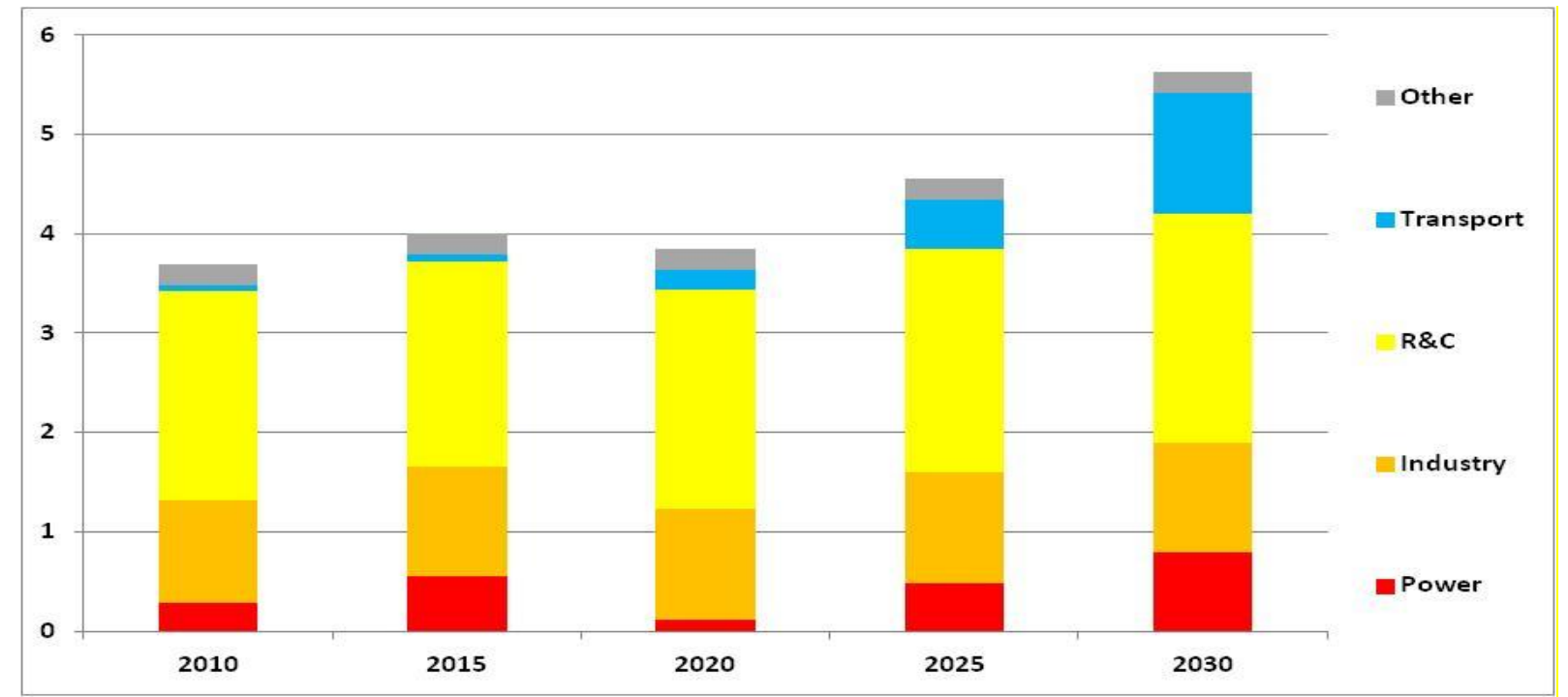

Source: 2010: IEA (2013a), table 3 for each country; scenario: Author 

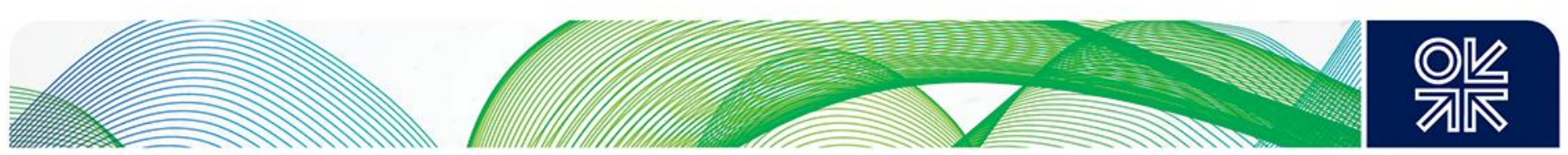

\section{Turkey}

\section{Background}

In 2012, TPES was dominated by gas (32\%), coal (30\%) and oil (27\%). The country imported about three quarters of the energy it consumed and almost $100 \%$ of its natural gas. ${ }^{316}$

Total gas consumption was just over $45.3 \mathrm{Bcm}$ in 2012, almost $24 \%$ above its pre-crisis level (2008). The power sector was the largest consumer in 2011 (48\%), the R\&C sector accounted for $25 \%$ and the R\&C sector for $21 \% .{ }^{317}$ All sectors have grown rapidly in the 2000 s, included post 2008 . Between 2008 and 2012, gas consumption by the power sector grew by $7.5 \%$ and it was multiplied by 2.5 in the industrial sector.

Power supply was 219 TWh in 2011, 15.4\% above 2008 levels. Gross production was slightly higher at $230 \mathrm{TWh}$ (240 TWh the following year). ${ }^{318}$ In 2012, gas was the predominant fuel (44\%), followed by coal $(28 \%)$ and hydropower (24\%). Renewables accounted for only $3 \% .{ }^{319}$

If the assumptions on available gas-fired capacity in 2008 and 2012, which are based on Eurelectric and IEA data, are correct, ${ }^{320}$ then the average load factor of the gas-fired power plants in 2012 was about $63 \%$, down from about $72 \%$ in 2008 .

\section{Targets and assumptions}

GDP growth bounced back quickly after dropping in 2009. According to the IMF November 2013 outlook, it is expected to remain at about $4 \%$ up to 2018 as seen in Figure 130.

Figure 130: GDP annual growth in Turkey (\%), in constant prices, 2000-2018 (forecast from 2012)

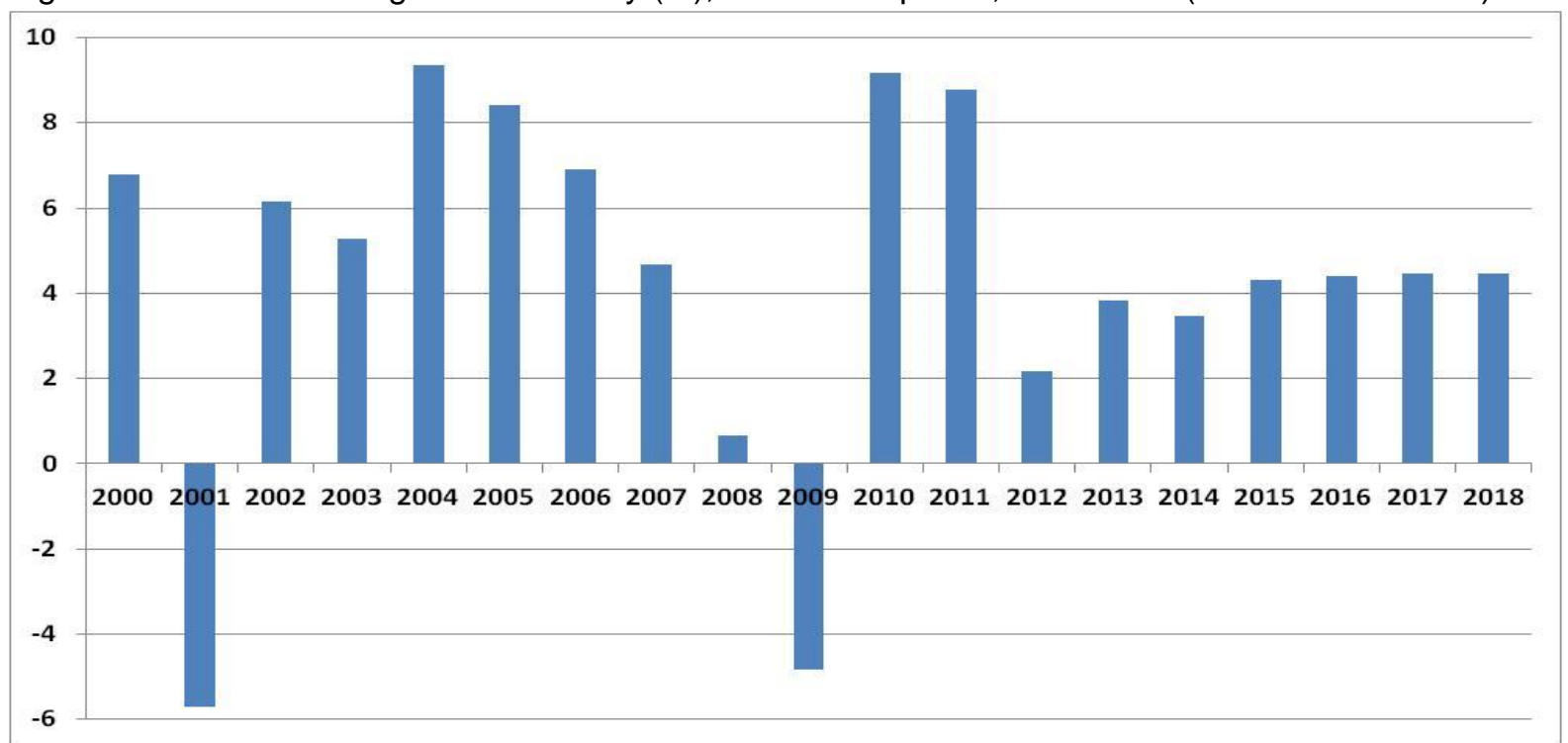

Source: IMF (2013)

\footnotetext{
${ }^{316}$ IEA (2013a), Country data, table 1

317 IEA (2010a) and IEA (2013a), Country data, table 3

${ }^{318}$ IEA (2010b) and IEA (2013e), Part III, tables 1.1 and 1.2

319 IEA (2013e), Part III, Country data, table 3

${ }^{320}$ IEA (2013e), Part III, table 2.12; Eurelectric (2012), table 3.1.1.3.
} 
The country's energy use is still relatively low compared to the rest of Europe, although it is increasing at a very fast pace and it is likely that it will continue to grow up to 2030 but how fast is the key question. Meeting any kind of fast level of growth would require significant investment in the energy sector, especially in gas and electricity infrastructure, including new generation capacity. However, despite scarcity of generation capacity in the early 2010s, the market was already starting to show signs of oversupply through lower day-ahead prices by 2014. As a result, working hours of lessefficient gas-fired plants had already dropped to about 2000-3000 hours/year compared to 6000 hours/year in previous years (68\% load factor) as they struggle against new and more efficient gasfired plants. ${ }^{321}$ The shift will slow down the use of gas for power in existing plants. In addition, due to its heavy reliance on high priced gas imports and gas supply and transmission problems, the government wants to reduce the share of natural gas in power generation from $45 \%$ down to $30 \%$ by 2030 despite expected power consumption growth of 6-7\%/year according to the Turkish Electricity Transmission Company (TEIAS). ${ }^{322}$ According to the MENR Strategic Plan 2010-2014, ${ }^{323}$ which outlines priorities for the coming decade (up to 2023), the main targets for power generation are to consider pretty much everything but gas, including additional renewables, nuclear power, renewed exploitation of indigenous coal resources and - rapidly growing - generation capacity burning imported coal. $^{324}$

\section{Scenario}

In our scenario, the role of natural gas does not grow as fast as overall power generation thanks to additional coal, renewables and eventually nuclear to fill in the gap. However, if nuclear does not happen by the early 2020s, additional gas may be required in the power generation sector as seen in Figure 131.

Figure 131: Scenario for power generation mix in Turkey, up to 2030, in GWh

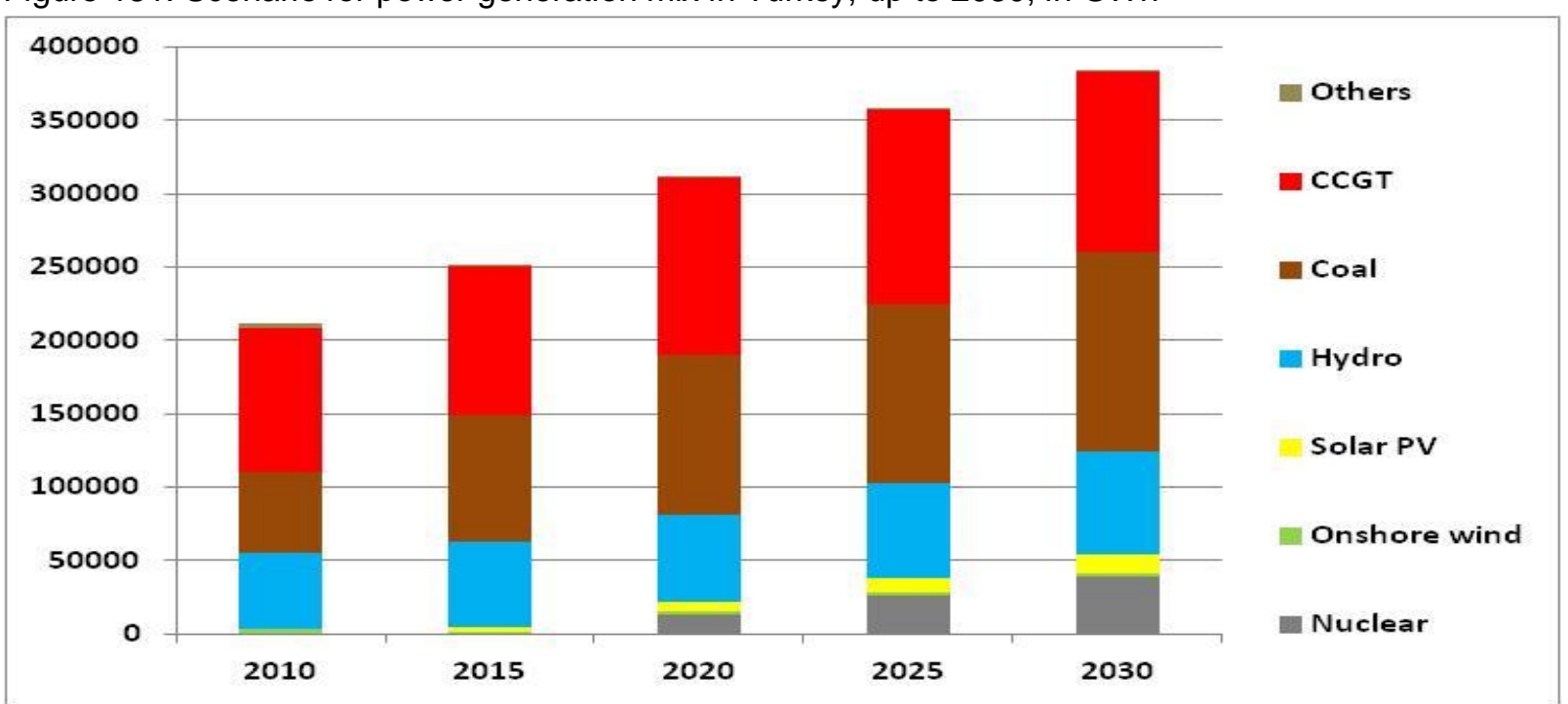

Source: 2010: IEA (2013e), table 3 for each country; scenario: Author

\footnotetext{
${ }^{321}$ Platts (April 2014b), p.16

322 Rzayeva (2014), p.2

${ }^{323}$ Republic of Turkey (2009)

324 U.S. Energy Information Administration (2014)
} 
Gas demand in Turkey shows a fast increase in our scenario as shown in Figure 132. The three main sectors are increasing, including the $R \& C$ sector thanks to population growth and its urbanisation. The gas for power sector increases but not as fast the other sectors for the reasons explained above but this assumption will need to be revised upward if nuclear power does not happen in the 2020s. The transport sector will also increase, although this is dependent on strong political support.

Figure 132: Scenario for natural gas demand in Turkey, up to 2030, in Bcm

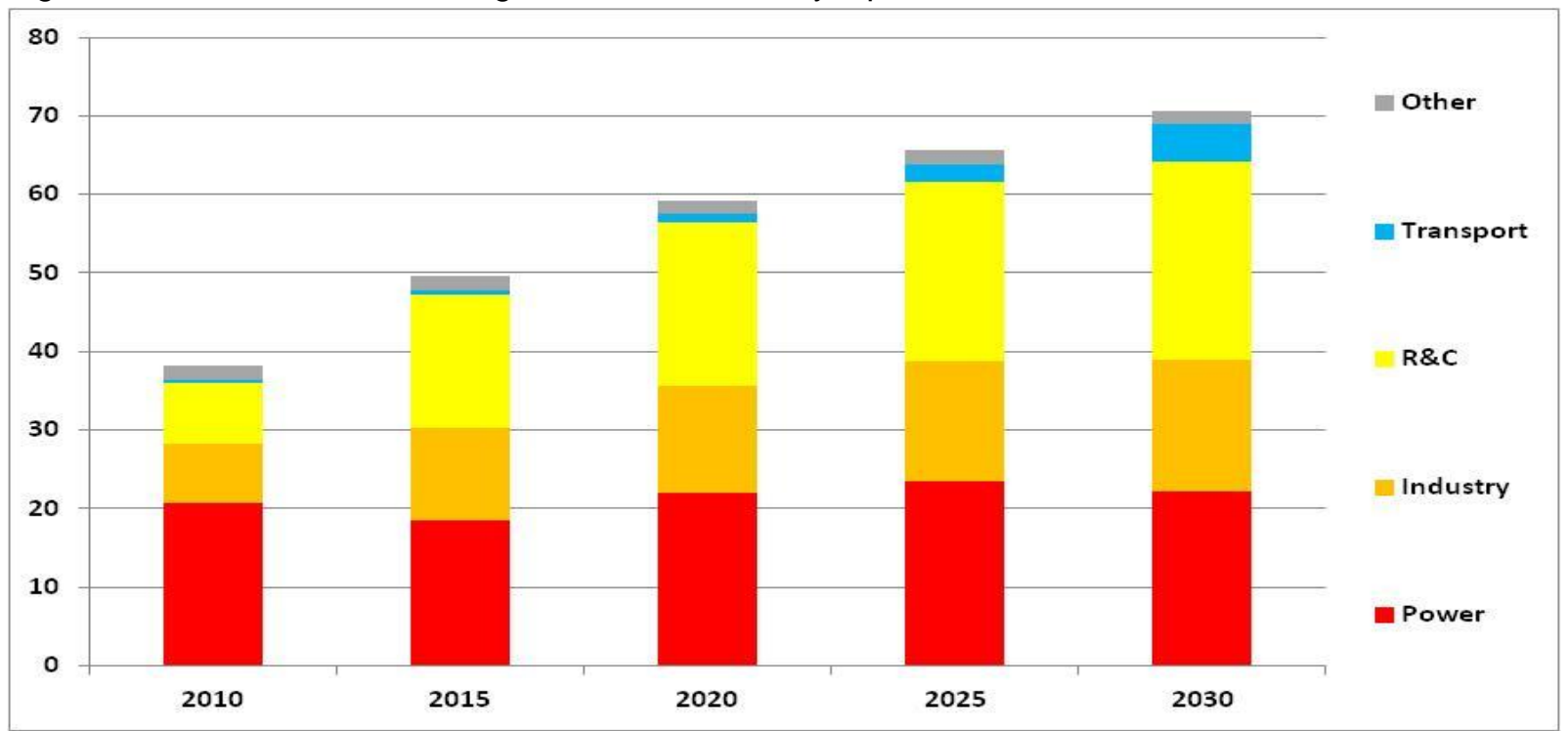

Source: 2010: IEA (2013a), table 3 for each country; scenario: Author 

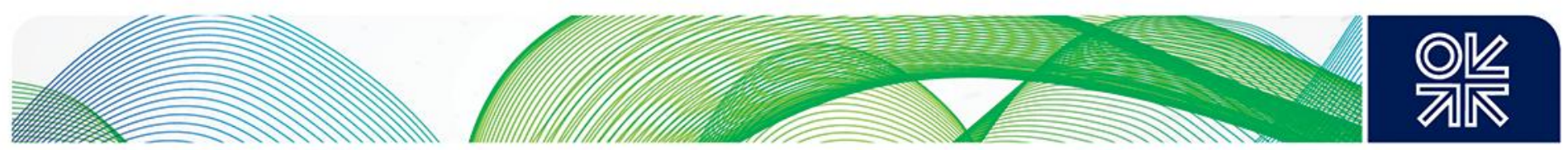

\section{United Kingdom}

\section{Background}

In 2012, TPES was dominated by gas (35\%) and oil (31\%). Coal accounted for $20 \%$ and nuclear for $10 \%$ of the total. The country imported about $40 \%$ of the energy it consumed and $47 \%$ of its natural gas. $^{325}$

Total gas consumption was just over $78 \mathrm{Bcm}$ in 2012 , about $21 \%$ below its pre-crisis level (2008). The $R \& C$ sector was the largest consumer in 2011 (39\%), the power sector followed close behind (37\%) while the industrial lagged far behind (14\%). ${ }^{326}$

Power supply was 354 TWh in 2011, 6.6\% above 2008 levels. Gross production was slightly higher by $4 \% .{ }^{327}$ In 2012 , coal was the predominant fuel in the generation mix (40\%), followed by gas $(27 \%)$, nuclear $(19 \%)$, renewables $(6 \%)$ and hydropower $(2 \%)$.

If the assumptions on available gas-fired capacity in 2008 and 2012, which are based on Eurelectric and IEA data, are correct, ${ }^{329}$ then the average load factor of the gas-fired power plants in 2012 was about 33\% (49\% in 2011), down from about 65\% in 2008.

\section{Targets and assumptions}

GDP declined in 2008 and dropped by 5\% in 2009. After some uncertainties in 2010-2012, the IMF in its November 2013 outlook expects economic growth to continue until 2018 at annual growth rates close to $2 \%$ as seen in Figure 133.

Figure 133: GDP annual growth in the UK (\%), in constant prices, 2000-2018 (forecast from 2012)

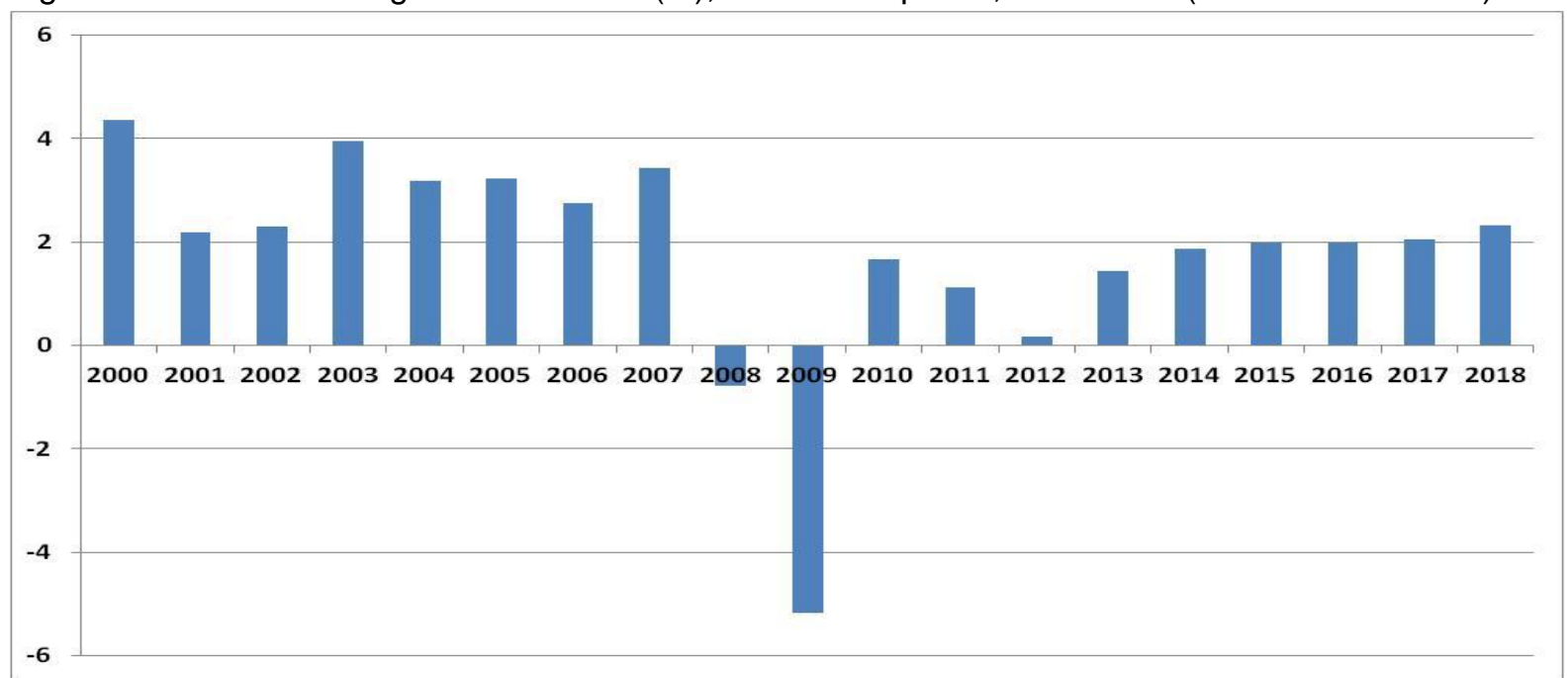

Source: IMF (2013)

The UK government has been strongly committed to fighting climate change and decarbonising the economy especially following the 2008 Climate Change Act. Its 2020 targets include achieving $15 \%$ of its energy consumption from renewables, which according to DECC can be achieved with a $30 \%$

\footnotetext{
325 IEA (2013a), Country data, table 1

${ }^{326}$ IEA (2010a) and IEA (2013a), Country data, table 3

${ }^{327}$ IEA (2010b) and IEA (2013e), Part III, tables 1.1 and 1.2

${ }^{328}$ IEA (2013e), Part III, Country data, table 3

${ }^{329}$ IEA (2013e), Part III, table 2.12 ; Eurelectric (2012), table 3.1.1.3.
} 

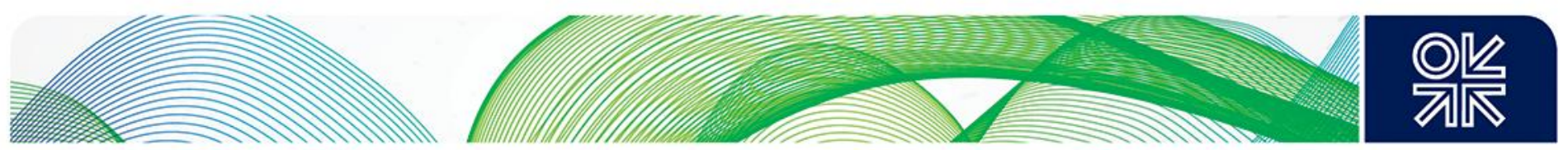

share of renewables in electricity demand, $12 \%$ of heat and $10 \%$ of transport). The UK needs to decrease its emissions not covered by the EU ETS by $16 \%$ compared to 2005 according to the ESD (a target that should be met with existing policies). In the longer term, the country wants to decrease its emissions by a least $80 \%$ by 2050 as compared to 1990 . Much will depend on the application of Electricity Market Reform (EMR) ${ }^{330}$ (2012) and its impacts on new capacity.

The UK is facing a complex situation in the power generation sector. Because of the LCPD the country will have lost about 12 GW by the end of 2015 . The IED could also potentially force about 15 $17 \mathrm{GW}$ of additional plants to shut down as additional coal plants and older CCGTs will probably not comply with the ELV limits, although it was too soon to tell precisely at the time of writing (end 2013). Nuclear plants are reaching the end of their lifetime, which could create the loss of about $11 \mathrm{GW}$ by 2025. In total, the UK will lose a minimum of about a third of its generation capacity if not more. Even with slow electricity demand growth, new capacity will be needed to produce both baseload and peak generation. This concern is addressed by the various measures proposed in the EMR designed to attract the investment needed to replace the infrastructure. ${ }^{331}$ New gas plants identified as critical for ensuring security of supply and are especially addressed in DECC's Gas Generation Strategy (2012) ${ }^{332}$ New CCGTs will most probably come on line in the late 2010 s and 2020 s to be used as back up to the intermittent renewable energy but also to replace some baseload generation (coal/nuclear).

\section{Scenario}

The generation mix of the UK is expected to evolve quite rapidly following the impacts of the LCPD/IED in the 2010s and early 2020s (the country will lose about a third of its coal capacity) as seen in Figure 134. The role of gas is expected to increase to fill in the gap, together with renewables. How much renewable capacity is developed and how much nuclear remains in the system (closure of old plants/timing of new plant(s)) will determine the level of gas used in power generation. There is a high possibility of a wind and gas dominated system by $2030 .{ }^{333}$

\footnotetext{
330 The principal aspects of the Electricity Market Reform (EMR) include FIT Contract for Difference for renewables and nuclear, Emissions Performance Standard, Carbon Price Floor (introduced from April 2013) and a Capacity Market. The carbon price floor was set to increase each year, from around $£ 16$ per tonne of carbon dioxide in 2013 , to around £70 by 2030 , but as part of his 2014 budget the chancellor announced a freeze at $£ 18$ per tonne from 2016 for the rest of the decade in order to lower energy prices to make British manufacturing more competitive globally.

For more information on the EMR, see https://www.gov.uk/government/policies/maintaining-uk-energy-security-2/supporting-pages/electricity-market-reform

For more information on the Gas Generation Strategy, see https://www.gov.uk/government/publications/gas-generationstrategy

For more information, see the National Renewable Energy Action Plan to the European Commission, ; Ecologic Institute \& Eclareon (United Kingdom)
} 


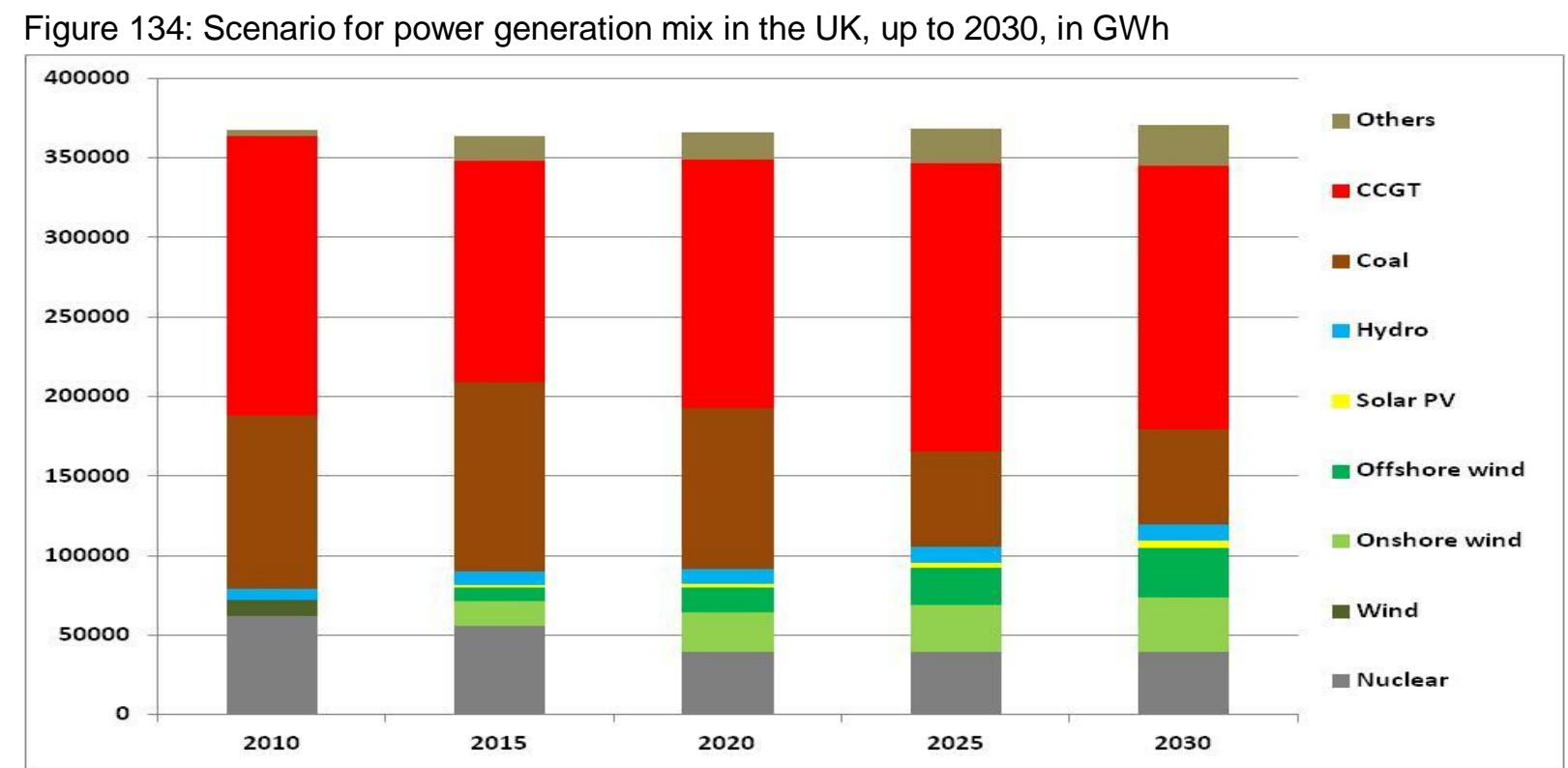

Source: 2010: IEA (2013e), table 3 for each country; scenario: Author

No major changes are expected in the industrial and R\&C sectors, apart from the effects of additional efficiency measures. The major changes continue to lie in the power sector, and if the scenario above is realised, then total gas demand will show some growth in the second half of the 2010 s to remain at about $90 \mathrm{Bcm} / \mathrm{y}$ up to 2030 as shown in Figure 135.

Figure 135: Scenario for natural gas demand in the UK, up to 2030, in $\mathrm{Bcm}$

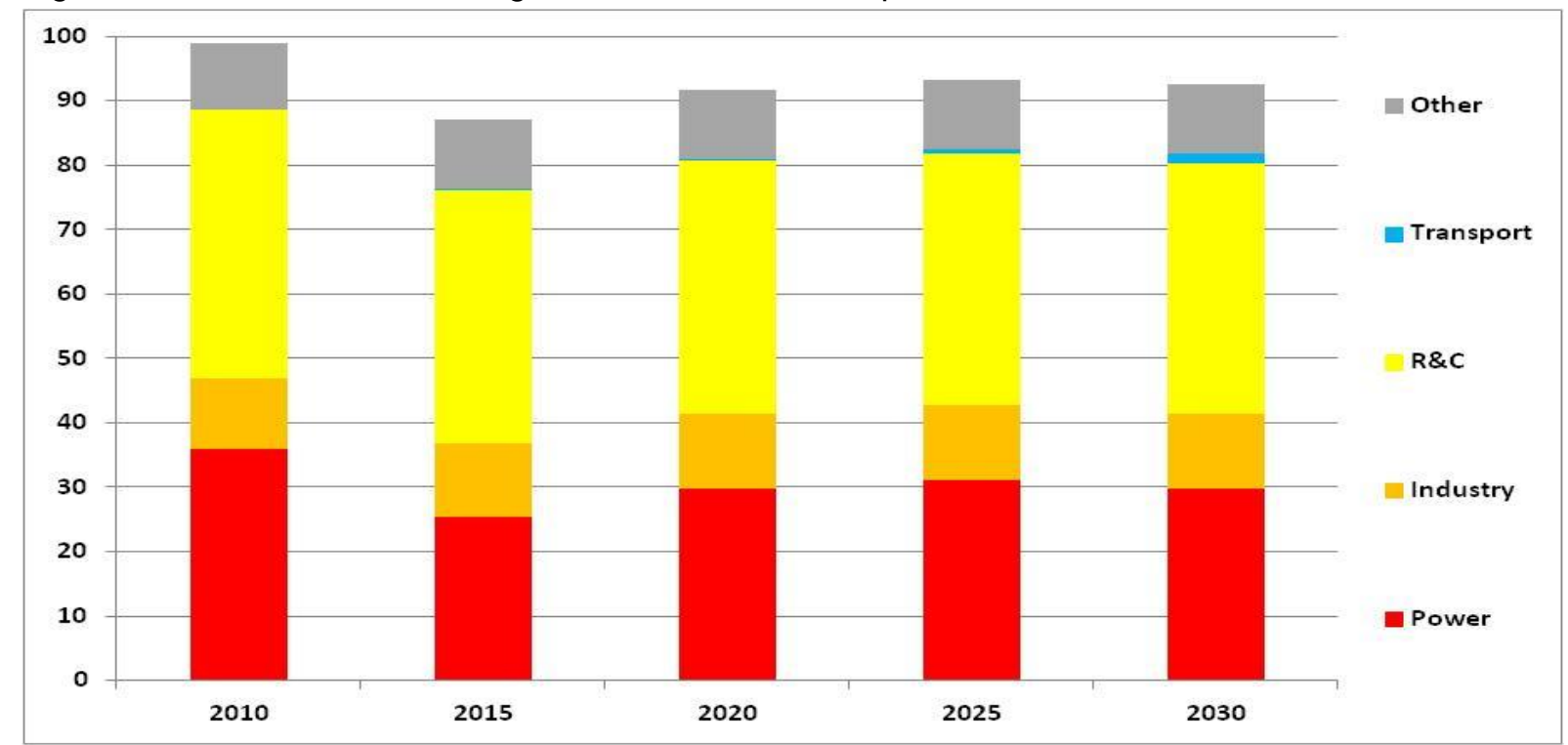

Source: 2010: IEA (2013a), table 3 for each country; scenario: Author 


\section{Appendix 3: Definitions and statistics}

\section{A3.1: Definitions of the European region}

\section{OECD Europe}

Austria, Belgium, Czech Republic, Denmark, Estonia, Finland, France, Germany, Greece, Hungary, (Iceland*), Ireland, Italy, Luxembourg, the Netherlands, Norway, Poland, Portugal, Slovakia, Slovenia, Spain, Sweden, Switzerland, Turkey and United Kingdom.

* Iceland is not considered in this study.

\section{European Union 28}

Austria, Belgium, Bulgaria, Croatia, Cyprus, Czech Republic, Denmark, Estonia, Finland, France, Germany, Greece, Hungary, Ireland, Italy, Latvia, Lithuania, Luxembourg, Malta, the Netherlands, Poland, Portugal, Romania, Slovakia, Slovenia, Spain, Sweden and United Kingdom.

\section{Europe with 35 countries considered in this study}

Albania, Austria, Belgium, Bosnia and Herzegovina, Bulgaria, Croatia, Cyprus, Czech Republic, Denmark, Estonia, Finland, France, Germany, Greece, Hungary, Ireland, Italy, Latvia, Lithuania, Luxembourg, Macedonia, Malta, the Netherlands, Norway, Poland, Portugal, Romania, Serbia, Slovakia, Slovenia, Spain, Sweden, Switzerland, Turkey and United Kingdom.

\section{A3.2: Statistics}

Analysing natural gas consumption patterns involves substantial statistical and methodological problems. There is a wide range of statistics on natural gas in the public domain, ${ }^{334}$ but, despite this apparent profuseness, adequate statistics on natural gas demand are at best unsatisfactory and at worst, unavailable, especially for individual sectors.

Data is hard to reconcile and it is complicated (and sometimes unfeasible) to obtain accurately defined, consistent or temperature-corrected historical series across countries for the 35 European markets we study in this book due to differences in end-user classifications, calorific value/temperature/pressure, units and conversion factors and regional areas defined as 'Europe': EU15, EU25, OECD Europe, EGTA (European Gas Trading Area) and major markets.

\footnotetext{
${ }^{334}$ Statistics on natural gas are available from most TSO websites, some Energy Ministries' websites, some companies such as BP for instance, some organisations such as Eurogas and GIIGNL, and some international organisations such as Eurostat, the IEA and the EIA. There is also a lot of information available for sale.
} 
As a consequence, it is important to use the same source of data as much as possible throughout the analysis in order to keep some consistency. In this study, the statistics published by the IEA are used in most cases. The reasons are fivefold:

- In order to compare statistics in different markets, there was a need to find statistics calculated with the same methodology and presented in the same unit. This eliminated the statistics published by the national bodies.

- The IEA statistics are collected directly from official bodies of member countries.

- A transparent methodology is explained at the beginning of the IEA Natural Gas Information's annual reports. ${ }^{335}$

- A source with a significant time span was essential to analyse evolving trends.

- Data at country level was critical, not just aggregated for a region.

- In addition, details on sub-sector categories, which the IEA provides for its annual data for its Member countries, were also vital. ${ }^{336}$

- Monthly consumption for the member countries is available, but the data is provided for the IEA member countries only. These statistics are on-the-spot numbers ${ }^{337}$ and have no sectoral breakdown.

- Finally, 22 countries in the Europe 35 region are members of the IEA, which added credibility to the statistical source.

The IEA statistics on natural gas demand are the best data we could find in the public domain for an analysis that needs to compare 35 European markets. More importantly, they are the ones that provide the most comprehensive details and explanations of the methodology, which makes them easier to understand. Additional remarks regarding IEA statistics should be made:

- IEA statistics on natural gas supply and demands are actual data; they are not temperaturecorrected.

- IEA data in million cubic metres are measures at $15^{\circ} \mathrm{C}$ and at $760 \mathrm{~mm} \mathrm{Hg}$, i.e. Standard Conditions. ${ }^{338}$

- There is a lag in the availability of IEA statistics on gas consumption in the annual reports Natural Gas Information (IEA (annual data_a)). For annual consumption, the time lag is one year, but it increases to two years for detailed statistics by sector. ${ }^{339}$

- A detailed definition of natural gas (supply and) consumption items used in the IEA statistics can be found in IEA (annual), Natural Gas Information, pp.xi-xiii.

- Additional information on IEA data on natural gas can be found in 'Energy Statistics, Manual', pp. 55-68 (gas consumption on pp. 64-65).

When the IEA statistics were not available or when we were looking at one market in particular, we have used other sources of statistics. The source of all the statistics used in this study is provided in the text.

\footnotetext{
${ }^{335}$ Annual IEA statistics are published in the Natural Gas Information reports (bibliography see: IEA (annual data_a)

${ }^{336}$ Data by sector is only available for the IEA member countries ( 25 countries in Europe). The IEA also published statistics for the non-member countries, but at a different level of details than for its member countries.

The IEA monthly statistics are not revised to correct possible mistakes or include up-dates later calculated by the IEA statisticians. There is therefore a margin of possible error in those numbers.

${ }^{338}$ IEA (annual data_a), Part 3. Definitions, p.xi

${ }^{339}$ The time lag for monthly statistics is three months.
} 


\section{Glossary}

\begin{tabular}{|c|c|}
\hline$€$ & Euros \\
\hline$€ / M W h$ & Euros per megawatt hour \\
\hline$€ / t$ & Euros per ton \\
\hline \$/MMBtu & US dollars per Million British thermal units \\
\hline$£ / t$ & GB Pound Sterling per tonne \\
\hline Bcm & Billion cubic metres \\
\hline $\mathrm{Bcm} / \mathrm{y}$ & Billion cubic metres per year \\
\hline CCGTs & Combined-Cycle Gas Turbines \\
\hline CCS & Carbon capture and storage \\
\hline CEO & Chief Executive Officer \\
\hline CNG & Compressed natural gas \\
\hline $\mathrm{CO}_{2}$ & Carbon Dioxide \\
\hline EC & European Commission \\
\hline ELV & Emission limit value \\
\hline EMR & Electricity Market Reform \\
\hline ESD & Effort Sharing Decision \\
\hline EU & European Union \\
\hline EWEA & European Wind Energy Association \\
\hline FGD & Flue Gas Desulphurisation \\
\hline FID & Final Investment Decision \\
\hline GDP & Gross Domestic Product \\
\hline GHG & Greenhouse gas \\
\hline GW & Gigawatt \\
\hline GWh/d & Gigawatt hour per day \\
\hline Hours/y & Hours per year \\
\hline IEA & International Energy Agency \\
\hline IED & Industrial Emissions Directive \\
\hline IMF & International Monetary Fund \\
\hline IPPC & Integrated Pollution Prevention and Control \\
\hline $\mathrm{Kg}$ & Kilogram \\
\hline LCPD & Large Combustion Plant Directive \\
\hline LNG & Liquefied Natural Gas \\
\hline LRMC & Long run marginal cost \\
\hline MMcm & Million Cubic Metres \\
\hline $\mathrm{MMt} \mathrm{CO}_{2} \mathrm{eq}$ & Million tons of carbon dioxide equivalent \\
\hline MMtoe & Million tons of oil equivalent \\
\hline MS & Member States \\
\hline MW & Megawatt \\
\hline MWh & Megawatt hour \\
\hline NAP & National Allocation Plan \\
\hline NBP & National Balancing Point \\
\hline NEAP & National Environmental Action Plan \\
\hline NOx & Oxides of nitrogen \\
\hline
\end{tabular}


OCGT Open Cycle Gas Turbine

OECD Organisation for Economic Cooperation and Development

PS Pumped storage

R\&C Residential and commercial

RES Renewables

SCR Selective catalytic reduction

SOx Sulphur dioxide

TNP Transitional National Plan

TPES Total Primary Energy Supply

TSO Transport System Operator

TWh Terawatt hour

UK United Kingdom

US / USA United States of America

WEO World Energy Outlook 


\section{Bibliography}

ACER/CEER (2012): Agency for the Cooperation of Energy Regulators (ACER) \& Council of European Energy Regulators (CEER), 'Annual Report on the Results of Monitoring the Internal Electricity and Natural Gas Markets in 2011', November 29, 2012, http://www.acer.europa.eu/Official documents/Publications/Documents/ACER\%20Market\%20Monitor ing\%20Report.pdf

Argus (February 2014): Argus, Power Europe, February 19, 2014, 'France grapples with nuclear repairs'

Bloomberg (January 2014): Bloomberg, January 21, 2014, 'EU Must Contain Energy Costs or Risk 'Deindustrialization", http://www.bloomberg.com/news/2014-01-21/eu-must-get-grip-on-energy-costsor-risk-deindustrialization-.html

Bloomberg (February 2014): Bloomberg, February 3, 2014, 'German Utilities Asked to Close 42 Power Generators: Regulator'

Bloomberg (April 2013): Bloomberg, April 4, 2013, 'Saft to deliver high power Li-ion energy storage system to SAET to support renewable integration in Enel's Italian', http://www.bloomberg.com/article/2013-04-04/arsi2xd3t6lY.html

Buchan (2014): Buchan D., 'The French disconnection: reducing the nuclear share in France's energy mix', SP 32, Energy Comment, Oxford Institute for Energy Studies, January 2014, http://www.oxfordenergy.org/wpcms/wp-content/uploads/2014/01/SP-32.pdf

Buchan \& Keay (2014): Buchan D., Keay M., 'The EU's new energy and climate goals for 2030 under-ambitious and over-bearing?', Energy Comment, Oxford Institute for Energy Studies, 30 January 2014, https://www.oxfordenergy.org/2014/01/the-eus-new-energy-and-climate-goals-for2030-under-ambitious-and-over-bearing/

Cornot-Gandolphe (2012): Cornot-Gandolphe S., The European Coal Market: will coal survive the EC's energy and climate policies?, Institut Français des Relations Internationales, October 2012, http://www.ifri.org/?page=detail-contribution\&id $=7352$

DECC website: Department of Energy \& Climate Change, Increasing the use of low-carbon technologies,

https://www.gov.uk/government/policies/increasing-the-use-of-low-carbon-technologies

Dickel (2014): Dickel R., 'The New German Energy Policy, What role for gas in a decarbonisation policy?', 2014, http://www.oxfordenergy.org/wpcms/wp-content/uploads/2014/03/NG-85.pdf

Ecologic Institute \& Eclareon (country): Ecologic Institute \& Eclareon, Assessment of climate change policies in the context of the European Semester, Country reports, June 2013,

http://ec.europa.eu/clima/policies/g-gas/progress/studies en.htm

Enagás (2014): Enagás, El sistema gasista español, informe 2013,

http://www.enagas.es/cs/StaticFiles/ENAGAS/informe-2013-enagas-GTS/index.html\#62

Enagás (2011): Enagás, El sistema gasista español, Informe 2010,

http://www.enagas.es/cs/Satellite?blobcol=urldata\&blobheader=application\%2Fpdf\&blobkey=id\&blobt $\underline{\text { able }=\text { MungoBlobs } \& \text { blobwhere }=1146252425705 \& \text { ssbinary }=\text { true }}$ 
EurActiv.com (December 2013): EurActiv.com, December 18, 2013, 'Romania slashes renewable energy subsidies', http://www.euractiv.com/energy/romania-slashes-renewable-energy-news532416?utm source=EurActiv\%20Newsletter\&utm campaign=6f9fa2a09enewsletter energy\&utm medium=email\&utm term=0 bab5f0ea4e-6f9fa2a09e-245740553

Eurelectric (2012): Eurelectric, Power statistics and trends 2012, 2012 edition, http://www.eurelectric.org/powerstats2012

European Commission website: Large Combustion Plant Directive, http://ec.europa.eu/environment/air/pollutants/stationary/lcp/legislation.htm

European Commission (2014): European Commission, European Economic Forecast, Winter 2014, Directorate General for Economic and Financial Affairs, February 2014, http://ec.europa.eu/economy finance/publications/european economy/2014/pdf/ee2 en.pdf

European Commission (2013): European Commission, Quarterly report on European Electricity Markets, Volume 6, Issue 2, Second Quarters 2013

European Commission (January 2013): European Commission, 'EU launches clean fuel strategy', Press release, 24 January 2013, http://europa.eu/rapid/press-release IP-13-40 en.htm

European Commission (2012): European Commission, Quarterly report on European Electricity Markets, Volume 5, Issues 3 \& 4, Third and Fourth Quarters 2012, http://ec.europa.eu/energy/observatory/electricity/electricity en.htm

European Commission (2010): European Commission, Council Decision of 10 December 2010 on State aid to facilitate the closure of uncompetitive coal mines (2010/787/EU), http://eurlex.europa.eu/legal-content/EN/TXT/PDF/?uri=CELEX:32010D0787\&from=EN

European Commission, Energy Roadmap 2050:

http://ec.europa.eu/energy/energy2020/roadmap/index en.htm

European Environment Agency (2013): European Environment Agency, Annual EU greenhouse gas inventory 1990-2011, Inventory report 2013, http://www.eea.europa.eu/publications/european-uniongreenhouse-gas-inventory-2013

European Parliament and Council (2009): The European Parliament and the Council, 'Decision No 406/2009/EC of the European Parliament and of the Council of 23 April 2009 on the effort of Member States to reduce their GHG emissions to meet the 2020 target', http://eurlex.europa.eu/LexUriServ/LexUriServ.do?uri=OJ:L:2009:140:0136:0148:EN:PDF

Eurostat (Monthly): Eurostat, Monthly News-release, Euro-Indicators

Eurostat (2014): Eurostat, Monthly News-release, Euro-Indicators, 58/2014, 14 April 2014

Eurostat database: Eurostat, Energy intensity of the economy: http://epp.eurostat.ec.europa.eu/tgm/table.do?tab=table\&init=1\&plugin=1\&language=en\&pcode=tsdec $\underline{360}$

EWEA (2014): European Wind Energy Association, Wind in Power, 2013 European Statistics, http://www.ewea.org/fileadmin/files/library/publications/statistics/EWEA Annual Statistics 2013.pdf

Gas to Power journal (March 2014): Gas to Power journal, March 6, 2014, 'Malta: Decision on gas power plant scheduled for March 24', http://www.gastopowerjournal.com/projectsafinance/item/3086malta-decision-of-gas-power-plant-scheduled-for-march-24\%20-\%20ixzz2vfT7rsBy

Gas to Power journal (October 2012): Gas to Power journal, October 19, 2012, 'Enel takes action to boost competitiveness of CCGT fleet', 
http://www.gastopowerjournal.com/technologyainnovation/item/1014-enel-takes-action-to-boostcompetitiveness-of-ccgt-fleet

GSE (2012): Gestore Servizi Energetici, 'Renewable energy statistical report 2011, Renewable energy power plants in Italy', http://www.gse.it/en/pressroom/News/Pages/statistical-report-2011.aspx

Hawkins (2013): Hawkins N., 'Italian market outlook', presentation to Gas to Power Europe, 25-26 February 2013, Brussels

Honoré (2013): Honoré A., 'The Italian Gas Market: Challenges and Opportunities', NG76, June 2013, Oxford Institute for Energy Studies, http://www.oxfordenergy.org/wpcms/wpcontent/uploads/2013/06/NG-76.pdf

Honoré (2011): Honoré A., 'The Spanish Gas Market: Demand Trends Post Recession and Consequences for the Industry', NG55, July 2011, Oxford Institute for Energy Studies, http://www.oxfordenergy.org/wpcms/wp-content/uploads/2011/08/NG 552.pdf

Honoré (2010): Honoré A., European Natural Gas Demand, Supply and Pricing, cycles, seasons and the impact of $L N G$ price arbitrage, 2010, Oxford University Press

ICIS Heren (November 2013): ICIS Heren, November 22, 2013, 'Belgium to tender for subsidised gas-fired electricity generation', http://www.icis.com/resources/news/2013/11/22/9728775/belgium-totender-for-subsidised-gas-fired-electricity-generation/

ICIS Heren (December 2012): ICIS Heren, December 28, 2012, 'Italian spark spreads face swathe of bearish drivers', http://www.icis.com/heren/articles/2012/12/28/9627326/power/edem/italian-sparkspreads-face-swathe-of-bearish-drivers.html

ICIS Heren (September 2011): ICIS Heren, September 26, 2011, 'Italian electricity industry calls for interim capacity payment', http://www.icis.com/heren/articles/2011/09/26/9495176/italian-electricityindustry-calls-for-interim-capacity.html

IEA (annual data_a): International Energy Agency, Natural gas information, various issues, OECD:IEA

IEA (annual data_b): International Energy Agency, Energy Balances of OECD countries, various issues, OECD:IEA

IEA (annual data_c): International Energy Agency, Electricity information, various issues, OECD:IEA IEA (WEOs): International Energy Agency, World Energy Outlook, annual publications, OECD:IEA, http://www.iea.org/publications/worldenergyoutlook/publications/

IEA (2013a): International Energy Agency, Natural gas information edition 2013, 2013, OECD:IEA IEA (2013b), International Energy Agency, Non-OECD Statistics edition 2013, 2013, OECD: IEA IEA (2013c), International Energy Agency, Non-OECD Balances edition 2013, 2013, OECD: IEA IEA (2013d): International Energy Agency, Medium Term renewables energy market report, 2013, OECD: IEA

IEA (2013e): International Energy Agency, Electricity information edition 2013, 2013, OECD:IEA

IEA (2013f): International Energy Agency, World Energy Outlook 2013, 2013, OECD:IEA

IEA (2013g): International Energy Agency, Medium-term gas market report, 2013, OECD:IEA

IEA (2012a): International Energy Agency, World Energy Outlook 2012, presentation to the press, London, 12 November 2012, OECD:IEA 
IEA (2012b): International Energy Agency, Medium-term gas market report, 2012, OECD:IEA

IEA (2011): International Energy Agency, World Energy Outlook 2011, Are we entering a Golden Age for gas?, 2011, OECD:IEA,

http://www.iea.org/media/weowebsite/2011/WEO2011 GoldenAgeofGasReport.pdf

IEA (2010a): International Energy Agency, Natural gas information edition 2010, 2010, OECD:IEA

IEA (2010b): International Energy Agency, Electricity information edition 2010, 2010, OECD:IEA

IEA (2009a): International Energy Agency, Natural gas information edition 2009, 2009, OECD:IEA

IEA (2009b): International Energy Agency, Electricity information edition 2009, 2009, OECD:IEA

IMF (2013): International Monetary Fund, Economic Outlook, November 2013

IMF (2009a): International Monetary Fund, 'World Economic Outlook, crisis and recovery', April 2009, http://www.imf.org/external/pubs/ft/weo/2009/01/pdf/text.pdf

IMF (2009b): International Monetary Fund, 'World Economic Outlook, update, Global Economic Slump Challenges Policies', 28 January 2009, http://www.imf.org/external/pubs/ft/weo/2009/update/01/pdf/0109.pdf

Le Fevre (2014): Le Fevre C., 'The prospects for natural gas as a transport fuel in Europe', NG84, Oxford Institute for Energy Studies, March 2014, http://www.oxfordenergy.org/wpcms/wpcontent/uploads/2014/03/NG-84.pdf

Le Figaro (January 2014) : Le Figaro, January 29, 2014, 'L'essor des énergies vertes jugé trop coûteux', http://www.lefigaro.fr/conjoncture/2014/01/29/20002-20140129ARTFIG00325-I-essor-desenergies-vertes-juge-trop-couteux.php

Ministry of Petroleum and Energy (2013): Ministry of Petroleum and Energy, National Renewable Energy Action Plan under 2009/28/EC, Norway, January 30, 2013,

http://ec.europa.eu/energy/renewables/transparency platform/doc/dir 20090028 action plan norwa y nreap.pdf

Le Monde (May 2014): Le Monde, May 28, 2014, 'La géopolitique de l'énergie expliquée en 7 graphiques', http://www.lemonde.fr/planete/article/2014/05/27/sept-graphiques-pour-comprendre-lanouvelle-donne-energetique-mondiale $44268653244 . \mathrm{html}$

National Renewable Energy Action Plan: Member States' national renewable energy action plans to the European Commission: http://ec.europa.eu/energy/renewables/action plan en.htm

OECD (2010): Organisation for Economic Cooperation and Development, 'OECD Economic Outlook n.88', November 2010, http://stats.oecd.org/Index.aspx?DataSetCode=EO88 INTERNET

OECD database: http://stats.oecd.org/

Platts (January 2014), Platts, European gas daily, January 20, 2014, 'Market awaits $\mathrm{CO}_{2}$ trading reforms'

Platts (February 2014): Platts, European Gas Daily Monthly Averages, February 2014

Platts (March 2014a): Platts, Power in Europe, March 3, 2014, 'Power markets weaken further into 2014'

Platts (March 2014b): Platts, Power in Europe, March 3 2014, 'Divining the Baltic curve'

Platts (April 2014a): Platts, European gas daily, April 29, 2014 
Platts (April 2014b): Platts, Power in Europe, April 30, 2014, 'Bank forecasts 6 GW of Turkish closures'

Platts (May 2013a): Platts, May 7, 2013, 'Power Stations Nearing Completion, But Construction Starts Slow on Uncertainty', http://www.platts.com/pressreleases/2013/050713

Platts (May 2013b): Platts, Power in Europe, May 27 2013, 'CEOs call for revitalized policy' Platts (July 2013): Platts, European Gas Daily, July 17, 2013, 'E.ON to mothball Slovak CCGT' Platts (May 2012): Platts, Power In Europe, May 14, 2012, 'European power's 'lost decade” Platts (November 2012): Platts, Power In Europe, November 26, 2012, 'Enel leans on coal' Platts (December 2012): Platts Power In Europe, December 10, 2012, 'Italy's energy strategy - a viewpoint'

Republic of Serbia (2013): Republic of Serbia, Ministry of Energy, Development and Environmental Protection, 'National Renewable energy Action Plan of the Republic of Serbia' (in accordance with the template foreseen in the Directive 2008/29/EC - decision 2009/548/EC), 2013, http://www.merz.gov.rs/sites/default/files/NREAP\%200F\%20REPUBLIC\%20OF\%20SERBIA\%2028 June 2013.pdf

Republic of Turkey (2009): Republic of Turkey, Ministry of Energy and Natural Resources, 'Strategic Plan (2014-2014)', 2009, http://www.enerii.gov.tr/yayinlar raporlar EN/ETKB 20102014 Stratejik Plani EN.pdf

Reuters (July 2011): Reuters, July 15, 2011, 'Italy power grid to develop 130 MW storage systems', http://www.reuters.com/article/2011/07/15/terna-power-idAFLDE76E1AZ20110715

Rogers (2012): Rogers H., 'Gas with CCS in the UK: waiting for Godot?', NG66, Oxford Institute for Energy Studies, September 2012, http://www.oxfordenergy.org/wpcms/wpcontent/uploads/2012/09/NG-66.pdf

Rzayeva (2014): Rzayeva G., 'Natural gas in the Turkish domestic energy market: polices and challenges', NG82, Oxford Institute for Energy Studies, February 2014, http://www.oxfordenergy.org/wpcms/wp-content/uploads/2014/02/NG-82.pdf

Scarpa (2012): Scarpa C., 'Italy between excess supply and shortage', Presentation in Berlin, November 22, 2012

Shale gas new today (April 2014): Shale gas new today, April 10, 2014, 'Czech energy firm scraps nuclear plant expansion', http://shalegas.einnews.com/country/czech

U.S. Energy Information Administration (2014): U.S. Energy Information Administration, Turkey, country analysis briefs, April 17, 2014, http://www.eia.gov/countries/analysisbriefs/Turkey/turkey.pdf

The Wall Street Journal (January 2014): The Wall Street Journal, January 21, 2014, 'GDF Suez Looks Outside Europe', http://online.wsj.com/article/BT-CO-20140121-701011.html 